\title{
Recomendações para o projeto de cálices de fundação
}

Dissertação apresentada à Escola de Engenharia de São Carlos da Universidade de São Paulo, como parte dos requisitos para obtenção do título de Mestre em Engenharia de Estruturas.

Orientador: Prof. Titular Mounir Khalil El Debs

São Carlos

2010 
AUTORIZO A REPRODUÇÃO E DIVULGAÇÃO TOTAL OU PARCIAL DESTE TRABALHO, POR QUALQUER MEIO CONVENCIONAL OU ELETRÔNICO, PARA FINS DE ESTUDO E PESQUISA, DESDE QUE CITADA A FONTE.

Ficha catalográfica preparada pela Seção de Tratamento da Informação do Serviço de Biblioteca - EESC/USP

Campos, Gabriela Mazureki
Recomendaçós para o projeto de cálices de fundação /
Gabriela Mazureki Campos; orientador Mounir Khalil El
Debs. -- São Carlos, 2010 .
Dissertação (Mestrado-Programa de Pós-Graduação e Área
de Concentraço em Engenharia de Estruturas) -- Escola de
Engenharia de São Carlos da Universidade de São Paulo,
2010.
1. Concreto pré-moldado. 2. Ligação. 3. Cálice de
I. Título. Colarinho. 5. Base de pilares pré-moldados.


Candidata: Engenheira GABRIELA MAZUREKI CAMPOS

Dissertação defendida e julgada em 5.3.2010 perante a Comissão Julgadora:

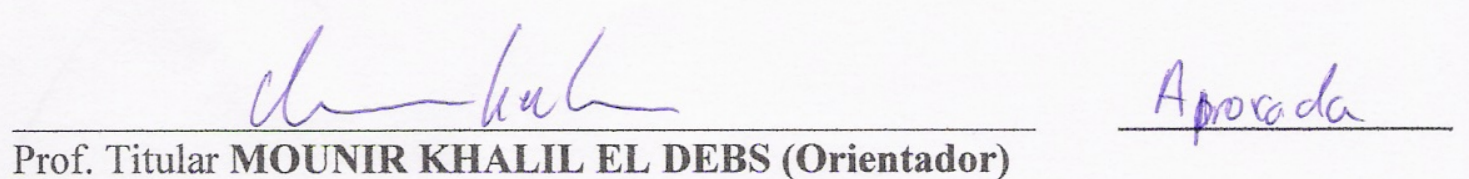

Prof. Titular MOUNIR KHALIL EL DEBS (Orientador)

(Escola de Engenharia de São Carlos/USP)

Prof. Dr. JOSE SAMUEL GIONGO

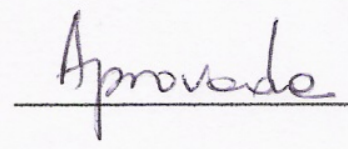

(Escola de Engenharia de São Carlos/USP)

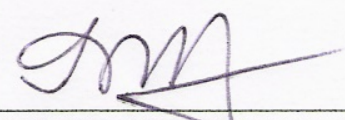

Aprovade

Prof. Dr. ANGELO RUBENS MIGLIORE JUNIOR

(Fundação Educacional de Barretos/FEB)
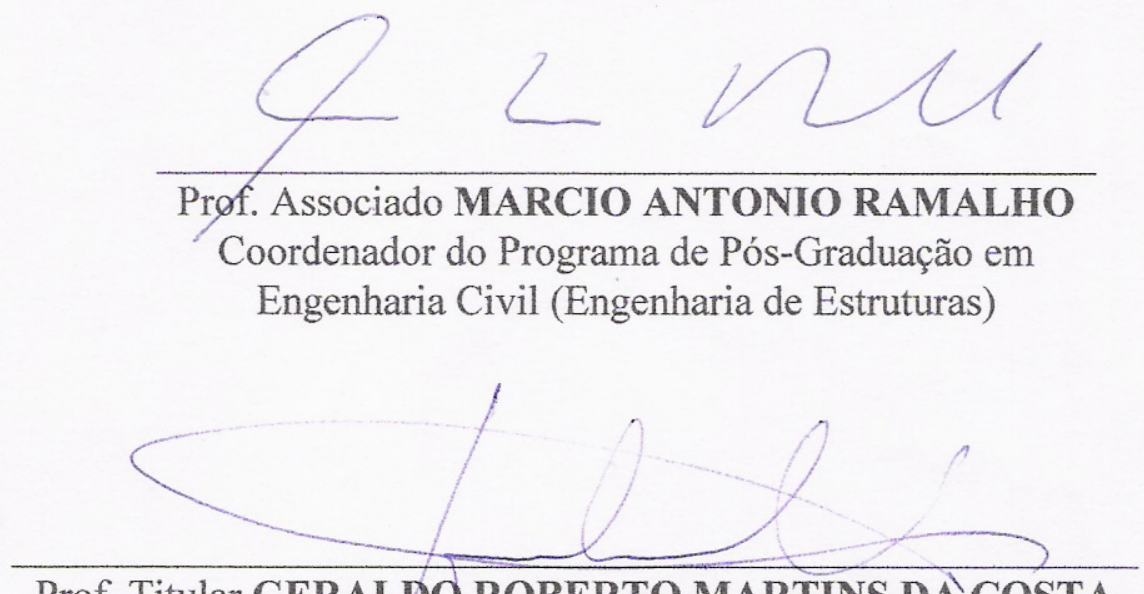

Prof. Titular GERALDO ROBERTO MARTINS DA' COSTA

Presidente da Comissão de Pós-Graduação 


\section{AGRADECIMENTOS}

Agradeço a Deus por me abençoar no decorrer de toda minha vida.

Ao professor Mounir Khalil El Debs pela ótima orientação, incentivo e confiança em meu trabalho.

À minha família, meus pais Luiz Carlos e Arlete pela educação, amor e ensinamentos passados. E às minhas irmãs Patrícia e Denize pela amizade sincera e por sempre me apoiarem.

Ao meu namorado Theodoro, pelo amor, companheirismo e contribuição em alguns desenhos da dissertação.

À Rejane M. F. Canha pela valiosa ajuda e contribuição com seus conhecimentos no desenvolvimento e correção desse estudo.

Às amizades iniciadas durante o mestrado, que me ajudaram a superar a distância de casa, em especial aos amigos “mc”: Ellen, Marliane, André, Hidelbrando, Calil e Raphael.

Aos demais amigos: Fernando, Andreilton e Aline, Carlos, Bianca, Cátia, Wagner, Higor, Danielle, Rodrigo, Jonas, Chicão, Denis, Wellison, Rodolfo, Chris, Valmiro, Marcela, Érika e Jesus.

A todos os colegas, professores e funcionários do Departamento de Estruturas da Escola de Engenharia de São Carlos.

Ao professor João Amilton Mendes pelos anos de orientação durante a graduação e contribuição na decisão de cursar o mestrado.

À CAPES - Coordenação de Aperfeiçoamento de Pessoal de Nível Superior pelo apoio financeiro.

E a todos que, de alguma maneira, contribuíram para a realização dessa conquista. 


\section{RESUMO}

CAMPOS, G. M. Recomendações para o projeto de cálices de fundação. 2010. 183 f. Dissertação (Mestrado) - Escola de Engenharia de São Carlos, Universidade de São Paulo, São Carlos, 2010.

Essa pesquisa apresenta um estudo a respeito de cálices de fundação com colarinho. $\mathrm{O}$ trabalho foi elaborado a partir de uma análise crítica e síntese de resultados de estudos experimentais e numéricos desenvolvidos na Escola de Engenharia de São Carlos Universidade de São Paulo (EESC-USP) sobre a ligação pilar-fundação por meio de cálice para estruturas de concreto pré-moldado. Esses estudos englobam uma tese de doutorado e três dissertações de mestrado, em que foram abordadas diversas situações de projeto dessa ligação. A partir dos resultados dessas pesquisas são elaboradas recomendações para o projeto do cálice com interface lisa e rugosa e da base do pilar pré-moldado. Incluem-se ainda avaliação da situação de montagem e disposições construtivas gerais a respeito da ligação por meio de cálice. Mediante aplicações, são avaliadas as recomendações de projeto e simulados casos reais de emprego da ligação pilar-fundação por meio de cálice. Com base nesse estudo, as principais conclusões incorporadas às recomendações foram em relação: a) a posição de aplicação da resultante de pressão superior na parede frontal; b) ao comportamento das paredes transversais; c) a força normal com pequena excentricidade; d) a determinação da espessura mínima da parede do colarinho e; e) adaptação do modelo de comportamento da base do pilar pré-moldado com o modelo do cálice. Ao final, são elaborados exemplos de dimensionamento da ligação cálice de fundação com interface lisa e rugosa e da base do pilar pré-moldado, além de um roteiro simplificado com recomendações de projeto desses elementos.

Palavras-chave: concreto pré-moldado. Ligação. Cálice de fundação. Colarinho. Base de pilares pré-moldados. 


\section{ABSTRACT}

CAMPOS, G. M. Recommendations for design of socket base connections. 2010. 183f. Dissertation (Master degree) - Escola de Engenharia de São Carlos, Universidade de São Paulo, São Carlos, 2010.

This research presents a study about the socket base with pedestal walls. The paper was drawn from a review and synthesis of results of experimental and numerical studies carried out at the Engineering School of São Carlos - University of São Paulo (EESC-USP) about the socket base connection by pedestal walls in precast concrete structures. These studies include a Phd thesis and three MSc dissertations, which addressed several situations of design of that kinf of connection. From the results, recommendations are drawn for the design of socket with smooth and rough interface and precast column base. Included also evaluated at the erection situation and constructive provisions regarding socket base. With some applications are analyzed the design recommendations and simulated real cases of use of column-base connection by socket. Based on this study, the main conclusions that were incorporated into the recommendations were about: a) local of application of the top pression resultant; b) behavior of transversal walls; c) normal force with small eccentricity; d) determination of the thickness of pedestal wall and; e) adaptation of column base model with the socket model. Finally, examples are drawn about socket foundation design with smooth and rough interface and of the precast column base, beyond simplified script with recommendations for the design of these elements.

Keywords: precast concrete. Connection. Socket base. Pedestal walls. Precast columns base. 


\section{LISTA DE SÍMBOLOS}

$A_{c c}$

$A_{s}$

$A_{s, b}$

$A_{s, h f t}$

$A_{s, h \text { inf }}$

$A_{s, h p}$

$A_{s, h p l}$

$A_{\text {s, hple }}$

$A_{s, h p l i}$

$A_{s, h p t}$

$A_{\text {s, hpte }}$

$A_{s, h p t i}$

$A_{s, h s}$

$A_{s, h s l}$

$A_{s, h s t}$

$A_{s, h \text { sup }}$

$A_{s, t o t}$

$A_{s, v p}$

Área da seção de concreto comprimido

Área de aço

Armadura em forma de "U" disposta na base do pilar para resistir a força $H_{\text {inf, } d}$

Área de armadura horizontal de flexão para parede transversal 1 do cálice com interface lisa

Armadura disposta horizontalmente na região inferior do colarinho

Área de armadura horizontal principal

Área de armadura horizontal principal longitudinal

Área do ramo externo da armadura horizontal principal longitudinal

Área do ramo interno da armadura horizontal principal longitudinal

Área de armadura horizontal principal transversal

Área do ramo externo da armadura horizontal principal transversal

Área do ramo interno da armadura horizontal principal transversal

Área de armadura horizontal secundária

Área de armadura horizontal secundária longitudinal

Área de armadura horizontal secundária transversal

Área de armadura horizontal superior longitudinal para transmitir a força $H_{\text {sup }} / 2$, referente a uma parede longitudinal

Área de armadura vertical equivalente a $2 . A_{s, v p}+A_{s, v s t}$

Área de armadura vertical principal 


$\begin{array}{ll}A_{s, v p 1}=A_{s, v p 2}= & \text { Armadura vertical principal localizada no canto } 1,2,3 \text { e } 4 \text { calculada } \\ A_{s, v p 3}=A_{s, v p 4} & \text { para o caso de flexão oblíqua } \\ A_{s, v s} & \text { Área de armadura vertical secundária } \\ A_{s, v s l} & \text { Área de armadura vertical secundária longitudinal } \\ A_{s, v s t} & \text { Área de armadura vertical secundária transversal } \\ A_{s v, b f} & \text { Área de armadura vertical que chega à base da fundação } \\ A_{s x, b f} & \text { Área de armadura da base da fundação na direção } x \\ A_{s x, b f}, & \text { Área de armadura da base da fundação na direção x no trecho } b_{t p} \\ A_{s y, b f} & \text { Área de armadura da base da fundação na direção } y \\ A_{s y, b f} & \text { Área de armadura da base da fundação na direção yo trecho } h_{t p} \\ A_{t o t} & \text { Área da fundação } \\ b & \text { Base da seção transversal do pilar } \\ b_{b f} & \text { Base da seção em planta da base da fundação } \\ b_{e x t} & \text { Base externa entre as paredes do colarinho } \\ b_{\text {int }} & \text { Base interna entre as paredes do colarinho } \\ b_{j} & \text { Espessura da junta } \\ b_{t p} & \text { Baronento da armadura } \\ c & \end{array}$

Distância do centróide da armadura de tração e de compressão à fibra extrema tracionada e comprimida, respectivamente

$d_{1}, d_{2}, d_{3} \quad$ Distância da borda comprimida do cálice ao centro da armadura

$d_{b f} \quad$ Altura útil da base da fundação

$d_{c} \quad$ Altura útil do consolo ou do cálice para o cálculo da resistência monolítica

$d_{c c} \quad$ Altura útil do cálice para o caso de interface rugosa

$\begin{array}{ll}d_{h p t} & \text { Altura útil do ramo interno ou } \\ \text { transversal da parede frontal } 1\end{array}$

$d_{x} \quad$ Altura útil da base da fundação referente à armadura na direção $x$ 


\begin{tabular}{|c|c|}
\hline$d_{y}$ & Altura útil da base da fundação referente à armadura na direção $y$ \\
\hline$e$ & Excentricidade da força normal \\
\hline$E_{c}$ & Módulo de elasticidade do concreto \\
\hline$e_{c h}$ & Espaçamento entre eixos das chaves de cisalhamento \\
\hline$e_{c h}^{\prime}$ & Espaçamento interno entre chaves de cisalhamento \\
\hline$e_{h p t}$ & $\begin{array}{l}\text { Distância de } R_{h p t e, d} \text { e } R_{h p t i, d} \text { ao nó central do modelo de biela e tirante } \\
\text { da parede transversal frontal } 1\end{array}$ \\
\hline$e_{n b}$ & $\begin{array}{l}\text { Excentricidade da força normal na base da fundação em relação ao } \\
\text { centro de gravidade do pilar }\end{array}$ \\
\hline$e_{r s}$ & Excentricidade da força $R_{\text {solo }}$ \\
\hline$E_{s}$ & Módulo de elasticidade do aço \\
\hline$e_{v}$ & Excentricidade da força horizontal $V / V_{d}$ em relação ao topo da ligação \\
\hline$F_{1}, F_{2}, F_{3}, F_{4}$ & Forças internas na biela e tirante do modelo para análise da base do \\
\hline$F_{5}, F_{6}, F_{7}, F_{8}$ & pilar pré-moldado \\
\hline$F_{a t 1, d}, F_{a t 2, d}$ & Forças de atrito de acordo com o modelo do Manual da Munte \\
\hline$F_{a t, b f}$ & Força de atrito na base da fundação \\
\hline$F_{a t, b f, d}$ & Valor de cálculo da força de atrito na base da fundação \\
\hline$F_{a t, \text { inf }}$ & Força de atrito na região inferior da parede transversal posterior \\
\hline$F_{a t, \text { inf }, d}$ & $\begin{array}{l}\text { Valor de cálculo da força de atrito na região inferior da parede } \\
\text { transversal posterior }\end{array}$ \\
\hline$F_{a t, \text { sup }}=F_{a t \text {,sup } f}$ & Força de atrito na região superior da parede transversal frontal \\
\hline$F_{a t, \text { sup }, d}=F_{a t, \text { sup } f, d}$ & $\begin{array}{l}\text { Valor de cálculo da força de atrito na região superior da parede } \\
\text { transversal frontal }\end{array}$ \\
\hline$F_{b u, x}$ & Força resultante horizontal de aderência \\
\hline$F_{b u, y}$ & Força resultante vertical de aderência \\
\hline$f_{c d}$ & Resistência de cálculo do concreto a compressão \\
\hline$f_{c k}$ & Resistência característica do concreto a compressão \\
\hline$f_{c t}$ & Resistência do concreto à tração direta \\
\hline$f_{c t d}$ & Resistência de cálculo do concreto à tração direta \\
\hline
\end{tabular}




\begin{tabular}{|c|c|}
\hline$f_{c t d, \text { inf }}$ & $\begin{array}{l}\text { Valor de cálculo da resistência característica inferior do concreto à } \\
\text { tração direta }\end{array}$ \\
\hline$f_{c t k}$ & Resistência característica do concreto à tração direta \\
\hline$f_{c t k, \text { inf }}$ & Resistência característica inferior do concreto à tração direta \\
\hline$f_{c t m}$ & Resistência média do concreto à tração direta \\
\hline$f_{s d}$ & Resistência solicitante de cálculo da armadura \\
\hline$F_{v p}$ & Força vertical principal na armadura do consolo \\
\hline$F_{v p, d}$ & Valor de cálculo da força vertical principal na armadura do consolo \\
\hline$f_{y}$ & Resistência ao escoamento do aço \\
\hline$f_{y d}$ & Resistência de cálculo ao escoamento do aço \\
\hline$f_{y k}$ & Resistência característica ao escoamento do aço \\
\hline$h$ & Largura da seção transversal do pilar \\
\hline$H_{a f}, H_{a t}$ & $\begin{array}{l}\text { Reações horizontais na viga da modelagem do comportamento da } \\
\text { parede transversal frontal }\end{array}$ \\
\hline$h_{b f}$ & Largura da seção em planta da base da fundação \\
\hline$h_{b i e}$ & Espessura da biela de compressão do consolo \\
\hline$h_{b i e}^{\prime}$ & $\begin{array}{l}\text { Espessura da biela de compressão do consolo na direção vertical das } \\
\text { paredes longitudinais }\end{array}$ \\
\hline$h_{c}$ & Espessura da parede do colarinho \\
\hline$h_{c h}$ & Altura da chave de cisalhamento \\
\hline$h_{\text {ext }}$ & Largura externa entre as paredes do colarinho \\
\hline$H_{f}$ & $\begin{array}{l}\text { Resultante de pressão horizontal na parede transversal frontal do cálice } \\
\text { rugoso }\end{array}$ \\
\hline$H_{\mathrm{inf}}$ & $\begin{array}{l}\text { Força de compressão inferior oriunda da pressão do pilar na parede } \\
\text { transversal posterior }\end{array}$ \\
\hline$H_{\text {inf } 1}$ & Força de compressão mais alta na parede transversal posterior \\
\hline$H_{\text {inf } 2}$ & Força de compressão mais baixa na parede transversal posterior \\
\hline$H_{\mathrm{inf}, d}$ & $\begin{array}{l}\text { Valor de cálculo da força de compressão inferior oriunda da pressão do } \\
\text { pilar na parede transversal posterior }\end{array}$ \\
\hline
\end{tabular}




$$
\begin{aligned}
& H_{\text {inf } 1, d} \\
& H_{\text {inf } 2, d} \\
& h_{\text {int }} \\
& h_{j} \\
& H_{p} \\
& \text { HST } \\
& H_{\text {sup }}=H_{\text {sup } f} \\
& H_{\text {sup }-f}=H_{\text {sup } f-f} \\
& H_{\text {sup }-t}=H_{\text {sup } f-t} \\
& H_{\text {sup }, d}=H_{\text {sup } f, d} \\
& H_{\text {sup }-f, d}=H_{\text {sup } f-f, d} \\
& H_{\text {sup }-t, d}=H_{\text {sup } f-t, d} \\
& H_{\text {sup } \bmod 1, d} \\
& H_{\text {sup mod 2,d }} \\
& H_{\text {sup } p} \\
& H_{\text {sup } p-f} \\
& H_{\text {sup } p-t} \\
& H_{\text {sup } p, d}
\end{aligned}
$$




\begin{tabular}{|c|c|}
\hline$H_{\text {sup } p-f, d}$ & $\begin{array}{l}\text { Valor de cálculo da parcela da força de compressão superior que causa } \\
\text { flexão na parede transversal posterior }\end{array}$ \\
\hline$H_{\text {sup } p-t, d}$ & $\begin{array}{l}\text { Valor de cálculo da parcela da força de compressão que causa tração na } \\
\text { parede transversal posterior }\end{array}$ \\
\hline$h_{t p}$ & Largura do tronco piramidal de punção \\
\hline$I_{c}$ & Momento de inércia da seção bruta de concreto \\
\hline$I L$ & Cálice de interface lisa \\
\hline$I R$ & Cálice de interface rugosa \\
\hline$l_{a n c}=l_{b}$ & Comprimento de ancoragem \\
\hline$l_{b f}$ & Espessura da base da fundação \\
\hline$l_{c}$ & Comprimento do consolo \\
\hline$l_{c h}$ & Base maior da chave de cisalhamento \\
\hline$l_{c h}^{\prime}$ & Base menor da chave de cisalhamento \\
\hline$l_{\text {emb }}$ & $\begin{array}{l}\text { Comprimento de embutimento do pilar no cálice (não se considera a } \\
\text { altura da junta abaixo do pilar) }\end{array}$ \\
\hline$l_{f}$ & Altura da fundação \\
\hline$l_{o}$ & $\begin{array}{l}\text { Distância da força } H_{\text {sup }, d} / 2 \text { ao nó inferior do modelo de biela e tirante } \\
\text { do consolo das paredes longitudinais } 3 \text { e } 4 \text { (CNR 10025:1998) }\end{array}$ \\
\hline$M$ & Momento fletor \\
\hline$M_{1 d}$ & Momento fletor de cálculo do modelo 1 (OSANAI et al. (1996)) \\
\hline$M_{2 d}$ & Momento fletor de cálculo do modelo 2 (OSANAI et al. (1996)) \\
\hline$M_{b d}$ & Momento fletor de cálculo na base do cálice \\
\hline$M_{d}$ & Momento fletor de cálculo \\
\hline$M_{m o n t}$ & $\begin{array}{l}\text { Momento fletor causado na fase de montagem da ligação cálice- } \\
\text { fundação }\end{array}$ \\
\hline$M_{m o n t, d}$ & $\begin{array}{l}\text { Valor de cálculo do momento fletor causado na fase de montagem da } \\
\text { ligação cálice-fundação }\end{array}$ \\
\hline$M_{\text {sup } f-f}$ & Momento fletor causado pela atuação da pressão $H_{\text {sup } f-f}$ \\
\hline$M_{r}$ & Momento de fissuração \\
\hline$N$ & Força normal \\
\hline
\end{tabular}




\begin{tabular}{|c|c|}
\hline$n_{1}$ & $\begin{array}{l}\text { Grau do polinômio da modelagem do comportamento da parede } \\
\text { transversal frontal } 1\end{array}$ \\
\hline$N_{b f}$ & Força normal na base da fundação \\
\hline$N_{b f, d}$ & Valor de cálculo da força normal na base da fundação \\
\hline$N_{d}$ & Força normal de cálculo \\
\hline$N_{\text {sup } f-f}$ & Força normal oriunda da atuação da pressão $H_{\text {sup } f-f}$ \\
\hline$p_{b f 1, d}$ & Maior pressão na base da fundação \\
\hline$p_{b f 2, d}$ & Menor pressão na base da fundação \\
\hline$p_{b f f}$ & Pressão na base da fundação na parede frontal \\
\hline$p_{b f p}$ & Pressão na base da fundação na parede posterior \\
\hline$p_{\text {inf }}$ & Pressão na base da parede transversal posterior \\
\hline$p_{\text {inf }, d}$ & Valor de cálculo da pressão na base da parede transversal posterior \\
\hline$p_{\text {sup } f}$ & Pressão no topo da parede transversal frontal \\
\hline$p_{\text {sup } p}$ & Pressão no topo da parede transversal posterior \\
\hline$p_{\text {sup }, d}$ & Valor de cálculo da pressão no topo da parede transversal frontal \\
\hline$R_{c}$ & Resultante de compressão no concreto \\
\hline$R_{c b}$ & Resultante de compressão na biela \\
\hline$R_{c c}$ & Resultante de compressão no concreto do cálice \\
\hline$R_{c d}$ & Valor de cálculo da resultante de compressão no concreto \\
\hline$R_{\text {hpte, }}$ & $\begin{array}{l}\text { Reação do modelo de biela e tirante da parede transversal frontal } 1 \\
\text { referente ao ramo externo da armadura horizontal principal }\end{array}$ \\
\hline$R_{h p t i, d}$ & $\begin{array}{l}\text { Reação do modelo de biela e tirante da parede transversal frontal } 1 \\
\text { referente ao ramo interno da armadura horizontal principal }\end{array}$ \\
\hline$R_{\text {inf } d}$ & $\begin{array}{l}\text { Valor de cálculo da resultante de compressão inferior na parede } \\
\text { transversal posterior, igual à soma de } H_{\mathrm{inf}, d} \text { e } F_{a t, b f, d}\end{array}$ \\
\hline$R_{p}$ & $\begin{array}{l}\text { Resultante de pressão na parede transversal frontal } 1 \text { com distribuição } \\
\text { parabólica }\end{array}$ \\
\hline$R_{s}$ & Força na armadura tracionada \\
\hline$R_{s 1}$ & Resultante de forças nas armaduras verticais $A_{s, v p}$ e $A_{s, v s t}$ \\
\hline
\end{tabular}




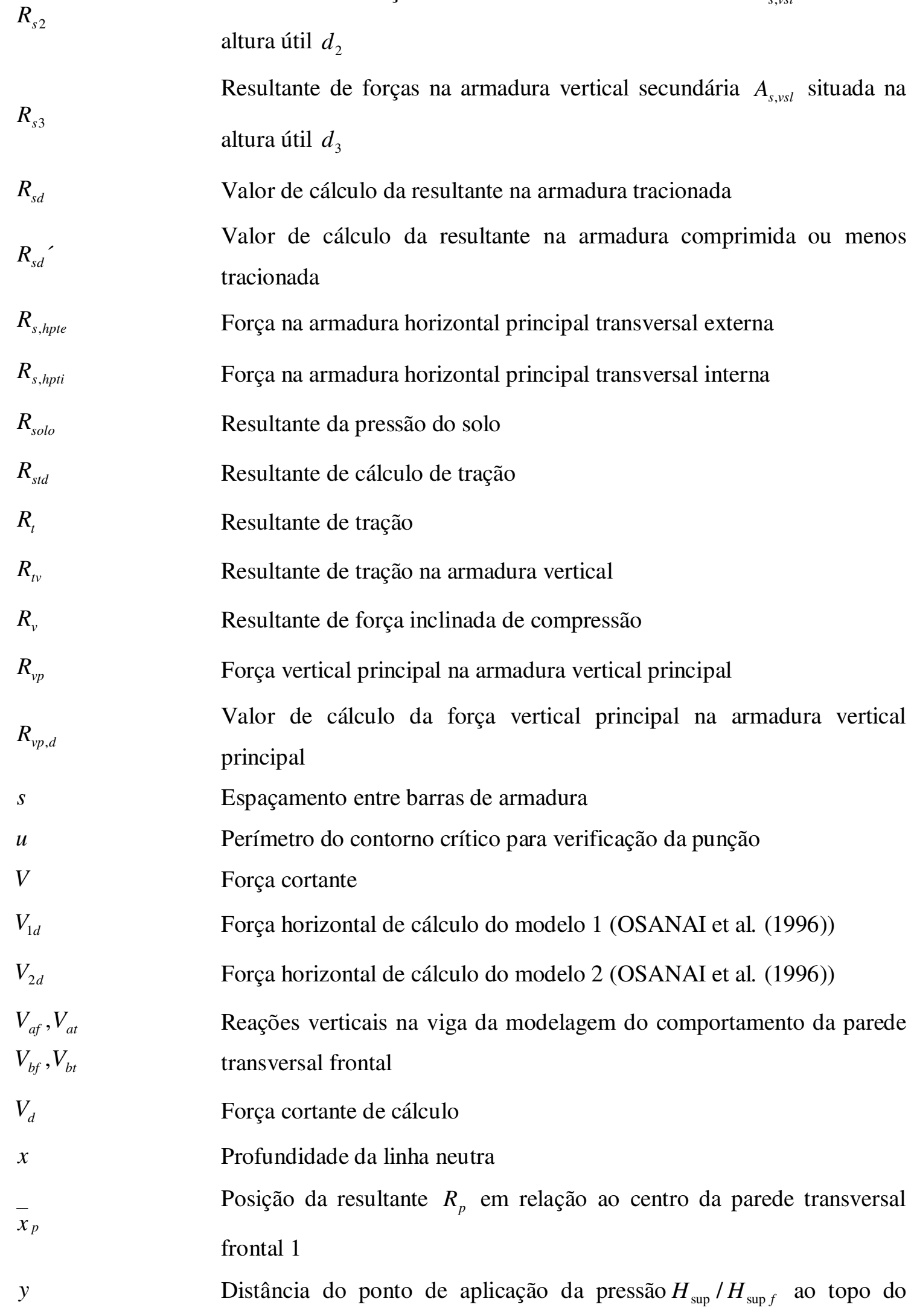
altura útil $d_{2}$

Resultante de forças na armadura vertical secundária $A_{s, v s l}$ situada na altura útil $d_{3}$

Valor de cálculo da resultante na armadura tracionada

Valor de cálculo da resultante na armadura comprimida ou menos tracionada

Força na armadura horizontal principal transversal externa

Força na armadura horizontal principal transversal interna

Resultante da pressão do solo

Resultante de cálculo de tração

Resultante de tração

Resultante de tração na armadura vertical

Resultante de força inclinada de compressão

Força vertical principal na armadura vertical principal

Valor de cálculo da força vertical principal na armadura vertical principal

Espaçamento entre barras de armadura

Perímetro do contorno crítico para verificação da punção

Força cortante

Força horizontal de cálculo do modelo 1 (OSANAI et al. (1996))

Força horizontal de cálculo do modelo 2 (OSANAI et al. (1996))

Reações verticais na viga da modelagem do comportamento da parede transversal frontal

Força cortante de cálculo

Profundidade da linha neutra

Posição da resultante $R_{p}$ em relação ao centro da parede transversal frontal 1

Distância do ponto de aplicação da pressão $H_{\text {sup }} / H_{\text {sup } f}$ ao topo do

Resultante de forças na armadura vertical secundária $A_{s, v s l}$ situada na 
colarinho

$y_{t}$

$y^{\prime}$

$y^{\prime \prime}$

$y^{*}$

$z$

$z_{c c}$

$z_{h p t}$

$z_{h \text { sup }}$

Letras gregas

$\alpha$

$\alpha_{c h}$

$\alpha_{e}$

$\alpha_{s, h p t}$

$\beta$

$\beta_{f}$

$\beta_{p}$

$\mathcal{E}_{c}$

$\varepsilon_{s}$

$\varepsilon_{y}$

$\eta$
Distância do centro de gravidade da seção à fibra mais tracionada

Distância do ponto de aplicação de $H_{\mathrm{inf}} / H_{\mathrm{inf}, d} / H_{\mathrm{inf} 2} / H_{\mathrm{inf} 2, d}$ à base do pilar

Distância do ponto de aplicação de $H_{\text {inf } 1} / H_{\text {inf 1,d }}$ à base do pilar

Distância do ponto de aplicação de $R_{\mathrm{inf}} / R_{\mathrm{inf}, d}$ à base do pilar

Braço de alavanca entre o binário de forças $H_{\text {sup }} / H_{\text {sup }, d}$ e $H_{\text {inf }} / H_{\text {inf, } d}$

Braço de alavanca entre o binário de forças $R_{c c}$ e $R_{v p}$

Distância entre os centróides dos ramos interno e externo da armadura horizontal principal transversal da parede frontal

Distância entre os centróides dos ramos interno e externo da armadura horizontal superior longitudinal das paredes longitudinais

Ângulo de inclinação da biela de compressão do concreto em relação à força horizontal

Inclinação da face da chave de cisalhamento em relação à linha paralela ao eixo da junta

Relação entre os módulos de elasticidade do aço e concreto

Relação entre as áreas dos ramos interno e externo da armadura horizontal principal transversal

Ângulo de inclinação da biela de compressão do concreto

Ângulo de inclinação da biela de compressão do concreto na parede transversal frontal

Ângulo de inclinação da biela de compressão do concreto na parede transversal posterior

Deformação no concreto

Deformação específica na armadura

Deformação específica de escoamento do aço

Coeficiente ponderador das pressões inferiores, que representa uma porcentagem de $H_{\text {sup }, d}$ 


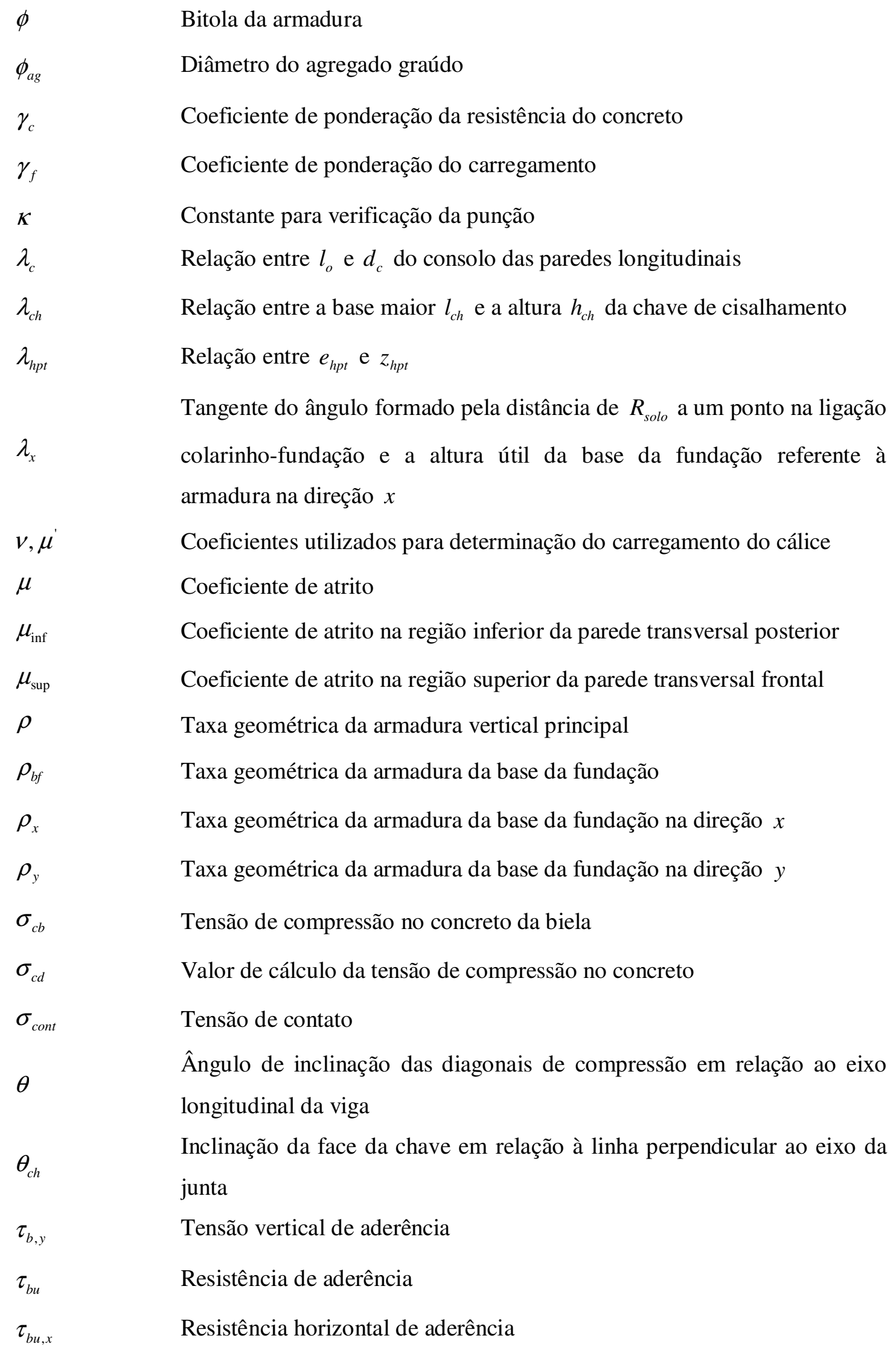

Bitola da armadura

$\phi_{a g}$

Diâmetro do agregado graúdo

$\gamma_{c}$

Coeficiente de ponderação da resistência do concreto

$\gamma_{f} \quad$ Coeficiente de ponderação do carregamento

$\kappa \quad$ Constante para verificação da punção

$\lambda_{c} \quad$ Relação entre $l_{o}$ e $d_{c}$ do consolo das paredes longitudinais

$\lambda_{c h} \quad$ Relação entre a base maior $l_{c h}$ e a altura $h_{c h}$ da chave de cisalhamento

$\lambda_{h p t} \quad$ Relação entre $e_{h p t}$ e $z_{h p t}$

Tangente do ângulo formado pela distância de $R_{\text {solo }}$ a um ponto na ligação

$\lambda_{x} \quad$ colarinho-fundação e a altura útil da base da fundação referente à

armadura na direção $x$

$v, \mu^{\prime} \quad$ Coeficientes utilizados para determinação do carregamento do cálice

$\mu \quad$ Coeficiente de atrito

$\mu_{\mathrm{inf}} \quad$ Coeficiente de atrito na região inferior da parede transversal posterior

$\mu_{\text {sup }} \quad$ Coeficiente de atrito na região superior da parede transversal frontal

$\rho \quad$ Taxa geométrica da armadura vertical principal

$\rho_{b f} \quad$ Taxa geométrica da armadura da base da fundação

$\rho_{x} \quad$ Taxa geométrica da armadura da base da fundação na direção $x$

$\rho_{y} \quad$ Taxa geométrica da armadura da base da fundação na direção $y$

$\sigma_{c b} \quad$ Tensão de compressão no concreto da biela

$\sigma_{c d} \quad$ Valor de cálculo da tensão de compressão no concreto

$\sigma_{\text {cont }} \quad$ Tensão de contato

$\theta$

Ângulo de inclinação das diagonais de compressão em relação ao eixo longitudinal da viga

$\theta_{c h}$

Inclinação da face da chave em relação à linha perpendicular ao eixo da junta

$\tau_{b, y} \quad$ Tensão vertical de aderência

$\tau_{b u} \quad$ Resistência de aderência

$\tau_{b u, x} \quad$ Resistência horizontal de aderência 
$\tau_{b u, y}$

$\tau_{w d}$

$\tau_{w u}$

$\xi$

Resistência vertical de aderência

Tensão de cisalhamento de cálculo

Tensão de cisalhamento última

Posição relativa do centróide da resultante de tensões de compressão do concreto 


\section{SUMÁRIO}

1 INTRODUÇÃ

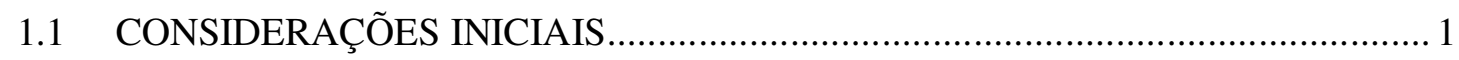

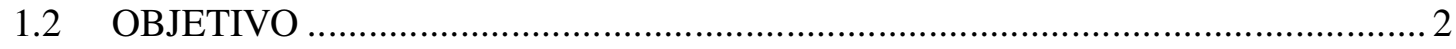

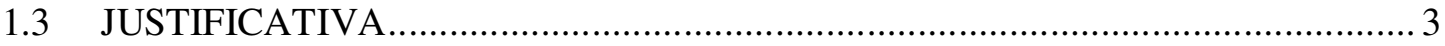

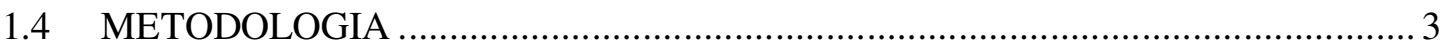

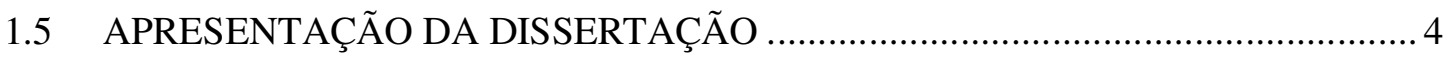

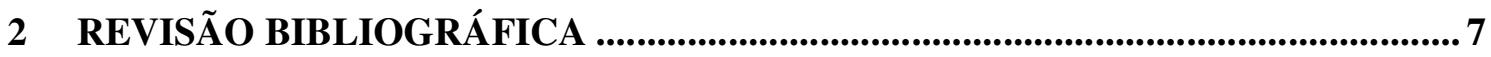

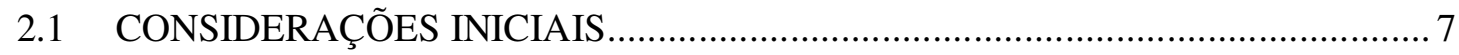

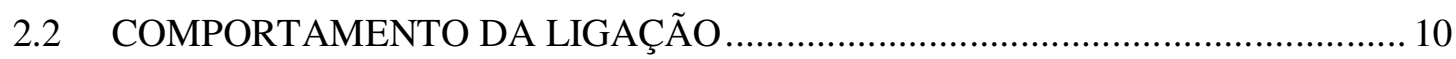

2.3 MODELO E RECOMENDAÇÕES DE PROJETO SEGUNDO LEONHARDT \& MÖNNIG (1978), ABNT NBR 9062:2006 e EL DEBS (2000)................................ 12

2.3.1 Propriedades geométricas e forças atuantes no cálice ......................................... 12

2.3.2 Dimensionamento das paredes do cálice ..................................................... 14

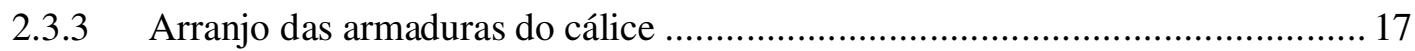

2.3.4 Recomendações para a base do cálice e base inferior do pilar........................... 19

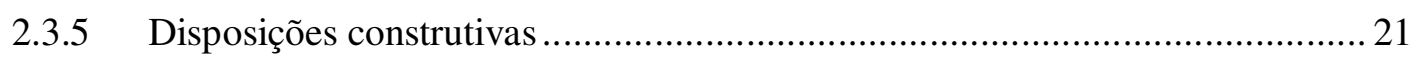

2.4 MODELO E RECOMENDAÇÕES DE PROJETO SEGUNDO OLIN ET AL.

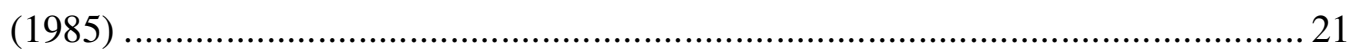

2.4.1 Propriedades geométricas e forças atuantes no cálice ........................................ 22

2.4.2 Tensões de cisalhamento atuantes na parede do cálice....................................... 23

2.4.3 Dimensionamento e arranjo das armaduras do cálice..........................................25

2.5 MODELO E RECOMENDAÇÕES DE PROJETO SEGUNDO OSANAI ET AL.

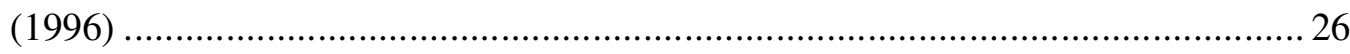

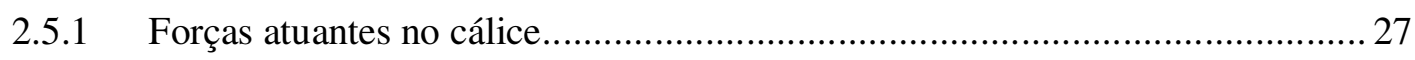

2.5.2 Modelo teórico e recomendações do modelo de projeto ……………………....... 31 
2.6 MODELO E RECOMENDAÇÕES DE PROJETO SEGUNDO A CNR

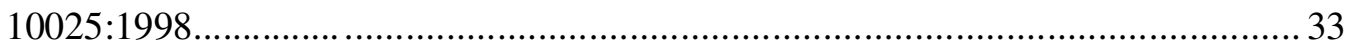

2.6.1 Propriedades geométricas e forças atuantes no cálice ........................................ 33

2.6.2 Dimensionamento das armaduras do cálice ......................................................... 34

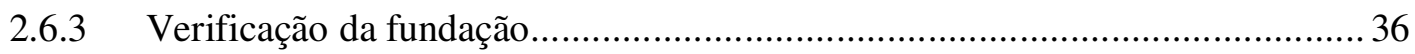

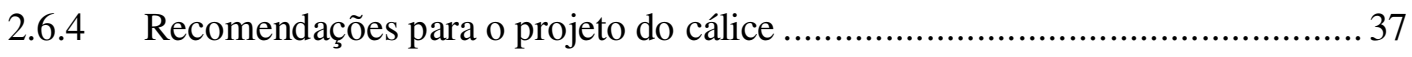

2.7 RECOMENDAÇÕES DE PROJETO SEGUNDO EUROCODE 2 (2004)............... 38

2.7.1 Propriedades geométricas e forças atuantes ........................................................ 38

2.7.2 Recomendações para o projeto do cálice ............................................................. 39

2.8 RECOMENDAÇÕES DE PROJETO DO MANUAL DA EMPRESA MUNTE

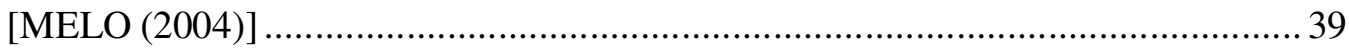

2.8.1 Propriedades geométricas e forças atuantes no cálice ......................................... 39

2.8.2 Dimensionamento das armaduras do cálice ..................................................... 41

3 ESTUDOS EXPERIMENTAIS DESENVOLVIDOS NA ESCOLA DE ENGENHARIA DE SÃO CARLOS .........................................................................45

3.1 MODELO DE PROJETO E RECOMENDAÇÕES DE CANHA (2004) ……….......45

3.1.1 Estudo experimental............................................................................ 46

3.1.2 Propriedades geométricas e modelo de projeto proposto.................................... 48

3.1.3 Recomendações de projeto............................................................................. 54

3.2 ENSAIOS E RECOMENDAÇÕES DE JAGUARIBE JR. (2005) ……………….... 55

3.2.1 Investigação experimental......................................................................... 55

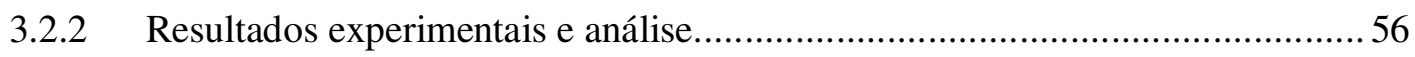

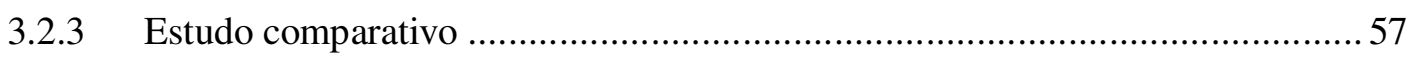

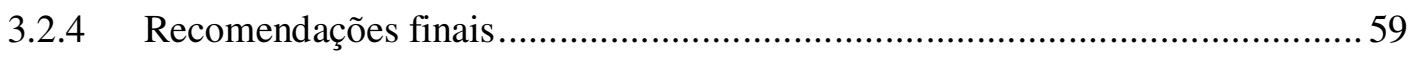

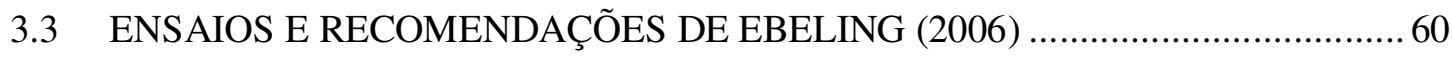

3.3.1 Investigação experimental e simulação numérica ……………………………..... 60

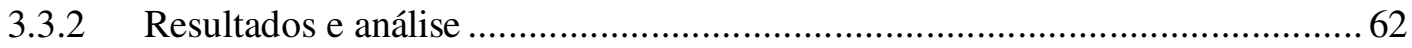

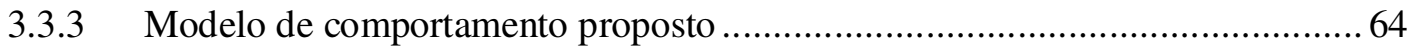

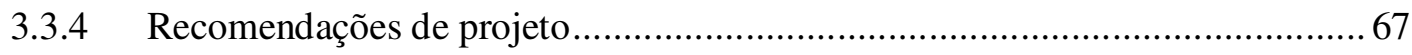

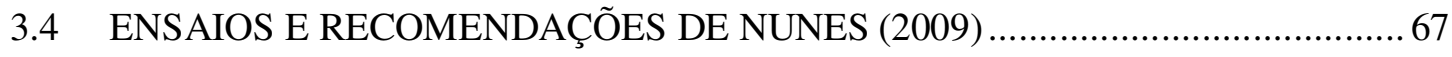

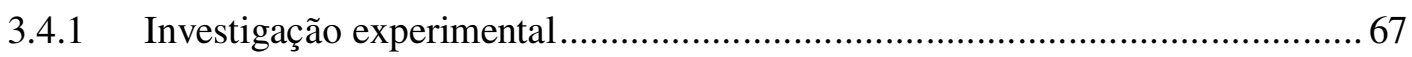

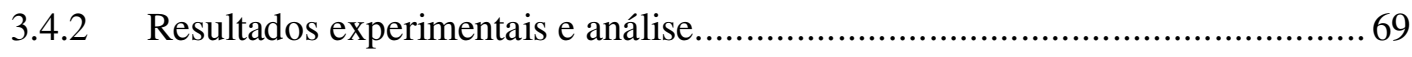




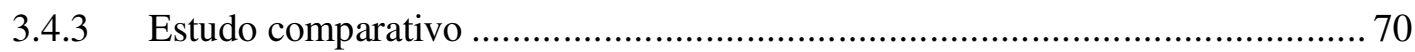

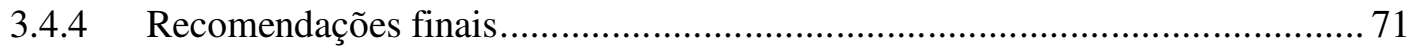

\section{RECOMENDAÇÕES PARA O PROJETO DE CÁLICES DE FUNDAÇÃO .......... 73}

4.1 CÁLICE COM INTERFACE LISA …………………….................................. 74

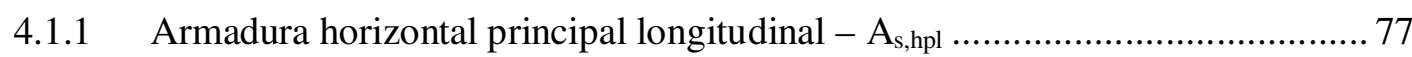

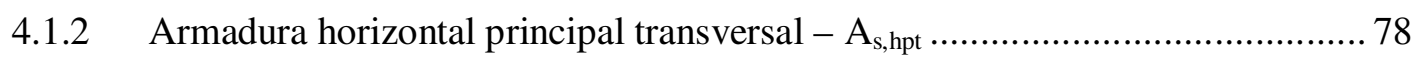

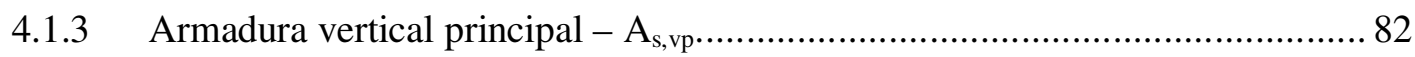

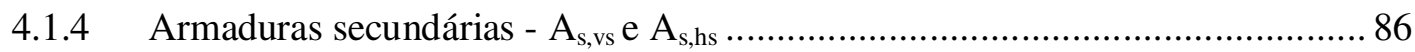

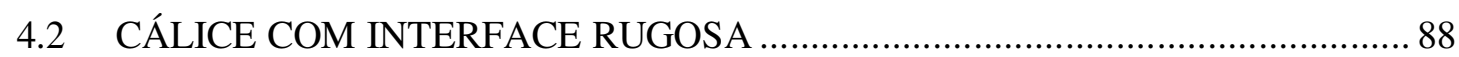

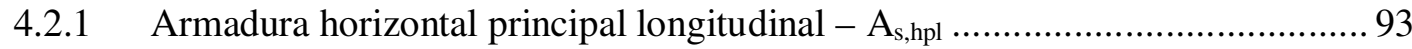

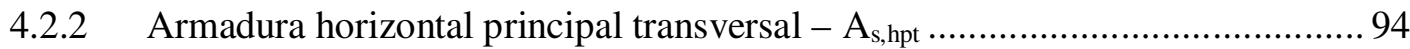

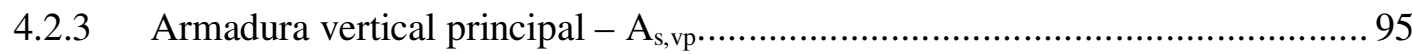

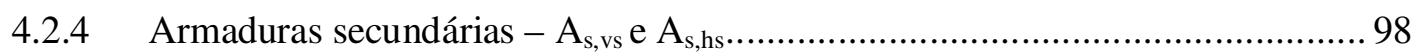

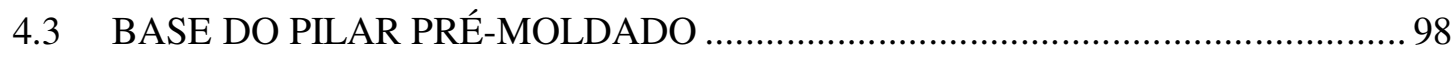

4.3.1 Modelo de projeto proposto por Canha et al. (2009a) ....................................... 99

4.3.2 Modelo de projeto adaptado ........................................................................ 100

4.3.3 Ancoragem da armadura longitudinal pilar...……………………………..... 102

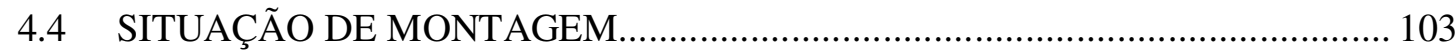

4.5 OUTRAS RECOMENDAÇÕES DE PROJETO................................................. 107

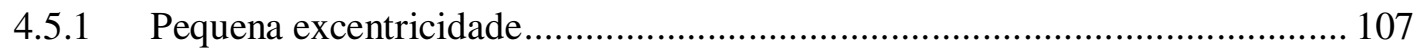

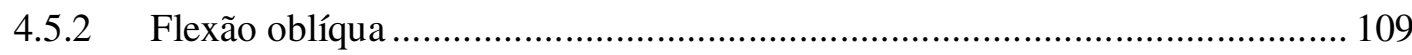

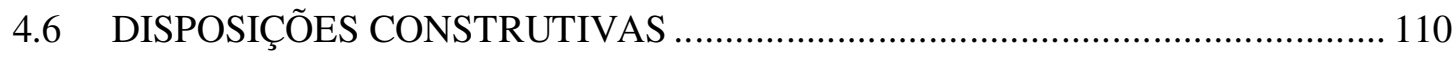

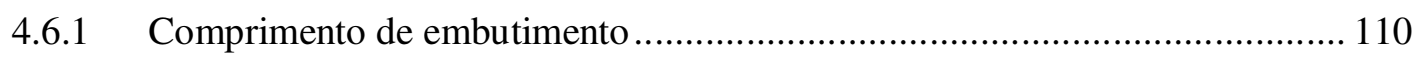

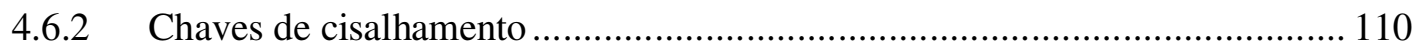

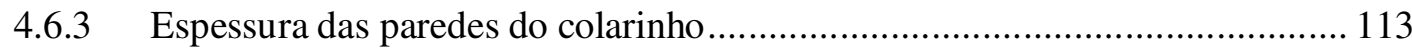

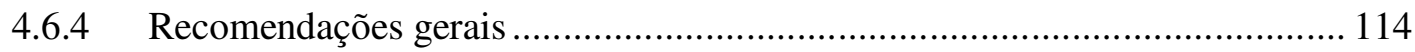

4.7 DETALHAMENTO DAS ARMADURAS ....................................................... 114

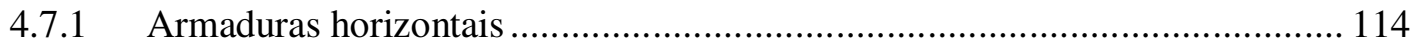

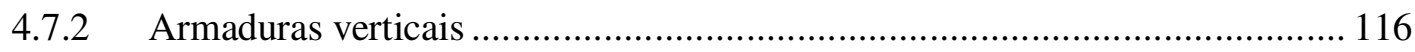

5 AVALIAÇÃO E APLICAÇÃO DAS RECOMENDAÇÕES ..................................... 117

5.1 VARIAÇÃO DAS SEÇÕES DOS PILARES …………………………................ 117 


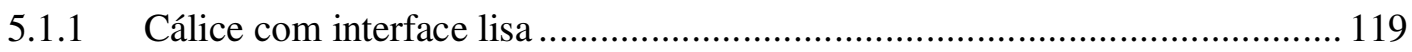

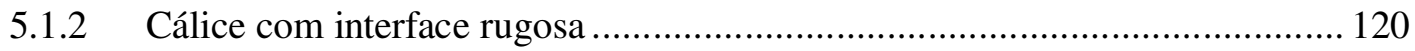

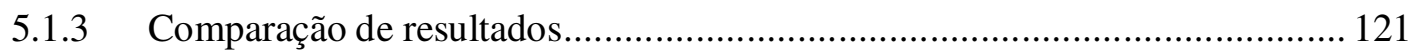

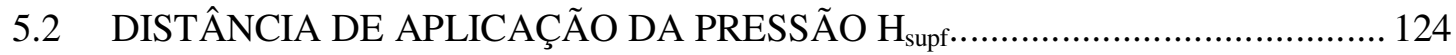

5.3 COMPORTAMENTO DAS PAREDES TRANSVERSAIS ................................... 125

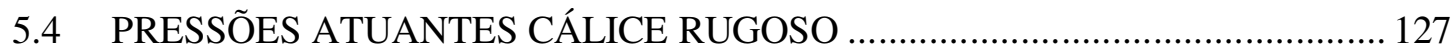

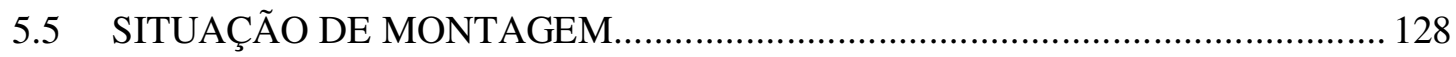

5.6 PEQUENA EXCENTRICIDADE ………………………………………......... 131

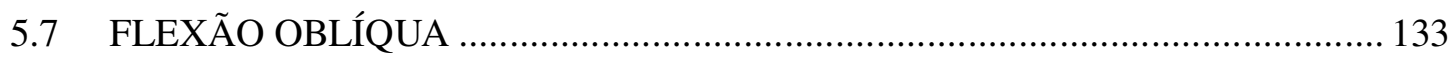

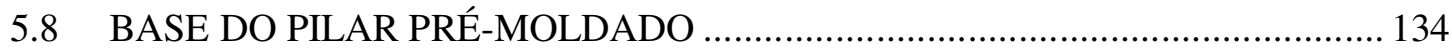

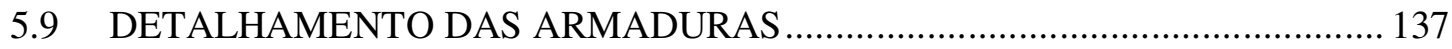

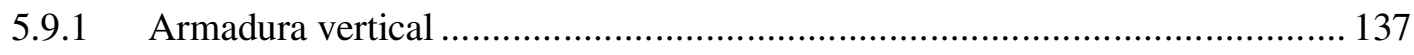

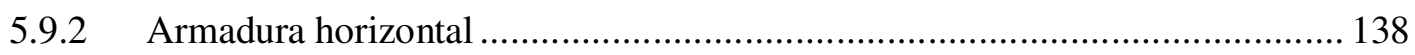

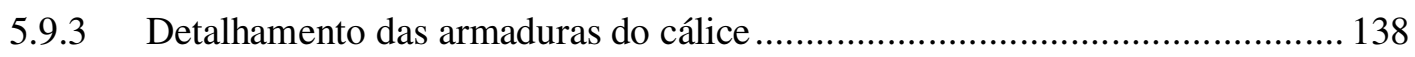

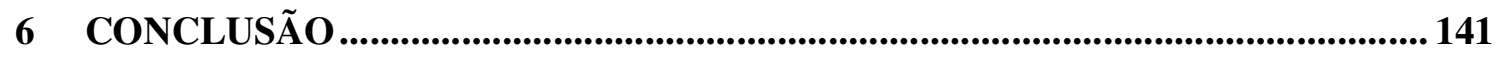

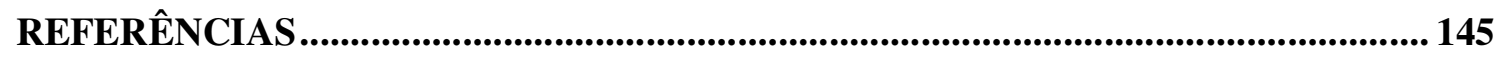

APÊNDICE A- EXEMPLO DE DIMENSIONAMENTO DE CÁLICE COM INTERFACE LISA ...................................................................................................... 149

APÊNDICE B- EXEMPLO DE DIMENSIONAMENTO DE CÁLICE COM INTERFACE RUGOSA ............................................................................................. 156

APÊNDICE C - EXEMPLO DE DIMENSIONAMENTO DE CÁLICE SUBMETIDO À FLEXÃO OBLÍQUA …….......................................................................................... 163

APÊNDICE D - ANÁlise do PILAR PRÉ-MOLdAdo NA REgIÃo DE EMBUTIMENTO ................................................................................................... 169

APÊNDICE E - SÍNTESE DAS RECOMENDAÇÕES DE PROJETO DE CÁLICES DE FUNDAÇÃO PARA SUBSIDIAR FUTURAS REVISÕES DA ABNT NBR

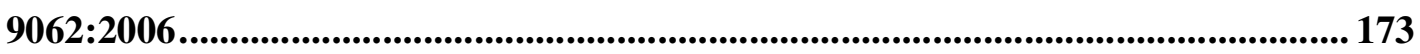




\section{INTRODUÇÃO}

\subsection{CONSIDERAÇÕES INICIAIS}

Desde o surgimento das estruturas de concreto pré-moldado, esse tipo de construção vem ganhando espaço na industrialização da construção civil. A principal diferença entre uma estrutura de concreto pré-moldado e uma estrutura convencional de concreto armado, em relação à análise estrutural, está na existência de ligações entre os seus elementos e também pela necessidade de verificar situações de montagem dos elementos constituintes da estrutura.

O principal objetivo estrutural de uma ligação é a transferência dos esforços entre os elementos, a fim de que se permita a interação estrutural entre todas as partes, garantindo a solidez e a estabilidade da construção ao longo de sua vida útil. Ligações são regiões de descontinuidade onde ocorrem concentrações de tensões e constituem um ponto delicado no que se refere ao dimensionamento e montagem das estruturas de concreto pré-moldado. Um projeto de qualidade é um dos pontos para o sucesso da pré-fabricação e o projeto das ligações devem atender uma série de critérios relativos à produção e execução. Assim, estudos a respeito das ligações são importantes, para que soluções econômicas possam ser sugeridas, sem afetar a segurança estrutural.

Nesse trabalho será estudada a ligação pilar-fundação, que pode ocorrer de diferentes formas: por meio de cálice, por chapa de base, por emenda da armadura com graute e bainha e por emenda de armaduras salientes, conforme ilustrado na Figura 1.1.

Segundo El Debs (2000), na ligação por meio de chapa de base, as ações atuantes no pilar são transmitidas para a fundação por meio da chapa metálica unida a armadura principal do pilar e com chumbadores dispostos no elemento de fundação. O nível e o prumo são atendidos por porcas e contra-porcas e o espaço entre a chapa e o elemento de fundação é preenchido com argamassa ou graute. A chapa de base pode ter dimensão igual ou maior que a dimensão do pilar. Esse tipo de ligação é similar a normalmente utilizada na fundação de pilares metálicos e é bastante empregada nos Estados Unidos e Europa. 

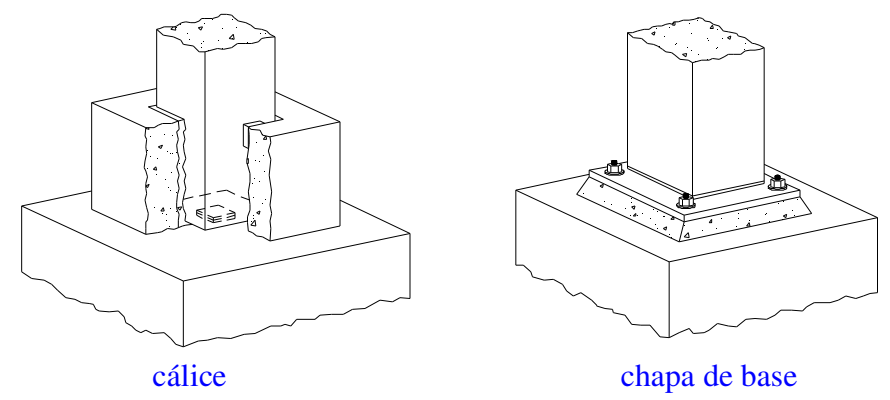

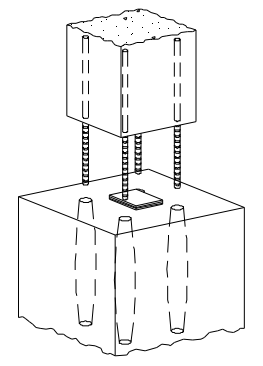

emenda da armadura com bainha e graute

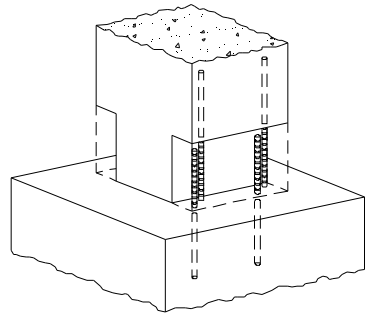

emenda da armadura saliente e concretagem posterior

Figura 1.1 - Tipos de ligação pilar-fundação (adaptada do PCI (1988))

$\mathrm{Na}$ ligação por emenda da armadura com graute e bainha, a armadura do pilar projetase do elemento e durante a montagem esta armadura é introduzida em bainha previamente colocada no elemento de fundação. $\mathrm{O}$ espaço entre a barra e bainha é preenchido com graute. Esse tipo de ligação tem boa capacidade de transmitir momento.

Na ligação com emenda de armadura salientes, parte da armadura do pilar fica evidente, e é emendada através de solda ou através de acopladores com posterior concretagem da emenda. Com esse tipo de ligação pilar-fundação reproduz-se praticamente a situação de estruturas monolíticas, porém existe a desvantagem da realização de solda no canteiro de obra.

E por fim, a ligação pilar-fundação por meio de cálice, consiste num certo embutimento de parte do pilar pré-moldado em uma cavidade na base do elemento de fundação e será objeto de estudo desse trabalho.

\subsection{OBJETIVO}

O principal objetivo dessa pesquisa é realizar uma análise crítica e síntese de resultados obtidos por estudos anteriores desenvolvidos na Escola de Engenharia de São Carlos da Universidade de São Paulo (EESC-USP) a respeito da ligação pilar-fundação por meio de cálice com colarinho. Esses estudos englobam uma tese de doutorado e três 
dissertações de mestrado, em que foram abordadas diversas situações de projeto e parâmetros como: comprimento de embutimento do pilar no cálice, atrito mobilizado nas interfaces, excentricidade da força normal no pilar, esforços nas paredes transversais e longitudinais do cálice e análise do comportamento da base do pilar na região de embutimento.

Como objetivos específicos têm-se:

a) Compatibilização e integralização dos resultados dos trabalhos anteriores;

b) Elaboração de recomendações para o projeto da ligação pilar-fundação por meio de cálice com colarinho e também para a base do pilar pré-moldado;

c) Aplicações práticas de forma a possibilitar uma análise da consistência e abrangência das recomendações.

\subsection{JUSTIFICATIVA}

Esse trabalho se justifica por contribuir com informações referentes ao comportamento da ligação pilar-fundação por meio de cálice e por unir resultados obtidos de pesquisas desenvolvidas por Canha (2004), Jaguaribe Jr. (2005), Ebeling (2006) e Nunes (2009). É necessário juntar e integralizar as conclusões encontradas em cada estudo, além de verificar a necessidade de adaptação dos modelos teóricos quando aplicados a casos reais, em situações convencionais de projeto que utilizam esse tipo de fundação.

Com isso, juntam-se os estudos a respeito de ligações pilar-fundação por meio de cálice, com ênfase no colarinho, no Departamento de Engenharia de Estruturas da EESCUSP.

Após o desenvolvimento desse estudo, pretende-se que as recomendações elaboradas possam subsidiar futuras revisões da ABNT NBR 9062:2006 - Projeto e Execução de Estruturas de Concreto Pré-Moldado, que atualmente é baseada principalmente no modelo de Leonhardt \& Mönnig (1978) no que diz respeito ao dimensionamento da ligação do cálice de fundação.

\subsection{METODOLOGIA}

A metodologia empregada para o desenvolvimento da pesquisa está dividida nas seguintes partes: revisão bibliográfica dos modelos da literatura a respeito do dimensionamento da ligação cálice de fundação, elaboração de recomendações gerais para o projeto do cálice e para a base do pilar, baseadas nos resultados obtidos das pesquisas 
experimentais, planejamento e aplicações dos modelos de projeto para verificação das recomendações e análise dos resultados obtidos.

A revisão bibliográfica está dividida em duas partes. Na primeira, são apresentados os principais modelos teóricos da literatura, e na segunda, são apresentados os estudos experimentais a respeito da ligação pilar-fundação por meio de cálice, desenvolvidos na EESC-USP.

$\mathrm{Na}$ elaboração das recomendações é feita uma integralização de todos os resultados obtidos incluindo todas as conclusões e comparações.

$\mathrm{Na}$ etapa de aplicação do modelo de projeto são determinadas as variáveis a serem utilizadas nos cálculos, como: seções de pilares, carregamentos, espessura da parede do colarinho e pontos de aplicações das resultantes. Nas aplicações, são analisadas todas as situações e simulados casos reais de emprego da ligação pilar-fundação por meio de cálice.

Posteriormente, os resultados são analisados criticamente, a fim de avaliar a melhor representação do comportamento da ligação e são elaboradas recomendações finais para o projeto de cálices de fundação e para a base do pilar pré-moldado.

\subsection{APRESENTAÇÃO DA DISSERTAÇÃO}

No Capítulo 1 é apresentada uma introdução inicial a respeito de ligações em estruturas de concreto pré-moldado, e especificamente, dos tipos de ligação pilar-fundação, seguida da exposição dos objetivos, justificativas e metodologia adotada para o desenvolvimento da pesquisa.

No Capítulo 2 descreve-se o comportamento da ligação por meio de cálice, indicando quais as principais variáveis que influenciam no seu comportamento. Logo após, são apresentadas recomendações e alguns modelos de projeto da literatura a respeito da ligação por meio de cálice.

No Capítulo 3 são revisados todos os estudos experimentais desenvolvidos na EESCUSP durante os últimos anos a respeito da ligação pilar-fundação por meio de cálice.

No Capítulo 4 são apresentadas recomendações gerais referentes ao projeto do cálice de fundação baseada nas conclusões obtidas dos estudos desenvolvidos.

Devido a diferentes conclusões ou verificação de melhoria das recomendações apresentadas, no Capítulo 5, são desenvolvidos exemplos práticos de aplicação da ligação cálice-fundação com avaliação dos parâmetros confrontantes.

Concluindo, no Capítulo 6 são apresentadas as considerações finais. 
Com o objetivo de apresentar exemplos de dimensionamento, nos apêndices é elaborado uma sequência de cálculo para o projeto da ligação de cálice com interface lisa e rugosa e para a base do pilar pré-moldado, além de apresentar uma sequência concisa e simplificada com recomendações gerais de dimensionamento que poderão subsidiar futuras revisões da ABNT NBR 9062:2006. 
Introdução 


\section{REVISÃO BIBLIOGRÁFICA}

\subsection{CONSIDERAÇÕES INICIAIS}

A ligação pilar-fundação por meio de cálice é a mais utilizada no Brasil e consiste num certo embutimento de parte do pilar pré-moldado em uma cavidade na base do elemento de fundação, conforme ilustrado na Figura 2.1. Após encaixe do pilar, para o prumo e posicionamento do pilar em planta são utilizadas cunhas de madeira como dispositivos de centralização e fixação temporária. O preenchimento do espaço entre as paredes do colarinho e do pilar é feito com graute ou concreto moldado no local.

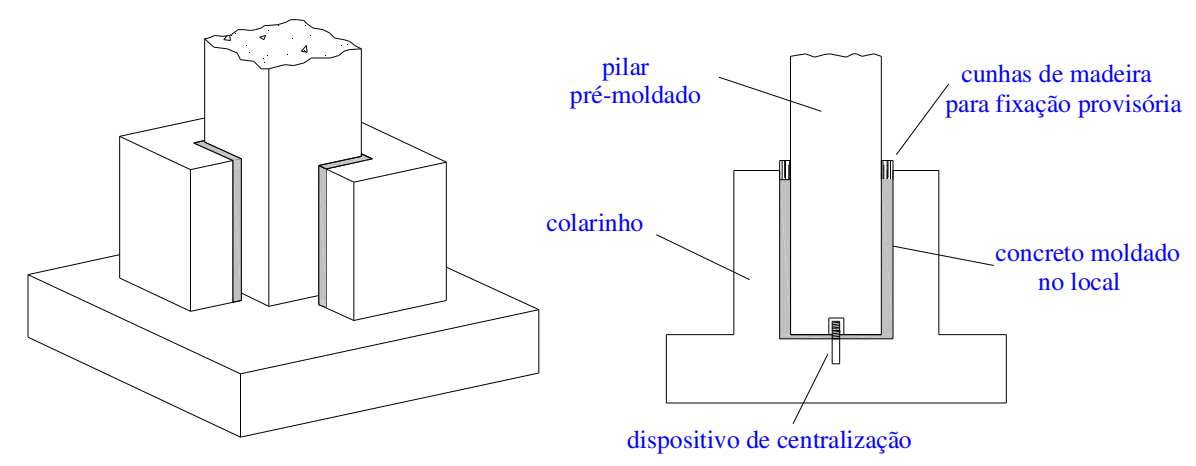

Figura 2.1 - Ligação pilar-fundação por meio de cálice (adaptado de EL DEBS (2000))

As vantagens da utilização desse tipo de ligação são:

a) Facilidade de montagem e consequente rapidez na execução dessa etapa construtiva;

b) Menor sensibilidade as imprecisões de projeto e montagem, facilitando ajustes aos desvios de execução;

c) Boa capacidade de transmissão de forças normais e momentos fletores, tendo as vezes comportamento muito próximo ao de uma ligação monolítica;

d) Dispensa cuidados especiais de proteção contra agentes atmosféricos e fogo pelo fato de não ter armaduras expostas.

Entende-se com uma desvantagem construtiva da ligação por meio de cálice, a necessidade de se fazer a completa inserção da fundação no solo, ou seja, o nível do topo do 
colarinho ficar abaixo do nível do solo. Além da necessidade de sempre existir, em obras de divisa, uma determinada distância entre o pilar e a divisa, devido à parede do colarinho.

Algumas variações da ligação pilar-fundação por meio de cálice são apresentadas na Figura 2.2.
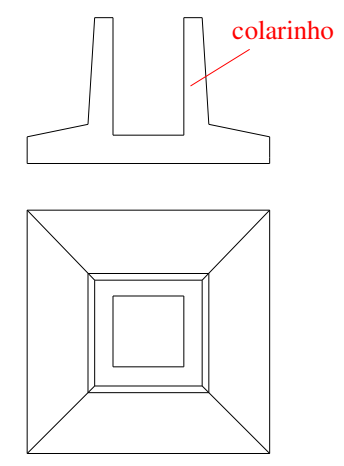

sapata

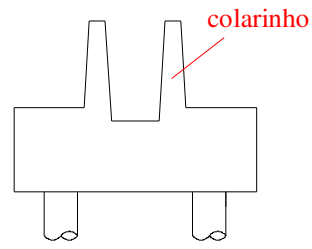

sobre o bloco

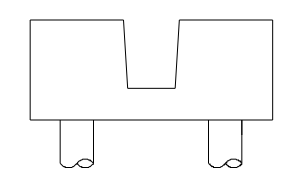

embutido no bloco

bloco sobre estacas

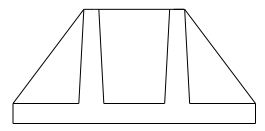

nervuras

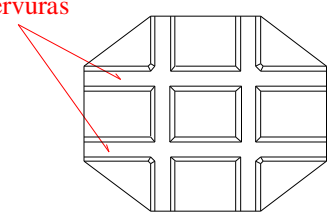

com nervuras e sapata
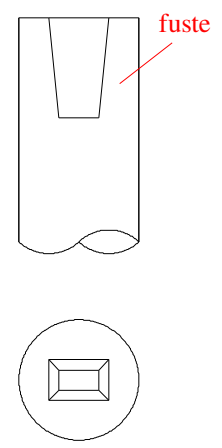

embutido no fuste de tubulão

Figura 2.2 - Formas de cálices de fundação (EL DEBS (2000))

Essas variações referem-se ao:

a) Tipo de fundação que será utilizado na edificação: sapata, bloco sobre estacas ou tubulão;

b) Forma do cálice: cálice embutido, semi-embutido ou com colarinho.

A ABNT NBR 9062:2006 diz que, colarinho é um tipo de cálice composto por um conjunto de paredes salientes que contornam a cavidade destinada ao encaixe dos pilares.

Para definição das características geométricas do cálice com colarinho é apresentada a Figura 2.3. 

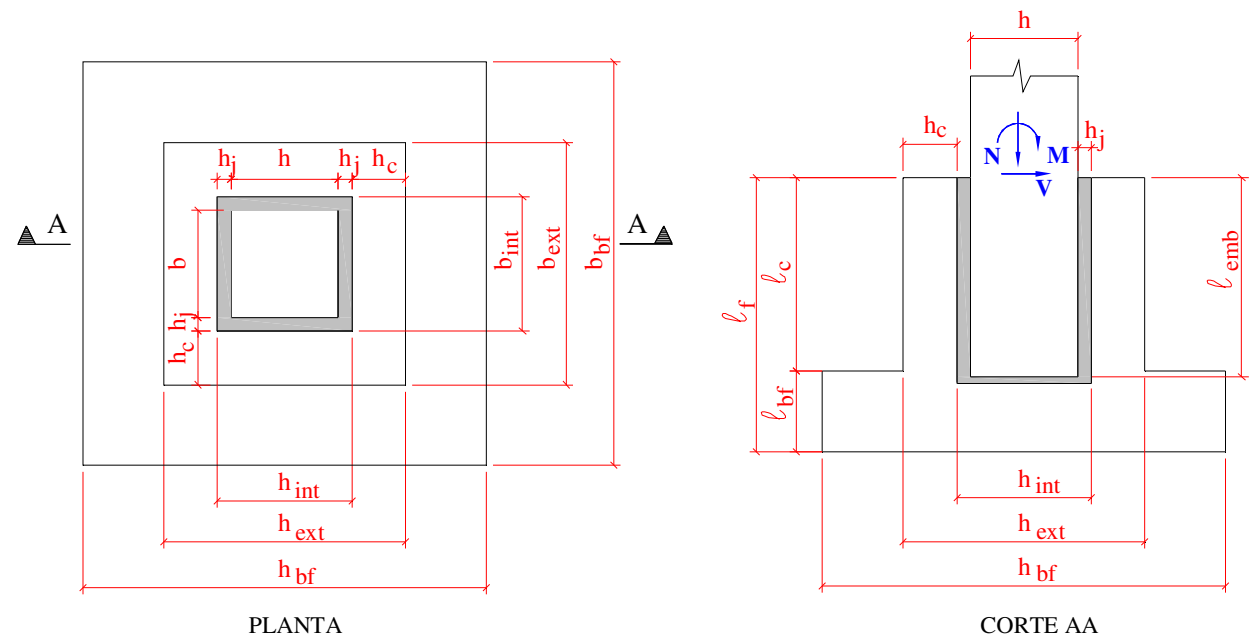

Figura 2.3 - Características geométricas do cálice de fundação

Nessa figura são determinadas as seguintes notações:

$b$ : Base da seção transversal do pilar

$b_{b f}$ : Base da seção em planta da base da fundação

$b_{\text {int }}:$ Base interna entre as paredes do colarinho

$b_{e x t}$ : Base externa entre as paredes do colarinho

$h$ : Largura da seção transversal do pilar

$h_{b f}$ : Largura da seção em planta da base da fundação

$h_{\text {int }}:$ Largura interna entre as paredes do colarinho

$h_{\text {ext }}:$ Largura externa entre as paredes do colarinho

$h_{j}$ : Espessura da junta de ligação do cálice com o pilar

$h_{c}$ : Espessura da parede do colarinho

$l_{b f}:$ Espessura da base da fundação

$l_{c}:$ Comprimento do consolo

$l_{e m b}$ : Comprimento de embutimento do pilar no cálice (não considerando a altura da junta abaixo do pilar)

$l_{f}:$ Altura da fundação

$N, M e V$ :Esforços solicitantes atuantes na ligação 


\subsection{COMPORTAMENTO DA LIGAÇÃO}

O comportamento da ligação pilar-fundação por meio de cálice ocorre de forma semelhante em relação aos diversos modelos existentes na literatura.

As paredes transversais e longitudinais são as responsáveis pela transferência de esforços provenientes do pilar até a fundação. A Figura 2.4 ilustra o comportamento do cálice de fundação com interface lisa.

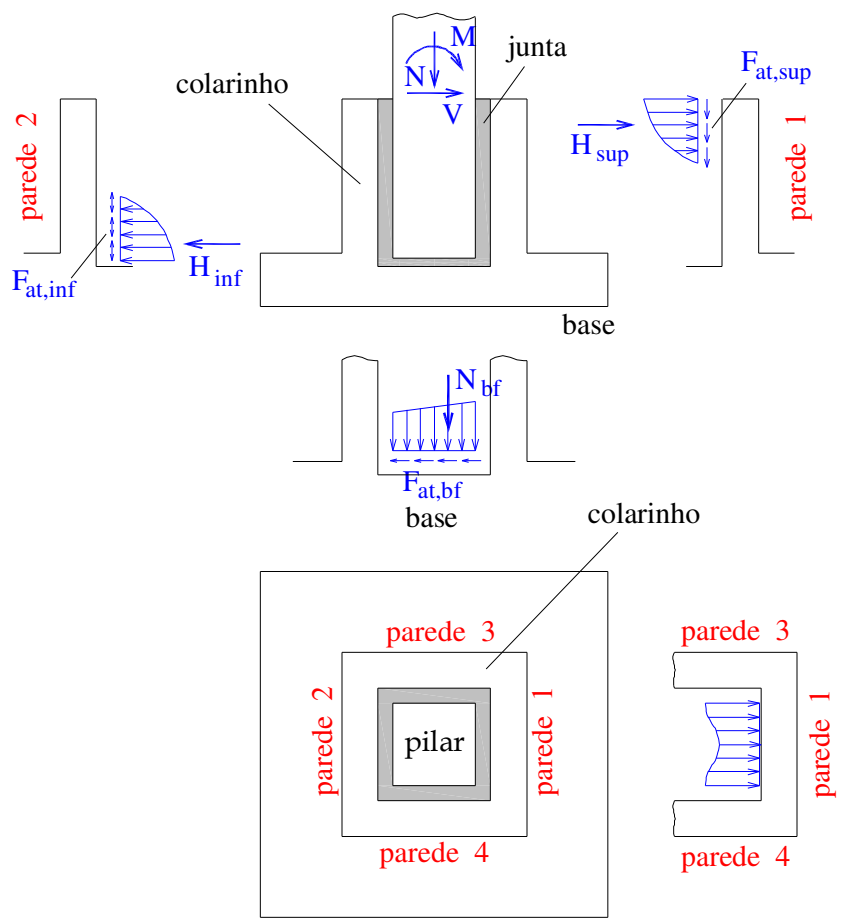

Figura 2.4 - Transferência dos esforços no cálice de fundação com interface lisa (CANHA (2004))

Por intermédio do concreto de preenchimento da junta, os esforços solicitantes momento fletor $M$ e a força cortante $V$ atuantes no pilar são transmitidas para as paredes transversais do cálice através das resultantes de pressões $H_{\text {sup }}$ e $H_{\text {inf }}$. Devido a essas pressões, forças de atrito surgem na interface pilar-colarinho das paredes transversais frontal 1 e posterior 2. O sentido da força de atrito na parede posterior 2 depende da relação entre as solicitações e da geometria. Na parede frontal 1 esse sentido é o mesmo da força normal. A intensidade da força normal transmitida para a base do cálice é reduzida pelas forças de atrito.

A pressão $H_{\text {sup }}$ que atua na parede transversal frontal 1 gera esforços transversais, que são transmitidos para as paredes longitudinais 3 e 4, por essas possuírem maior rigidez (Figura 2.5 (a)). Já a pressão $H_{\text {inf }}$ que atua na parede transversal posterior 2 é transmitida 
praticamente de forma direta para a base devido à pequena distância entre a resultante de pressão inferior e a base.

As paredes longitudinais 3 e 4 apresentam comportamento de consolo engastado na fundação, conforme indicado na Figura 2.5 (b). A pressão $H_{\text {sup }} / 2$ proveniente da parede transversal frontal 1 é transmitida para a base do cálice através de uma armadura vertical principal localizada na intersecção das paredes transversais e longitudinais no lado tracionado e também por meio de uma biela de compressão.

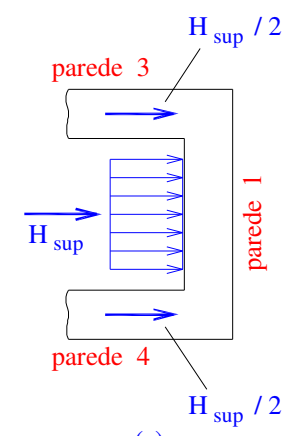

(a)

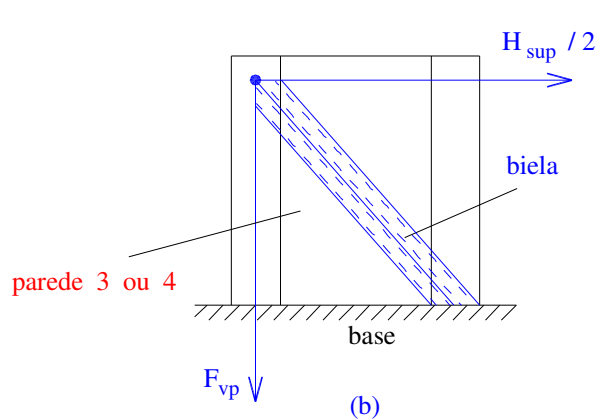

(b)

Figura 2.5 -Transmissão das pressões pelas paredes do colarinho (EL DEBS (2000))

Uma alternativa para melhorar a transmissão de esforços na ligação é através do emprego de rugosidade (chaves de cisalhamento) nas faces internas do colarinho e do pilar. Essa rugosidade faz com que ocorra o funcionamento conjunto entre pilar e fundação, similar ao que ocorre em uma ligação monolítica. Nesse caso além da mobilização das forças de atrito, ocorre a transferência de cisalhamento nas paredes e a força normal transmitida para a base da fundação é distribuída em uma área equivalente a do pilar mais o colarinho.

Existe uma grande quantidade de variáveis que influenciam no comportamento do cálice, sendo que cada variável isolada ou em conjunto exerce influência nesse comportamento. Alguns parâmetros são:

a) Rugosidade da superfície da interface;

b) Relação entre os esforços de momento fletor e força normal, que definirá se a ligação estará sujeita a uma grande ou pequena excentricidade;

c) Dimensões dos elementos, sendo o comprimento de embutimento o de maior influência.

Existem na literatura técnica, alguns modelos para o dimensionamento da ligação cálice de fundação. A seguir serão apresentados os modelos de cálculo mais representativos e que apresentam diferentes recomendações a respeito do comportamento da ligação. 


\subsection{MODELO E RECOMENDAÇÕES DE PROJETO SEGUNDO LEONHARDT \& MÖNNIG (1978), ABNT NBR 9062:2006 e EL DEBS (2000)}

O modelo de Leonhardt \& Mönnig (1978) e da ABNT NBR 9062:2006 serão apresentados juntamente devido às semelhanças das indicações e recomendações encontradas nesses modelos. Serão ainda acrescentadas informações apresentadas em El Debs (2000).

O modelo apresentado por Leonhardt \& Mönnig (1978) é o que tem sido mais empregado para dimensionamento da ligação pilar-fundação, porém este modelo apresenta algumas simplificações, como a não consideração das forças de atrito que surgem nos cálices com interface lisa durante a transmissão das pressões do pilar para as paredes do colarinho, resultando assim em resultados conservadores. A Norma ABNT NBR 9062:2006 e as indicações de El Debs (2000) são baseadas nesse modelo da literatura.

\subsubsection{Propriedades geométricas e forças atuantes no cálice}

Na Figura 2.6, são apresentadas as características geométricas e as resultantes de forças de um cálice de fundação baseada nos modelos que estão sendo revisados.
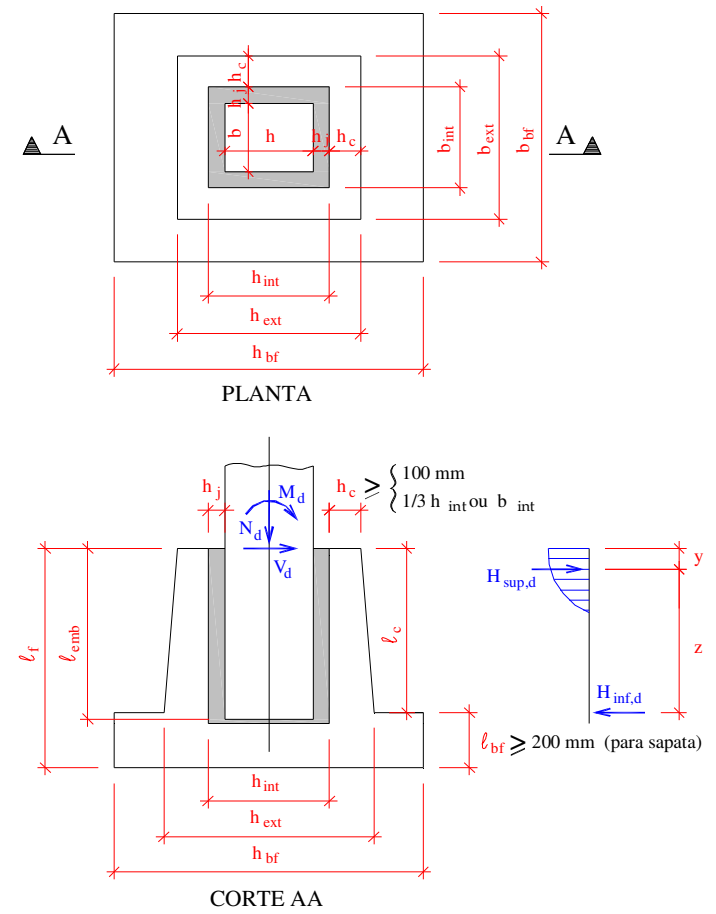

Figura 2.6 - Características geométricas e resultantes de forças no cálice (adaptado de EL DEBS (2000)) 
Analisando a Figura 2.6, identificam-se os parâmetros de distância da aplicação das pressões nas paredes transversais 1 e 2 e as espessuras mínimas das paredes do colarinho e da base da fundação. Quanto ao comprimento de embutimento, indicado na Tabela 2.1, as recomendações dos modelos de Leonhardt \& Mönnig (1978) e da ABNT NBR 9062:2006 são diferentes, com exceção do valor de 1,20h indicado para cálice com interface rugosa e pequena excentricidade.

Tabela 2.1 - Comprimentos de embutimento segundo ABNT NBR 9062:2006 e Leonhardt \& Mönnig (1978)

\begin{tabular}{c|c|c|c|c}
\hline \multirow{2}{*}{ Modelo } & \multicolumn{2}{|c|}{ Interface lisa } & \multicolumn{2}{c}{ Interface Rugosa } \\
\cline { 2 - 5 } & $\frac{M_{d}}{N_{d} \cdot h} \leq 0,15$ & $\frac{M_{d}}{N_{d} \cdot h} \geq 2$ & $\frac{M_{d}}{N_{d} \cdot h} \leq 0,15$ & $\frac{M_{d}}{N_{d} \cdot h} \geq 2$ \\
\hline $\begin{array}{c}\text { LEONHARDT } \\
\text { \& MÖNNIG }\end{array}$ & $1,68 h^{*}$ & $2,80 h$ & $1,20 h$ & $2,00 h$ \\
\hline $\begin{array}{c}\text { ABNT NBR } \\
\text { 9062:2006 }\end{array}$ & $1,50 h^{*}$ & $2,00 h$ & $1,20 h$ & $1,60 h$ \\
\hline
\end{tabular}

Percebe-se que os valores indicados pelo modelo de Leonhardt \& Mönnig (1978) são mais conservadores que os da Norma Brasileira, ocorrendo uma diferença de até $40 \%$ para o caso de grande excentricidade $\left(\mathrm{M}_{\mathrm{d}} / \mathrm{N}_{\mathrm{d}} \cdot \mathrm{h} \geq 2\right)$. Para valores intermediários de excentricidade pode-se interpolar linearmente a relação de momento fletor e força normal para definição do comprimento de embutimento.

De acordo com a ABNT NBR 9062:2006, o comprimento de embutimento mínimo a ser adotado é de $40 \mathrm{~cm}$, a espessura da base do cálice não deve ser inferior a $20 \mathrm{~cm}$ e, para os casos de tração no pilar, o comprimento de embutimento deve ser multiplicado pelo coeficiente de 1,15. Para $l_{\text {emb }}$ resultante maior que $200 \mathrm{~cm}$ podem ser adotados valores diferentes, desde que seja realizado um estudo da ligação entre o pilar e o colarinho.

É recomendado ainda que as superfícies internas do cálice tenham pelo menos a mesma característica superficial que a dos pilares. As interfaces são consideradas rugosas quando as superfícies laterais do pilar e das paredes internas do cálice tem rugosidade mínima de $1 \mathrm{~cm}$ a cada $10 \mathrm{~cm}$, obtendo assim menores valores para o comprimento de embutimento.

As resultantes das pressões nas paredes transversais e seus pontos de aplicação variam conforme os modelos e são apresentadas nas Tabela 2.2 e Tabela 2.3. A pressão $H_{\text {sup,d }}$ atua na 
parte superior da parede transversal frontal 1 e a pressão $H_{\text {inf, } d}$ atua na parte inferior na parede transversal posterior 2 .

As pressões resultantes indicadas pela ABNT NBR 9062:2006 são semelhantes aos valores apresentados no modelo de Leonhardt \& Mönnig (1978). A diferença está no valor de $y$ e no coeficiente da primeira parcela da equação para cálculo de $H_{\text {sup }, d}$ e $H_{\text {inf,d }}$, ambos para cálice com interface rugosa.

Tabela 2.2 - Resultantes de pressões e ponto de aplicação de $\mathrm{H}_{\text {sup,d }}$ segundo ABNT NBR 9062:2006

\begin{tabular}{c|c|c}
\hline Pressões & Interface lisa & Interface rugosa \\
\hline$H_{\text {sup }, d}$ & $\frac{M_{d}}{0,67 . l_{\text {emb }}}+1,25 . V_{d}$ & $\frac{M_{d}}{0,85 \cdot l_{\text {emb }}}+1,20 . V_{d}$ \\
\hline$H_{\text {inf }, d}$ & $\frac{M_{d}}{0,67 \cdot l_{e m b}}+0,25 . V_{d}$ & $\frac{M_{d}}{0,85 \cdot l_{\text {emb }}}+0,20 . V_{d}$ \\
\hline$y$ & $0,167 . l_{\text {emb }}$ & $0,150 \cdot l_{\text {emb }}$ \\
\hline
\end{tabular}

Tabela 2.3 - Resultantes de pressões e ponto de aplicação de $\mathrm{H}_{\text {sup,d }}$ segundo modelo de Leonhardt \& Mönnig (1978)

\begin{tabular}{c|c|c}
\hline Pressões & Interface lisa & Interface rugosa \\
\hline$H_{\text {sup }, d}$ & $\frac{M_{d}}{0,67 . l_{e m b}}+1,25 . V_{d}$ & $\frac{M_{d}}{0,83 \cdot l_{e m b}}+1,20 . V_{d}$ \\
\hline$H_{\text {inf, } d}$ & $\frac{M_{d}}{0,67 \cdot l_{e m b}}+0,25 . V_{d}$ & $\frac{M_{d}}{0,83 \cdot l_{e m b}}+0,20 . V_{d}$ \\
\hline$y$ & $0,167 . l_{e m b}$ & $0,167 . l_{e m b}$ \\
\hline
\end{tabular}

\subsubsection{Dimensionamento das paredes do cálice}

No dimensionamento do cálice, os elementos de fundação devem ser calculados para resistir à totalidade das forças verticais e horizontais e momentos transmitidos pelos pilares, incluindo os momentos de $2^{\circ}$ ordem globais.

Na Figura 2.7 é apresentada a distribuição das armaduras no cálice de fundação com denominações e respectivas posições de acordo com os modelos revisados. 


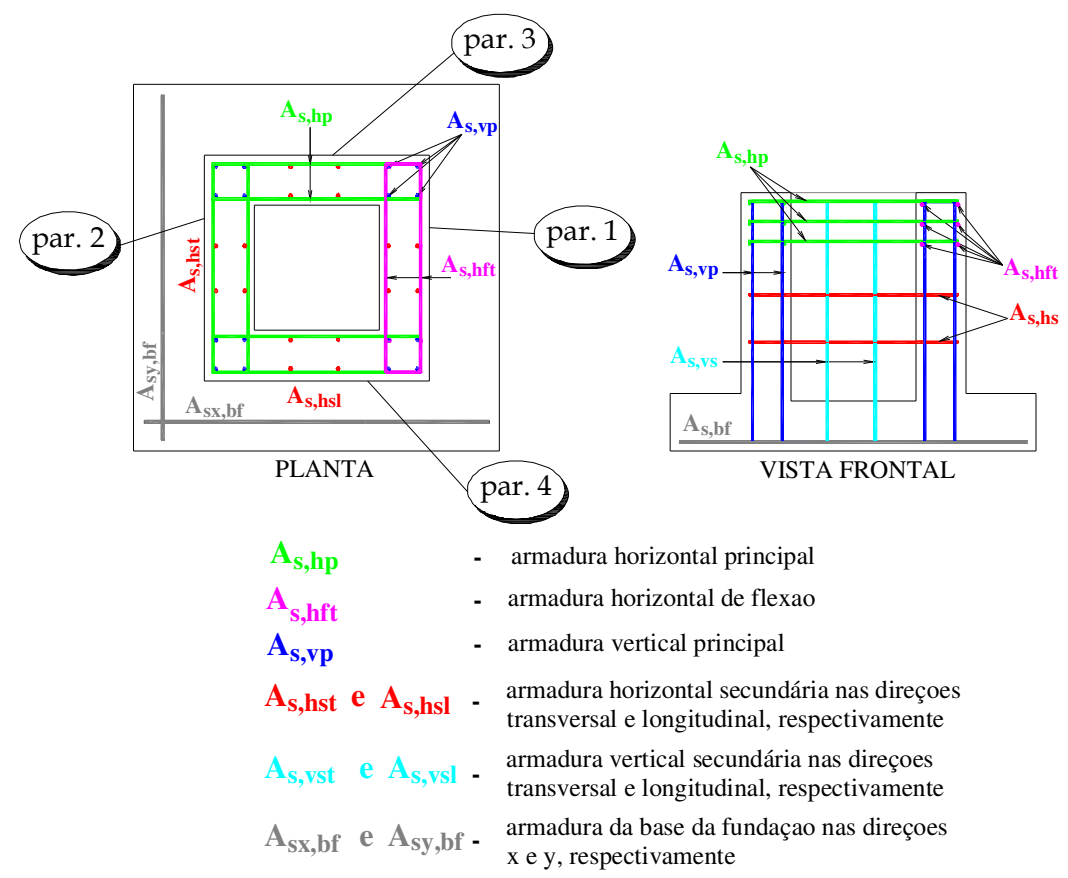

Figura 2.7 - Armaduras do cálice e suas posições

Um procedimento é apresentado em El Debs (2000) para cálculo da armadura $A_{s, h f t}$ da parede transversal 1 com interface lisa. Nesse modelo considera-se a elevada rigidez à flexão das paredes longitudinais 3 e 4 e a transferência praticamente direta da pressão inferior da parede transversal 2 para a base da fundação, sendo apenas a parte superior da parede transversal frontal 1 solicitada significativamente a momento fletor. A metodologia ilustrada na Figura 2.8 foi baseada na antiga Norma Italiana CNR 10025:1984. A norma italiana, em vigor, CNR 10025:1998 indica um comportamento da parte superior dessa parede submetido somente a força de tração.

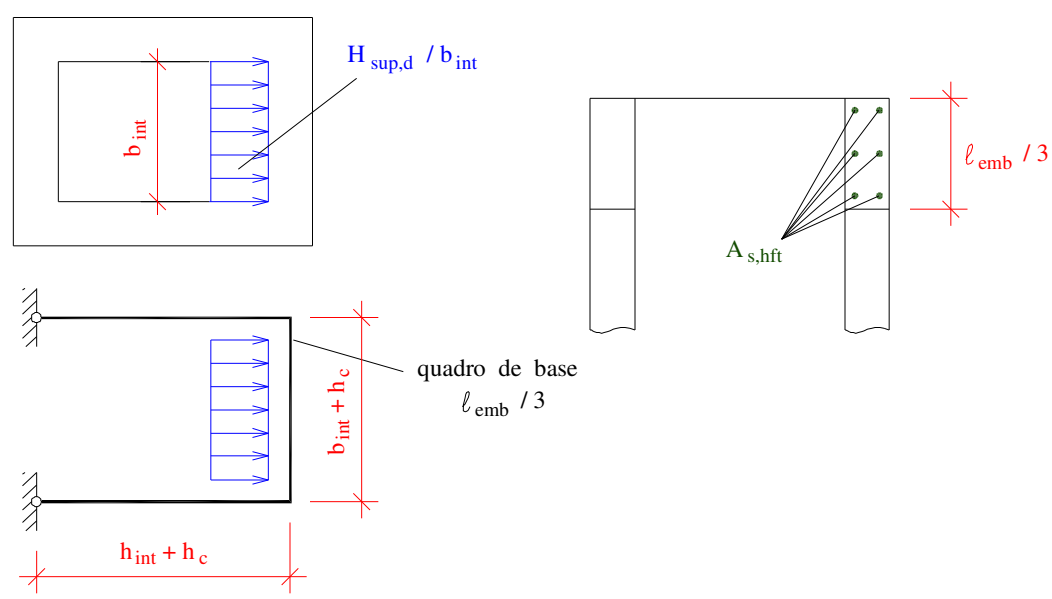

Figura 2.8 - Flexão e disposição da armadura $\mathrm{A}_{\mathrm{s}, \mathrm{hft}}$ na parede transversal 1 (EL DEBS (2000)) 
A tensão de contato, nessa região, é calculada conforme a Equação (2.1) e é limitada ao valor de $0,6 . f_{c d}$.

$$
\sigma_{\text {cont }}=\frac{H_{\text {sup }, d}}{\left(l_{\text {emb }} / 3\right) \cdot b_{\mathrm{int}}} \leq 0,6 \cdot f_{c d}
$$

A armadura horizontal principal para transmitir a força $H_{\text {sup }, d}$ por meio das paredes longitudinais é calculada conforme a Equação (2.2):

$$
A_{s, h p}=\frac{H_{\text {sup }, d}}{2 \cdot f_{y d}}
$$

Esta armadura deve ser distribuída em uma altura de $l_{e m b} / 3$ nas paredes longitudinais 3 e 4 , e repetida nas paredes transversais 1 e 2 . A armadura $A_{s, h f t}$ é calculada apenas para cálice com interface lisa e deve ser disposta no topo da parede transversal 1 no comprimento de $l_{e m b} / 3$, devendo-se adotar o maior valor entre $A_{s, h p}$ e $A_{s, h f t}$ para a armação dessa parede.

As paredes longitudinais 3 e 4 apresentam um comportamento de consolo e assim devem ser dimensionadas. A armadura vertical principal $A_{s, v p}$, as armaduras verticais secundárias $A_{s, v s}$ e as armaduras horizontais secundárias $A_{s, h s}$ são determinadas conforme o tipo de consolo, sendo especificado para cada tipo um modelo para o cálculo das armaduras. É necessário também verificar a ruptura do concreto da biela de compressão. No capítulo 4 , onde são apresentadas as recomendações para o projeto de cálice de fundação, está especificado como se procede ao dimensionamento para cada tipo de consolo.

De acordo com El Debs (2000), para o caso de flexão oblíqua, em que ocorre a atuação simultânea de momentos em duas direções ortogonais, conforme Figura 2.9, o cálculo da armadura pode ser feito considerando os momentos isoladamente, desde que:

a) Reduza-se a tensão última de contato de $0,6 . f_{c d}$ para $0,5 . f_{c d}$;

b) Sobreponha-se a armadura $A_{s, h p}$ com a armadura de flexão $A_{s, h f t}$ para transmitir a pressão $H_{\text {sup,d }}$ (cálice de interface lisa);

c) Somem-se as armaduras verticais principais calculadas para cada direção isoladamente. Por exemplo $A_{s, v p 1}=A_{s, v p 1 x}+A_{s, v p 1 y}$, sendo que $A_{s, v p 1 x}$ e $A_{s, v p 1 y}$ são as armaduras resultantes dos momentos $M_{x d}$ e $M_{y d}$. 


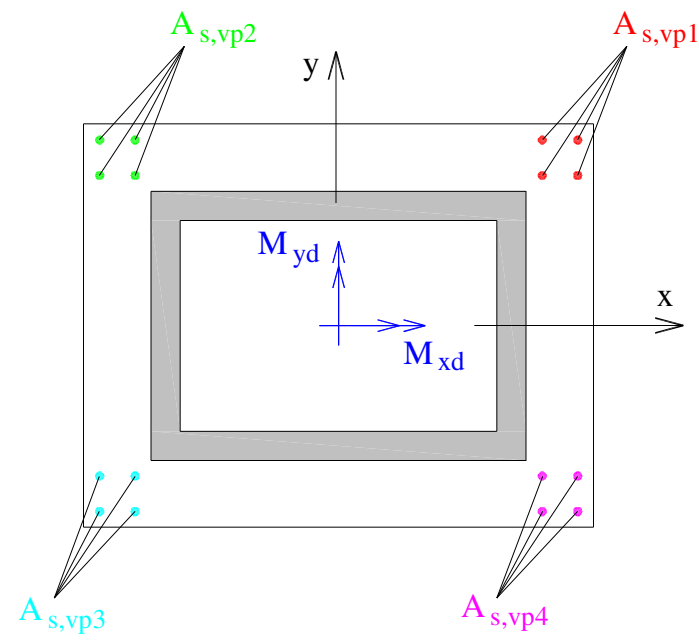

Figura 2.9 - Ocorrência de flexão oblíqua no cálice de fundação (EL DEBS (2000))

\subsubsection{Arranjo das armaduras do cálice}

É apresentado no modelo de Leonhardt \& Mönnig (1978) um arranjo de armaduras do cálice de fundação para as situações de grande e pequena excentricidade, como ilustrado na Figura 2.10 e Figura 2.11.

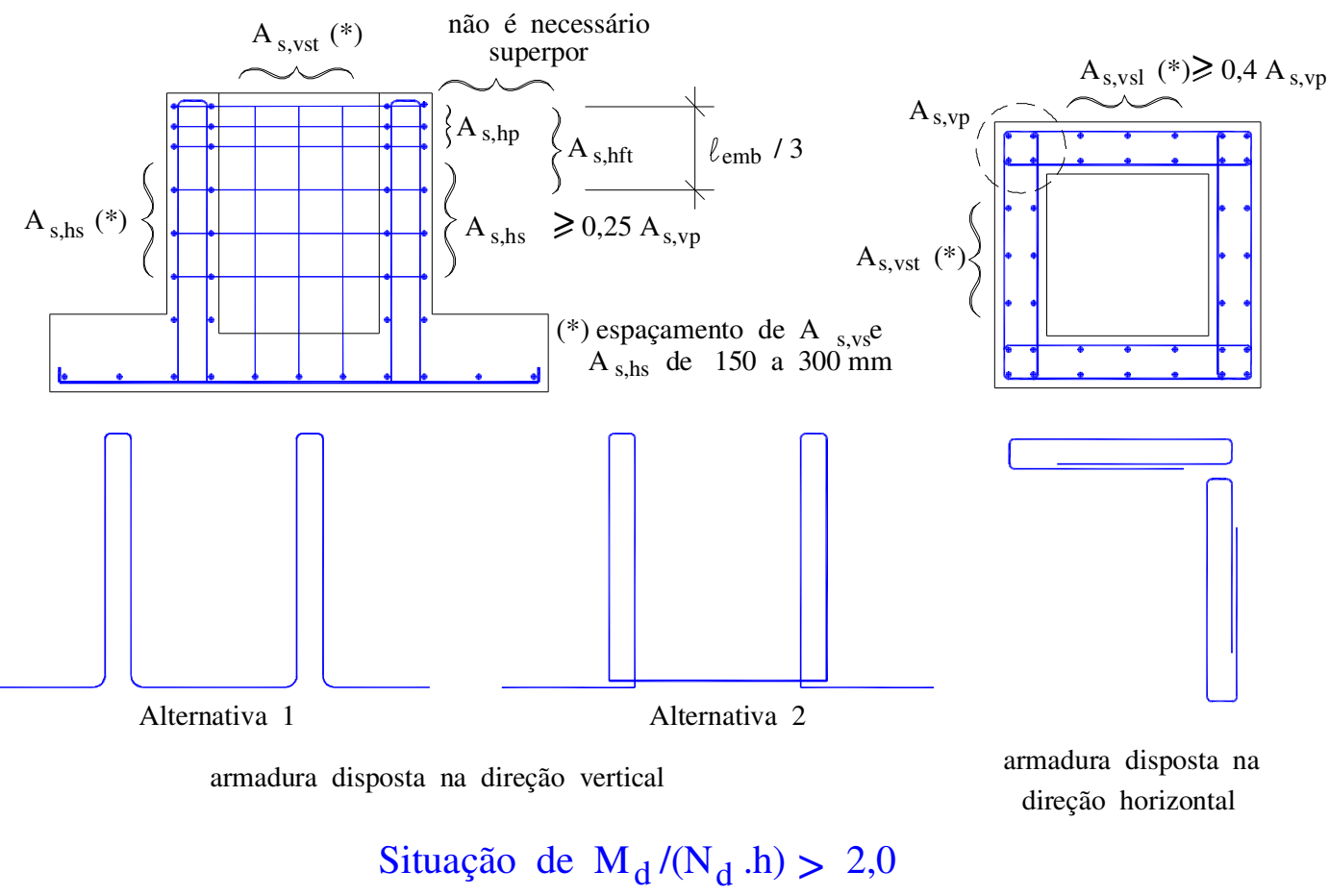

Figura 2.10 - Arranjo das armaduras do cálice para situação de grande excentricidade (LEONHARDT \& MÖNNIG (1978) adaptado por EL DEBS (2000)) 

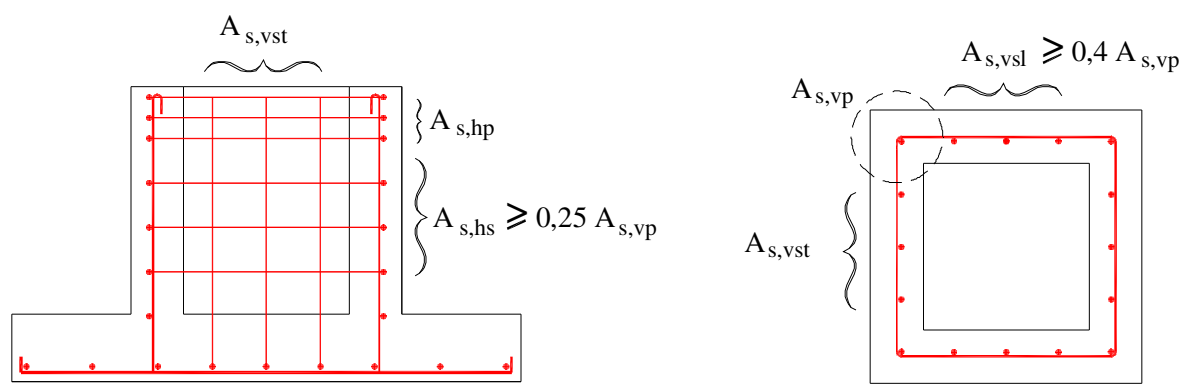

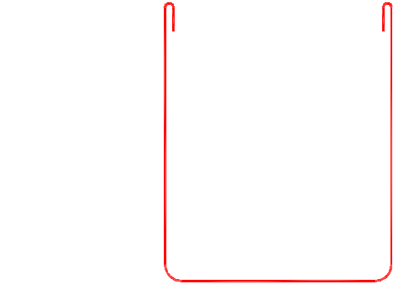

armadura disposta na direção vertical

$$
\text { Situação de } \mathrm{M}_{\mathrm{d}} /\left(\mathrm{N}_{\mathrm{d}} \cdot \mathrm{h}\right)<0,15
$$

Figura 2.11- Arranjo das armaduras do cálice para situação de pequena excentricidade (LEONHARDT \& MÖNNIG (1978) adaptado por EL DEBS (2000))

Conforme Leonhardt \& Mönnig (1978), para cálice de interface rugosa quando se dispuser de comprovação experimental, a armadura $A_{s, h p}$ disposta no topo das paredes longitudinais 3 e 4 pode ser reduzida em virtude da contribuição da aderência mecânica que ocasiona uma inclinação da biela de compressão em relação à horizontal maior que a admitida no cálculo como consolo, como indica a Figura 2.12. E nos pilares submetidos a carregamento excêntrico, a força de tração na armadura longitudinal do pilar é transmitida por traspasse para a armadura vertical do colarinho.

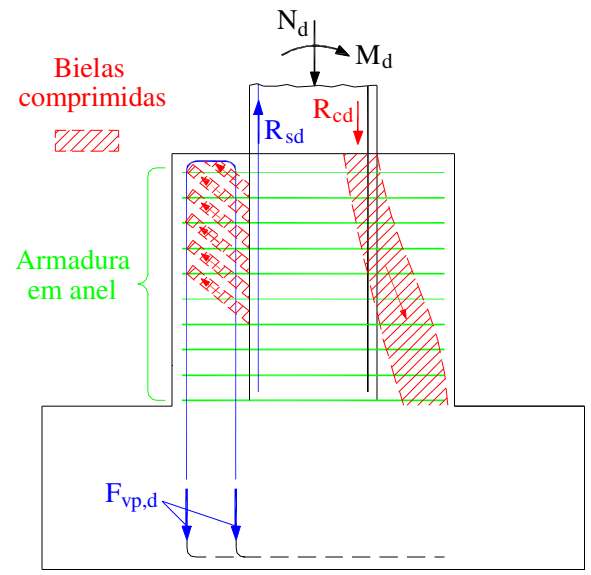

Figura 2.12 - Transmissão das forças de tração entre o pilar e o colarinho para cálice com interface rugosa (LEONHARDT \& MÖNNIG (1978)) 


\subsubsection{Recomendações para a base do cálice e base inferior do pilar}

Para o dimensionamento da fundação do cálice, deve ser considerada a existência ou não de rugosidade nas superfícies de contato, existindo situações e considerações distintas para cálice liso e rugoso.

a) Cálice com interface lisa: se houver ocorrência somente de força normal, não ocorre mobilização de atrito entre as interfaces devido à inexistência de momentos, não ocorrendo redução da força normal do pilar que chega a fundação. É permitido, no entanto, reduzir essa força quando houver atuação simultânea de momento fletor e força normal, pois há mobilização de atrito na superfície pilar-colarinho, conforme Figura 2.13. A verificação da punção em ambos os casos deve ser feita com as dimensões do pilar.

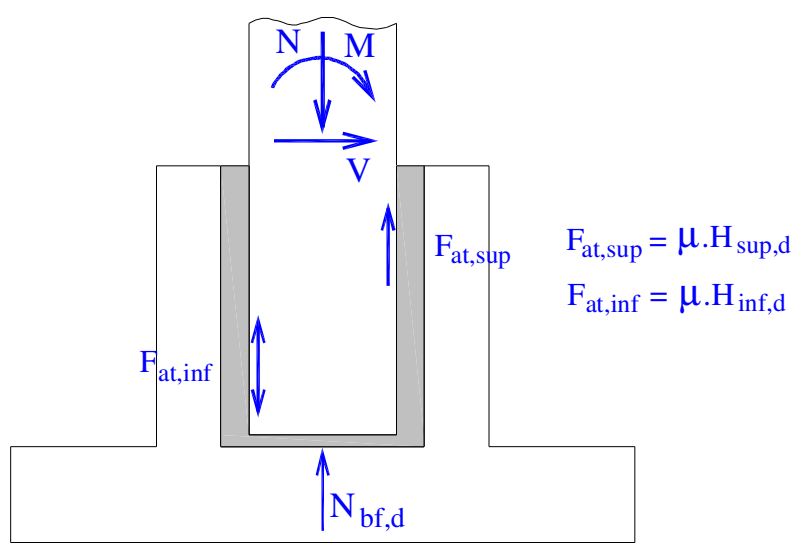

Figura 2.13 - Mobilização atrito na interface pilar-colarinho com paredes lisas (EL DEBS (2000))

Pode-se admitir ainda que parte da força normal é transmitida do colarinho para a base da fundação por meio de uma armadura de suspensão, como ilustra a Figura 2.14. A utilização dessa armadura otimiza o comportamento da fundação quanto à punção, com o deslocamento da superfície de separação. Em El Debs (2000), é indicado o valor máximo de 0,5. $N_{d} / f_{y d}$ para esta armadura. Já na ABNT NBR 9062:2006, é indicado o valor de 0,7. $N_{d} / f_{y d}$. 


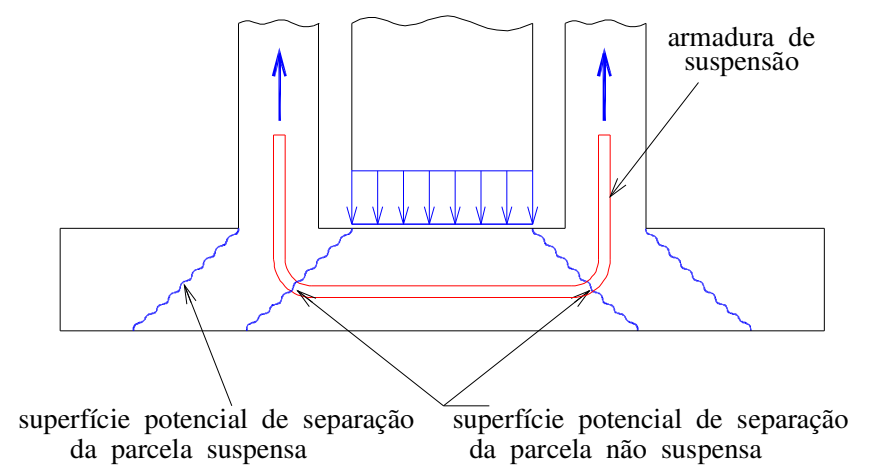

Figura 2.14 - Punção na base da fundação e armadura de suspensão para cálice de paredes lisas (EL

DEBS (2000))

b) Cálice com interface rugosa: considera-se que a força normal é transmitida para a base da fundação numa área equivalente a do pilar acrescida da área do colarinho. Assim, de acordo com a Figura 2.15, o dimensionamento e a verificação da punção são feitas com as dimensões externas do colarinho.

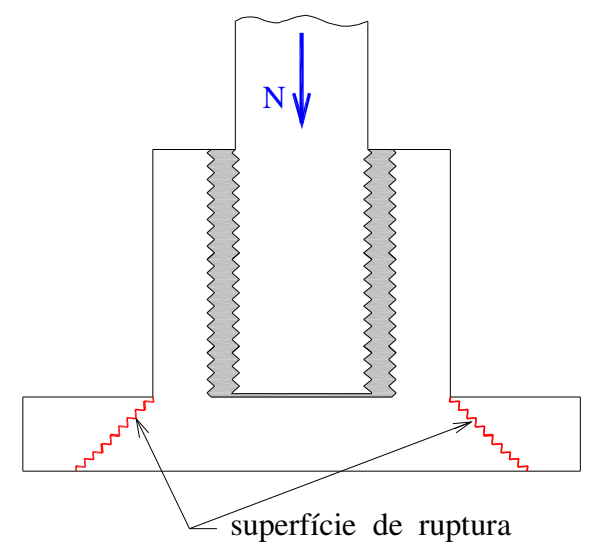

Figura 2.15 - Punção na base do cálice com interface pilar-colarinho com paredes rugosas (DEBS (2000))

Em relação à base do pilar, no caso de cálice com interface lisa, é apresentada em El Debs (2000) a recomendação da colocação de estribo na região de embutimento para resistir à força cortante $H_{\mathrm{inf}, d}$. O dimensionamento da armadura transversal pode ser feito através da consideração de flexo-compressão. É indicado ainda que deva ser disposta na base do pilar, uma armadura $A_{s, b}$ em forma de $\mathrm{U}$ para resistir à força $H_{\mathrm{inf}, d}$. A ancoragem é feita a partir da posição $y$ da resultante $H_{\text {sup }, d}$. Na Figura 2.16 visualizam-se os detalhes dessas armaduras. 


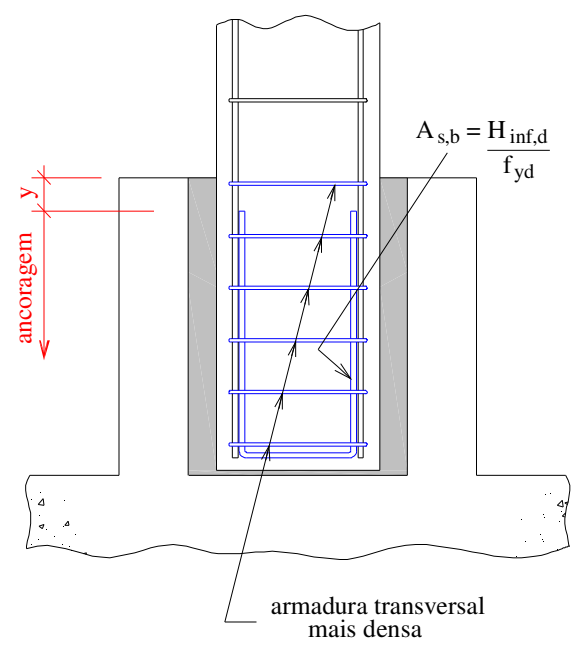

Figura 2.16 - Armadura na base do pilar para cálice de interface lisa (EL DEBS (2000))

\subsubsection{Disposições construtivas}

No projeto do cálice, é necessário atender algumas disposições construtivas para um perfeito funcionamento da ligação. Algumas indicações apresentadas em El Debs (2000) são:

a) Adotar para o concreto de preenchimento da junta uma resistência igual ou superior a resistência do concreto do pilar ou do colarinho, devendo ser feito o adensamento com vibrador de agulha;

b) O espaço mínimo entre as paredes internas do colarinho e do pilar deve ser suficiente para permitir a entrada do aparelho de vibração, esse espaço não deve ser inferior a 5 $\mathrm{cm}$;

c) O cobrimento da armadura que fica na face interna do cálice pode ser reduzido em relação aos demais cobrimentos adotados;

d) Espessura do colarinho deve ser maior que $1 / 3 . h_{\text {int }}$ ou $b_{\text {int }}$ e no mínimo $10 \mathrm{~cm}$, conforme indicado na Figura 2.6.

\subsection{MODELO E RECOMENDAÇÕES DE PROJETO SEGUNDO OLIN ET AL. (1985)}

De acordo com o modelo de Olin et al. (1985), os pilares geralmente são fixados a fundação em ligações rígidas, e o tipo de ligação mais utilizado é a por meio de cálice. As características e dimensionamento dessa ligação serão apresentados a seguir. 


\subsubsection{Propriedades geométricas e forças atuantes no cálice}

Para os autores, a capacidade efetiva da ligação é maior que as referidas nos métodos de cálculo. Esse acréscimo de resistência se deve às tensões de aderência na ligação e do deslocamento da reação na extremidade inferior do pilar. Na Figura 2.17, é apresentada a distribuição de forças na ligação proposta por este modelo.

No estado limite último, o momento resultante que atua na região de embutimento ocasiona uma excentricidade na reação normal na extremidade inferior do pilar. A posição da resultante depende de diversos fatores, tais como: a intensidade da força normal e as dimensões do colarinho. É utilizado o valor da excentricidade de $h / 6$ para os casos de ligações rígidas e as forças de atrito atuando na extremidade inferior do pilar não são consideradas, pois para os autores não se desenvolve uma força de atrito plena nessa região.

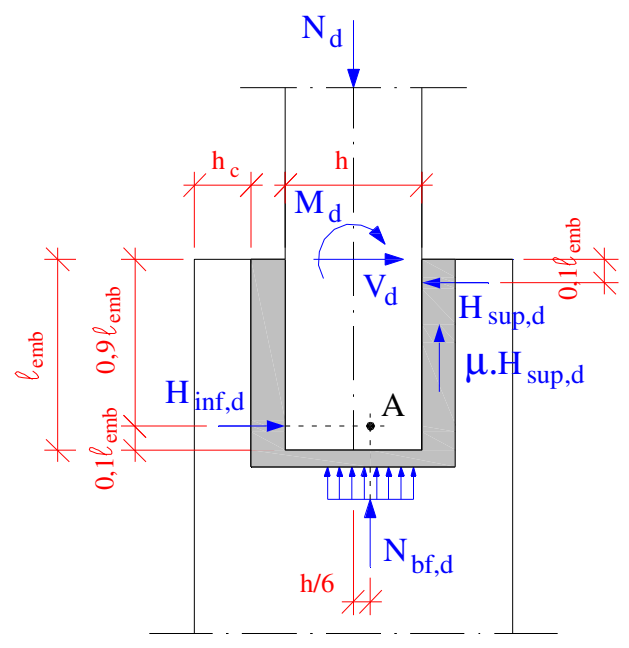

Figura 2.17 - Forças atuantes na ligação pilar-fundação por meio de cálice (OLIN et al. (1985) adaptado por CANHA (2004))

Com o equilíbrio de momentos em relação ao ponto A, define-se o valor da pressão $H_{\text {sup }, d}$.

$$
H_{\text {sup }, d}=\frac{M_{d}-0,17 \cdot h \cdot N_{d}+0,9 \cdot l_{e m b} \cdot V_{c}}{0,8 \cdot l_{e m b}+0,33 \cdot \mu \cdot h}
$$

Verifica-se que com a consideração das parcelas referentes a força de atrito e a força normal há uma redução da intensidade da força $H_{\text {sup }, d}$, resultando portanto em valores menos conservadores. 
Conforme indicação do modelo de Olin et al. (1985) para interface lisa, o coeficiente de atrito vale $\mu=0,3$ e o comprimento de embutimento é aproximadamente igual a 1,3 do maior lado da seção transversal $\left(l_{e m b}=1,3 \cdot h\right)$.

Fazendo-se as modificações na Equação (2.3), a pressão superior resultante fica:

$$
H_{\text {sup }, d}=1,14 \cdot \frac{M_{d}}{l_{\text {emb }}}+1,03 \cdot V_{d}-0,15 \cdot N_{d}
$$

Com o equilíbrio das forças horizontais é definido o valor da força $H_{\text {inf, } d}$.

$$
H_{\text {inf, } d}=H_{\text {sup }, d}-V_{d}
$$

\subsubsection{Tensões de cisalhamento atuantes na parede do cálice}

As tensões de cisalhamento atuantes na interface pilar-concreto de preenchimento são originadas devido à força de atrito e da adesão. As forças de atrito surgem na interface pela atuação da força de compressão produzida pelas forças externas e são consideradas através do coeficiente de atrito $\mu$, dependendo do tipo da superfície.

Quando não existirem forças horizontais produzidas por carregamento externo, as tensões de cisalhamento são consideradas causadas apenas pela adesão entre as superfícies do pilar e do concreto. Olin et al. (1985) mencionam a tensão de adesão com ocorrência de deslizamento como tensão de aderência. A direção e magnitude das tensões de aderência das superfícies laterais são determinadas em função do deslocamento no pilar na região de embutimento e são subdivididas em componentes horizontais e verticais. Por causa da magnitude do deslizamento entre as superfícies no estado limite último, a força horizontal de aderência $F_{b u, x}$ é assumida como uniformemente distribuída em uma área conforme ilustra a Figura 2.18.

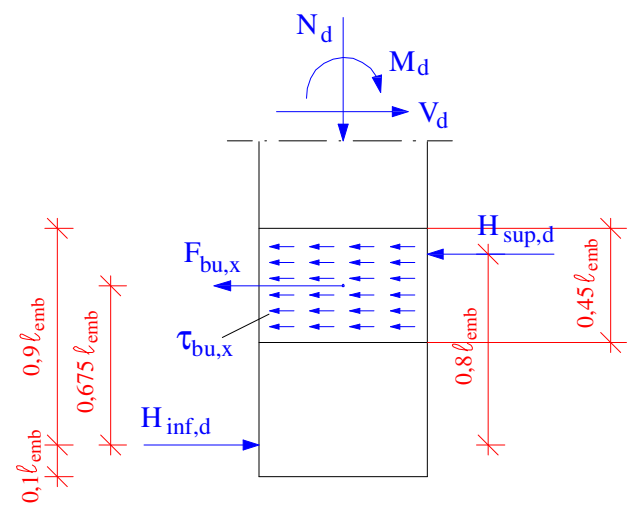

Figura 2.18 - Tensões horizontais de aderência nas superfícies laterais do pilar (OLIN et al. (1985) adaptado por CANHA (2004)) 
A posição da resultante $F_{b u, x}$ não difere muito da posição da resultante $H_{\text {sup }, d}$, ou seja, pode-se adotar com boa aproximação as duas forças atuando no mesmo ponto, tendo em vista que esta diferença não influencia significativamente no dimensionamento da ligação. As tensões distribuídas ao longo das paredes laterais do colarinho exigem praticamente a mesma armadura quando se considera a força concentrada $H_{\text {sup,d }}$, por essa razão elas não são consideradas no dimensionamento do colarinho.

Com relação à magnitude e a direção das tensões verticais de aderência é difícil definir o valor exato dessas tensões nas diferentes partes da ligação. Considerando grandes deslizamentos no estado limite último e comportamento dútil da ligação, a distribuição de tensões apresentada na Figura 2.19 determina o valor resultante de $F_{b u, y}$.

$$
F_{b u, y}=0,5 \cdot \tau_{b u, y} \cdot l_{e m b} \cdot h
$$

Considera-se que a tensão permanecerá constante ainda que haja o deslizamento entre as superfícies. Com uma rugosidade razoavelmente superficial, mantém-se a capacidade de aderência embora surjam fissuras devido à retração do concreto de preenchimento.
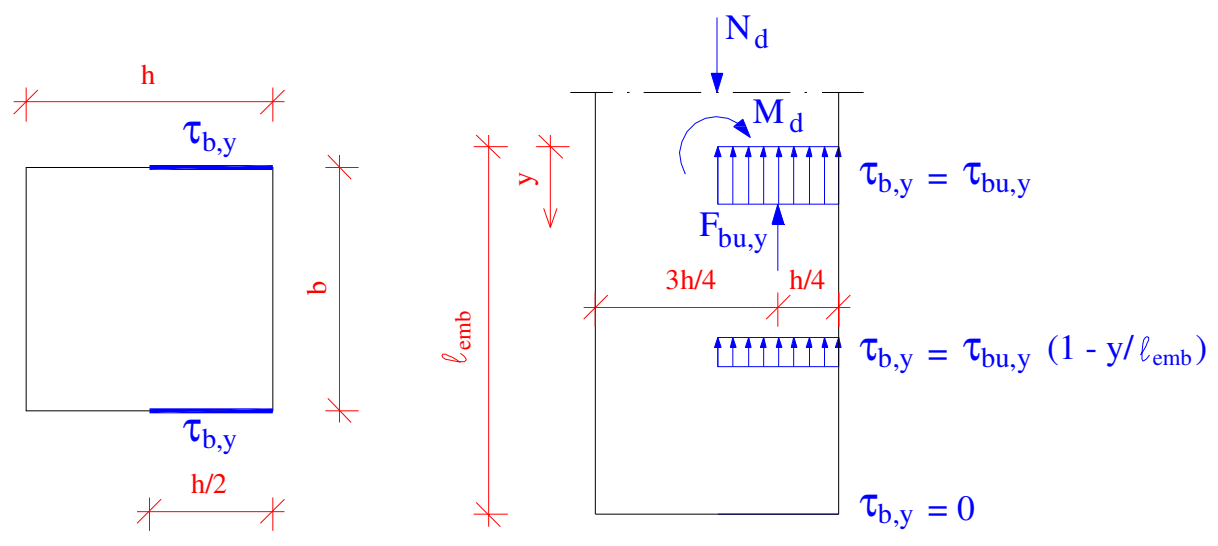

Figura 2.19 - Tensões verticais de aderência nas superfícies laterais do pilar no estado limite último (OLIN et al. (1985) adaptado por CANHA (2004))

Para o caso de interface rugosa considerando a tensão de aderência vertical conforme Equação (2.6) e com equilíbrio de momentos em relação ao ponto A da Figura 2.17, obtém-se o valor de $H_{\text {sup }, d}$.

$$
H_{\text {sup }, d}=\frac{M_{d}-0,17 \cdot h \cdot N_{d}+0,9 \cdot l_{e m b} \cdot V_{d}-0,083 \cdot h}{0,8 \cdot l_{e m b}+0,33 \cdot \mu \cdot h}
$$


Substituindo-se o valor do coeficiente de atrito para interface rugosa $\mu=0,6$ e o comprimento de embutimento $\left(h=l_{e m b} / 1,3\right)$, obtém-se pela Equação (2.8) a força resultante superior.

$$
H_{\text {sup }, d}=1,05 \cdot \frac{M_{d}}{l_{e m b}+0,95}+0,95 \cdot V_{d}-0,13 \cdot N_{d}-0,06 \cdot F_{b u, y}
$$

De acordo com Runko-Bes-Tutkimus ${ }^{1}$ (1983 apud OLIN et al. (1985)) a tensão última de aderência é função da resistência a tração do concreto de preenchimento conforme a Equação (2.9).

$$
\tau_{b u, y}=\tau_{b u}=0,3 \cdot f_{c t d}
$$

Substituindo-se esse valor na Equação (2.6), é definido $F_{b u, y}$ :

$$
F_{b u, y}=0,15 \cdot f_{c t d} \cdot l_{e m b} \cdot h
$$

\subsubsection{Dimensionamento e arranjo das armaduras do cálice}

No projeto da ligação cálice-fundação, a armadura horizontal necessária para transmitir a força $H_{\text {sup }, d}$ é calculada semelhantemente ao modelo de Leonhardt \& Mönnig (1978), conforme a Equação (2.11) diferindo, entretanto, no valor de $H_{\text {sup, } d}$.

$$
A_{s, h p}=\frac{H_{\text {sup }, d}}{2 \cdot f_{y d}}
$$

É considerada ainda uma armadura localizada na região inferior do colarinho que depende da força $H_{\mathrm{inf}, d}$ e da força de atrito que atua horizontalmente. Esta armadura é calculada de acordo com a Equação (2.12).

$$
A_{s, h \mathrm{inf}}=\frac{H_{\mathrm{inf}, d}-\mu \cdot N_{b f, d}}{2 \cdot f_{y d}}
$$

sendo que:

$$
N_{b f, d}=N_{d}-\mu \cdot H_{\text {sup }, d}-F_{b u, y}
$$

A parcela $\mu \cdot N_{b f, d}$ é referente à força de atrito entre a seção inferior do pilar e a base do cálice, sendo que se este valor for superior à resultante de compressão inferior $H_{\text {inf,d }}$, não é necessário dispor a armadura $A_{s, h \text { inf }}$ na região inferior do colarinho. Portanto, esse modelo é indicado quando a excentricidade da força normal for grande o suficiente para produzir uma

\footnotetext{
${ }^{1}$ Runko-BES-Tutkimus. Helsinki 1983, Suomen Betoniteollisuuden Keskusjärjestö, Julkaisut 1 - 7. 188p.
} 
reação $H_{\text {inf, } d}$ positiva, embora haja a ocorrência da força de atrito na extremidade inferior do pilar.

A armadura vertical do cálice $A_{s, v p}$ deve ser calculada como se a ligação fosse monolítica, de maneira que haja transferência de momento na ligação.

Para evitar o fendilhamento das paredes do colarinho provocado pela força normal aplicada no pilar e assegurar as tensões de aderência para cálices de interface rugosa, os autores recomendam distribuir estribos ao longo da altura do colarinho, que devem ter uma área mínima de:

$$
A_{s, h s}=0,17 \cdot h \cdot s \cdot \frac{f_{c t k}}{f_{y k}}
$$

Na Figura 2.20, são apresentadas as armaduras do cálice de fundação segundo esse modelo.
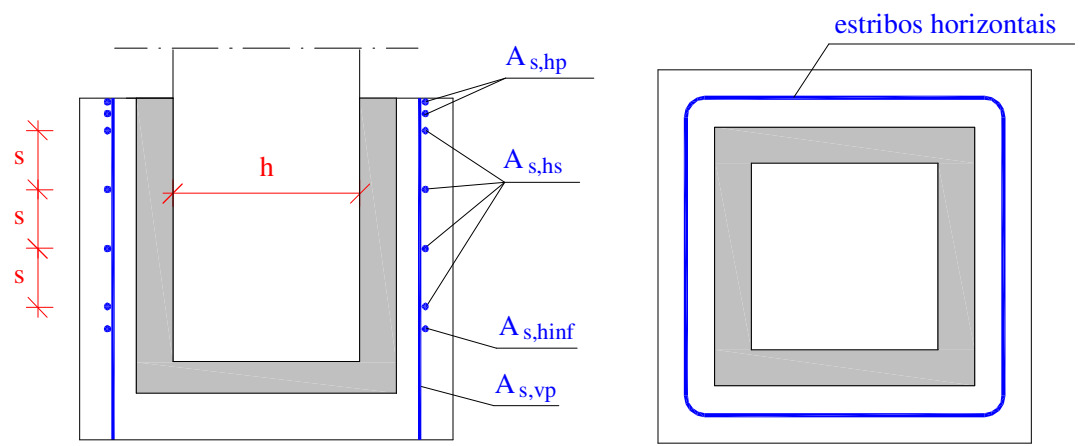

Figura 2.20 - Armaduras do colarinho (OLIN et al. (1985) adaptado por CANHA (2004))

\subsection{MODELO E RECOMENDAÇÕES DE PROJETO SEGUNDO OSANAI ET AL. (1996)}

Osanai et al. (1996) propuseram um método de projeto para a ligação cálice de fundação sob ações sísmicas, comprovando-o através de ensaios de modelos sob carregamento cíclico. Através das observações experimentais e de resultados do mecanismo de transferência das forças, foi proposto um modelo de cálculo para o dimensionamento da ligação. Também foi avaliado neste estudo recomendações dos modelos da $\mathrm{DIN}^{2}$ e $\mathrm{AIJ}^{3}$. Após os ensaios, os autores verificaram que as indicações dessas referências são conservadoras.

\footnotetext{
2 DIN 1045 (1972). Cálculo e execução de obras de concreto armado.

3 AIJ (1990). Recommendations for the design and fabrication of tubular structures in stell. Architectural Institute of Japan. p.237-42
} 


\subsubsection{Forças atuantes no cálice}

Considera-se que quando as forças axial e horizontal atuam no pilar, momento e força cortante são gerados na base do pilar. Essas forças resultam em reações horizontais, forças de atrito na interface e reação vertical na base do pilar. Na Figura 2.21 é ilustrado o equilíbrio das forças atuantes no cálice.

Para facilitar a resolução das equações de equilíbrio, é proposto pelos autores a divisão do modelo total em dois: modelo 1 e modelo 2, conforme Figura 2.22.

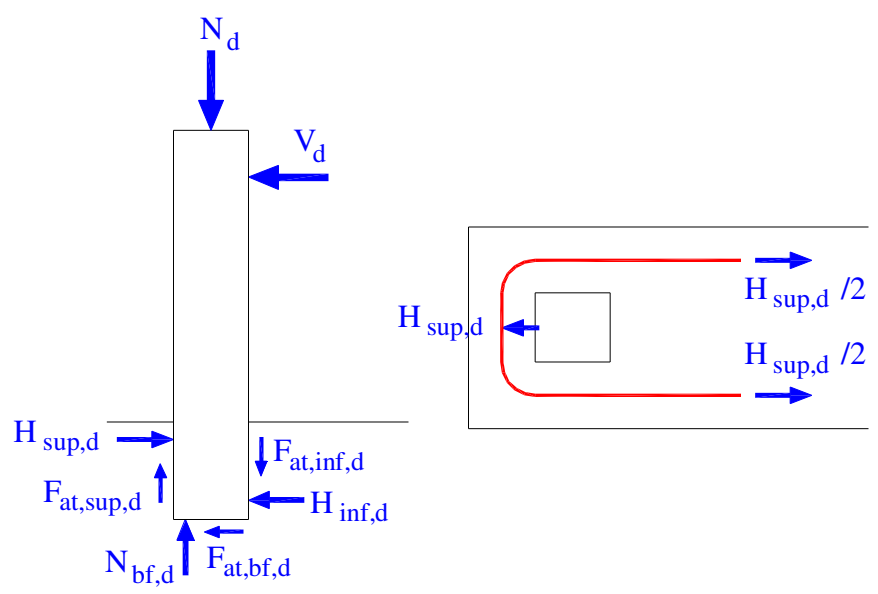

Figura 2.21 - Equilíbrio de forças na ligação e transmissão de tensão do pilar para a fundação (OSANAI et al.(1996) adaptado por CANHA (2004))

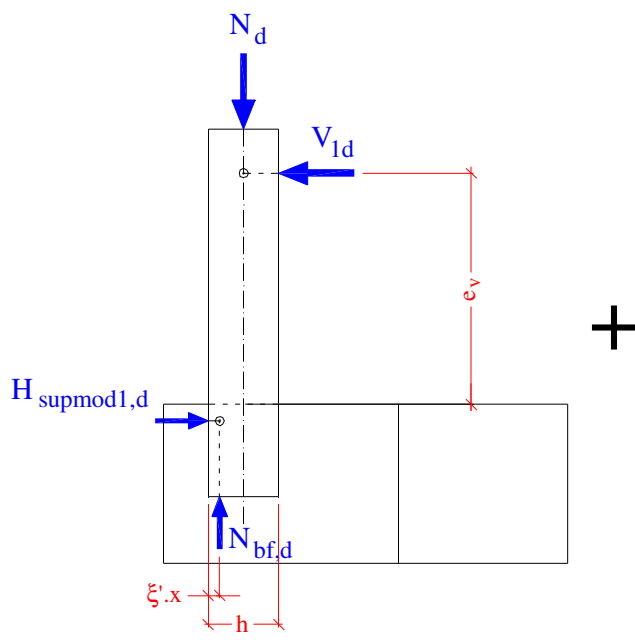

Modelo 1

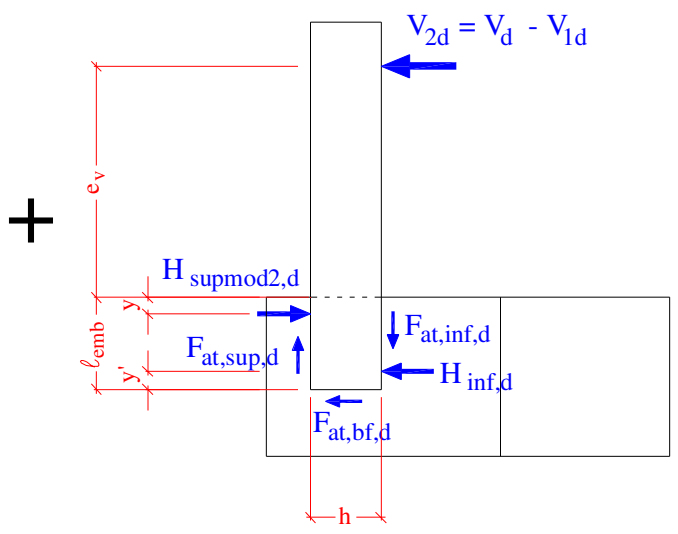

Modelo 2

Figura 2.22 - Modelo teórico (OSANAI et al. (1996) adaptado por CANHA (2004))

No Modelo 1, o carregamento, força horizontal e força normal, é resistido pela reação horizontal e pela reação normal na base do pilar. No Modelo 2, o carregamento, parte da força 
horizontal, é resistido pelas forças de reação horizontal e pelas forças de atrito geradas na interface da ligação.

As equações de equilíbrio foram formuladas adotando algumas hipóteses:

a) A resistência à tração do concreto da fundação é ignorada;

b) Assume-se que as forças de tração na fundação são absorvidas pela armadura da fundação, desconsiderando a contribuição de armaduras secundárias;

c) A força de atrito gerada entre as superfícies do pilar e do cálice são consideradas;

d) A reação vertical e as forças normais atuantes no pilar são consideradas agindo na face inferior do mesmo.

Para o cálculo da posição da resultante de compressão do concreto $\left(\xi^{\prime} \cdot x\right)$, é considerada a hipótese de Bernoulli, no qual as seções planas permanecem planas após as deformações. A Figura 2.23 apresenta a distribuição de tensões na seção do pilar.

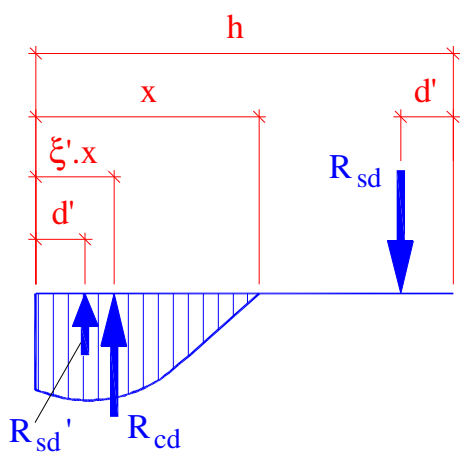

Figura 2.23 - Distribuição de tensões na seção do pilar (OSANAI et al. (1996) adaptado por CANHA (2004))

sendo que:

$\xi \cdot x^{\prime}$ : Distância da fibra externa de compressão ao ponto de atuação de $R_{c d}$.

Com as indicações de condições de equilíbrio, é definida a reação $H_{\text {sup }, d}$ e a força horizontal $V_{1 d}$ do Modelo 1, de acordo com a Equação (2.15).

$$
H_{\text {sup mod } 1, d}=V_{1 d}=\frac{M_{1 d}}{e_{v}+y} \cong \frac{M_{1 d}}{e_{v}}=\left(\frac{h}{2}-\xi^{\prime} \cdot x\right) \cdot \frac{N}{e_{1}}
$$

sendo que:

$N_{d}=N_{b f, d}$ e $y$ é desprezível quando comparado a $e_{v}$ $e_{v}$ : Excentricidade da força horizontal em relação ao topo da ligação 
A distribuição de tensões na região de embutimento do modelo 2 é mostrada na Figura 2.24. Com esses dados, é possível determinar as outras forças atuantes no cálice.

A soma da resultante de pressão $H_{\text {inf, } d}$ com a força de atrito mobilizada na base do pilar $F_{a t, b f, d}$ resulta na força $R_{\text {inf, } d}$ atuando na posição $y^{*}$.

$$
\begin{aligned}
& R_{\mathrm{inf}, d}=H_{\mathrm{inf}, d}+F_{a t, b f, d} \\
& y^{*}=\frac{\left(l_{e m b}-2 \cdot y\right)}{6}
\end{aligned}
$$

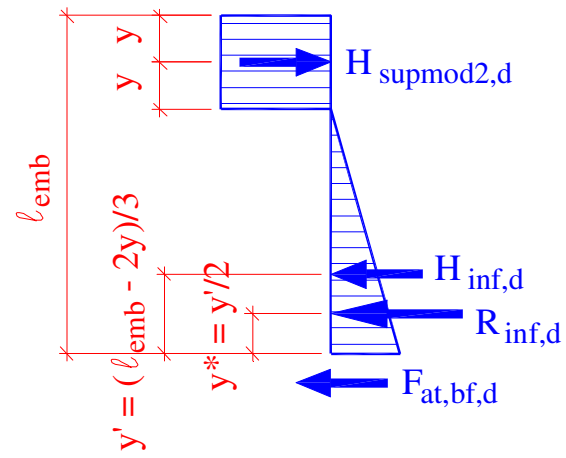

Figura 2.24 - Distribuição de tensões na região de embutimento do pilar do modelo 2 (OSANAI et al. (1996) adaptado por CANHA (2004))

Das condições de equilíbrio, são obtidas as equações de equilíbrio de momentos, de forças verticais e de forças horizontais, respectivamente:

$$
\begin{aligned}
& M_{2 d}+V_{2 d} \cdot l_{e m b}+R_{\mathrm{inf}, d} \cdot y^{*}-H_{\text {sup mod } 2, d} \cdot\left(l_{e m b}-y\right)-F_{a t, \text { sup }, d} \cdot h=0 \\
& F_{a t, \text { sup }, d}=F_{a t, \text { inf }, d} \\
& H_{\text {sup mod } 2, d}=V_{2 d}+R_{\mathrm{inf}, d}
\end{aligned}
$$

O momento fletor na seção crítica do pilar é dado por:

$$
M_{2 d}=V_{2 d} \cdot e_{v}
$$

As forças de atrito que atuam na interface do pilar com o colarinho são definidas por:

$$
\begin{aligned}
& F_{a t, \text { sup }, d}=\mu_{\text {sup }} \cdot H_{\text {sup mod } 2, d} \\
& F_{a t, \text { inf }, d}=\mu_{\text {inf }} \cdot H_{\text {inf }, d}
\end{aligned}
$$

E a reação total superior é obtida pela Equação (2.24):

$$
H_{\text {sup }, d}=H_{\text {supmod } 1, d}+H_{\text {sup mod } 2, d}
$$

Ou seja, é a soma das Equações (2.15) e (2.20). 
A expressão de $H_{\text {sup }, d}$ apresentada pelo modelo de Osanai et al. (1996) é formulada considerando as forças normal centrada e cortante. Assim, para obter uma equação que considerasse a atuação de força normal, momento fletor e força cortante, na pesquisa de Canha (2004) foi desenvolvida a Equação (2.25), sendo que a excentricidade da reação normal na base do pilar em relação ao centro de gravidade é definida por $e_{n b}=0,5 . l_{e m b}-\xi^{\prime} \cdot x$, definindo assim uma nova equação para a pressão $H_{\text {sup }, d}$.

$$
H_{\text {sup }, d}=\frac{M_{d}-\left[e_{n b}-\frac{\mu^{2} \cdot(0,5 \cdot h)+e_{n b}}{1+\mu^{2}}\right] \cdot N_{d}+\left[\frac{5 \cdot l_{e m b}}{6}+\frac{y}{3}+\frac{\mu \cdot(0,5 \cdot h) e_{n b}}{1+\mu^{2}}\right] \cdot V_{d}}{\frac{5 \cdot l_{e m b}}{6}-\frac{2 \cdot y}{3}+\mu \cdot h}
$$

Como comentado, dois modelos de dimensionamento do cálice de fundação são apresentados no estudo desenvolvido por Osanai et al. (1996). Um modelo é proposto pela AIJ e outro pela Norma Alemã DIN 1045.

No modelo proposto pela AIJ, a transferência de forças na ligação ocorre de acordo com a Figura 2.25 (a) e os valores das pressões superior e inferior são definidos através do equilíbrio de momento no centro do pilar e de acordo com as Equações (2.26) e (2.27).

$$
\begin{aligned}
& H_{\text {sup }, d}=\frac{M_{d}+V_{d} \cdot\left(0,5 \cdot l_{e m b}-y^{\prime}\right)}{l_{e m b}-y-y^{\prime}} \\
& H_{\text {inf }, d}=H_{\text {sup }, d}-V_{d}
\end{aligned}
$$

Pela Equação (2.26), verifica-se que a parcela correspondente ao momento devido à força cortante $V_{d}$ não foi considerada, pois o termo multiplicador de $V_{d}$ deveria ser $\left(l_{e m b}-y^{\prime}\right)$.

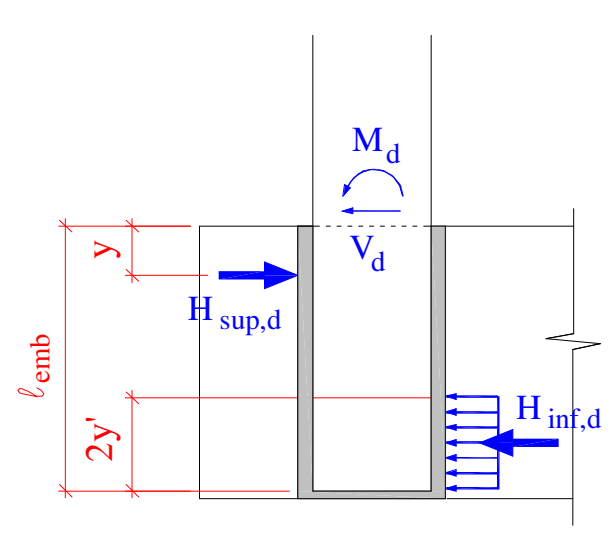

(a)

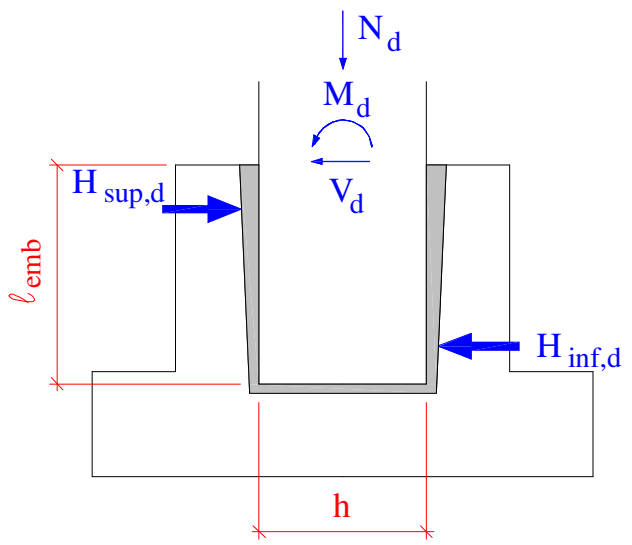

(b)

Figura 2.25 - Transferência de forças: (a) AIJ; (b) DIN 1045 (adaptado por CANHA (2004)) 
No modelo proposto pela DIN 1045 como ilustra a Figura 2.25 (b), a determinação da pressão superior resultante $H_{\text {sup }, d}$ é definida de acordo com o tipo de interface. A Equação (2.28) é utilizada para cálice com interface lisa e a Equação (2.29) para cálice com interface rugosa.

$$
\begin{aligned}
& H_{\text {sup }, d}=1,50 \cdot \frac{M_{d}}{l_{\text {emb }}}+1,25 \cdot V_{d} \\
& H_{\text {sup }, d}=1,20 \cdot \frac{M_{d}}{l_{\text {emb }}}+1,20 \cdot V_{d}
\end{aligned}
$$

\subsubsection{Modelo teórico e recomendações do modelo de projeto}

Nos modelos investigados pelos autores, foram variados para a realização dos cálculos o comprimento de embutimento do cálice, o coeficiente de atrito das interfaces e a força normal do pilar. Na Figura 2.26 são apresentados os resultados do modelo de Osanai et al. (1996), da DIN 1045 e da AIJ.

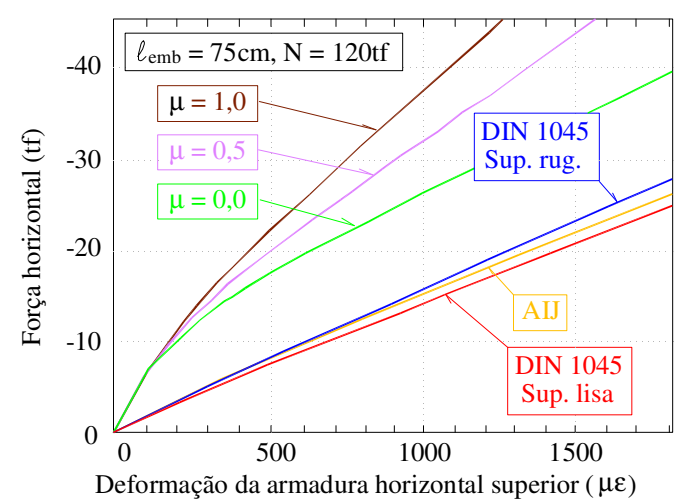

(a)

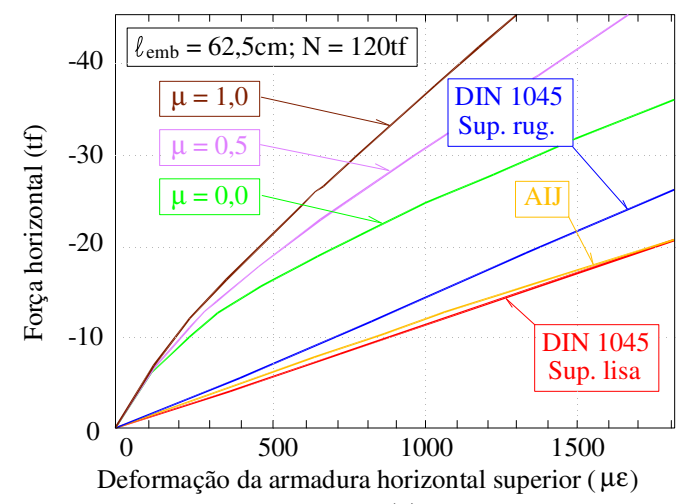

(c)

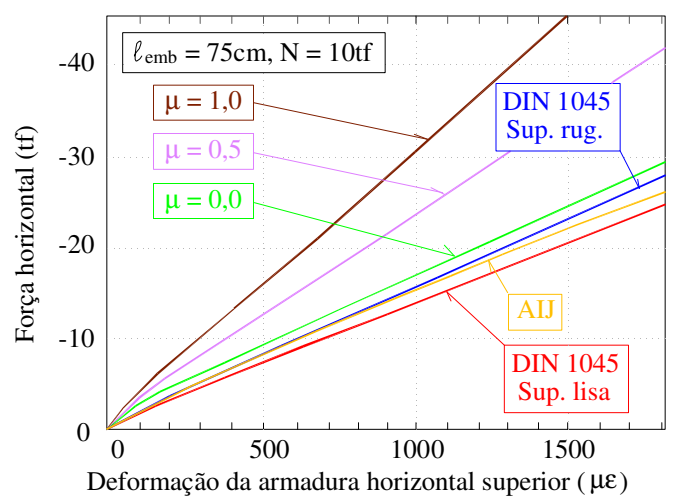

(b)

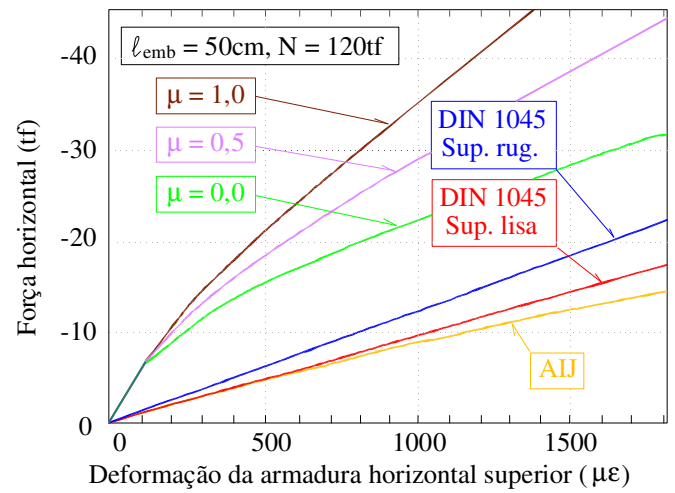

(d)

Figura 2.26 - Resultados teóricos e recomendações da DIN 1045 e AIJ (OSANAI et al. (1996) adaptado por CANHA (2004)) 
Analisando os gráficos, percebe-se que no modelo teórico proposto por Osanai et al. (1996), com o aumento da força normal e do coeficiente atrito, as deformações na armadura horizontal superior diminuem. Os resultados desse modelo teórico são menos conservadores que os resultados obtidos pela DIN 1045 e AIJ, que, por análise, verifica-se que resultam próximos entre si. Somente no cálculo com menor força normal do pilar de 10 tf $(100 \mathrm{kN})$ e sem consideração de atrito, é que o resultado do modelo teórico de Osanai et al. (1996) ficou mais próximo dos resultados encontrados pela DIN 1045 e AIJ.

Foi realizada ainda uma investigação experimental em modelos com interface lisa e rugosa para validar o modelo de cálculo teórico proposto por Osanai et al. (1996). Nesse estudo o comprimento de embutimento foi sendo variado nos seguintes valores $l_{\text {emb }}=h(50 \mathrm{~cm}), \quad l_{\text {emb }}=1,25 \cdot h(62,5 \mathrm{~cm})$ e $l_{\text {emb }}=1,5 \cdot h(75 \mathrm{~cm})$. Após os ensaios, os resultados experimentais foram comparados com os valores teóricos e com valores resultantes das normas DIN 1045 e AIJ chegando os autores a seguintes conclusões:

a) Quando o comprimento de embutimento for maior ou igual a $1,5 \cdot h$, a ligação pode ser considerado como rígida mesmo nos casos de interface lisa;

b) A capacidade da ligação pode ser melhorada com a utilização de chaves de cisalhamento. Ligações cálice-fundação com $l_{e m b} \geq h$ e interface rugosa fornecem resultados próximos a cálices com $l_{e m b}=1,5 \cdot h$ e interface lisa, podendo alcançar a resistência última do pilar;

c) Ligações com interface lisa não apresentam rigidez suficiente quando o comprimento de embutimento são menores que $1,25 \cdot h$, no entanto o pilar pode alcançar sua resistência última à flexão para situações de grandes flechas;

d) Para o coeficiente de atrito, são apresentadas as seguintes recomendações conforme o comprimento de embutimento: para $l_{e m b} \geq 1,5 \cdot h$ com interface lisa ou $l_{\text {emb }} \geq 1,25 \cdot h \mathrm{com}$ interface rugosa deve ser utilizado $\mu=1$ e para $l_{e m b}=h$ com interface rugosa deve ser utilizado $\mu=0,5$;

e) O início da degradação da rigidez pode ser retardado com a utilização de chaves de cisalhamento nas ligações cálice-fundação;

f) As equações teóricas propostas por Osanai et al. (1996) forneceram resultados mais próximos dos valores experimentais do que as equações das recomendações da AIJ e da DIN 1045. 


\subsection{MODELO E RECOMENDAÇÕES DE PROJETO SEGUNDO A CNR 10025: 1998}

De acordo com a Norma Italiana CNR 10025:1998, o cálice de fundação deve ser dimensionado para transmitir ações verticais, momentos fletores e ações de forças horizontais, e a superfície do cálice e do pilar pode ser lisa ou rugosa. Dessa maneira, são apresentadas indicações para os dois casos.

\subsubsection{Propriedades geométricas e forças atuantes no cálice}

Os cálculos das resistências são realizados de acordo com a Figura 2.27, sendo que as ações $M_{d}, N_{d}$ e $V_{d}$ transmitidas na ligação cálice-fundação atuam numa seção abaixo do topo do colarinho de $l_{\text {emb }} / 4$ e que está representada pelo ponto $\mathrm{O}$.
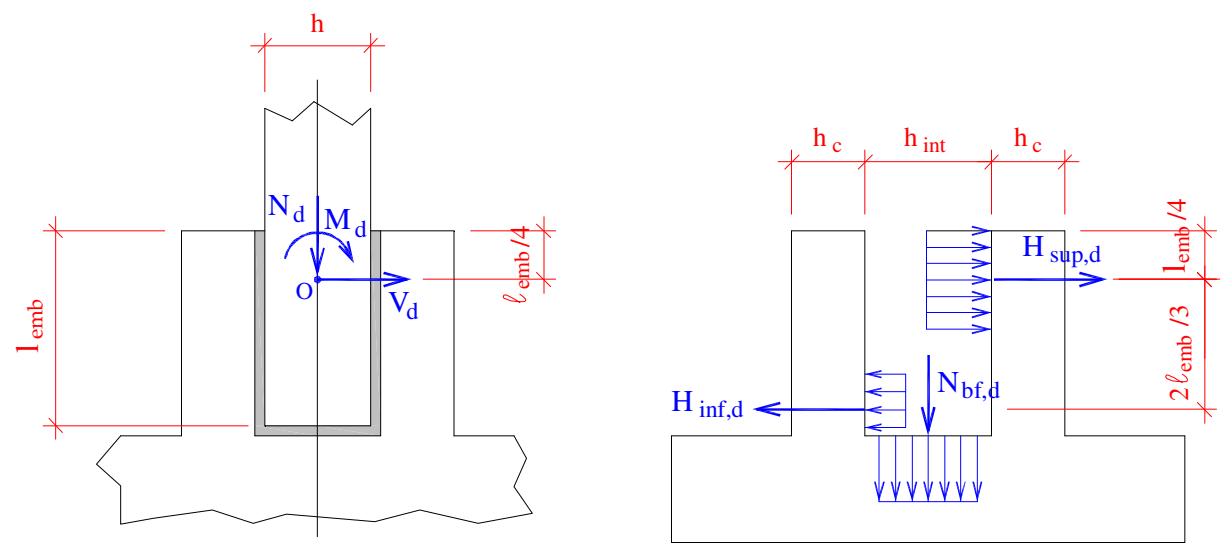

Figura 2.27 - Forças atuantes no cálice (CNR 10025:1998)

A Norma Italiana recomenda os seguintes valores para o comprimento de embutimento:

$$
\begin{aligned}
& l_{e m b} \geq 1,2 \cdot h \text { para } \frac{M_{d}}{N_{d}} \leq 0,15 \cdot h \\
& l_{e m b} \geq 2,0 \cdot h \text { para } \frac{M_{d}}{N_{d}} \geq 2,00 \cdot h
\end{aligned}
$$

pode-se interporlar linearmente os valores intermediários de excentricidade. Verifica-se que são definidas as mesmas indicações de comprimento de embutimento para cálice liso e rugoso. 
O modelo despreza as forças de atrito, considerando apenas forças de compressão no colarinho e na base da fundação. Pelas equações abaixo, são calculadas as pressões atuantes:

$$
\begin{aligned}
& H_{\text {sup }, d}=V_{d}+\frac{3}{2} \cdot \frac{M_{d}}{l_{e m b}} \\
& H_{\text {inf }, d}=\frac{3}{2} \cdot \frac{M_{d}}{l_{e m b}} \\
& N_{b f, d}=N_{d}
\end{aligned}
$$

\subsubsection{Dimensionamento das armaduras do cálice}

Para cálculo da parte superior da parede transversal 1, é aplicado o modelo de biela e tirante e considera-se somente tração nesta região, conforme ilustra a Figura 2.28.

Como parte da força é transmitida para o canto da parede transversal 1, os ramos externos e internos da armadura são submetidos à tração.
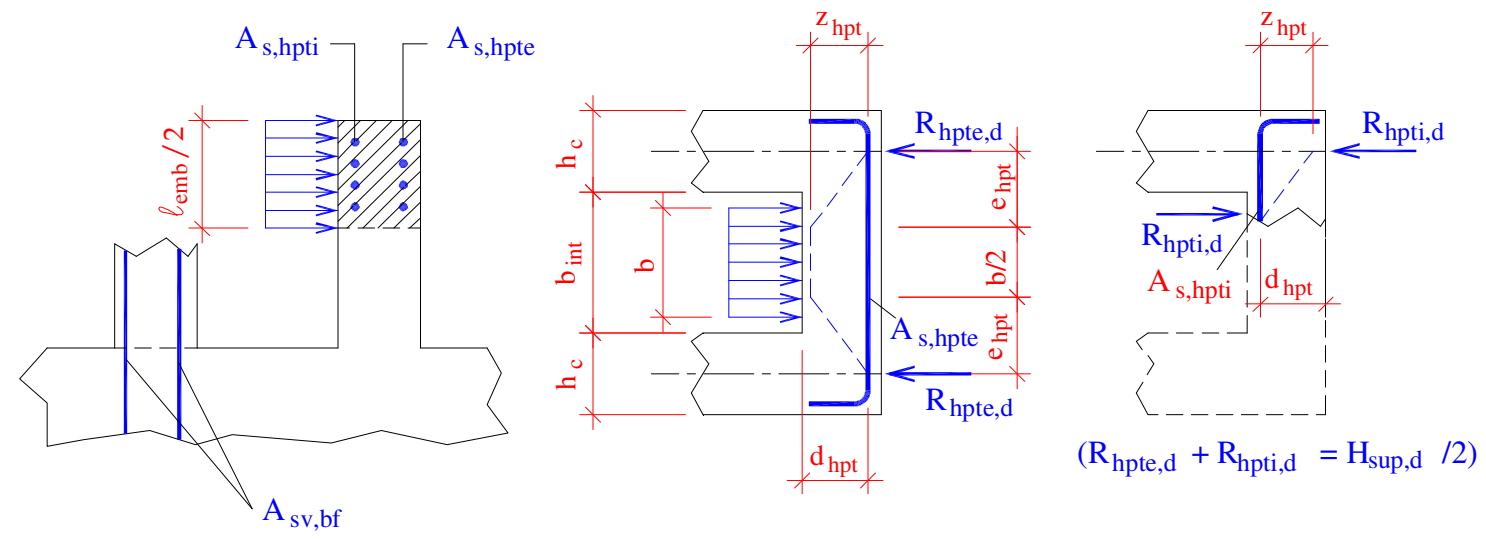

Figura 2.28 - Modelo de biela e tirante para parede transversal (CNR 10025:1998)

Através das Equações (2.35), (2.36) e (2.37), é verificada para a parede transversal, respectivamente, a resistência da armadura e do concreto no topo da parede 1 e a resistência à tração na região inferior da parede 2 .

$$
\begin{aligned}
& 2 \cdot A_{s, h p t e} \cdot\left(1+\alpha_{s, h p t}\right) \cdot f_{y d} / \lambda_{h p t}>H_{\mathrm{sup}, d} \\
& 2 \cdot 0,4 \cdot d_{h p t} \cdot\left(l_{e m b} / 2\right) \cdot \sigma_{c d} /\left(1+\lambda_{h p t}{ }^{2}\right)>H_{\mathrm{su}} \\
& {\left[h_{c} \cdot\left(b+h_{c}\right)+\alpha_{e} \cdot A_{s v, b f}\right] \cdot f_{c t d}>H_{\mathrm{inf}, d}}
\end{aligned}
$$

sendo que: 


$$
\alpha_{e}=\frac{E_{s}}{E_{c}}, \quad \quad \lambda_{h p t}=\frac{e_{h p t}}{z_{h p t}}, \quad e_{h p t}=\frac{b_{\text {int }}+h_{c}}{2}-\frac{b}{4}, \quad z_{h p t}=0,90 \cdot d_{h p t}
$$

Este modelo permite a utilização de estribos com os mesmos ou diferentes ramos através do parâmetro $\alpha_{s, h p t}$, que é a relação entre armadura principal transversal interna e armadura principal transversal externa.

$$
\alpha_{s, h p t}=\frac{A_{s, h p t i}}{A_{s, h p t e}}
$$

As verificações necessárias para as paredes longitudinais de acordo com a Figura 2.29 são para a resistência das armaduras externa e interna na região superior das paredes longitudinais 3 e 4, dimensionamento da armadura vertical $A_{s, v p}$ e verificação da biela de compressão das paredes longitudinais que têm comportamento de consolo.

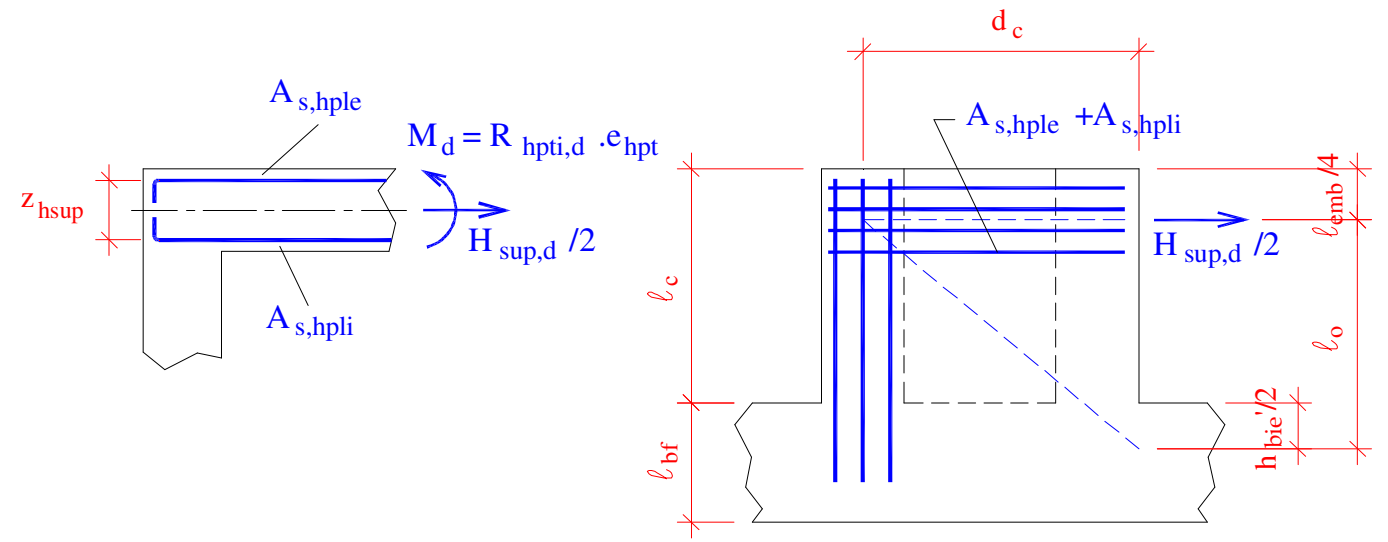

Figura 2.29 - Forças e armaduras da parede longitudinal (CNR 10025:1998)

De acordo com as Equações (2.39) e (2.40), calcula-se a armadura horizontal principal longitudinal para a região superior das paredes longitudinais 3 e 4 :

$$
\begin{aligned}
& 2 \cdot A_{s, h p l e} \cdot f_{y d} /\left(1-\alpha_{s, h p t} \cdot e_{h p t} / z_{h \text { sup }}\right)>H_{\text {sup }, d} \\
& 2 \cdot A_{s, h p l i} \cdot f_{y d} /\left(1-\alpha_{s, h p t} \cdot e_{h p t} / z_{h \text { sup }}\right)>H_{\text {sup }, d}
\end{aligned}
$$

E a armadura vertical principal é calculada de acordo com as equações abaixo, considerando as paredes longitudinais como consolo.

$$
\begin{aligned}
& 2 \cdot A_{s, v p} \cdot f_{y d} / \lambda_{c}>H_{\text {sup }, d} \\
& 2 \cdot 0,4 \cdot d_{c} \cdot h_{c} \cdot \sigma_{c d} /\left(1+\lambda_{c}^{2}\right)>H_{\text {sup }, d}
\end{aligned}
$$

sendo que: 
$\lambda_{c}=\frac{l_{o}}{d_{c}} \quad l_{o}=l_{c}-\frac{l_{\text {emb }}}{4}+\frac{h_{b i e}{ }^{\prime}}{2} \quad d_{c}=h_{e x t}-\frac{h_{c}}{2}$

$\frac{h_{b i e}{ }^{\prime}}{2}$ é o menor valor entre $0,2 . d_{c} \mathrm{e} \frac{l_{b f}}{2}$

\subsubsection{Verificação da fundação}

A verificação da laje da fundação é feita pelo modelo de biela e tirante para consolo curto em que é considerada uma pressão elástica do terreno sobre a fundação conforme a Equação (2.43) e a Figura 2.30.

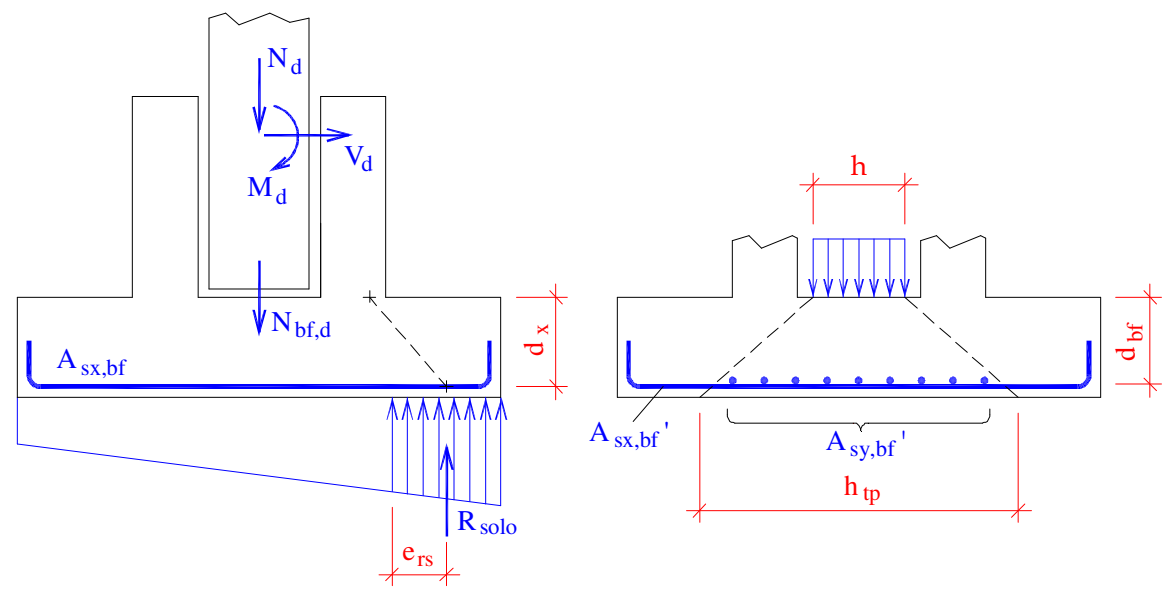

Figura 2.30 - Forças na laje da fundação (CNR 10025:1998)

$$
A_{s x, b f} \cdot f_{y d} / \lambda_{x}>R_{\text {solo }}
$$

sendo que:

$$
\lambda_{x}=\left(e_{r s}+0,2 \cdot d_{x}\right) / d_{x}
$$

A verificação do puncionamento da laje do fundo é feita de acordo com a Equação (2.45) e com a Figura 2.30, tomando-se como referência a força vertical atuando em uma seção equivalente a do pilar.

$$
0,25 \cdot d_{b f} \cdot u \cdot f_{c t d} \cdot \kappa \cdot\left(1,2+40 \cdot \rho_{b f}\right)>N_{d} \cdot\left(1-h_{t p .} \cdot b_{t p}\right.
$$

sendo que:

$$
\begin{array}{lll}
d_{b f}=\left(d_{x}+d_{y}\right) / 2 & u=2 \cdot h+2 \cdot b+3 \cdot \pi \cdot d_{b f} & \kappa=1,6-d_{b f} \geq 1, \text { sendo } d_{b f} \text { em } m m \\
\rho_{b f}=\sqrt{\rho_{x} \cdot \rho_{y}} \leq 0,02 & \rho_{x}=\frac{A_{s x, b f^{\prime}}}{b_{t p}} & \rho_{y}=\frac{A_{s y, b f^{\prime}}}{h_{t p}}
\end{array}
$$




$$
h_{t p}=h+3 \cdot d_{b f} \quad b_{t p}=b+3 \cdot d_{b f}
$$

Para condição de alto momento fletor, deve ser introduzido no perímetro $u$ a parte referente à área comprimida, e a força normal $N_{d}$ não deve ser reduzida.

\subsubsection{Recomendações para o projeto do cálice}

Como no modelo apresentado em Leonhardt \& Mönnig (1978), a espessura da parede do colarinho deve ser maior que $1 / 3 \cdot\left(b_{\text {int }}\right.$ ou $\left.h_{\text {int }}\right)$ e no mínimo $10 \mathrm{~cm}$. A junta deve ter um espaço suficiente para um bom preenchimento de concreto abaixo e em torno do pilar e o espaço entre o pilar, e o colarinho deve ser definido levando-se em conta o valor mínimo de 3 cm, considerando as tolerâncias do pilar, do seu posicionamento e da distância interna entre as paredes do colarinho.

A norma indica, para cálices de fundação com rugosidade na interface, a consideração de uma ligação monolítica, desde que se assegure a perfeita adesão entre as partes. Assim, nas verificações de resistência, estabilidade e punção são consideradas as dimensões externas do colarinho para o cálculo.

A transmissão da força de tração do pilar para a fundação é feita com ancoragem das armaduras do pilar na armadura da fundação. Esta ancoragem é feita por traspasse, conforme indicado na Figura 2.31. O comprimento de traspasse deve ser igual à parcela referente à aderência aço-concreto mais o espaçamento entre as armaduras. Estribos horizontais devem ser dispostos para a união destas armaduras na região de ancoragem.

Ainda é recomendado que na fase de montagem dos pilares e em situações transitórias, os dispositivos de centralização e as cunhas utilizadas para fixação temporária assegurem estabilidade adequada aos pilares.

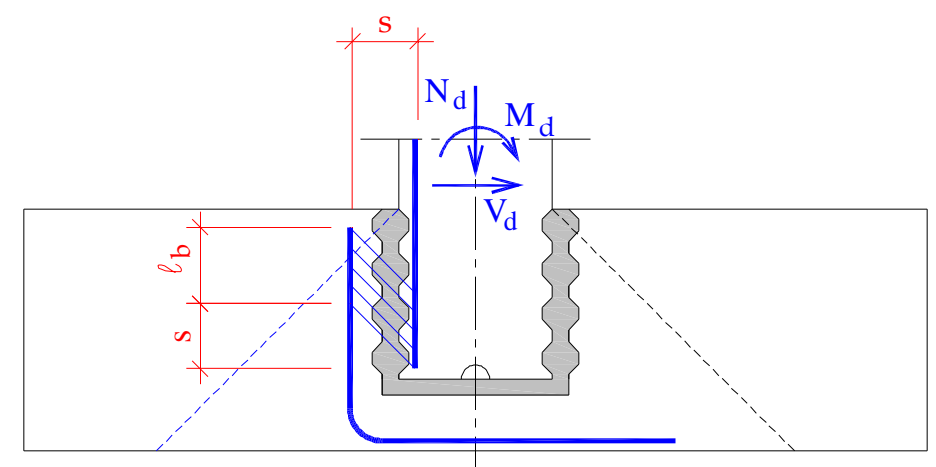

Figura 2.31 - Ancoragem das armaduras na ligação cálice-fundação com interface rugosa (CNR 10025:1998) 


\subsection{RECOMENDAÇÕES DE PROJETO SEGUNDO EUROCODE 2 (2004)}

Segundo esta norma, os cálices de fundação devem ser capazes de transferir ações verticais, momentos fletores e força cortante do pilar à fundação. As recomendações para o cálice são divididas de acordo com a superfície: lisa ou rugosa.

\subsubsection{Propriedades geométricas e forças atuantes}

Nos cálices com interface lisa, a força normal e o momento fletor podem ser assumidos sendo transferidos do pilar para a fundação pelas forças de compressão $H_{\text {sup, } d}$, $H_{\text {inf,d }}$ e $N_{b f, d}$ através do concreto de preenchimento da junta e pelas correspondentes forças de atrito, como ilustrado na Figura 2.32.

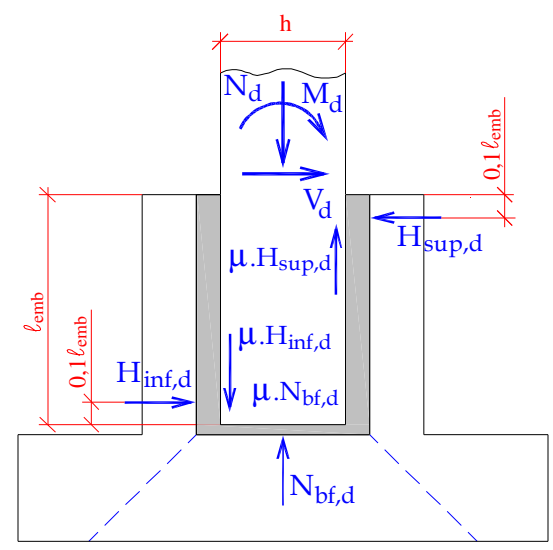

Figura 2.32 - Cálice com interface lisa (EUROCODE 2 (2004))

Nesse modelo, o comprimento de embutimento é definido de acordo com a equação (2.46) e o coeficiente de atrito $\mu$ adotado para projeto não deve ser maior que 0,3 .

$$
l_{\text {emb }} \geq 1,2 \cdot h
$$

Em cálices com interface rugosa, com dentes ou chaves de cisalhamento, considera-se que a transferência dos esforços é semelhante ao que ocorre em uma ligação monolítica. Onde ocorrer tensão vertical devido à transferência de momento é necessário um cuidadoso detalhamento da armadura que se sobrepõe na região do pilar e da fundação. 


\subsubsection{Recomendações para o projeto do cálice}

É necessário que haja espaço suficiente, em volta e abaixo do pilar, para o concreto de preenchimento da junta.

A verificação da punção no elemento de fundação deve ser feito como na ligação monolítica pilar-fundação, desde que ocorra transferência de cisalhamento na interface entre estes elementos. Caso contrário, a verificação da punção deve ser feita somente com a dimensão do pilar, casos de cálices com interface lisa.

A norma Eurocode 2 recomenda atenção no que diz respeito a transferência da força $H_{\text {sup }, d}$ que age no topo da parede transversal frontal, e no detalhamento da armadura que resiste à esta força. Deve-se verificar a ancoragem da armadura principal do pilar e das paredes do cálice e a resistência ao cisalhamento do pilar com o cálice.

\subsection{RECOMENDAÇÕES DE PROJETO DO MANUAL DA EMPRESA MUNTE [MELO (2004)]}

Um dos modelos da literatura utilizados para o dimensionamento do cálice é encontrado no Manual Munte de Projetos em Pré-Fabricados de Concreto. A proposta desse Manual é dar recursos de pesquisa sobre a tecnologia dos elementos pré-fabricados de concreto para profissionais da área. Em um dos capítulos do Manual, são apresentadas recomendações para o dimensionamento do colarinho, nicho onde ocorre o encaixe dos pilares. Geralmente, o elemento pré-fabricado utilizado em galpões está submetido a grandes momentos fletores e pequenas forças normais.

\subsubsection{Propriedades geométricas e forças atuantes no cálice}

No Manual, é definida a utilização obrigatória de ranhuras no colarinho e no pilar para uma melhor consolidação da ligação. Assim, as recomendações aqui apresentadas referem-se a cálice com interface rugosa.

São indicados os seguintes valores para o comprimento de embutimento: $1,2 \cdot h$ para pequena excentricidade e $1,6 \cdot h$ para grande excentricidade. Pode ser feita interpolação linear para valores intermediários de excentricidade e o valor mínimo a ser adotado para o comprimento de embutimento é de $40 \mathrm{~cm}$. Os valores indicados são os mesmos da Norma ABNT NBR 9062:2006 para cálices com interface rugosa, respectivamente. 
O Manual sugere ainda que o comprimento de embutimento deve ser padronizado, de maneira que somente seja utilizado o valor de $1,6 \cdot h$ para todos os casos de excentricidade. Essa medida é a favor da segurança e não há um aumento no custo global da fundação em virtude do cálice apresentar menos armadura em função do binário resistente.

Quanto à espessura da parede do colarinho, o Manual indica que esse valor deve ser maior que $10 \mathrm{~cm}$, no entanto indica-se variação entre $15 \mathrm{~cm}$ e $20 \mathrm{~cm}$.

Na Figura 2.33, é apresentado o modelo teórico para cálice com interface rugosa do Manual, onde estão representadas as forças atuantes e características geométricas do colarinho. Em função da rugosidade, o atrito entre o colarinho e o pilar é grande, sendo assim o principal responsável pela transmissão dos esforços.

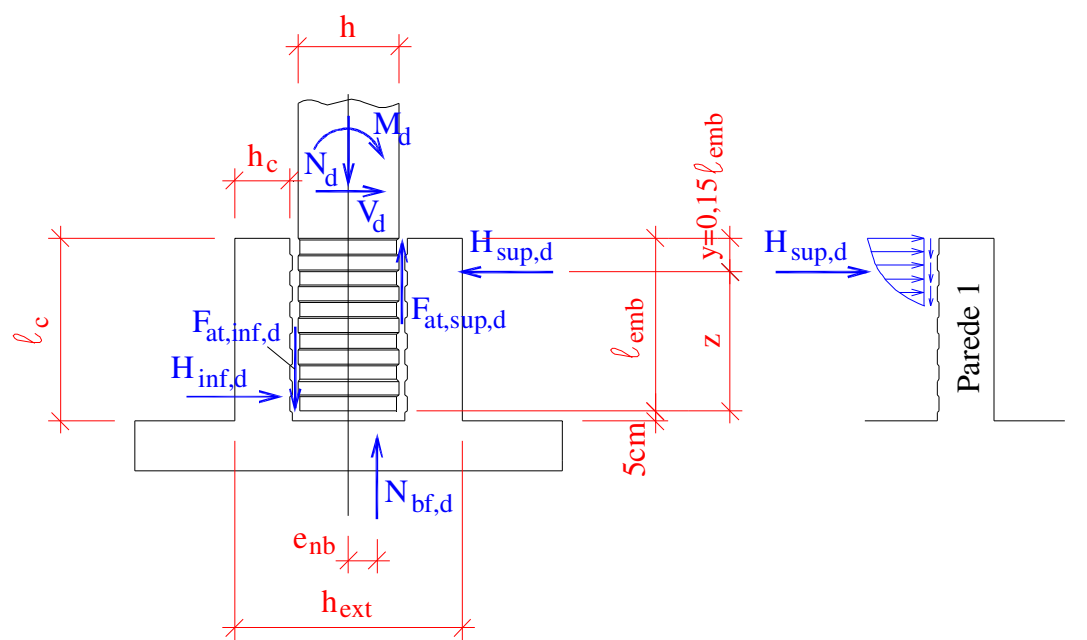

Figura 2.33 - Modelo teórico apresentado no Manual da Empresa Munte (CANHA (2004))

Os esforços solicitantes no colarinho ocorrem simultaneamente, mas pode-se decompor esses esforços para uma melhor avaliação de cada parcela. Assim, para cada força atuante, existem os esforços equivalentes de equilíbrio, que são apresentados nas equações abaixo:

$$
\begin{aligned}
& M_{d}=F_{a t 1, d} \cdot h+H_{\text {sup }, d} \cdot z+N_{b f, d} \cdot e_{n b} \\
& N_{d}=N_{b f, d}+F_{a t, \text { sup }, d}-F_{a t, \text { inf }, d} \\
& V_{d}=H_{\text {sup }, d}-H_{\text {inf }, d}
\end{aligned}
$$

As forças atuantes são divididas em parcelas resistentes ao momento solicitante $M_{d}$, onde cada parcela resiste a uma parte percentual, cuja soma resulta maior que $100 \%$. Isso 
ocorre por não haver conhecimento do valor exato de cada parcela resistente e pelo embutimento dos coeficientes de segurança nas equações.

No total, existem oito equações e oito incógnitas, que definirão todas as forças atuantes no colarinho.

$$
\begin{aligned}
& F_{a t 1, d} \cdot h=0,45 \cdot M_{d} \\
& H_{\text {sup }, d} \cdot z=0,85 \cdot M_{d}+1,20 \cdot V_{d} \cdot z \\
& N_{b f, d} \cdot e_{n b}=0,10 \cdot M_{d} \\
& N_{d}=N_{b f, d}+F_{a t, \text { sup }, d}-F_{a t, \text { in }, d} \\
& V_{d}=H_{\text {sup }, d}-H_{\text {inf }, d} \\
& N_{b f, d}=0,10 \cdot N_{d} \\
& F_{a t, \text { inf }, d}=F_{a t 1, d}-F_{a t 2, d} \\
& F_{a t 2, d}=\left(N_{d}-N_{b f, d}\right) / 2
\end{aligned}
$$

É considerado que a força normal na base da fundação é igual a $10 \%$ da força normal de cálculo atuante, e substituindo esse valor na equação (2.52) é definido o valor da excentricidade $e_{n b}$ da reação normal. Não deve ser adotado valor maior que $e_{n b}=h / 2$. Caso o valor da excentricidade resulte maior que este limite, é necessário redefinir um novo percentual para a equação (2.55). Posteriormente, as equações (2.50) e (2.51) devem ser ajustadas para que a somas percentuais sejam de $1,4 . M_{d}$.

Das Equações (2.50) e (2.57), é obtido o valor de $F_{a t 1, d}$ e $F_{a t 2, d}$, que, sendo subtraídos um do outro, é determinado o valor da força de atrito inferior $F_{a t, \text { inf }, d}$. Se esse valor resultar positivo, a força é de tração, e se for negativo, a força é de compressão. Finalmente, com as Equações (2.51) e (2.54), são determinadas as pressões superior e inferior.

\subsubsection{Dimensionamento das armaduras do cálice}

O dimensionamento do colarinho é feito a partir do cálculo dos esforços solicitantes. O cálculo da armadura para as paredes transversais 1 e 2 e para as paredes longitudinais 3 e 4 conforme o Manual serão apresentados a seguir.

Observa-se que a pressão superior $H_{\text {sup }, d}$ gera tensões de compressão na parede do colarinho e que essas tensões atuam na largura interna do colarinho a uma altura equivalente a 
$1 / 3 \cdot l_{e m b}$. Essas tensões atuantes na parede transversal frontal 1 geram momentos semelhantes a uma viga engastada nas extremidades, como ilustrado na Figura 2.34. Considerando a plastificação desse momento, a armadura horizontal principal transversal $A_{s, h p t}$ é dimensionada com o momento positivo, que é igual ao momento negativo.

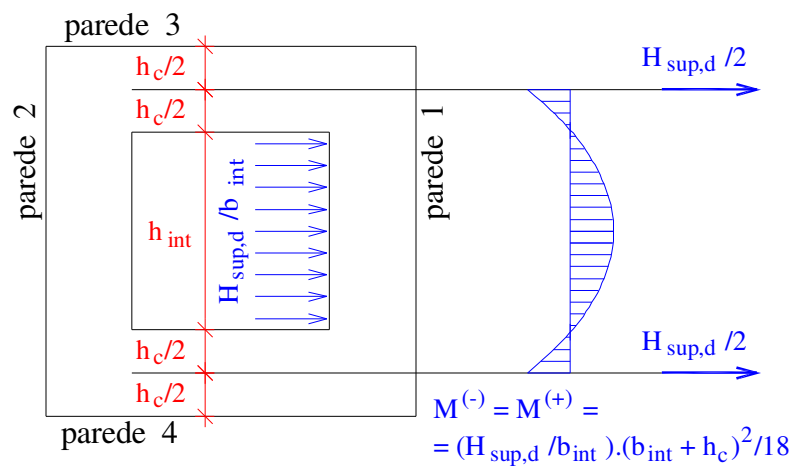

Figura 2.34 - Dimensionamento da armadura $\mathrm{A}_{\mathrm{s}, \mathrm{hpt}}$ conforme modelo apresentado no Manual da Empresa Munte

A armadura horizontal principal longitudinal $A_{s, h p l}$ responsável pela transmissão da força $H_{\text {sup }, d}$ para as paredes longitudinais 3 e 4 é definida da mesma maneira ao apresentado em Leonhardt \& Mönnig (1978).

$$
A_{s, h p l}=\frac{H_{\text {sup }, d}}{2 \cdot f_{s d}}
$$

Pelo fato da armadura $A_{s, h p l}$ e $A_{s, h p t}$ estarem localizadas na mesma altura na parede longitudinal e na parede transversal, respectivamente, deve-se adotar a maior armadura entre essas resultantes.

As paredes longitudinais 3 e 4 trabalham como consolos e devem resistir à força $F_{v p, d}$ através de uma armadura vertical. A força vertical principal e a área de armadura vertical principal $A_{s, v p}$ são calculadas pelas equações abaixo:

$$
\begin{aligned}
& F_{v p, d}=\frac{\left(H_{\text {sup }, d} / 2\right) \cdot\left(l_{c}-y\right)}{\left(0,85 \cdot h_{e x t}-h_{c} / 2\right)}+0,7 \cdot F_{a t, \text { inf }, d} \\
& A_{s, v p}=\frac{F_{v p, d}}{f_{s d}}
\end{aligned}
$$


Utilizar $f_{s d}=420 \mathrm{MPa}$ e verificar se a armadura $A_{s, v p}$ resulta maior que a armadura mínima de $0,15 \% \cdot h_{c} \cdot\left(h_{\mathrm{int}}+h_{c}\right)$. Na Equação (2.59), não devem ser utilizados valores menores de zero para situações de $F_{a t, \text { inf,d }}$ negativo (compressão).

No caso de flexão oblíqua, podem ser tratadas as forças separadamente em cada direção, devendo-se, no entanto, limitar a máxima tensão de contato em $\sigma_{c o n t} \leq 0,5 \cdot f_{c d}$, sendo a tensão de contato calculada de acordo com a Equação (2.1).

As áreas de armaduras secundárias horizontal $A_{s, h s} \mathrm{e}$ vertical $A_{s, v s}$ nas direções transversais e longitudinais devem ter o maior valor entre:

$$
A_{s, h s}=A_{s, v s} \geq\left\{\begin{array}{l}
0,70 \cdot F_{a t, \text { inf }, d} / f_{s d} \\
0,25 \cdot A_{s, v p}
\end{array}\right.
$$

Com a consideração de superfície rugosa, não há necessidade de verificar a punção para a força normal $N_{d}$ na base do pilar, mas somente para a carga de peso próprio do pilar pré-moldado durante a fase de montagem.

O Manual indica, para o elemento de fundação, a espessura mínima de $25 \mathrm{~cm}$, para que a base seja suficiente para resistir aos esforços. 
Revisão Bibliográfica 


\section{ESTUDOS EXPERIMENTAIS DESENVOLVIDOS NA ESCOLA DE ENGENHARIA DE SÃO CARLOS}

Há alguns anos vem sendo realizado na Escola de Engenharia de São CarlosUniversidade de São Paulo estudos a respeito da ligação pilar-fundação por meio de cálice, tanto na ligação com colarinho, que é a parte do cálice que se projeta da fundação, quanto para a ligação com cálice embutido.

Os estudos a respeito de cálice com colarinho englobam teses de doutorado e dissertações de mestrados desenvolvidas através de trabalhos experimentais e numéricos que serão apresentados a seguir e servirão de base para o desenvolvimento desta dissertação.

\subsection{MODELO DE PROJETO E RECOMENDAÇÕES DE CANHA (2004)}

O primeiro trabalho a respeito da ligação cálice-fundação foi desenvolvido por Canha (2004) e contribui por acrescentar novos conhecimentos a respeito do cálice através de ensaios experimentais, simulações numéricas e aplicações de modelos de projeto. Canha (2004) ressalta que nenhum estudo experimental já realizado nesse tipo de ligação teve enfoque para as paredes do colarinho e os estudos existentes não apresentam detalhadamente o comportamento e o local de ruína dos modelos físicos. Em relação aos modelos teóricos, a maioria considera o atrito na contribuição da resistência da ligação, mas também não apresentam comprovação experimental da sua validade. Por isso, esse trabalho acrescenta uma grande contribuição no entendimento do funcionamento da ligação cálice-fundação.

Inicialmente, nesse estudo, foi feita uma completa revisão dos principais modelos da literatura sobre cálice de fundação e, posteriormente, com o objetivo de apresentar as principais diferenças entre esses modelos, foi feita uma aplicação para casos de grande excentricidade da força normal, tanto para cálice com interface lisa quanto para cálice com 
interface rugosa. Após os cálculos e análise, compararam-se os resultados dos esforços principais e das armaduras necessárias resultantes de cada modelo e verificaram-se diferenças significativas entre esses.

\subsubsection{Estudo experimental}

Canha (2004) abordou no estudo experimental o comportamento da transferência de tensões do pilar para o colarinho. Esse estudo contou com uma parte experimental, onde foram ensaiados cinco modelos físicos em escala 1:1, sob força normal com grande excentricidade, variando-se o tipo de interface entre o pilar e o cálice. Três modelos continham interface lisa e foram denominados de IL-1, IL-2 e IL-3 e dois modelos eram de interface rugosa, sendo denominados de IR-1 e IR-2.

Em dois dos modelos de interface lisa e nos dois com interface rugosa, foi aplicado óleo nas interfaces para eliminar a adesão, afim de melhor representar a real situação da ligação. Devido à retração do concreto moldado no local e da carga de vento que pode atuar durante a fase de montagem, a adesão entre as interfaces das paredes do colarinho e do concreto moldado no local e entre a base do pilar e do concreto moldado no local pode ser perdida. Para os modelos de interface rugosa, foram utilizadas duas configurações de chaves de cisalhamento, sendo uma especificada pela ABNT NBR 9062:2006 e a outra definida com menores dimensões e espaçamentos.

Na Figura 3.1, é ilustrado o modelo físico juntamente com as peças metálicas que formaram o esquema de ensaio. O modelo foi fixado por chumbadores ao dispositivo de transição, e este acoplado na base metálica. Na cabeça do pilar, foi conectada uma viga metálica para aplicação da força normal excêntrica. Entre a viga e o atuador servo-hidráulico, foram parafusadas duas rótulas para permitir o movimento vertical e horizontal da viga. $\mathrm{O}$ carregamento foi aplicado pelo atuador, o qual foi fixado por um dispositivo na base metálica de reação, com o deslocamento do pistão para baixo, ou seja, tracionando o conjunto de rótulas e viga metálica. O sistema de teste é autoequilibrado.

Como o objetivo da pesquisa era a ruína do modelo físico pela ruína do cálice, foi utilizado o procedimento inverso para o dimensionamento das armaduras. Primeiramente, foi adotada a armadura vertical principal, depois foram calculadas as armaduras secundárias verticais e horizontais e por último foi determinada a armadura horizontal principal conforme o modelo de consolo curto. 
Para análise do comportamento do cálice, foram utilizados extensômetros de modo a avaliar as deformações nas principais armaduras situadas nas paredes do colarinho e, para quantificar a deformabilidade dos modelos, foram utilizados transdutores de deslocamentos em pontos específicos do cálice.

Após confecção dos modelos físicos tanto de interface lisa quanto rugosa, procederamse os ensaios. Antes do início do ensaio foi feito o escorvamento dos modelos, a fim de eliminar acomodações durante o início do ensaio e para retirar a adesão entre os concretos do pilar, junta e paredes do cálice. Esses ciclos não interferiram na resistência da ligação, pois houve pouca alteração na rigidez e as deformações residuais das armaduras mais solicitadas foram pequenas.

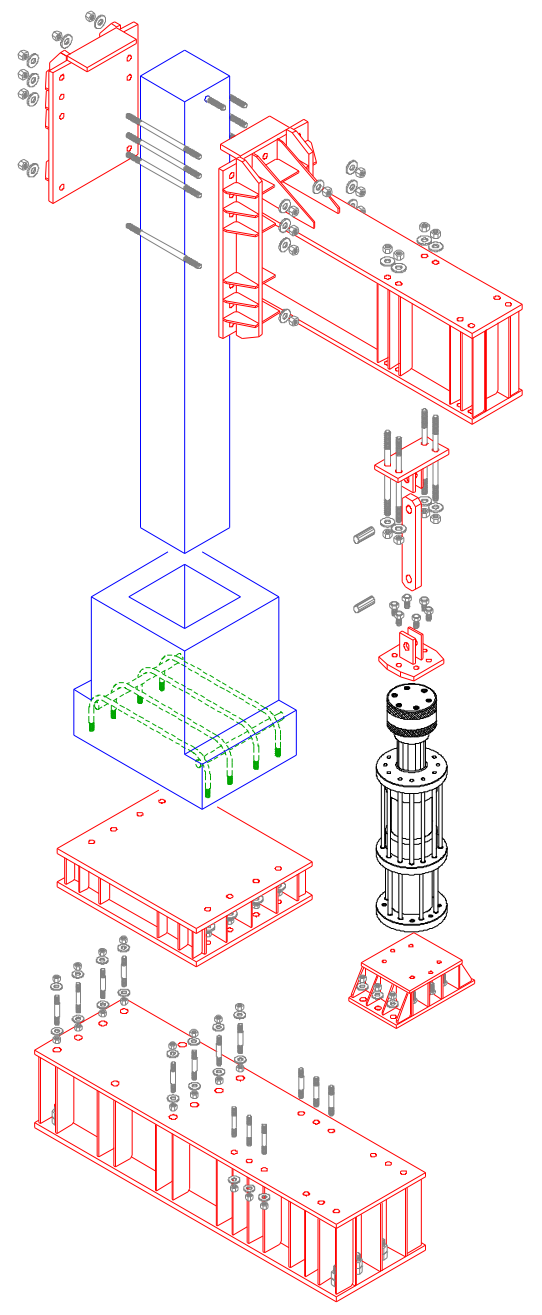

(a) Peças explodidas
Modelo

Chumbadores de fixação do cálice

Dispositivos metálicos

Atuador (INSTRON)

Parafusos, barras rosqueadas e

pinos para ligação das peças

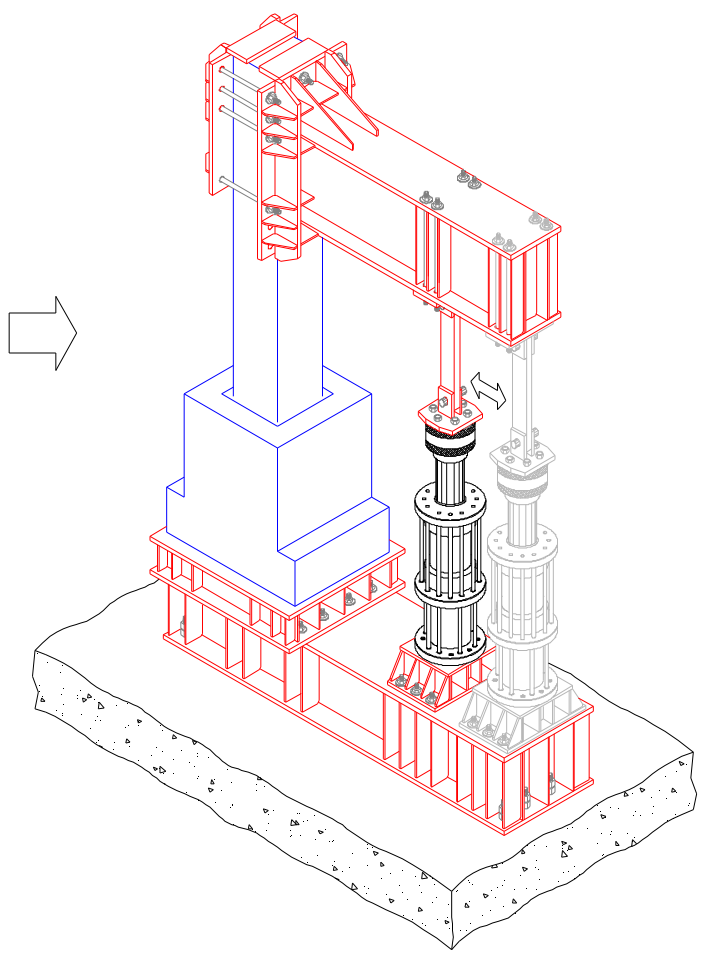

(b) Modelo montado

Figura 3.1 - Esquema de ensaio dos modelos físicos (CANHA (2004)) 
Verificou-se que o modelo de interface rugosa, que continha as chaves de cisalhamento de menores dimensões, apresentou um comportamento mais rígido quando comparado ao modelo que adotou a rugosidade mínima recomendada pela ABNT NBR 9062:2006.

Após os ensaios dos cálices com interface lisa, comprovou-se que o modelo de Leonhardt \& Mönnig (1978) subestima a capacidade da ligação, mostrando que é importante a consideração do atrito no projeto do cálice. Verificou-se também que o modelo de Osanai et al. (1996) foi o que resultou em menores diferenças entre os resultados teóricos e experimentais. Todos os modelos de projeto de cálices com interface rugosa se apresentaram bastantes conservadores.

\subsubsection{Propriedades geométricas e modelo de projeto proposto}

Para o dimensionamento dos modelos físicos foram recomendadas as seguintes dimensões geométricas para o cálice:

a) O comprimento de embutimento deve ser definido de acordo com a ABNT NBR 9062:2006;

b) A espessura da parede do colarinho é de no mínimo $10 \mathrm{~cm}$ ou determinada por $h_{c} \geq 1 / 3 \cdot\left(h_{\mathrm{int}}\right.$ ou $\left.b_{\mathrm{int}}\right)$;

c) A espessura da junta deve ser no mínimo $5 \mathrm{~cm}$, de maneira que permita a entrada do vibrador para adensamento do concreto. Para graute autoadensável, essa espessura pode ser reduzida;

d) As dimensões da base da fundação são definidas conforme o tipo de fundação. Para sapata, recomenda-se o valor mínimo de $20 \mathrm{~cm}$, podendo reduzir este valor com utilização de armaduras de suspensão e verificação da punção na base.

Baseado em todos os resultados experimentais e de análise numérica, a autora propõe um modelo de projeto para o cálice com interface lisa que considera a contribuição das forças de atrito e da excentricidade da reação normal na base do pilar. O esquema de forças atuantes na ligação está representado na Figura 3.2.

As forças de atrito são definidas pela multiplicação do coeficiente de atrito $\mu$ pela força normal correspondente e estão apresentadas nas Equações (3.1) a (3.3).

$$
F_{a t, \text { sup }, d}=\mu \cdot H_{\text {sup }, d}
$$




$$
\begin{aligned}
& F_{a t, \text { inf }, d}=\mu \cdot H_{\mathrm{inf}, d} \\
& F_{a t, b f, d}=\mu \cdot N_{b f, d}
\end{aligned}
$$

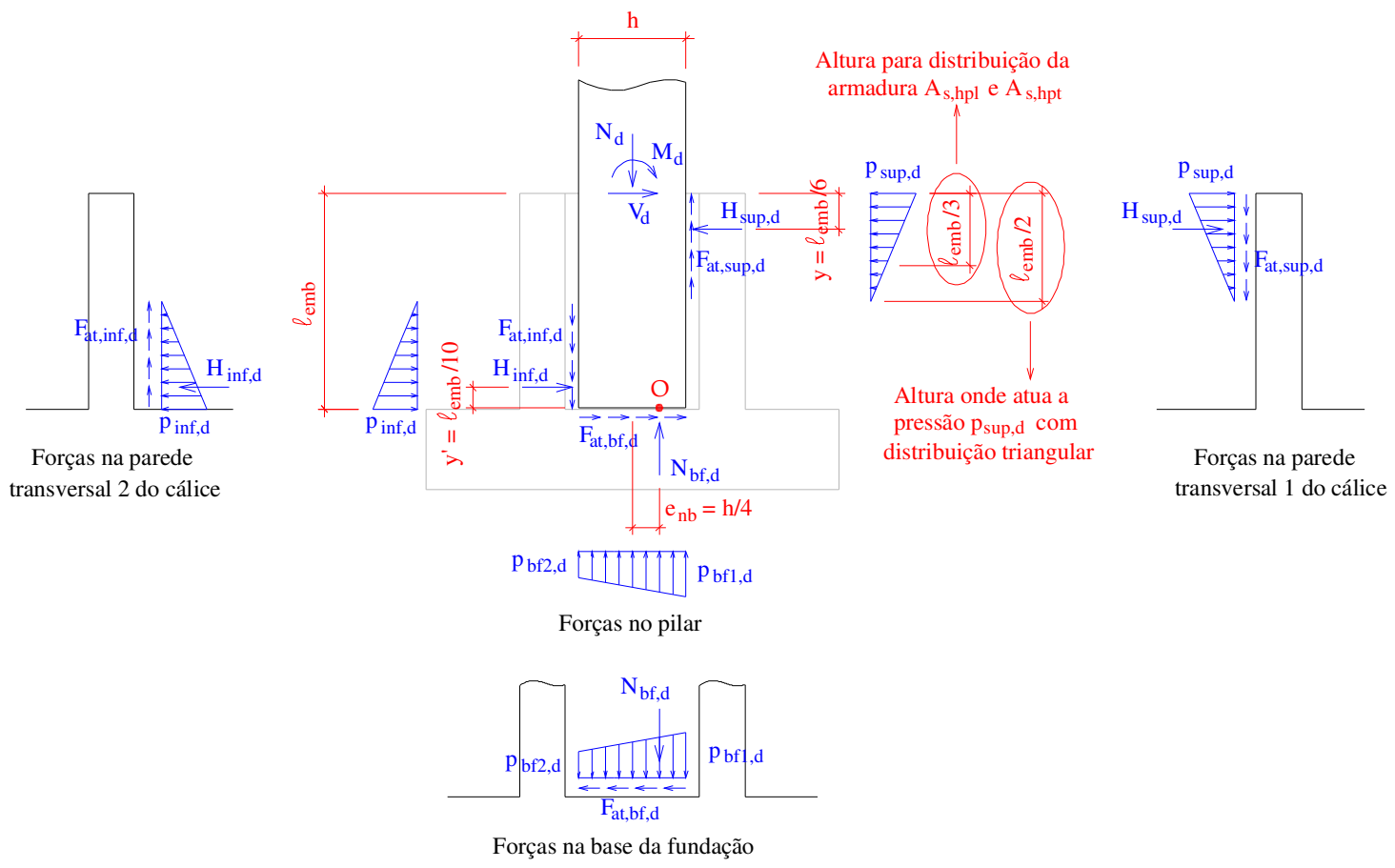

Figura 3.2 - Esquema de forças atuantes no modelo de projeto proposto para cálice com interface lisa (CANHA (2004))

Através das condições de equilíbrio das forças verticais, das forças horizontais e de momentos no ponto $\mathrm{O}$, resultam as equações (3.4), (3.5) e (3.6), respectivamente.

$$
\begin{aligned}
& N_{d}-N_{b f, d}-F_{a t, \text { sup }, d}+F_{a t, \text { inf }, d}=0 \\
& V_{d}+F_{a t, b f, d}-H_{\text {sup }, d}+H_{\mathrm{inf}, d}=0 \\
& M_{d}-N_{d} \cdot e_{n b}+V_{d} \cdot l_{e m b}-H_{\text {sup }, d} \cdot\left(l_{e m b}-y\right)+H_{\mathrm{inf}, d} \cdot y^{\prime}-F_{a t, \text { sup }, d} \cdot\left(0,5 \cdot h-e_{n b}\right)+ \\
& -F_{a t, \text { in }, d} \cdot\left(0,5 \cdot h+e_{n b}\right)=0
\end{aligned}
$$

Combinando-se as Equações (3.4) e (3.5) e substituindo-se os valores das forças de atrito têm-se, respectivamente, os valores de $F_{a t, b f, d}$ e $H_{\text {inf }, d}$.

$$
\begin{aligned}
& F_{a t, b f, d}=\frac{\mu \cdot N_{d}-\mu^{2} \cdot V_{d}}{1+\mu^{2}} \\
& H_{\text {inf. } d}=H_{\text {sup }, d}-\frac{\mu \cdot N_{d}+V_{d}}{1+\mu^{2}}
\end{aligned}
$$


Substituindo os valores de $H_{\text {inf, }, d}, F_{a t \text { sup, } d}$ e $F_{a t, \text { inf }, d}$ na Equação (3.6), resulta a Equação (3.9) para o cálculo de $H_{\text {sup }, d}$ para cálice de interface lisa.

$$
H_{\text {sup }, d}=\frac{M_{d}-N_{d} \cdot\left(e_{n b}+\frac{\mu \cdot y^{\prime}-\mu^{2} \cdot\left(0,5 \cdot h+e_{n b}\right)}{1+\mu^{2}}\right)+V_{d} \cdot\left(l_{e m b}-\frac{y^{\prime}-\mu \cdot\left(0,5 \cdot h+e_{n b}\right)}{1+\mu^{2}}\right)}{l_{\text {emb }}-y-y^{\prime}+\mu \cdot h}
$$

Para o caso de ligações em que a força cortante horizontal for nula e $M_{d}=N_{d} \cdot e$ obtemos a seguinte equação para o cálculo de $H_{\text {sup }, d}$ :

$$
H_{\mathrm{sup}, d}=\frac{N_{d} \cdot\left(e-e_{n b}-\frac{\mu \cdot y^{\prime}-\mu^{2} \cdot\left(0,5 \cdot h+e_{n b}\right)}{1+\mu^{2}}\right)}{l_{e m b}-y-y^{\prime}+\mu \cdot h}
$$

Para a calibração da equação acima com a força experimental última, foram variados a excentricidade $e_{n b}$ da reação normal $N_{b f, d}$ na base do pilar, a altura $y^{\prime}$ da resultante de pressão $H_{\text {inf, } d}$ e a posição $y$ da resultante de pressão superior $H_{\text {sup }, d}$. E os parâmetros definidos para o cálculo de $H_{\text {sup }, d}$, quando utilizados comprimentos de embutimento recomendados pela ABNT NBR 9062:2006, são:

a) Coeficiente de atrito $\mu=0,6$ para cálice com interface lisa;

b) Excentricidade da reação na base da fundação $e_{n b}=h / 4$

c) $y=l_{\text {emb }} / 6$

d) $y^{\prime}=l_{\text {emb }} / 10$

Adotou-se para a excentricidade $e_{n b}$ o valor de $h / 4$, devido à excentricidade da força de compressão $R_{c d}$ resultante do dimensionamento do pilar para o limite dos domínios de deformação 3 e 4 ficar em torno dessa grandeza. O valor de $e_{n b}=h / 6$ proposto por Olin et al. (1985) é muito conservador para os casos de grande excentricidade $(e \geq 2 \cdot h)$, sendo mais indicado para média excentricidade $(0,15 \cdot h \leq e \leq 2 . h)$.

O valor de $y^{\prime}=l_{e m b} / 10$ é o mesmo indicado por Olin et al. (1985), e apesar da força de compressão inferior $H_{\text {inf, } d}$ ser absorvida diretamente pela base da fundação devido à sua pequena altura em relação a base, é prudente considerar um valor diferente de zero para $y^{\prime}$, de forma a abranger todo o intervalo de grande excentricidade. 
O valor de $y=l_{e m b} / 6$ é sugerido para a aplicação da força $H_{\text {sup }, d}$ considerando distribuição triangular das tensões de compressão na parede transversal 1. Se fosse considerada uma distribuição parabólica, o valor de $y$ seria de $3 \cdot l_{e m b} / 16$ resultando em valores mais distantes dos resultados experimentais. Porém, a armadura $A_{s, h p}$ deve ser distribuída uniformemente no trecho superior de $l_{\text {emb }} / 3$, que é onde ocorre a maior concentração de tensões.

Este modelo de projeto proposto é aplicável para casos de grande excentricidade, em que a ação de momento é predominante à força normal e tende a gerar força de atrito $F_{a t, b f, d}$ na base da fundação com o mesmo sentido de $H_{\text {inf,d }}$, e que a força de atrito $F_{a t, \text { inf, } d}$ atuante na parede transversal 2 tenha sentido para cima no colarinho e sentido para baixo no pilar. Para o caso de pequena excentricidade, a equação proposta pode ser utilizada após investigação experimental e análise do sentido da força de atrito $F_{a t, \text { inf, } d}$ que é influenciada pela relação dos esforços $M_{d}, V_{d}$ e $N_{d}$ e pela geometria do cálice.

A fim de se propor um modelo para o dimensionamento da armadura horizontal principal transversal $A_{s, h p t}$ disposta no topo da parede transversal frontal 1 mais consistente do que o apresentado no Manual da Munte e na CNR 10025:1998, Canha (2004) fez um estudo do comportamento dessa parede. Através dos resultados experimentais, constatou-se que todos os modelos físicos foram submetidos a uma flexo-tração, apresentando a parede transversal frontal 1 um comportamento de uma viga biapoiada. Parte da pressão oriunda do pilar foi transmitida diretamente para os apoios com diferentes inclinações e a outra parcela ocasionou flexão na parede. Existem ainda forças de atrito que resultam da pressão de contato do pilar e da junta no cálice que não são direcionadas para os apoios. Uma distribuição idealizada dessas pressões pode ser visualizada na Figura 3.3.

Uma modelagem do comportamento da parede está apresentada na Figura 3.4. A modelagem consistiu em variar o percentual da força $H_{\text {sup }-f, d}$ que causa flexão na parede transversal com distribuição parabólica no meio do vão e da força $H_{\text {sup-t,d }}$ que causa tração na parede transversal que vai direto para os apoios da viga, fazendo o ajuste do grau $n_{1}$ da parábola. Adotou-se um ângulo $\theta=45^{\circ}$ de inclinação das fissuras, devido às dimensões nas duas direções serem iguais. Calibrando o modelo com os resultados dos modelos ensaiados, 
Canha (2004) sugeriu os valores de $H_{\text {sup }-f, d} / H_{\text {sup }, d}=0,35, H_{\text {sup }-t, d} / H_{\text {sup }, d}=0,65$ e $n_{1}=5$ indicando que a parede está submetida a $35 \%$ de flexão e a $65 \%$ de tração.

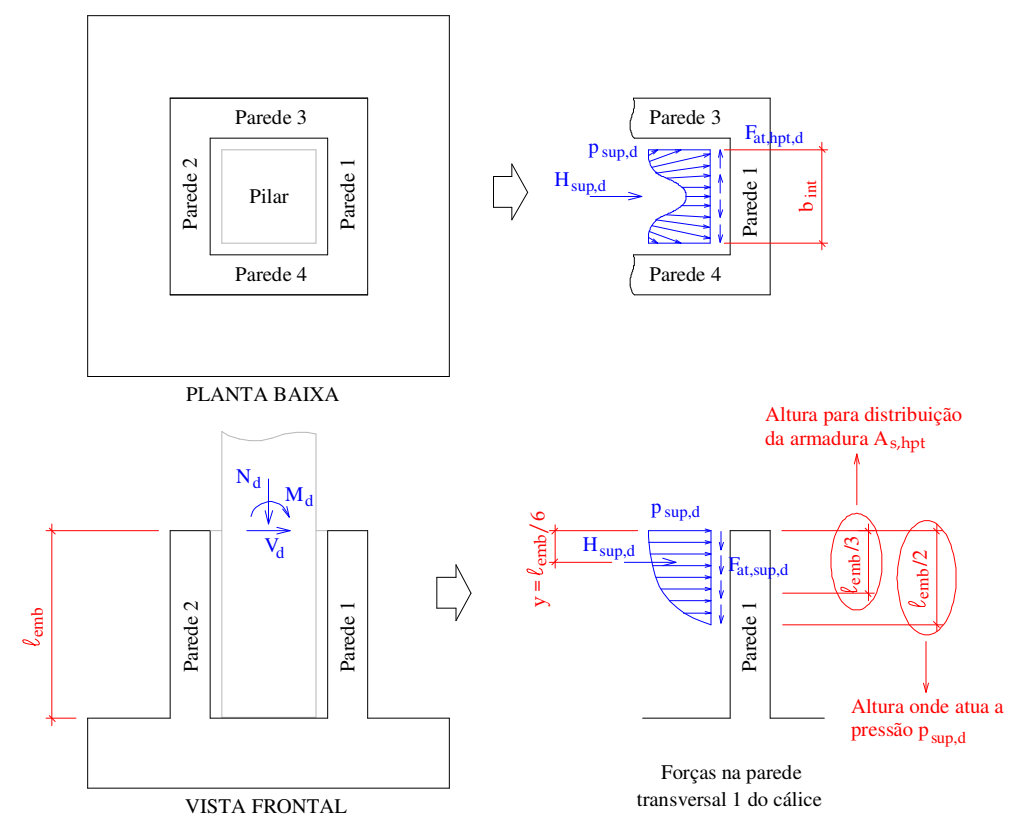

Figura 3.3 - Idealização de pressões na parede transversal 1 do cálice com interface lisa (CANHA (2004))
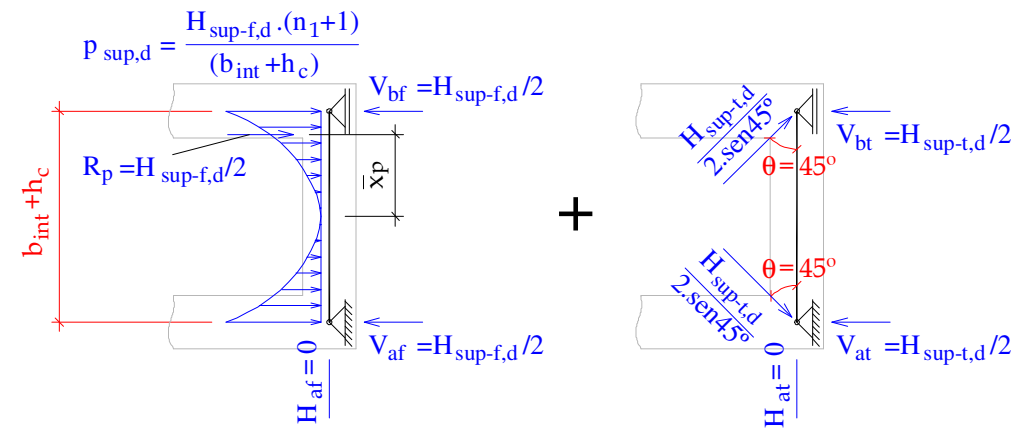

PLANTA

$$
\begin{aligned}
& \text { Obs.: } \mathrm{H}_{\text {sup }, \mathrm{d}}=\mathrm{H}_{\text {sup-f,d }}+\mathrm{H}_{\text {sup-t,d }} \\
& \overline{\mathrm{x}} \mathrm{p}=\frac{\left(\mathrm{b}_{\text {int }}+\mathrm{h}_{\mathrm{c}}\right) \cdot\left(\mathrm{n}_{1}+1\right)}{2 .\left(\mathrm{n}_{1}+2\right)} \\
& \mathrm{n}_{1}: \text { grau da parábola } \\
& \mathrm{M}_{\mathrm{d}}=\frac{\mathrm{H}_{\text {sup-f,d } \mathrm{d} \cdot\left(\mathrm{b}_{\text {int }}+\mathrm{h}_{\mathrm{c}}\right)}^{4 .\left(\mathrm{n}_{1}+2\right)}}{\mathrm{N}_{\mathrm{d}}}=\mathrm{H}_{\text {sup-t,d }} / 2
\end{aligned}
$$

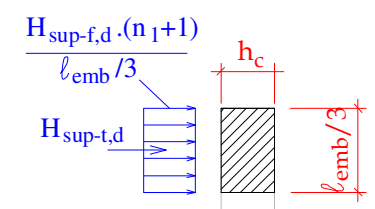

VISTA FRONTAL

Figura 3.4 - Modelagem do comportamento da parede transversal 1 do cálice com interface lisa (CANHA (2004)) 
Para cálice de interface rugosa, foi determinada a resistência monolítica da fundação pela teoria da flexão, ou seja, com a transferência total do momento fletor e força normal.

Nos modelos rugosos ensaiados pela autora, a ruína ocorreu na base do cálice, caracterizando o escoamento da armadura vertical principal e da armadura vertical secundária da parede transversal 2, além da contribuição da armadura vertical secundária localizada na parede longitudinal 3 e 4 . Essa contribuição foi indicada pelo nível das deformações e formação das bielas inclinadas nas paredes longitudinais.

Na Figura 3.5, são ilustradas as fissuras na parede transversal posterior 2 dos modelos com interface rugosa. Esse padrão de fissuras é o mesmo esperado para uma ligação monolítica, onde as fissuras predominantes aparecem na base do cálice na direção horizontal e no topo a tração é indicada pelas fissuras verticais atravessando a parede.
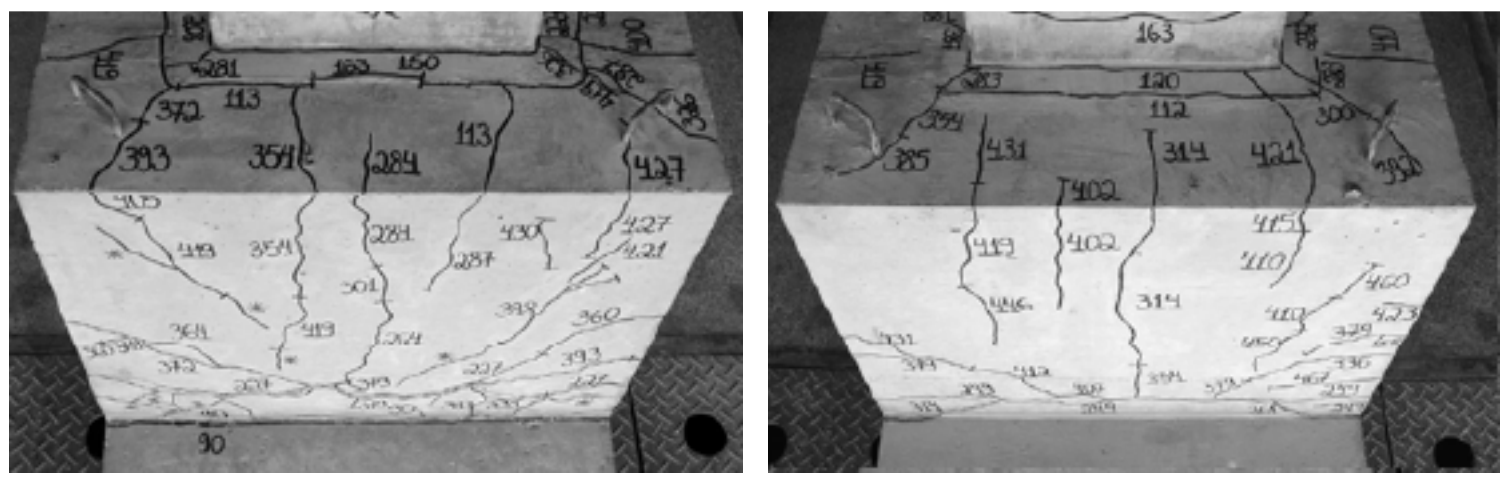

Figura 3.5 - Configuração de fissuras na parede transversal posterior dos modelos IR-1 e IR2 ensaiados por Canha (2004)

Conforme indicado na Figura 3.6, é recomendado adotar a armadura $A_{s, v s l}$, situada no primeiro terço da altura útil do cálice, contribuindo para resistência da ligação. No entanto, este procedimento só deve ser utilizado quando a armadura vertical secundária for determinada de acordo com as recomendações da ABNT NBR 9062:2006. Caso contrário, deve ser utilizado apenas à armadura vertical secundária $A_{s, v s t}$ disposta na parede transversal posterior 2 contribuindo na capacidade resistente da ligação 


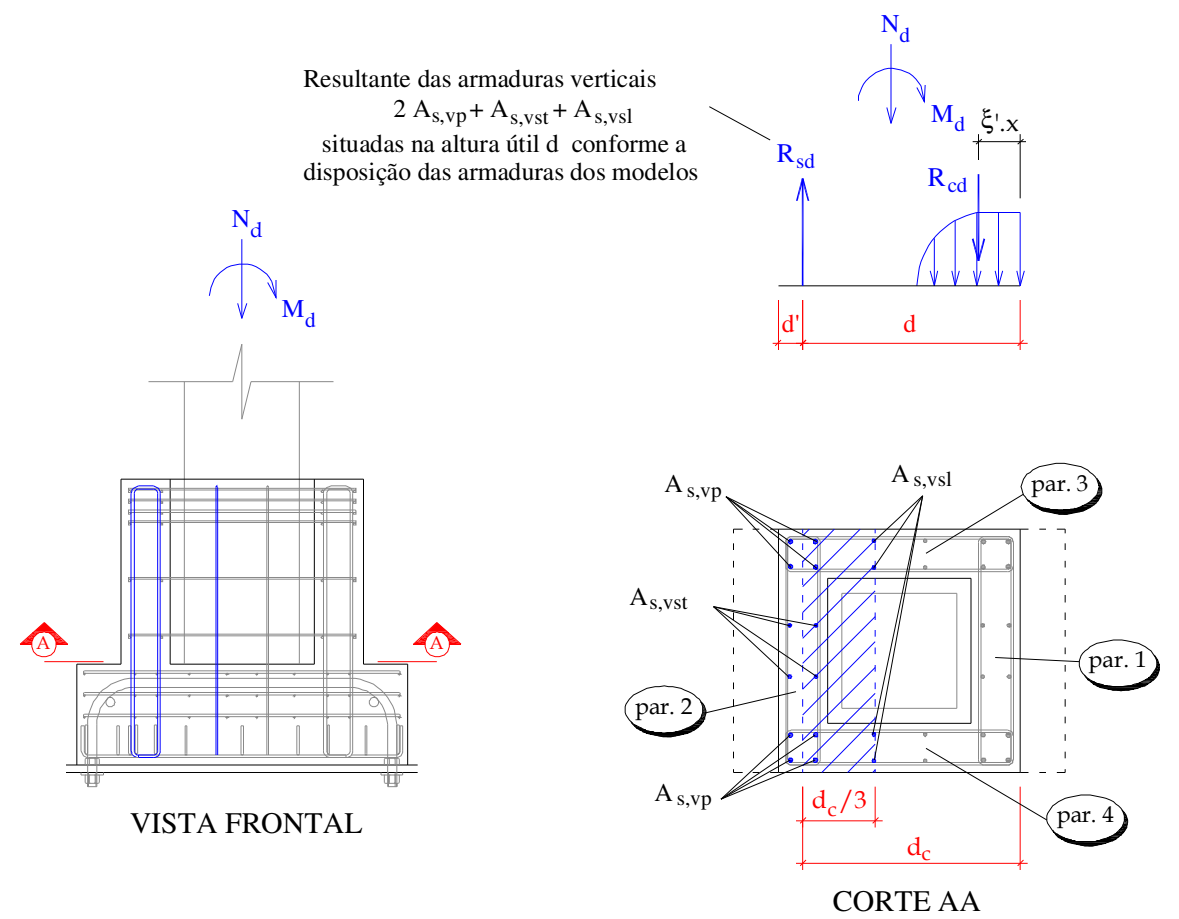

Figura 3.6 - Dimensionamento das armaduras verticais para cálice com interface rugosa (CANHA (2004))

\subsubsection{Recomendações de projeto}

A seguir, seguem as recomendações finais de projeto apresentadas em Canha (2004):

a) Para cálice com interface lisa, o dimensionamento da armadura $A_{s, v p}$ e a verificação da resistência a compressão do concreto devem ser feitos considerando as paredes longitudinais 3 e 4 como consolo. A armadura horizontal secundária $A_{s, h s}$ e a armadura vertical secundária transversal e longitudinal $A_{s, v s t}$ e $A_{s, v s l}$ devem ser calculadas conforme as recomendações de consolo da ABNT NBR 9062:2006;

b) Verificou-se que o dimensionamento das armaduras $A_{s, v p}$ e $A_{s, v s t}$ da parede transversal 2 foi racional, pois essas duas armaduras nos ensaios experimentais atingiram o escoamento. Embora as armaduras $A_{s, h s}$ e $A_{s, v s l}$ tenham sido pouco solicitadas nos ensaios, elas não podem ser dispensadas, pois a presença das mesmas contribui no controle da fissuração;

c) Para cálice com interface rugosa o dimensionamento da armadura $A_{s, v p}$ é feito como uma ligação monolítica pela teoria da flexão, com a contribuição na altura útil $d_{c}$ do cálice da armadura da parede transversal $2\left(A_{s, v p}+A_{s, v s t}\right)$ mais a armadura $A_{s, v s l}$ 
pertencente ao primeiro terço da altura útil. Para utilização deste procedimento, deve ser adotado um percentual de $A_{s, v p}$ para a armadura $A_{s, v s}$ conforme o tipo do consolo em que a parede longitudinal é classificada;

d) A resistência experimental alcançada pelos modelos rugosos (IR-1 e IR-2) ensaiados por Canha (2004) foi praticamente à mesma, comprovando que diferentes configurações de chaves, dentro de certos limites indicados na tese, não influenciam na resistência final dos modelos, apenas na rigidez.

\subsection{ENSAIOS E RECOMENDAÇÕES DE JAGUARIBE JR. (2005)}

Esse trabalho deu continuidade aos estudos da pesquisa de doutorado de Canha (2004) e consistiu em uma análise experimental da ligação pilar-fundação por meio de cálice em que a profundidade de embutimento foi reduzida em relação aos valores recomendados pela Norma ABNT NBR 9062:2006, apresentados na Tabela 2.1.

Considerando a carência de resultados experimentais e a necessidade de se avaliar a influência do comprimento de embutimento no comportamento da ligação, esse trabalho contribuiu com dados referentes ao funcionamento do cálice. Foram analisadas as armaduras do colarinho, a rugosidade da ligação, o desenvolvimento de fissuras e a capacidade resistente de cada modelo ensaiado devido à redução da profundidade de embutimento.

Através de uma revisão dos principais modelos da literatura a respeito dessa ligação, Jaguaribe Jr. (2005) elaborou uma planilha comparativa que apresenta os diferentes métodos de dimensionamento da ligação com suas recomendações.

\subsubsection{Investigação experimental}

No programa experimental, foram ensaiados dois modelos físicos em escala 1:1, submetidos a força normal com grande excentricidade. Um modelo físico continha interface lisa e outro com interface rugosa. Nos dois modelos, a adesão foi impedida para melhor representar a situação de projeto.

As propriedades geométricas dos modelos físicos e dimensionamento das armaduras do colarinho foram determinadas segundo as recomendações de Leonhardt \& Mönnig (1978), ABNT NBR 9062:2006 e El Debs (2000), porém foram adotados comprimentos de embutimento menores, podendo com isso avaliar o comportamento de transferência das ações do pilar para as paredes do colarinho. 
Os valores de comprimento de embutimento adotados foram de $1,6 \cdot h$ e $1,2 \cdot h$ para cálices com interface lisa e rugosa, respectivamente. Vale lembrar que os valores de comprimentos de embutimento recomendados pela Norma Brasileira são de $2,0 \cdot h$ e $1,6 \cdot h$ para cálices com interface lisa e rugosa, respectivamente. No modelo rugoso as chaves de cisalhamento empregadas foi a recomendada pela ABNT NBR 9062:2006.

\subsubsection{Resultados experimentais e análise}

Após realização dos ensaios, Jaguaribe Jr. (2005) constatou que, mesmo com uma profundidade de embutimento inferior que a recomendada pela Norma Brasileira, o modelo com interface rugosa teve maior capacidade resistente em relação ao modelo com interface lisa. Foi verificado também no modelo liso separação e deslizamento entre a junta e os elementos na região de embutimento no decorrer do ensaio.

Quanto ao comportamento da parede transversal frontal 1 para o cálice com interface lisa, nota-se que o ramo externo da armadura foi mais solicitado e chegou próximo ao escoamento, enquanto que o ramo interno foi pouco solicitado, apontando um modelo de projeto que considere uma flexo-tração dessa parede. Este mesmo comportamento foi verificado nos estudos de Canha (2004). Já no cálice com interface rugosa, as armaduras horizontais dessa parede não foram muito solicitadas.

No modelo rugoso, o topo da parede transversal posterior 2 foi submetida a elevados esforços de flexo-tração, enquanto para o modelo com interface lisa as armaduras horizontais não foram totalmente solicitadas e os deslocamentos pouco consideráveis, concluindo assim que para os modelos lisos, os esforços por flexão na parede transversal posterior 2 são pequenos. Os deslocamentos na parede transversal 2 do modelo rugoso foram bem mais significativos, devido ao travamento das chaves de cisalhamento.

Quanto às armaduras verticais, no cálice com interface lisa, concluiu-se que as armaduras verticais da parede transversal 2 contribuíram na resistência da ligação e que as armaduras verticais das paredes longitudinais não foram solicitadas até a perda da adesão. No cálice com interface rugosa, a armadura vertical principal foi muito solicitada atingindo a plastificação.

No modelo de cálice com interface lisa, foi verificada a transferência de esforços primeiramente para as armaduras verticais da parede transversal 2. Após a ruptura completa da adesão, em que o pilar sofreu um deslizamento, é que ocorreu a transmissão da pressão 
$H_{\text {sup }}$ por flexo-tração da parede transversal 1 , acionando a armadura $A_{s, h p t}$ que por sua vez transferiu a parcela restante dos esforços para as paredes longitudinais 3 e 4 .

Nota-se que o mecanismo observado não segue o recomendado por Leonhardt \& Mönnig (1978), em que as armaduras verticais e horizontais deveriam ser solicitadas simultaneamente e desde o início do carregamento, com os esforços oriundos da resultante de

pressão $H_{\text {sup }}$ absorvidos pela armadura $A_{s, h p t}$, seguindo para a armadura $A_{s, h p l}$ e desta para a armadura $A_{s, v p}$ com as paredes longitudinais funcionando como consolo.

Antes da perda da adesão no modelo liso, o único mecanismo resistente da ligação eram as armaduras verticais localizadas na parede transversal 2 e a adesão entre a junta e os elementos. Após o rompimento da adesão é que as armaduras horizontais foram solicitadas, diferentemente do que aconteceu nos modelos ensaiados por Canha (2004).

No modelo de cálice com interface rugosa, as armaduras verticais da parede transversal posterior 2 e as mais tracionadas das paredes longitudinais 3 e 4 foram efetivamente solicitadas. As armaduras horizontais foram pouco solicitadas em relação às verticais que plastificaram. Apesar desse comportamento rígido, esse modelo não pode ser dimensionado considerando a transferência total dos esforços atuantes no pilar para o cálice, pois a capacidade resistente foi menor que o calculado pelo modelo da teoria e flexão (ligação monolítica).

\subsubsection{Estudo comparativo}

Como o principal objetivo do trabalho desenvolvido por Jaguaribe Jr. (2005) foi analisar o comportamento da ligação pilar-fundação por meio de cálice com profundidade de embutimento inferiores aos recomendados pela Norma Brasileira, foi realizada uma análise comparativa entre os modelos ensaiados nesta pesquisa (IL-4 e IR-3) com os ensaiados por Canha (2004). Os modelos ensaiados por Canha (2004) (IL-1, IL-2, IL-3, IR-1 e IR-2) seguiram as indicações da norma para determinação da profundidade de embutimento.

Na Tabela 3.1, é apresentada a resistência experimental alcançada por esses modelos, indicando a força normal e o momento último alcançado pelos modelos. Nota-se pelos resultados que os modelos com menores comprimentos de embutimento tiveram menor resistência do que aqueles com profundidade de embutimento indicado pela ABNT NBR 9062:2006, ou seja, os modelos ensaiados na pesquisa de Canha (2004). Na Figura 3.7, um gráfico apresenta uma comparação da capacidade resistente de todos os modelos. 
Tabela 3.1 - Resistência experimental dos modelos com interface lisa e rugosa (JAGUARIBE JR. (2005))

\begin{tabular}{c|c|c|c}
\hline Modelos & $\begin{array}{c}\text { Excentricidade } \\
\mathrm{e}(\mathrm{m})\end{array}$ & $\begin{array}{c}\text { Força normal } \\
\text { última }(\mathrm{kN})\end{array}$ & $\begin{array}{c}\text { Momento último } \\
(\mathrm{kN} . \mathrm{m})\end{array}$ \\
\hline IL-1 & 1,85 & 241 & 446 \\
\hline IL-2 & 1,85 & 203 & 376 \\
\hline IL-3 & 1,20 & 336 & 403 \\
\hline IL-4 & 1,20 & 275 & 330 \\
\hline IR-1 & 1,20 & 448 & 538 \\
\hline IR-2 & 1,20 & 469 & 563 \\
\hline IR-3 & 1,20 & 360 & 432 \\
\hline
\end{tabular}

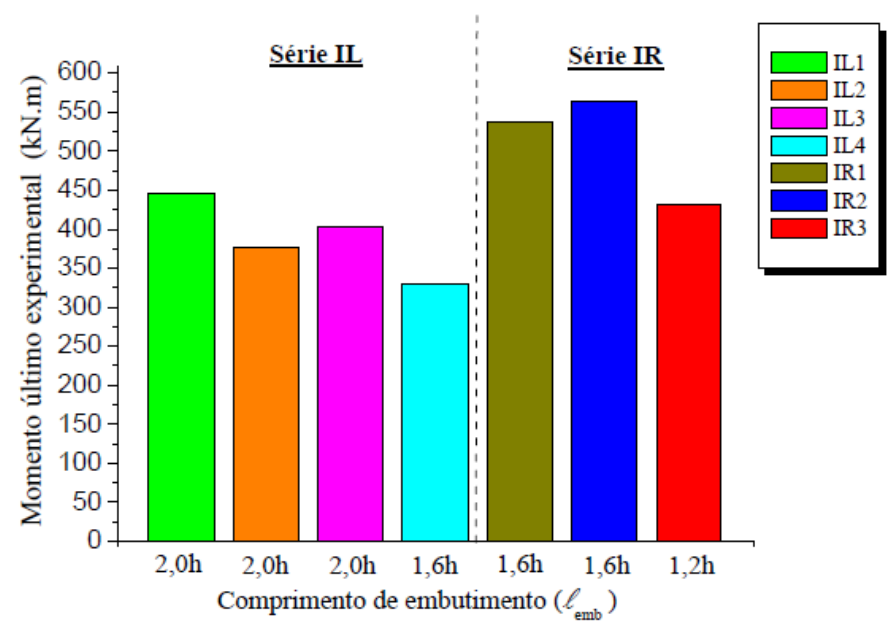

Figura 3.7 - Capacidade resistente dos modelos físicos (JAGUARIBE JR. (2005))

O modelo IL-1 foi o que obteve a maior força normal última e momento último entre os modelos com interface lisa por possuir adesão nas interfaces contribuindo com a resistência. Os modelos IL-2 e IL-3 tiveram capacidades resistentes próximas entre si e podem ser calculados pelo modelo proposto por Canha (2004) para cálice liso. Já o modelo IL-4 teve resistência inferior aos demais, isso é explicado pelo fato desse modelo possuir um comprimento de embutimento inferior em relação aos outros. Teoricamente, todos os modelos deveriam possuir resistências próximas, pois a diminuição da altura de embutimento do modelo IL-4 foi compensada pelo acréscimo de armadura horizontal de acordo com o modelo teórico de Leonhardt \& Mönnig (1978). Isso comprova que este modelo não representa bem o comportamento de cálices com comprimentos de embutimento inferiores aos recomendados pela ABNT NBR 9062:2006. 
Nos modelos rugosos, com chaves de cisalhamento, o comportamento foi muito próximo ao de uma ligação monolítica. A resistência dos modelos IR-1 e IR-2 foram praticamente iguais, enquanto que o modelo IR-3 com comprimento de embutimento reduzido teve uma menor resistência. A determinação da resistência dos modelos pela teoria da flexão se aproximou da resistência experimental dos modelos IR-1 e IR-2, ao contrário do que se verifica no modelo IR-3.

Com a finalidade de observar qual modelo de projeto da literatura mais se aproximava da resistência última experimental e analisar a capacidade dos modelos que tinham profundidade de embutimento inferiores as recomendadas pela ABNT NBR 9062:2006, foram aplicados alguns modelos de projeto nos modelos físicos estudados. Em resumo, Jaguaribe Jr. (2005) afirma que o modelo IL-4 não foi bem representado pelos modelos da literatura, sendo que a maioria superestima a capacidade resistente do modelo físico. No caso do modelo IR-3, ao contrário dos outros, o modelo da teoria da flexão resultou num valor contra a segurança, mostrando que para cálices com comprimentos de embutimento inferiores a $1,60 \cdot h$, esta teoria não se aplica.

\subsubsection{Recomendações finais}

A seguir, seguem as recomendações finais apresentadas em Jaguaribe Jr. (2005):

a) Com a redução do comprimento de embutimento para cálice com interface lisa do valor de $2,00 \cdot h$ para $1,60 \cdot h$, a capacidade resistente da ligação diminuiu em média $15 \%$, mesmo com um aumento da armadura horizontal em $33 \%$. Isto comprova a importância de se obter um modelo de cálculo que se aproxime da capacidade da ligação para cálice com comprimento de embutimento reduzido;

b) Entre os modelos com comprimentos de embutimento iguais, porém com interfaces diferentes observa-se um aumento da resistência determinada experimentalmente em média de $67 \%$ quando se utiliza chaves de cisalhamento na interface entre os elementos. Como os modelos físicos possuem a mesma quantidade de armadura, comprova-se que a utilização de chaves de cisalhamento aumenta a capacidade resistente da ligação;

c) Com a redução do comprimento de embutimento para cálice com interface rugosa do valor de $1,60 \cdot h$ para $1,20 \cdot h$ a capacidade resistente da ligação diminui em média $20 \%$, mesmo com um aumento a armadura horizontal em $17 \%$. 


\subsection{ENSAIOS E RECOMENDAÇÕES DE EBELING (2006)}

Esse foi o terceiro trabalho desenvolvido na EESC-USP a respeito da ligação cálicefundação com colarinho e o enfoque foi no comportamento da base de pilares de concreto prémoldado na ligação de cálice com interface lisa. Essa pesquisa preenche a falta de informações a respeito do comportamento dos pilares na região de embutimento e também ao dimensionamento da base do pilar.

O estudo foi baseado na análise da ligação de cálice por colarinho, mas as informações referentes à base do pilar são as mesmas para os casos de cálice embutido. Apesar de o cálice embutido apresentar uma maior rigidez e, portanto um comportamento diferente, a base do pilar não apresenta mudanças significativas na intensidade e na posição das forças atuantes, como apresentado na Figura 3.8.

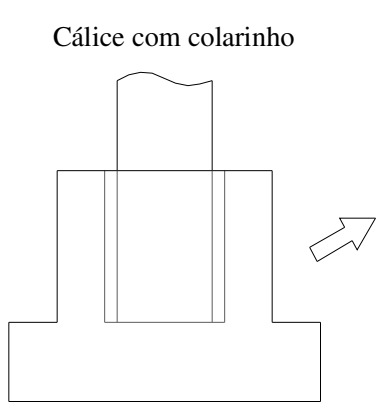

Figura 3.8 - Comportamento equivalente do pilar para cálices com e sem colarinho (adaptado de
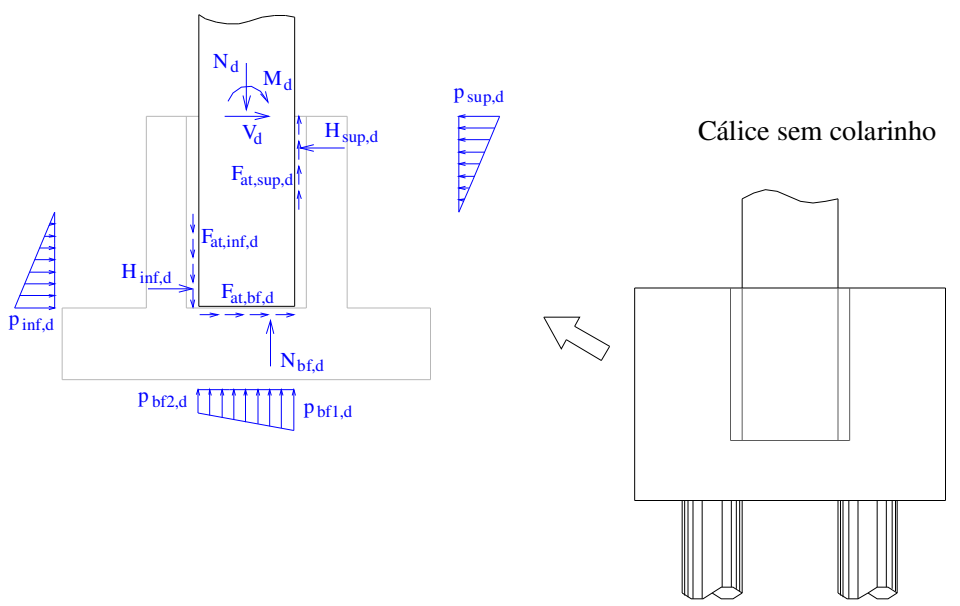
EBELING (2006))

\subsubsection{Investigação experimental e simulação numérica}

Foi realizada uma investigação experimental com dois modelos em escala $1: 1$, de interface lisa e submetidos à força normal de grande excentricidade da ordem de $3 \mathrm{~h}$, resultando numa excentricidade de $120 \mathrm{~cm}$. Os modelos ensaiados possuíam comprimentos de embutimento diferentes.

Os pilares tinham seção constante de $40 \times 40 \mathrm{~cm}^{2}$ ao longo do eixo longitudinal e altura de $290 \mathrm{~cm}$. Ebeling (2006) verificou a capacidade resistente do pilar para que essa não fosse superior à capacidade resistente do cálice, evitando assim que as armaduras do cálice 
escoassem. Também foi analisada a força última experimental, de maneira que não ultrapassasse a capacidade do atuador servo-hidráulico.

Para a armadura transversal na base do pilar foi adotado o valor mínimo da área de aço, bem como o espaçamento mínimo entre estribos. Isso porque teoricamente a força cortante é nula até o topo do colarinho.

Os cálices foram aproveitados de ensaios anteriores e com a finalidade de assegurar que as armaduras dos cálices não atingiriam novamente o escoamento, foi dimensionado um reforço de modo a absorver uma parcela da força a ser resistida pelos cálices. Esse reforço consistiu na utilização de três camadas de manta composta por fibras de carbono coladas no cálice de forma, a contribuir para a resistência das armaduras.

Antes da colagem da manta foi necessário realizar o tratamento das fissuras, já que essas apresentavam aberturas maiores que 0,50 $\mathrm{mm}$, e de acordo com as recomendações, deveriam ser reparadas. O reparo consistiu na abertura da fissura e posterior aplicação de epóxi. A manta foi aplicada na direção da armadura vertical principal e da armadura horizontal principal dos cálices, como indicado na Figura 3.9.

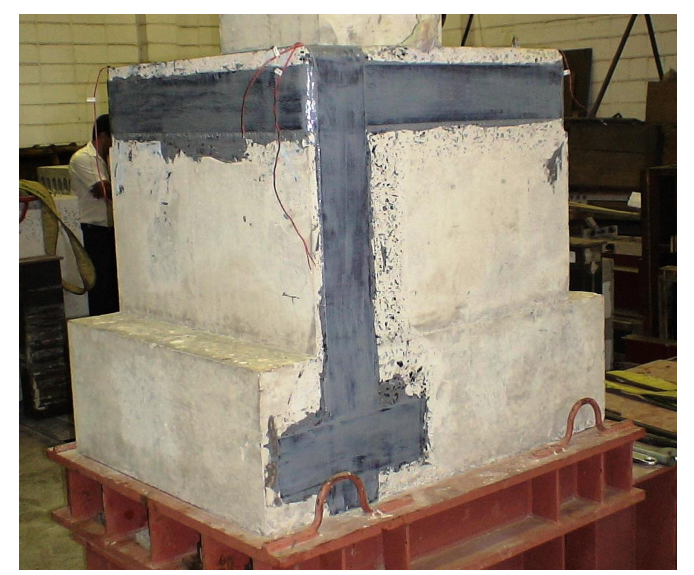

Figura 3.9 - Reforço aplicado nos cálices ensaiados por Ebeling (2006)

Foi instrumentada a armadura longitudinal e transversal da base dos pilares através de extensômetros. Além desses, foram também colocados extensômetros no reforço de um dos modelos ensaiados por Ebeling (2006), que ainda apresentavam identificação dos extensômetros das armaduras do cálice, a fim de avaliar a eficácia desse procedimento. Com essa instrumentação, pode ser feita uma comparação entre as deformações da manta com as deformações da armadura, determinando a parcela de força absorvida por cada um dos componentes. Os resultados dessa análise encontram-se na dissertação de Ebeling (2006). 
Pela dificuldade em observar experimentalmente o comportamento da base dos pilares na ligação cálice-fundação, foi desenvolvida uma análise numérica a fim de comparação dos resultados obtidos. A simulação numérica foi realizada pelo programa ANSYS 8.0, com modelagem tridimensional, consideração de não-linearidades físicas, geométricas e de contato. Alguns parâmetros utilizados foram obtidos da calibração já realizada por Canha (2004) e os demais foram determinados através da caracterização dos materiais. A modelagem numérica foi realizada de maneira a se aproximar o máximo possível dos modelos físicos.

\subsubsection{Resultados e análise}

Apesar dos modelos estudados apresentarem diferenças no comprimento de embutimento, a resistência última dos pilares foi praticamente à mesma. A ruína dos modelos ocorreu por deformação plástica excessiva da armadura tracionada e a ruína por flexão ocorreu fora da região de embutimento. Observa-se assim, que a base dos pilares apresenta segurança nesse tipo de ligação, mesmo estando com armadura transversal mínima.

Armadura Longitudinal

Para avaliação da armadura longitudinal do pilar, Ebeling (2006) analisou as armaduras tracionadas separadamente das armaduras comprimidas.

Nos dois modelos ensaiados, percebe-se que a deformação das armaduras tracionadas aumenta conforme aumenta a distância em relação à base do pilar. Isso fica evidenciado pela diminuição das deformações nas armaduras longitudinais mais próximas da base.

Comparando os modelos, verifica-se que o modelo com menor comprimento de embutimento teve maiores deformações nas armaduras longitudinais tracionadas quando comparado ao modelo com comprimento de embutimento indicado pela ABNT NBR 9062:2006 para uma mesma força aplicada, o que comprova a influência do comprimento de embutimento no comportamento do pilar.

Foi ainda observado que a transferência de tensões da armadura para o concreto ocorre à meia altura do comprimento de embutimento, o mesmo valor é indicado em Leonhardt \& Mönnig (1978) para ancoragem da armadura.

Para os dois modelos, o sistema de ancoragem de barra transversal soldada para a armadura longitudinal tracionada apresentou um bom desempenho.

Quanto à armadura longitudinal comprimida, foi verificado que a deformação máxima ocorreu em pontos localizados fora do colarinho. O mesmo acontece com a armadura 
tracionada, onde as intensidades de deformações são maiores à medida que aumenta a distância da base do pilar em direção ao topo do colarinho.

As intensidades de tensão diminuem nas seções mais próximas da base porque há uma maior seção de concreto comprimido e também por causa da transferência de tensões do pilar para o cálice por meio do atrito existente na interface de contato.

\section{$\underline{\text { Armadura Transversal }}$}

Nos dois modelos físicos, observou-se que as armaduras transversais não atingiram o valor da deformação de escoamento, o que confere uma segurança na região de embutimento da ligação. Os estribos localizados na base do cálice tiverem deformações muito pequenas, indicando que não há necessidade de uma armadura transversal adicional.

Os estribos localizados próximo ao topo do colarinho não apresentaram grandes deformações, porque no modelo experimental não havia força cortante. Ao contrário, se houvesse, provavelmente as deformações seriam maiores.

Foi comprovado pelos deslocamentos no topo do pilar que o comprimento de embutimento influencia na rigidez dos modelos, pois o deslocamento final é maior para o modelo com menor comprimento de embutimento.

\section{Fissuração e fluxo de tensões}

Observou-se que os modelos numéricos apresentaram maior rigidez que os modelos experimentais, no entanto, a principal justificativa da simulação numérica é a obtenção das situações de fissuração e do fluxo de tensões na região de embutimento.

A configuração das fissuras na base do pilar, para a força última aplicada, observada por Ebeling (2006) está representada na Figura 3.10 e Figura 3.11, respectivamente, para os modelos: com comprimento de embutimento de acordo com a ABNT NBR 9062:2006 e com comprimento de embutimento reduzido.

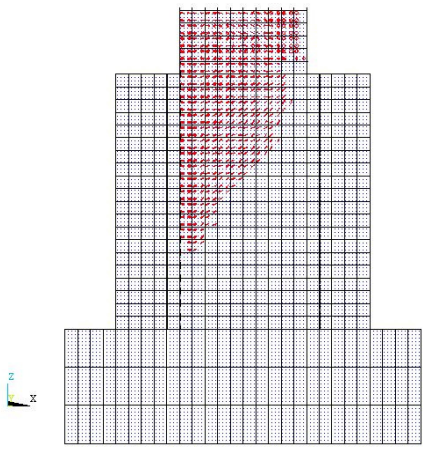

Figura 3.10- Fissuração na base do pilar do modelo liso com $1_{\mathrm{emb}}$ de acordo com a ABNT NBR 9062:2006 (EBELING (2006))

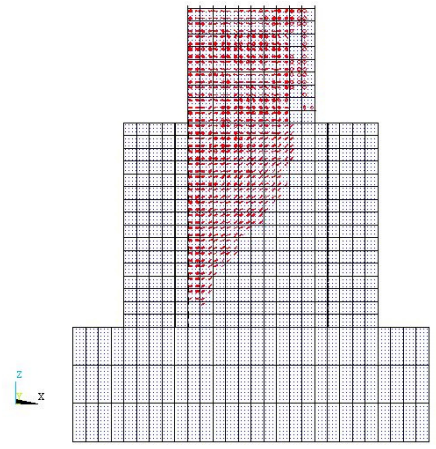

Figura 3.11- Fissuração na base do pilar do modelo liso com $l_{\text {emb }}$ reduzido (EBELING (2006)) 
A fissuração na região de embutimento dos pilares apresenta semelhanças com a fissuração da região de apoio das vigas, onde as fissuras deixam de ser perpendiculares e são inclinadas em torno de $45^{\circ}$ próximas aos apoios.

Nos dois modelos, a região da base do pilar não apresenta fissuração, porém no modelo com comprimento de embutimento reduzido a fissuração chega mais próxima a base da fundação. Verifica-se assim, que existe um confinamento do concreto e que as tensões de tração existentes nessa região não são maiores que a resistência a tração do concreto.

Perpendicularmente às tensões de tração, que causam as fissuras, existem as tensões de compressão. Na Figura 3.12 e Figura 3.13 está ilustrado o fluxo das tensões principais para o os dois modelos.

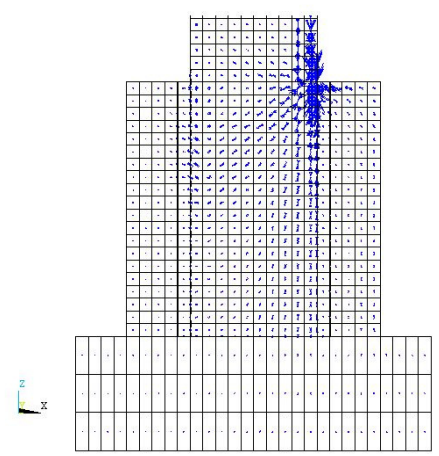

Figura 3.12 - Fluxo das tensões principais do pilar do modelo liso com $1_{\text {emb }}$ de acordo com a ABNT NBR 9062:2006 (EBELING (2006))

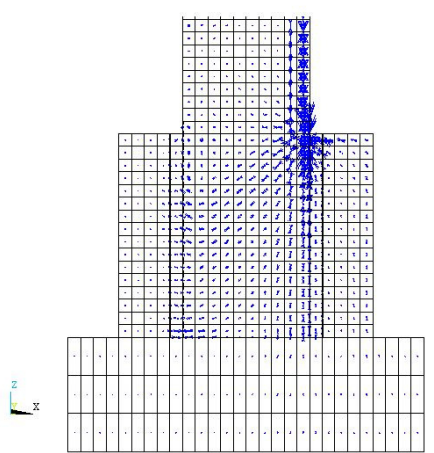

Figura 3.13 - Fluxo das tensões principais do pilar do modelo liso com $1_{\text {emb }}$ reduzido (EBELING (2006))

Em ambos os modelos, o fluxo de tensões no lado comprimido do pilar, segue na direção vertical com sentido colarinho-base, porém com diminuição de intensidade. Verificase também a formação de uma biela inclinada atravessando o pilar e acabando a meia altura do comprimento de embutimento. Logo abaixo da biela, o fluxo de tensões continua inclinado, porém menos intenso.

\subsubsection{Modelo de comportamento proposto}

Ebeling (2006), após análise dos resultados propôs, um modelo de bielas e tirantes que representa o comportamento da base de pilares pré-moldados na ligação com cálice de fundação, como ilustrado na Figura 3.14. 


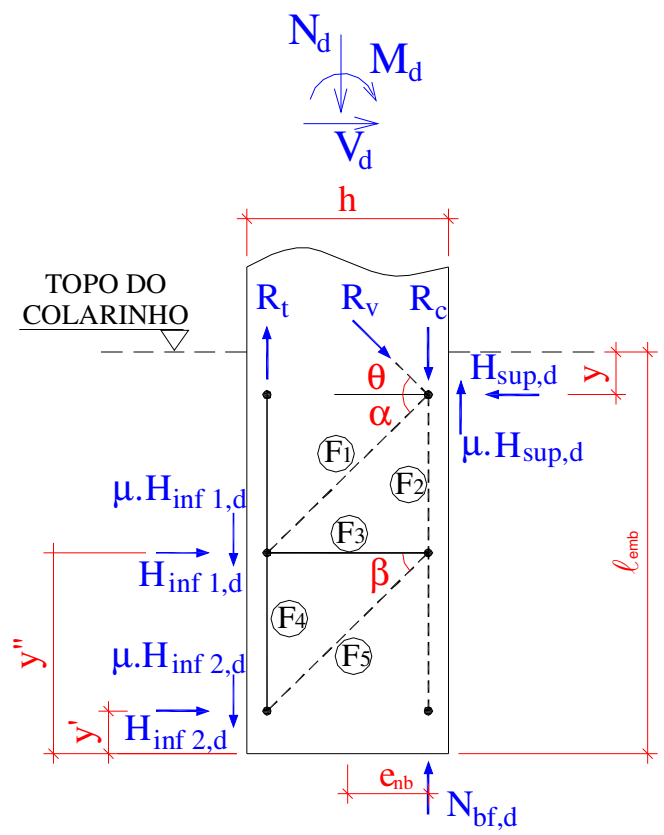

Figura 3.14 - Modelo de biela e tirante proposto (adaptado de EBELING (2006))

Os valores de $\operatorname{tg} \alpha$ e $\operatorname{tg} \beta$ são calculados pelas Equações (3.11) e (3.12):

$$
\begin{aligned}
& \operatorname{tg} \alpha=\frac{l_{e m b}-y-y^{\prime}}{d-0,5 \cdot h+e_{n b}} \\
& \operatorname{tg} \beta=\frac{y^{\prime}-y^{\prime \prime}}{d-0,5 \cdot h+e_{n b}}
\end{aligned}
$$

sendo que:

$$
y=\frac{l_{e m b}}{6} \quad y^{\prime}=\frac{l_{e m b}}{10} \quad y^{\prime \prime}=\frac{5}{6} \cdot l_{e m b}-\left(0,4 \cdot h+e_{n b}\right) \quad e_{n b}=0,5 \cdot h-\frac{0,8 \cdot x}{2}
$$

Esses valores devem ser adotados de maneira que satisfaçam a condição de que o ângulo formado entre os eixos da biela diagonais e os banzos esteja entre $18,4^{\circ}$ e $45^{\circ}$, conforme o critério de dimensionamento do código modelo CEB-FIP (1990).

As forças internas do modelo são determinadas de acordo com a Figura 3.14 e as Equações (3.13) a (3.17).

$$
\begin{aligned}
& F_{1}=\frac{1}{\cos \alpha} \cdot\left(H_{\text {sup }, d}-V_{d)}\right. \\
& F_{2}=N_{d}+R_{\text {std }}-H_{\text {sup }, d} \cdot(\mu+\operatorname{tg} \alpha)+V_{d} \cdot \operatorname{tg} \alpha \\
& F_{3}=H_{\text {inf } 2, d} \\
& F_{4}=R_{\text {std }}-\mu \cdot H_{\text {in } 1, d}-\operatorname{tg} \alpha \cdot\left(H_{\text {sup }, d}-V_{d}\right)
\end{aligned}
$$




$$
F_{5}=\frac{1}{\cos \beta} \cdot H_{\mathrm{inf} 2, d}
$$

Os valores de $R_{t}, R_{v}$ e $R_{c}$ são obtidos pela teoria da flexo-compressão utilizada no cálculo de pilares e estão apresentadas nas Equações (3.18), (3.19) e (3.20):

$$
\begin{aligned}
& R_{t}=R_{\text {std }} \\
& R_{v}=\frac{1}{\cos \theta} \cdot V_{d} \\
& R_{c}=N_{d}+R_{s t d}-V_{d} \cdot \operatorname{tg} \theta
\end{aligned}
$$

O problema é estaticamente indeterminado, pois temos três equações de equilíbrio e quatro incógnitas a serem determinadas. Pelo equilíbrio de forças, obtemos as seguintes equações:

$$
\begin{aligned}
& H_{\text {inf } 1, d}+H_{\text {inf } 2, d}=H_{\text {sup }, d}-V_{d} \\
& N_{b f, d}=N_{d}-\mu . V_{d}
\end{aligned}
$$

O valor das pressões $H_{\text {inf } 1, d}$ e $H_{\text {inf } 2, d}$ podem ser definidos com porcentagens da pressão $H_{\text {sup }, d}$ subtraída da força cortante $V_{d}$, e apresentados nas equações abaixo.

$$
\begin{aligned}
& H_{\text {inf } 1, d}=(1-\eta) \cdot\left(H_{\text {sup }, d}-V_{d}\right) \\
& H_{\text {inf } 2, d}=\eta \cdot\left(H_{\text {sup }, d}-V_{d}\right)
\end{aligned}
$$

Sendo que $\eta$ é o coeficiente ponderador das pressões inferiores, e que representa uma porcentagem de $H_{\text {sup,d }}$. Esse coeficiente é definido em função do coeficiente de atrito e calculado pela Equação (3.25):

$$
\eta=0,42 \cdot e^{-1,64 . \mu}
$$

A Equação (3.25) foi definida representando-se o modelo de bielas e tirantes proposto por uma treliça hiperestática, onde os apoios dessa treliça são as forças $H_{\text {inf } 1, d}, H_{\text {inf } 2, d}, H_{\text {sup }, d}$ e $N_{b f, d}$. Foram aplicadas na treliça as forças $R_{t}, R_{v}$ e $R_{c}$ obtidas com o valor último do ensaio realizado.

Para o valor de $\mu=0,6$, o coeficiente ponderador vale $\eta=0,16$. Fazendo o equilíbrio dos nós, é obtido o valor da pressão $H_{\text {sup }, d}$.

$$
H_{\text {sup }, d}=\frac{R_{\text {std }}+V_{d} \cdot(1+\mu+\eta \cdot \operatorname{tg} \beta)}{\operatorname{tg} \alpha+\mu+\eta \cdot \operatorname{tg} \beta}
$$


O modelo proposto é válido para os casos de grande excentricidade e para comprimentos de embutimento com intervalo de $1,6 \mathrm{~h}$ a $2,0 \mathrm{~h}$.

\subsubsection{Recomendações de projeto}

A seguir, apresentam-se as recomendações finais apresentadas de Ebeling (2006):

a) A base dos pilares na região de embutimento apresenta segurança, pois a ruína dos modelos ensaiados ocorreu fora dessa região;

b) A plastificação da armadura longitudinal do pilar é observada a uma altura de $l_{e m b} / 2$, entendendo que a transferência de tensões da armadura para o concreto ocorra deste ponto para baixo, portanto a recomendação de Leonhardt \& Mönnig (1978) determinando que a ancoragem seja feita a partir deste ponto é válida;

c) Deve ser realizada uma ancoragem adequada das armaduras longitudinais tracionadas por gancho ou barra transversal soldada, pois o espaço existente não é suficiente para ancoragem reta.

\subsection{ENSAIOS E RECOMENDAÇÕES DE NUNES (2009)}

O trabalho desenvolvido por Nunes (2009) apresenta uma análise da ligação pilarfundação por meio de cálice, em que o principal objetivo da pesquisa foi a avaliação dos esforços nas paredes transversais do colarinho, além de dar continuidade aos estudos desenvolvidos por Canha (2004), Jaguaribe Jr. (2005) e Ebeling (2006).

\subsubsection{Investigação experimental}

No programa experimental, foram ensaiados modelos físicos em escala 1:1 para analisar o comportamento da ligação submetida à força normal com grande excentricidade. Dois modelos foram ensaiados, um com interface lisa (IL-5) e outro com interface rugosa (IR4). Os modelos foram submetidos aos mesmos carregamentos e possuíam as mesmas propriedades dos modelos ensaiados anteriormente por Canha (2004) e Jaguaribe Jr. (2005). Algumas modificações na geometria, detalhamento e instrumentação foram adotadas por Nunes (2009) e a numeração dos modelos seguiu a metodologia utilizada nos estudos anteriores. 
Para o comprimento de embutimento foram adotados os valores recomendados pela Norma Brasileira, de $2,00 \cdot h$ e $1,60 \cdot h$ para os modelos com interface lisa e rugosa, respectivamente. A seção transversal do pilar foi de $40 \times 40 \mathrm{~cm}^{2}$ e a espessura da parede do colarinho foi inferior ao valor de $h_{c}=h_{\text {int }} / 3=17 \mathrm{~cm}$ recomendado pelo modelo de Leonhardt $\&$ Mönnig (1978). Reduziu-se esta espessura para $h_{c}=h_{\text {int }} / 3,5=15 \mathrm{~cm}$, alterando-se assim a geometria dos modelos para efeito de avaliação dessa modificação. Todas as armaduras do colarinho foram dimensionadas pelo modelo de Leonhardt \& Mönnig (1978) e a chave de cisalhamento do modelo rugoso foi adotada conforme as dimensões mínimas recomendadas pela ABNT NBR 9062:2006.

Assim como nos outros ensaios desenvolvidos, foi aplicado desmoldante na face interna do colarinho e face externa do pilar na região de embutimento para se retirar a adesão. Com essa situação, apenas a parcela do atrito é mobilizada na interface pilar-colarinho.

Para as armaduras verticais foi adotado um detalhamento diferenciado com o objetivo de analisar o comportamento da região de intersecção das paredes do colarinho. Dessa maneira, as armaduras verticais secundárias foram concentradas próximas aos cantos (intersecção paredes), como ilustrado na Figura 3.15, de maneira que essas funcionassem como armadura vertical principal.

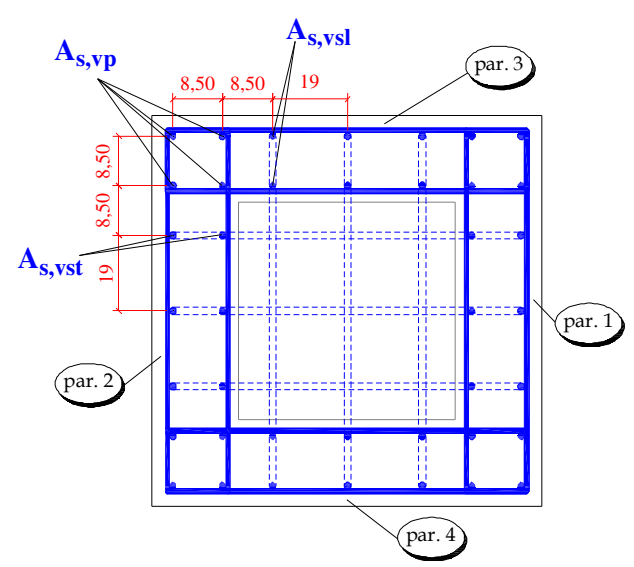

Figura 3.15- Distribuição das armaduras verticais dos modelos ensaiados por NUNES (2009)

Com o objetivo de facilitar a instrumentação da armadura horizontal principal, essa foi detalhada conforme apresentado na Figura 3.16, assim como adotado em Jaguaribe Jr. (2005). No trabalho de Canha (2004), o detalhamento dessa armadura seguiu o modelo de Leonhardt \& Mönnig (1978). 
Após ensaios e resultados experimentais, verifica-se que o detalhamento no qual é disposta uma armadura perimetral externa, complementada por quatro barras internas em forma de U por camada, é mais prático e fácil de ser armado. Dessa maneira, nesse trabalho, esse detalhamento será adotado para as armaduras $A_{s, h p}$ e $A_{s, h s}$.

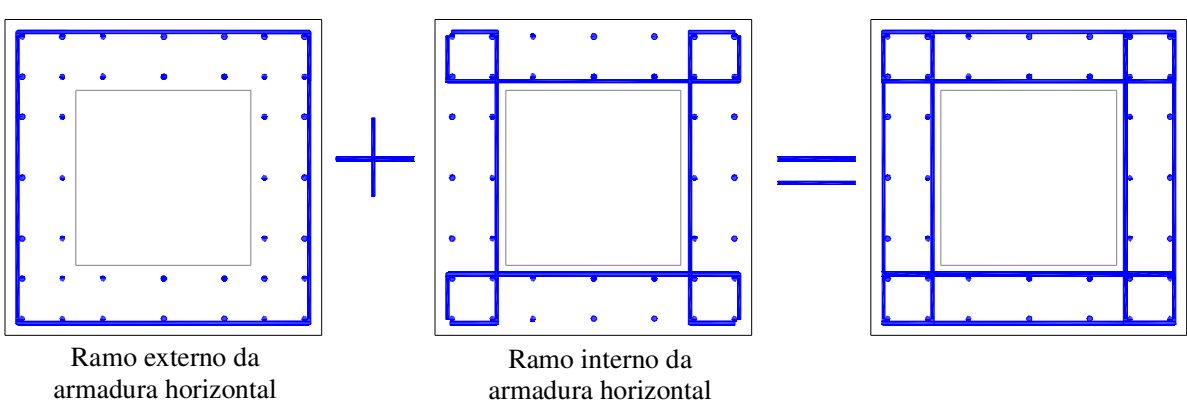

Figura 3.16 - Detalhe da armadura horizontal

Antes do início dos ensaios, foram aplicados ciclos de pré-carregamento com o objetivo de retirar a adesão e acomodação. Verificou-se que houve pouca alteração na rigidez durante o re-carregamento e que as deformações residuais nas armaduras foram muito pequenas.

\subsubsection{Resultados experimentais e análise}

A resistência dos modelos foi determinada pela força última absorvida pelo cálice, ocorrendo em geral escoamento das armaduras verticais principais e secundárias. Verificou-se que o modelo com interface rugosa apresentou maior capacidade resistente quando comparado ao modelo liso. Para o modelo liso, o descolamento da junta ocorreu com um valor de $70 \%$ da força última, ao contrário do que esperava, pois foi utilizado desmoldante nas interfaces. Para o modelo rugoso essa ruptura ocorreu a $77 \%$ do valor da força última.

Armadura horizontal principal transversal

A armadura $A_{s, h p t}$ do modelo liso foi efetivamente solicitada a partir do momento que ocorreu fissura na região da junta, o que indica a ruptura da adesão. Os dois ramos da armadura foram tracionados, o que indica uma flexo-tração da parede.

Verificou-se que a partir do rompimento da adesão, ocorreu uma redistribuição das forças nas regiões centrais dos ramos externos. Antes dessa perda, a ligação tem um 
comportamento muito próximo ao de uma ligação monolítica. Para o modelo rugoso, percebese que essas armaduras foram pouco solicitadas.

\section{Armadura vertical principal e secundária}

No cálice de interface lisa, todos os ramos das armaduras verticais principais escoaram durante a realização do ensaio, sendo esse mesmo comportamento observado em Canha (2004). Foi observado também que as armaduras verticais secundárias, especificamente as localizadas próximas a intersecção da parede transversal posterior $2 \mathrm{com}$ as paredes longitudinais 3 e 4 (Figura 3.15), contribuíram para a resistência da ligação. Os ramos localizados na parede transversal posterior 2 foram bastante solicitados, atingindo $o$ escoamento, e os ramos das armaduras verticais secundárias localizados nas paredes longitudinais 3 e 4 contribuíram efetivamente após a ruptura da adesão.

Observou-se no modelo rugoso que, à medida que a armadura vertical principal se aproxima do topo da parede, as deformações diminuem. Isso comprova a hipótese de que as bielas formadas pelas chaves de cisalhamento diminuem de inclinação em relação a horizontal a medida que se aproxima a parte superior do colarinho. Verificou-se também que as armaduras verticais principais e verticais secundárias situadas na parede frontal foram comprimidas e na parede posterior foram tracionadas. As armaduras tracionadas alcançaram o escoamento e contribuíram significativamente para a resistência da ligação.

\subsubsection{Estudo comparativo}

Com o objetivo de fazer uma análise do comportamento dos ramos interno e externo da armadura $A_{s, h p t}$, os resultados experimentais da pesquisa de Nunes (2009) foram comparados com resultados teóricos resultantes do modelo de projeto proposto por Canha et al. (2009c) para os modelos com interface lisa e rugosa. Esse modelo de projeto, para cálculo da armadura $A_{s, h p t}$, assume que as pressões nas paredes transversais são transferidas para as paredes longitudinais por duas partes: uma por flexão e a outra por tração. O valor total da pressão superior é definido como a soma das duas parcelas.

Considerou-se primeiramente para os cálculos teóricos a pressão $H_{\text {sup }}$ causando $15 \%$ de flexão e $85 \%$ de tração na parede transversal frontal 1 e depois adotou-se o total de $H_{\text {sup }}$ causando $100 \%$ de tração na parede. 
Comparando os resultados, Nunes (2009) concluiu que no modelo com interface lisa a melhor aproximação ocorreu na situação de flexo-tração da parede transversal.

Para o modelo rugoso na situação de flexo-tração, verificou-se que a parede transversal 2 é mais solicitada que a parede transversal 1, e que o modelo teórico proposto por Canha et al. (2009c) fornece melhores resultados para a parede transversal 2.

\subsubsection{Recomendações finais}

A seguir, apresentam-se as recomendações finais de Nunes (2009):

Modelo liso

a) Os ramos interno e externo da armadura foram tracionados, sendo também constatado deformações negativas nessa armadura. Isto caracteriza um comportamento conjunto de flexo-tração da parede transversal;

b) Verificou-se que além das armaduras verticais principais, as armaduras verticais secundárias situadas nas proximidades das intersecções da parede transversal $2 \mathrm{com}$ as paredes longitudinais contribuem para a resistência da ligação;

c) O modelo de cálculo proposto por Canha et al. (2009c) forneceu bons resultados para a resultante de forças nos ramos externo e interno da armadura $A_{s, h p t}$, especialmente na situação de flexo-tração.

\section{$\underline{\text { Modelo rugoso }}$}

a) Foi constatado um comportamento semelhante ao de uma ligação monolítica, e que o topo da parede transversal 2 é mais solicitado que o topo da parede transversal 1;

b) Na região inferior da parede transversal posterior 2, as armaduras verticais principais foram mais solicitadas à tração, e à medida que o ramo da armadura se aproximou do topo do colarinho, essa solicitação foi diminuindo, o que demonstra a hipótese que as bielas diminuem de inclinação em relação à horizontal à medida que se aproximam da região superior da ligação. 


\section{RECOMENDAÇÕES PARA O PROJETO DE CÁLICES DE FUNDAÇÃO}

Recomendações gerais serão apresentadas para o projeto da ligação pilar-fundação, por meio de cálice com colarinho, baseadas na síntese de resultados de pesquisas experimentais desenvolvidas na EESC-USP por uma tese de doutorado e três dissertações de mestrado já revisadas e apresentadas no Capítulo 3. As recomendações englobam várias situações de projeto como: cálice com interface lisa, cálice com interface rugosa, situação de montagem da ligação cálice-fundação, análise da base do pilar na região de embutimento e detalhamento das armaduras. Também serão indicadas disposições construtivas para garantir a qualidade da execução e dimensões mínimas dos elementos constituintes da ligação.

Na Figura 4.1 é apresentada a nomenclatura que será utilizada para identificação das paredes do colarinho.

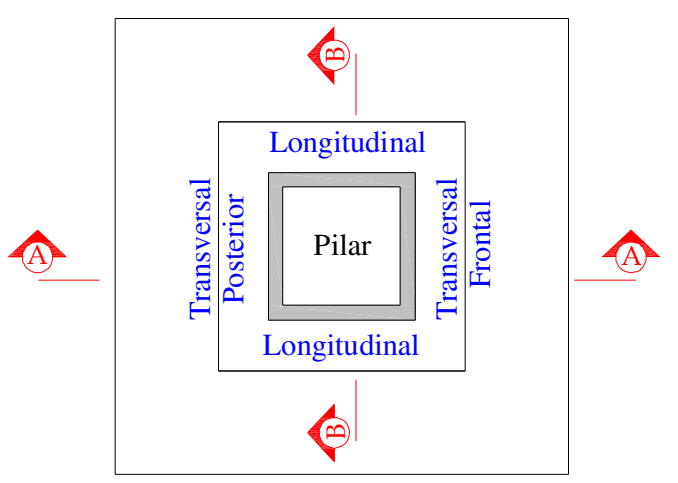

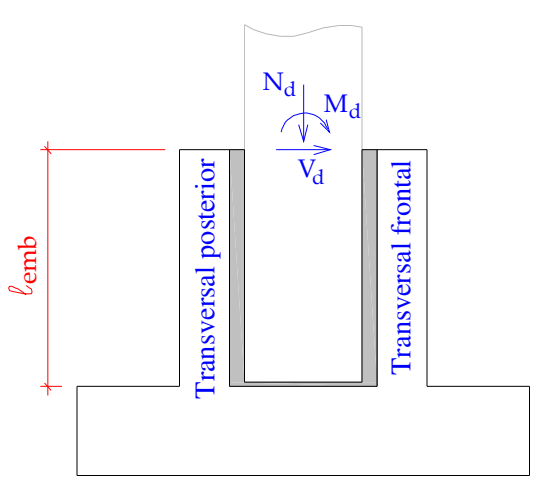

CORTE AA

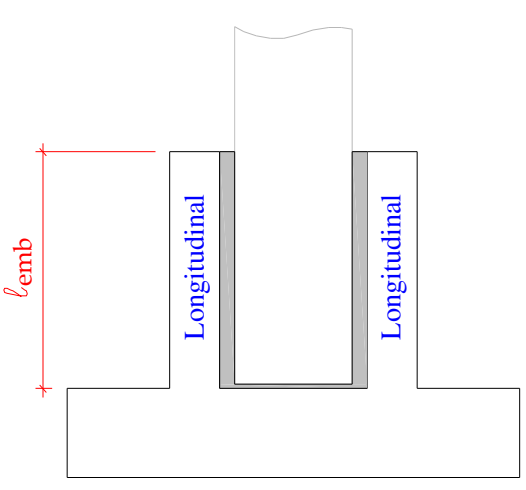

CORTE BB

Figura 4.1 - Nomenclatura das paredes componentes do colarinho 
E na Figura 4.2 é apresentada a distribuição das armaduras no cálice de fundação com denominações e respectivas posições que serão utilizadas no desenvolvimento desse trabalho.

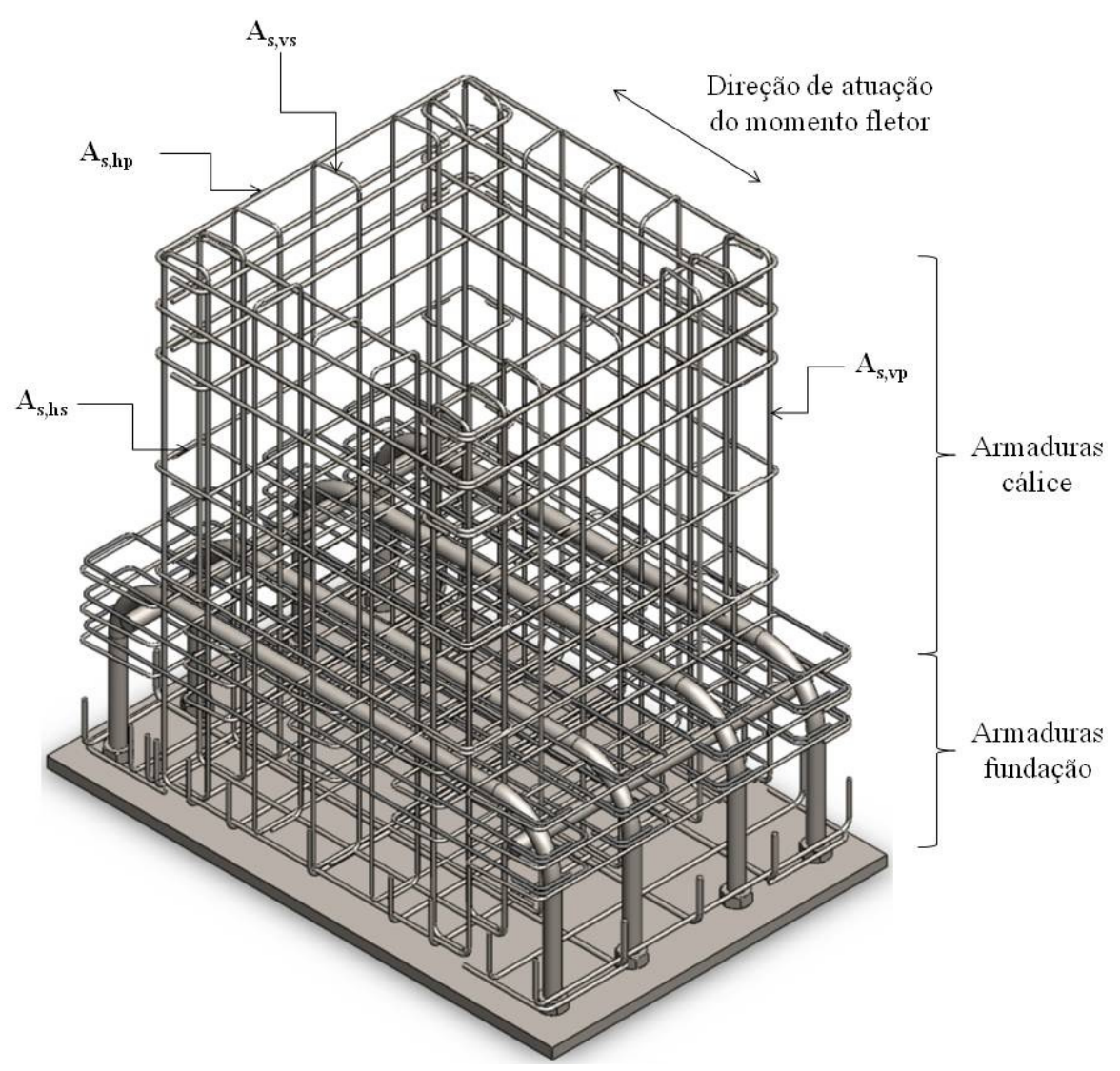

Figura 4.2 - Armaduras constituintes de um cálice de fundação

\subsection{CÁLICE COM INTERFACE LISA}

O comportamento e transferência de esforços em um cálice de fundação com interface lisa já foi apresentado segundo vários modelos da literatura, porém com intuito de ilustrar a nomenclatura a ser adotada nesse estudo é apresentado novamente na Figura 4.3 um esquema de transferência de esforços nas paredes transversais e longitudinais no cálice.

O comportamento do modelo da Figura 4.3 considera a contribuição de três forças de atrito $F_{a t, \text { sup } f}, F_{a t, \text { inf }}$ e $F_{a t, b f}$ atuando, respectivamente, na parede transversal frontal, na parede transversal posterior e na base da fundação, além de considerar a excentricidade $e_{n b}$ da reação da força $N_{b f}$ na base do pilar. Essas variáveis contribuem para a resistência da ligação. A excentricidade deve ser considerada, pois, devido à flexo-compressão, a reação na base do 
pilar é excêntrica. Além disso, pode ocorrer o deslizamento do pilar e junta em relação à base e consequentemente um acréscimo do deslocamento dessa reação.

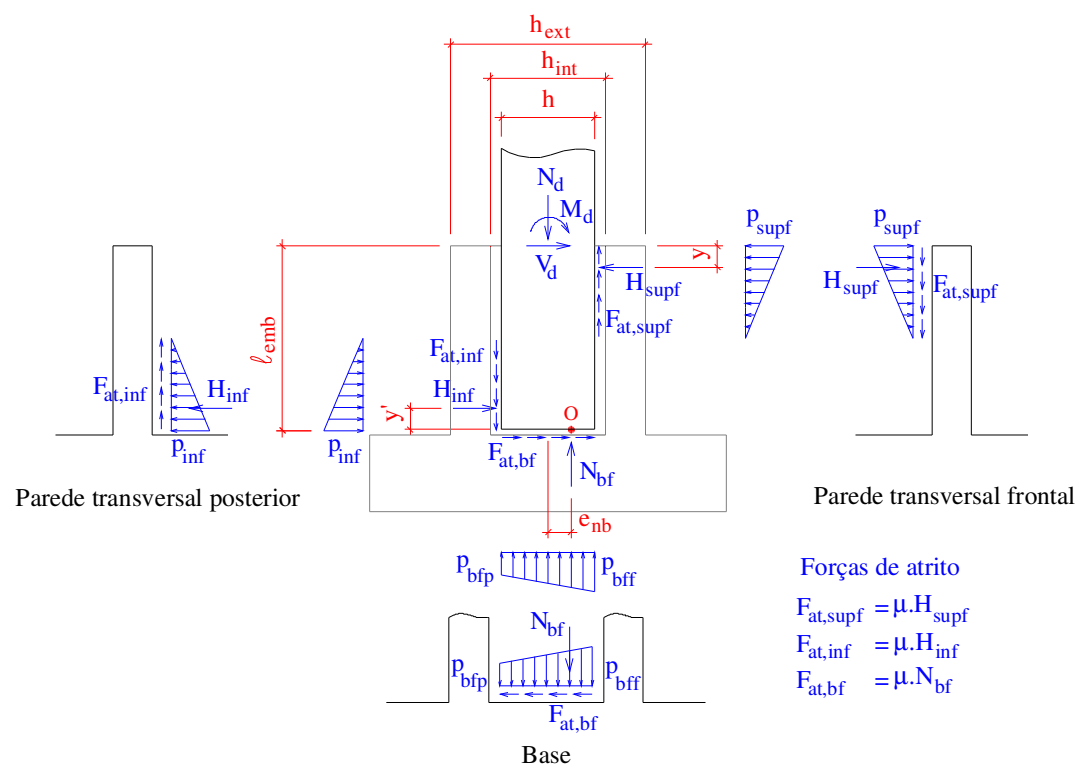

(a) Principais forças atuantes nos cálices com interface lisa

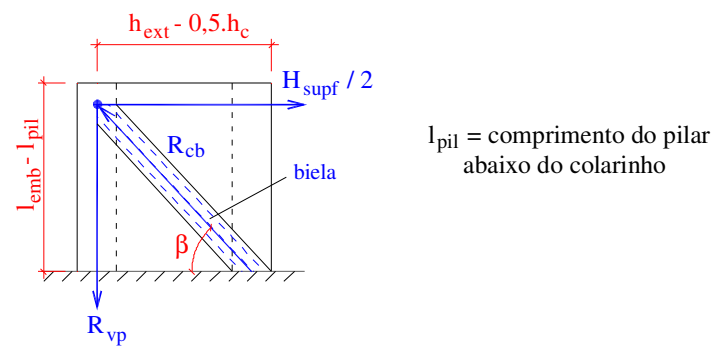

(b) Comportamento das paredes longitudinais

de cálices com interface lisa

Figura 4.3 - Transferência de forças no cálice com interface lisa (adaptado de CANHA et al. (2009b))

Baseado no estudo de Canha (2004), a determinação da pressão superior é determinada pela Equação (3.9) já apresentada no Capítulo 3. Essa mesma equação será novamente descrita abaixo, a fim de apresentar uma sequência de cálculo para o dimensionamento da ligação de cálice com interface lisa.

$$
H_{\text {sup } f}=\frac{M_{d}-N_{d} \cdot\left(e_{n b}+\frac{\mu \cdot y^{\prime}-\mu^{2} \cdot\left(0,5 \cdot h+e_{n b}\right)}{1+\mu^{2}}\right)+V_{d} \cdot\left(l_{e m b}-\frac{y^{\prime}-\mu \cdot\left(0,5 \cdot h+e_{n b}\right)}{1+\mu^{2}}\right)}{l_{e m b}-y-y^{\prime}+\mu \cdot h}
$$

sendo que:

$\mu$ : Coeficiente de atrito

$e_{n b}$ : Excentricidade da força normal na base da fundação 
$y$ : Distância do ponto de aplicação da resultante de pressão $H_{\text {sup } f}$ ao topo do colarinho

y': Distância do ponto de aplicação da resultante de pressão $H_{\text {inf }}$ à base do pilar

Baseado nas pesquisas experimentais verifica-se que um dos principais parâmetros na avaliação do comportamento da ligação cálice-fundação, é a interface entre a junta e os elementos pilar e cálice. Dessa maneira, a definição do coeficiente de atrito para cálice de interface lisa é de relevante importância, pois influencia na determinação do valor resultante da pressão superior de compressão atuante nas paredes transversais do cálice.

No artigo publicado por Canha et al. (2007) são recomendados os seguintes coeficientes de atrito:

a) $\quad \mu=0,3$ para cálice de fundação moldado com utilização de forma metálica;

b) $\mu=0,6$ para cálice de fundação moldado com utilização de forma de madeira.

É considerado um coeficiente de atrito menor quando utilizado forma metálica, porque esse material apresenta superfície mais regular e lisa, apresentando, portanto menos irregularidades no acabamento das paredes do cálice.

Em Canha et al. (2009b) o coeficiente de atrito utilizado na análise experimental é de $\mu=0,6$, no entanto como recomendação de projeto, um coeficiente de atrito $\mu=0,3$ é indicado. Esse valor é o mesmo indicado pelo Eurocode 2, e é mais seguro para o dimensionamento da ligação.

Sendo assim, recomenda-se adotar o valor de $\mu=0,3$ para o coeficiente de atrito no caso de cálice com interface lisa.

Para o cálculo da excentricidade da força normal, duas fórmulas podem ser utilizadas. A primeira, apresentada na Equação (4.2), é indicado por Ebeling (2006) e considera a posição da linha neutra na determinação da excentricidade $e_{n b}$. E a outra, apresentada na Equação (4.3), é uma maneira mais prática e rápida para cálculo de $e_{n b}$.

A Equação (4.3) está indicada na referência de Canha (2004), e foi definida a partir do posicionamento da força de compressão $R_{c d}$, resultante do dimensionamento do pilar para o limite dos domínios de deformação 3 e 4, ficar em torno dessa grandeza.

$$
\begin{aligned}
& e_{n b}=0,5 \cdot h-\frac{0,8 \cdot x}{2} \\
& e_{n b}=h / 4
\end{aligned}
$$

Para o ponto de aplicação da pressão superior, o valor recomendado por Canha (2004) e pelo modelo de Leonhardt \& Mönnig (1978) é o indicado na Equação (4.4), que admite uma 
distribuição triangular de pressões na altura de $l_{e m b} / 2$, como ilustrado na Figura 4.3. Na referência de Canha et al. (2009b), sugere-se o cálculo desse parâmetro pela Equação (4.5), que é a mesma indicação do Eurocode 2. Com essa fórmula, admite-se um bloco retangular de pressões concentrado no topo do colarinho com altura de $l_{e m b} / 5$.

$$
\begin{aligned}
& y=l_{\text {emb }} / 6 \\
& y=l_{\text {emb }} / 10
\end{aligned}
$$

Para o ponto de aplicação $y^{\prime}$ da força $H_{\text {inf }}$ será adotada a mesma indicação de Canha (2004), que é de:

$$
y^{\prime}=l_{\text {emb }} / 10
$$

O cálculo dos parâmetros $y, y^{\prime}$ e $e_{n b}$ pelas fórmulas acima indicadas são apropriados para cálice liso com comprimento de embutimento mínimo de $2,0 \cdot h$ e aplicado para os casos de grande excentricidade, pois elevados momentos fletores tendem a gerar forças de atrito forças de atrito $F_{a t, \text { inf }}$ descendentes atuando no pilar.

Para pequenas excentricidades, as direções das forças de atrito podem mudar e, dessa maneira, a Equação (4.1) deve ser avaliada. No item 4.5, haverá um estudo que aborda os casos de pequena excentricidade da força normal.

Para a situação em que não existir força cortante no cálice, a pressão superior é determinada pela Equação (4.7):

$$
H_{\text {sup } f}=\frac{M_{d}-N_{d} \cdot\left(e_{n b}+\frac{\mu \cdot y^{\prime}-\mu^{2} \cdot\left(0,5 \cdot h+e_{n b}\right)}{1+\mu^{2}}\right)}{l_{e m b}-y-y^{\prime}+\mu \cdot h}
$$

A diferença das Equações (4.1) e (4.7) é a redução do termo referente à parcela que multiplica $V_{d}$.

\subsubsection{Armadura horizontal principal longitudinal $-A_{s, h p l}$}

A armadura horizontal principal longitudinal é responsável por transmitir a força $H_{\text {sup } f}$ por meio das paredes longitudinais até a armadura vertical principal localizada na intersecção das paredes transversais e longitudinais, como ilustrado na Figura 4.3 (b). Na realidade, a armadura $A_{s, h p l}$ funciona como uma armadura de suspensão da força $H_{\sup f}$ do canto superior da parede transversal frontal até o canto superior da parede transversal 
posterior, ocorrendo uma aplicação indireta dessa força nas paredes longitudinais, que se comportam como consolos.

A armadura horizontal principal longitudinal é composta de dois ramos: ramo externo - $A_{s, h p l e}$ - localizado no perímetro externo das paredes longitudinais e representado pela cor vermelha na Figura 4.7; e pelo ramo interno - $A_{s, h p l i}$ - localizado na parte interna das paredes longitudinais e indicado na cor verde na Figura 4.7.

O dimensionamento de $A_{s, h p l}$ é determinado pela Equação (4.8):

$$
A_{s, h p l}=\frac{H_{\text {sup } f}}{2 \cdot f_{y d}}
$$

É indicado que a armadura $A_{s, h p l}$ seja distribuída nas paredes longitudinais em uma altura de $l_{e m b} / 3$ a partir do topo do colarinho.

\subsubsection{Armadura horizontal principal transversal $-A_{s, \text { hpt }}$}

$\mathrm{Na}$ referência de Canha et al. (2009c), artigo publicado na revista Engineering Strucutures, é apresentado um estudo que avaliou especificamente o comportamento das paredes transversais, pois os modelos de projeto comumente utilizados no dimensionamento de $A_{s, h p t}$ apresentam diferenças significativas em suas recomendações. O modelo apresentado no Manual da Empresa Munte, indica que a pressão superior aplicada na parede transversal frontal causa flexão na mesma. Já o modelo apresentado pela norma CNR 10025:1998, indica que essa pressão superior causa tração na parede. Devido a essas discordâncias, uma pesquisa teórico-experimental foi desenvolvida.

Após os ensaios e análise dos resultados os autores chegaram às seguintes conclusões:

a) Pelos resultados experimentais, verificou-se que a parte superior da parede transversal frontal da ligação é submetida à tração e a flexão, e que a tração prevalece sobre a flexão;

b) O fenômeno de tração e flexão é constatado pela tração dos ramos internos e externos da armadura horizontal principal transversal e pela configuração de fissuras no topo da parede (Figura 4.4). Devido às fissuras inclinadas de canto, a parte superior da parede transversal frontal apresenta um comportamento de viga simplesmente apoiada, em que as fissuras são causadas pela transferência por flexotração da força $H_{\text {sup }}$ para as paredes longitudinais. 


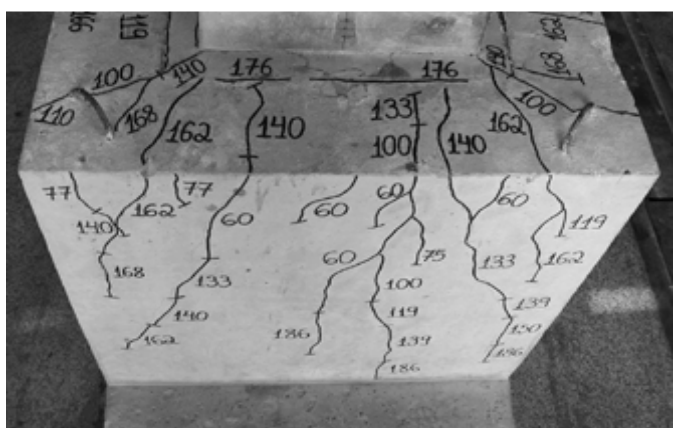

Parede transversal frontal

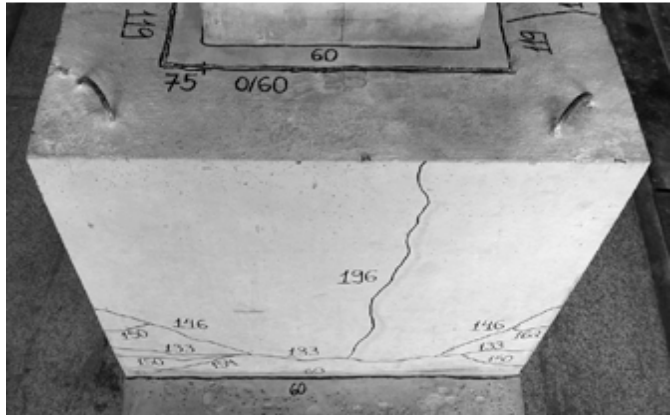

Parede transversal posterior

Figura 4.4 - Configuração das fissuras nas paredes transversais de cálice com interface lisa (CANHA et al. (2009c))

c) A deformação da parede transversal frontal e as fissuras correspondentes na parte superior da superfície indicam que há uma grande concentração de pressões no canto dessa parede. Portanto, essa distribuição de pressão pode ser aproximada em duas partes: uma pressão $H_{\sup f-f}$ que causa flexão na viga e tem uma distribuição parabólica de grau $n$, e em uma pressão $H_{\text {sup } f-t}$ que é transmitida para os apoios da viga com uma inclinação de ângulo $\theta$. O ângulo $\theta=45^{\circ}$ foi adotado, pois foi o valor médio das inclinações das fissuras dos modelos ensaiados;

Com a constatação do comportamento conjunto, Canha et al. (2009c) propuseram um modelo de projeto, ilustrado na Figura 4.5, para o cálculo da armadura $A_{s, h p t}$. Pela análise dos resultados observou-se que a distribuição de pressões na parede é parabólica $(n=2)$, porém para efeitos práticos e de simplificação a consideração de uma distribuição uniforme $(n=0)$ pode ser adotada.

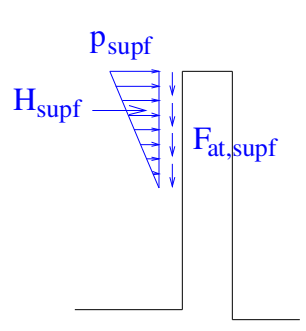

Parede transversal frontal

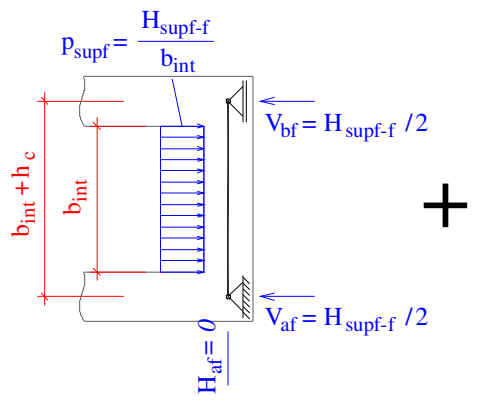

Planta da parede transversal frontal

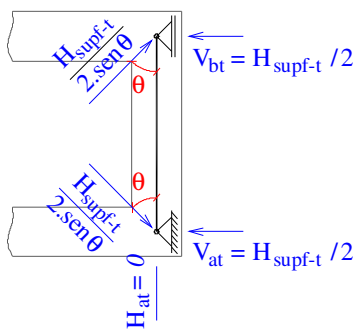

Figura 4.5- Modelo de projeto para a parede transversal frontal para cálice com interface lisa (adaptado de CANHA et al. (2009c))

Dessa maneira, o valor da pressão é uma soma de duas parcelas:

$$
H_{\text {sup } f}=H_{\text {sup } f-f}+H_{\text {sup } f-t}
$$


sendo que:

$H_{\text {sup } f-f}$ : parcela da pressão superior que causa flexão na parede transversal frontal $H_{\text {sup } f-t}:$ parcela da pressão superior que causa tração na parede transversal frontal

Com a consideração de distribuição uniforme de pressão para a maioria dos modelos ensaiados por Canha et al. (2009c) e Nunes (2009), as porcentagens observadas da pressão $H_{\text {sup } f-f}$ e $H_{\text {sup } f-t}$ foram de aproximadamente $15 \%$ e $85 \%$. Por questões construtivas também foi sugerido pelos autores as porcentagens de $0 \%$ para a força $H_{\text {sup } f-f}$ e $100 \%$ para a força $H_{\text {sup } f-t}$, considerando somente esforço de tração atuando na parede transversal frontal.

Se for definido comportamento conjunto de flexo-tração da parede, as Equações (4.10) e (4.11) devem ser utilizadas para determinação das parcelas de pressão superior de flexão e tração, respectivamente. Se a opção for considerar somente tração da parede, as resultantes são determinadas pelas Equações (4.12) e (4.13):

$$
\begin{aligned}
& H_{\sup f-f}=0,15 \cdot H_{\sup f} \\
& H_{\sup f-t}=0,85 \cdot H_{\sup f} \\
& H_{\sup f-f}=0 \\
& H_{\sup f-t}=H_{\sup f}
\end{aligned}
$$

Para determinar a área de aço necessária da armadura $A_{s, h p t}$, que também é composta de dois ramos, é necessário determinar as resultantes $R_{s, h p t e}$ (força na armadura externa) e $R_{s, h p t i}$ (força na armadura interna), que são calculadas pelas Equações (4.14) e (4.15), respectivamente.

$$
\begin{aligned}
& R_{s, h p t e}=\frac{N_{\sup f-t}}{2}+\frac{M_{\sup f-f}}{z} \\
& R_{s, h p t i}=\frac{N_{\sup f-t}}{2}-\frac{M_{\sup f-f}}{z}
\end{aligned}
$$

sendo que:

$M_{\text {sup } f-f}$ : Momento fletor oriundo da pressão $H_{\text {sup } f-f}$

$N_{\text {sup } f-t}$ : Força normal oriunda da pressão $H_{\sup f-t}$

$z$ : Distância entre as resultantes $R_{s, h p t e}$ e $R_{s, h p t i}$

Os esforços $M_{\text {sup } f-f}$ e $N_{\text {sup } f-t}$ são calculados segundo as Equações (4.16) e (4.17), respectivamente, e o braço z pela Equação (4.18): 


$$
\begin{aligned}
& M_{\text {sup } f-f}=H_{\text {sup } f-f} \cdot\left(\frac{b_{\text {int }}+h_{c}}{4}-\frac{b_{\text {int }}}{8}\right) \\
& N_{\sup f-t}=\frac{H_{\sup f-t}}{2 \cdot \operatorname{sen} \theta} \cdot \cos \theta \\
& z=d-d^{\prime}
\end{aligned}
$$

sendo que:

$\theta=45^{\circ}$

$d$ : Distância do centro de gravidade da armadura externa até a parte interna da parede

$d^{\prime}$ : Distância do centro de gravidade da armadura interna até a parte interna da parede

Na Figura 4.6 é indicada a localização das armaduras e identificação dos termos d e d'.

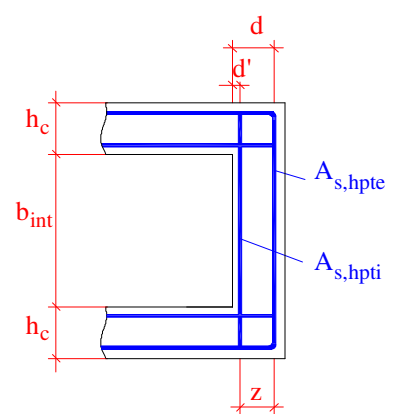

Figura 4.6 - Localização da armadura horizontal principal e respectivas alturas úteis

Verifica-se, que se for considerada a situação de tração da parede transversal frontal, as resultantes $R_{s, h p t e}$ e $R_{s, h p t i}$ serão iguais, pois o momento fletor é nulo nesse caso. Já para a situação de flexo-tração, o valor de $R_{s, h p t e}$ será maior que de $R_{s, h p t i}$.

O dimensionamento da armadura horizontal principal transversal é feito pela Equação (4.19) para o ramo externo e pela Equação (4.20) para o ramo interno.

$$
\begin{gathered}
A_{s, h p t e}=\frac{R_{s, h p t e}}{f_{y d}} \\
A_{s, h p t i}=\frac{R_{s, h p t i}}{f_{y d}}
\end{gathered}
$$

A indicação do trecho de $l_{e m b} / 3$ da parede transversal frontal para a distribuição da armadura $A_{s, h p t}$ no cálice com interface lisa é coerente com os resultados experimentais de Canha (2004) e Nunes (2009), desde que se utilizem os valores de $l_{\text {emb }}$ recomendados pela Norma ABNT NBR 9062:2006. 
No próximo Capítulo, serão realizadas aplicações práticas onde será possível analisar o comportamento das paredes transversais submetidas à flexo-tração ou somente a tração e comparar os resultados obtidos entre essas considerações.

Como as armaduras $A_{s, h p l}$ e $A_{s, h p t}$ são distribuídas na mesma altura do cálice, e pelo motivo de posicionamento do arranjo de armaduras do cálice na obra, deve-se adotar para o projeto dessa ligação o maior valor entre as armaduras e dispô-las simetricamente. Na Figura 4.7 está representada a localização dessas armaduras.

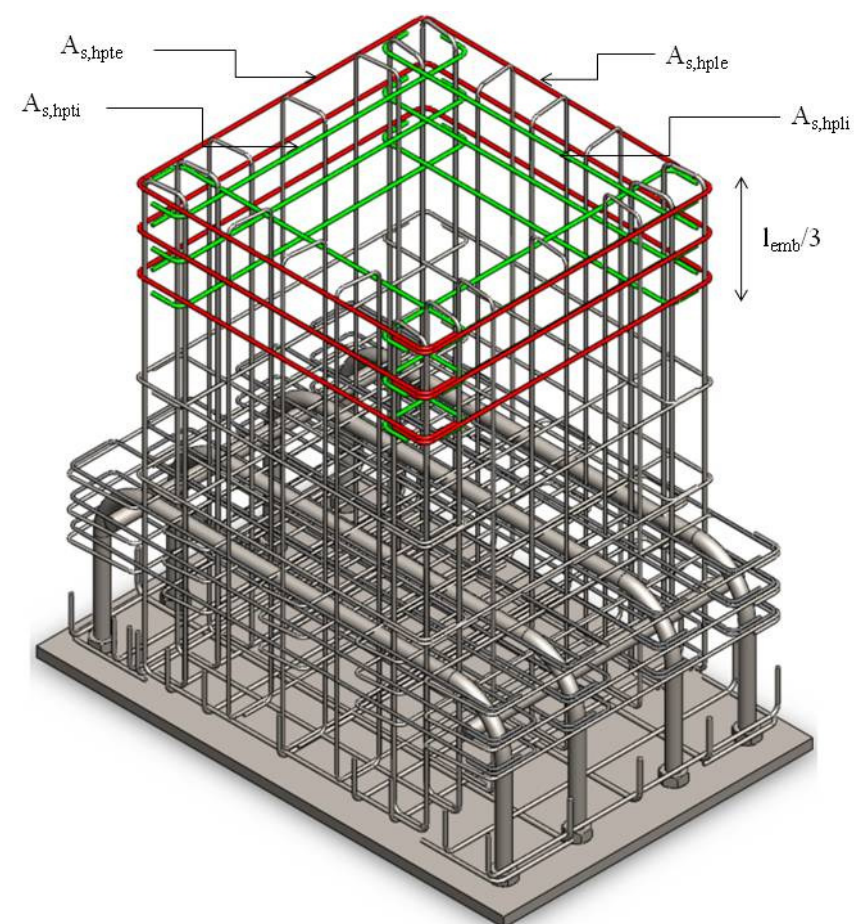

Figura 4.7 - Localização das armaduras horizontais principais no cálice com interface lisa

\subsubsection{Armadura vertical principal - $\boldsymbol{A}_{\mathrm{s}, \mathrm{vp}}$}

Para cálice com interface lisa, o dimensionamento da armadura $A_{s, v p}$ e verificação da resistência a compressão do concreto devem ser feitos considerando as paredes longitudinais como consolos, conforme indicado pelo modelo de Leonhardt \& Mönnig (1978). O comportamento de consolo foi comprovado nos estudos experimentais realizados e é adequado para representar as ligações de cálice com interface lisa. Como afirmado em Canha et al. (2009b), as armaduras $A_{s, v p}$ e $A_{s, h p}$ começaram a escoar quase simultaneamente nos ensaios, porém só é indicado adotar esse procedimento de cálculo quando o comprimento de embutimento do cálice for determinado pela ABNT NBR 9062:2006. 
As armaduras verticais principais localizam-se na intersecção das paredes transversais e longitudinais, como se visualiza na Figura 4.8 e é dimensionada conforme o tipo de consolo, sendo especificado, para cada tipo, um modelo de cálculo. A armadura $A_{s, v p}$ resultante do cálculo equivale à área de aço necessária para cada canto do cálice.

Além de dimensionar a armadura, é necessário verificar o esmagamento do concreto da biela de compressão.

Como apresentado na ABNT NBR 9062:2006 há três tipos de consolo e modelos de cálculo:

a) Consolo curto $(1,0 \geq \operatorname{tg} \beta>0,5)$ : modelo de biela e tirante

b) Consolo muito curto $(\operatorname{tg} \beta \leq 0,5)$ : modelo de atrito-cisalhamento

c) Consolo longo $(\operatorname{tg} \beta>1,0)$ : teoria da flexão

Sendo que $\beta$ é o ângulo formado entre a biela de compressão e o eixo horizontal, calculado de acordo com a Equação (4.21):

$$
\beta=\operatorname{arctg} \frac{l_{c}-y}{0,85 \cdot h_{e x t}-h_{c} / 2}
$$

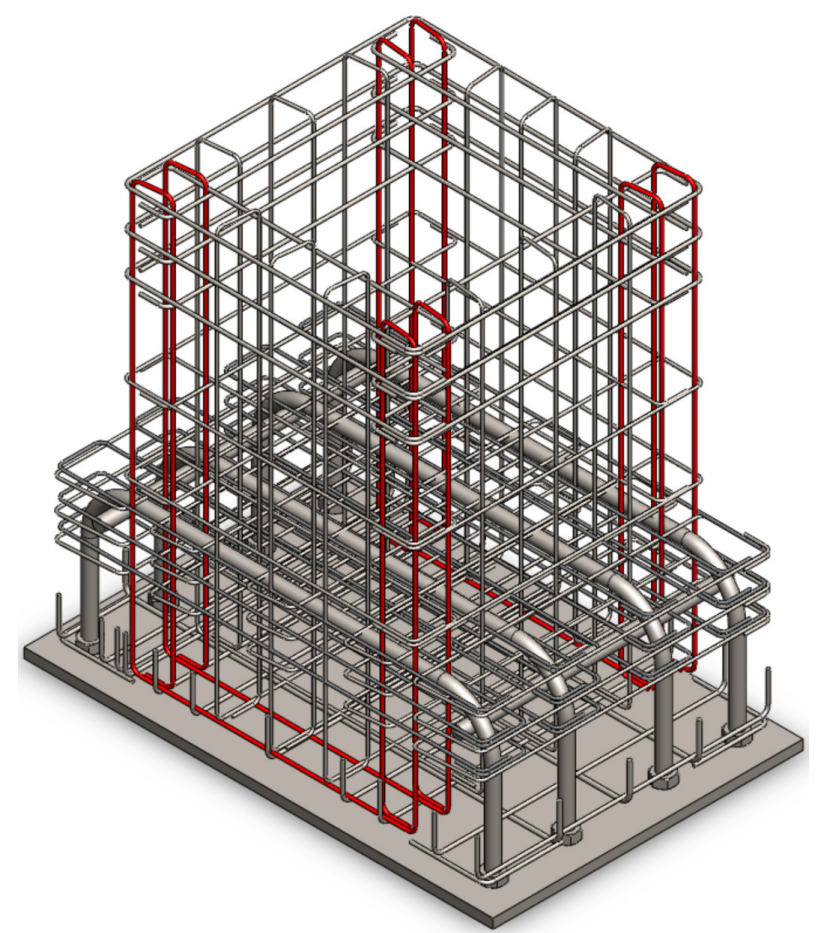

Figura 4.8- Localização da armadura vertical principal no cálice com interface lisa

A seguir, serão apresentados detalhes específicos do cálculo para cada tipo de consolo. 
Consolo curto

No modelo de bielas e tirantes para consolo curto, onde a tangente do ângulo de inclinação está entre $1,0 \geq \operatorname{tg} \beta>0,5$, o cálculo da armadura vertical principal e a verificação do esmagamento da biela comprimida devem ser feitos segundo um modelo matemático composto de duas barras, uma tracionada e outra comprimida. O cálculo deve ser feito segundo as Equações (4.22) e (4.23) e como ilustrado na Figura 4.9.

$$
\begin{aligned}
& A_{s, v p}=\frac{R_{v p}}{f_{y d}} \\
& \sigma_{c b}=\frac{R_{c b}}{h_{b i e} \cdot h_{c}} \leq 0,85 \cdot f_{c d}
\end{aligned}
$$

Limita-se a tensão na armadura em $435 M P a$ e a tensão do concreto em $0,85 \cdot f_{c d}$, por considerar atuação de carga indireta.

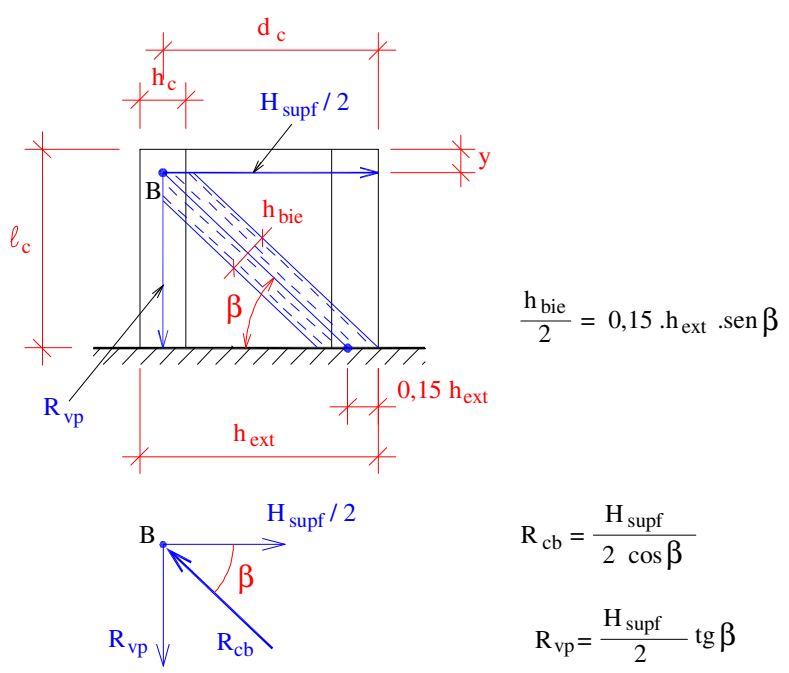

Figura 4.9 - Dimensionamento das paredes longitudinais como consolo curto (adaptado de EL DEBS (2000))

\section{Consolo muito curto}

No caso de consolo muito curto ( $\operatorname{tg} \beta \leq 0,5)$, o dimensionamento de $A_{s, v p}$ é feito pelo modelo de atrito e cisalhamento. A armadura vertical principal é calculada pela Equação (4.24):

$$
A_{s, v p}=\frac{0,8 \cdot\left(H_{\mathrm{sup} f} / 2\right)}{f_{y d} \cdot \mu}
$$


Sendo que o valor de $\mu$ é definido segundo a ABNT NBR 9062:2006 de acordo com as situações abaixo:

a) $\mu=1,4$, para concreto lançado monoliticamente;

b) $\mu=1,0$, para concreto lançado sobre concreto endurecido intencionalmente rugoso ( $5 \mathrm{~mm}$ de profundidade a cada $30 \mathrm{~mm}$ );

c) $\mu=0,6$, para concreto lançado sobre concreto endurecido com interface lisa.

A verificação do esmagamento do concreto é feito em função da tensão de cisalhamento de cálculo, de acordo com a Equação (4.25):

$$
\tau_{w d}=\frac{H_{\sup f}}{2 \cdot h_{c} \cdot d_{c}} \leq \tau_{w u}=3,0+0,9 \cdot \rho \cdot f_{y d} \leq 6 \mathrm{MPa}
$$

Sendo que $\rho$ é a taxa geométrica da armadura vertical principal.

A armadura $A_{s, v p}$ também pode ser calculada pela Equação (4.25) igualando a tensão de cisalhamento de cálculo com a tensão de cisalhamento última, o que resulta em:

$$
A_{s, v p}=\frac{\left(H_{\mathrm{sup} f} / 2\right)-3 \cdot h_{c} \cdot d_{c}}{0,9 \cdot f_{y d}}
$$

Adotar a maior área de aço entre as calculadas pelas Equações (4.24) e (4.26) para a armadura $A_{s, v p}$. A tensão na armadura também deve ser limitada em $435 \mathrm{MPa}$ e o resultado de $A_{s, v p}$ não deve ter valor menor que a calculada para o caso de consolo curto.

\section{Consolo longo}

Quando $\operatorname{tg} \beta>1,0$, as paredes longitudinais devem ser dimensionadas como uma viga em balanço engastada na fundação, onde uma força $H_{\text {sup } f} / 2$ atuante na extremidade gera um

momento de engastamento. Para o dimensionamento de $A_{s, v p}$, nesse caso, devem ser adotadas as indicações da ABNT NBR 6118:2003.

Essa situação geralmente representará uma situação limite de consolo curto, pois analisando a Equação (4.21), que determina o ângulo de inclinação da biela, verifica-se que a relação gira próxima de um.

Assim, como no caso de consolo muito curto, a armadura $A_{s, v p}$, resultante do dimensionamento, não deve ter área menor quando comparada com a calculada para consolo curto. 


\subsubsection{Armaduras secundárias - $A_{s, v s}$ e $A_{s, h s}$}

As armaduras verticais secundárias e as armaduras horizontais secundárias são utilizadas na ligação cálice-fundação para resistir a esforços secundários e controlar a fissuração nas paredes do colarinho. Como ilustrado na Figura 4.10, a armadura $A_{s, v s}$ é disposta no meio das paredes do colarinho e na Figura 4.11 a armadura $A_{s, h s}$ é distribuída ao longo dos 2/3 inferiores da altura útil das paredes longitudinais e transversais.

Verificou-se, pelos estudos realizados, que o dimensionamento da armadura $A_{s, v s t}$ da parede transversal posterior é bem racional, pois essa armadura nos ensaios experimentais atingiu o escoamento. Embora as armaduras $A_{s, h s}$ (armadura horizontal secundária) e $A_{s, v s l}$ (armadura vertical secundária da parede longitudinal) tenham sido pouco solicitadas nos ensaios, essas não podem ser dispensadas, pois como já dito, a presença das mesmas contribui no controle da fissuração do concreto.

As armaduras secundárias também são calculadas conforme as recomendações de consolo da ABNT NBR 9062:2006.

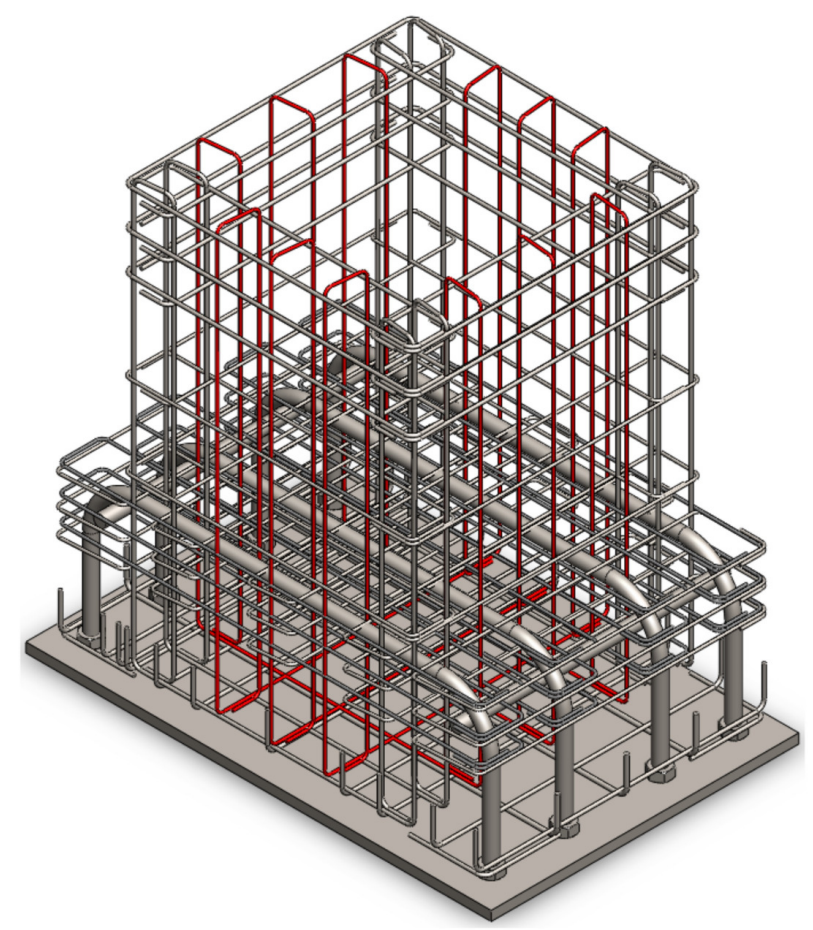

Figura 4.10 - Localização da armadura vertical secundária no cálice com interface lisa 


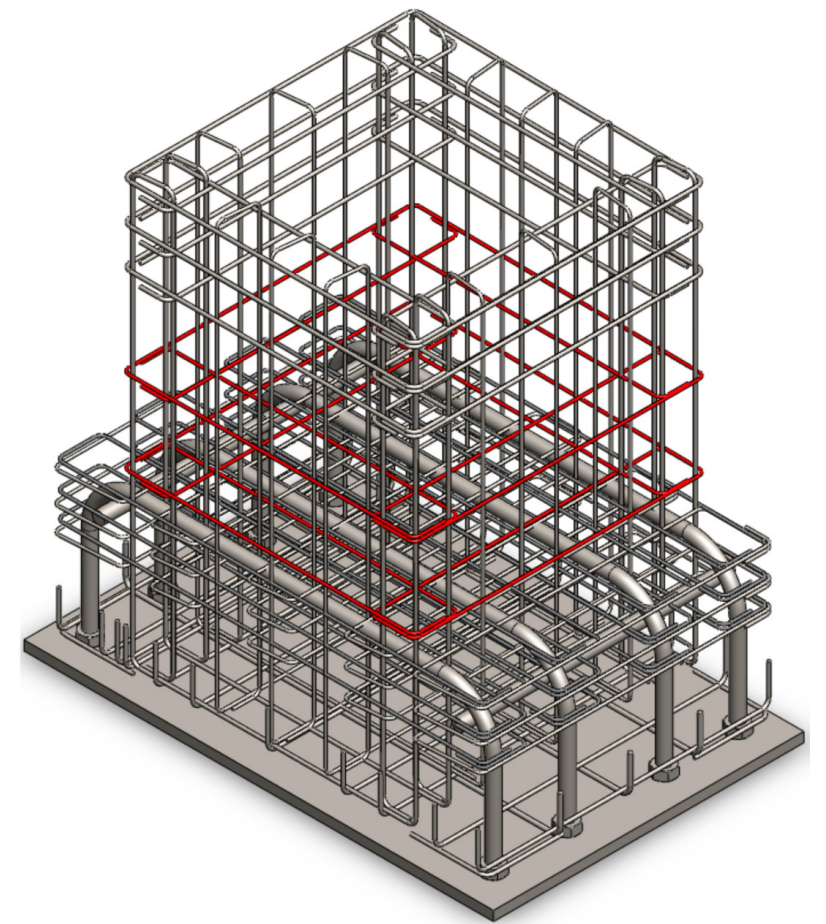

Figura 4.11 - Localização da armadura horizontal secundária no cálice com interface lisa

\section{Consolo curto}

Para o caso de consolo curto $(1,0 \geq \operatorname{tg} \beta>0,5)$ as armaduras secundárias verticais e horizontais devem ser dispostas nas paredes longitudinais e transversais com espaçamento entre $15 \mathrm{~cm}$ e $30 \mathrm{~cm}$ e com área de armadura igual ao apresentado nas Equações (4.27) e (4.28):

$$
\begin{aligned}
& A_{s, v s}=0,40 \cdot A_{s, v p} \\
& A_{s, h s}=0,25 \cdot A_{s, v p}
\end{aligned}
$$

Consolo muito curto

Para consolo muito curto, $\operatorname{com} \operatorname{tg} \beta \leq 0,5$, o dimensionamento das armaduras secundárias verticais e horizontais deve ser feito segundo as Equações (4.29) e (4.30) e as armaduras também devem ser dispostas nas paredes transversais e longitudinais com espaçamento entre $15 \mathrm{~cm}$ e $30 \mathrm{~cm}$.

$$
\begin{aligned}
& A_{s, v s}=0,50 \cdot A_{s, v p} \\
& A_{s, h s}=0,25 \cdot A_{s, v p}
\end{aligned}
$$


Como no caso de $A_{s, v p}$, os valores obtidos para $A_{s, v s}$ e $A_{s, h s}$ não devem ser menores que os calculados para o caso de consolo curto.

\section{Consolo longo}

Quando $\operatorname{tg} \beta>1,0$, as paredes longitudinais devem ser dimensionadas como uma viga em balanço engastada na fundação e a armadura $A_{s, v s}$ é calculada como uma armadura de pele da viga de acordo com a Equação (4.31):

$$
A_{s, v s}=0,10 \% \cdot h_{c} \cdot h_{e x t}
$$

Na distribuição de $A_{s, v s}$, o espaçamento deve ser menor que $d_{c} / 3$ ou $20 \mathrm{~cm}$. Para os casos de cargas próximas aos apoios, a armadura $A_{s, v s}$ pode vir a contribuir na resistência do consolo.

A armadura horizontal secundária para resistir ao esforço cortante de $H_{\sup f} / 2$ deve ser calculada segundo os modelos de cálculo I ou II da ABNT NBR 6118:2003 para elementos lineares sujeitos a força cortante.

Assim como no caso de consolo muito curto, as armaduras $A_{s, v s}$ e $A_{s, h s}$ não devem ter área menor quando comparadas com as calculadas para consolo curto.

\subsection{CÁLICE COM INTERFACE RUGOSA}

O cálice é definido como rugoso quando são executadas, nas paredes internas do colarinho e no pilar pré-moldado na região de embutimento, chaves de cisalhamento que contribuem para a transferência de esforços na ligação. A configuração das chaves de cisalhamento será motivo de estudo do item 4.7.2, onde será apresentada uma discussão sobre disposições construtivas da ligação cálice de fundação.

Assim como no cálice com interface lisa, alguns modelos de comportamento já foram apresentados para cálice de interface rugosa. Para determinar a pressão superior no cálice com interface rugosa, é possível considerar dois métodos:

a) O primeiro método sugerido na tese de doutorado de Canha (2004) considera um coeficiente de atrito $\mu=1$ e utiliza a Equação (4.1) para determinar o valor da pressão $H_{\text {sup } f}$ atuante na parede transversal frontal. A posição da resultante de pressão 
para cálice rugoso é calculado pela Equação (4.32), como indicado na ABNT NBR 9062:2006.

$y=0,150 \cdot l_{\text {emb }}$

b) O segundo método é apresentado em Canha et al. (2009c) e considera uma pressão $H_{\text {sup } f}$ agindo na parede transversal frontal e outra pressão $H_{\text {sup } p}$ agindo na parede posterior do cálice, como ilustrado na Figura 4.12.

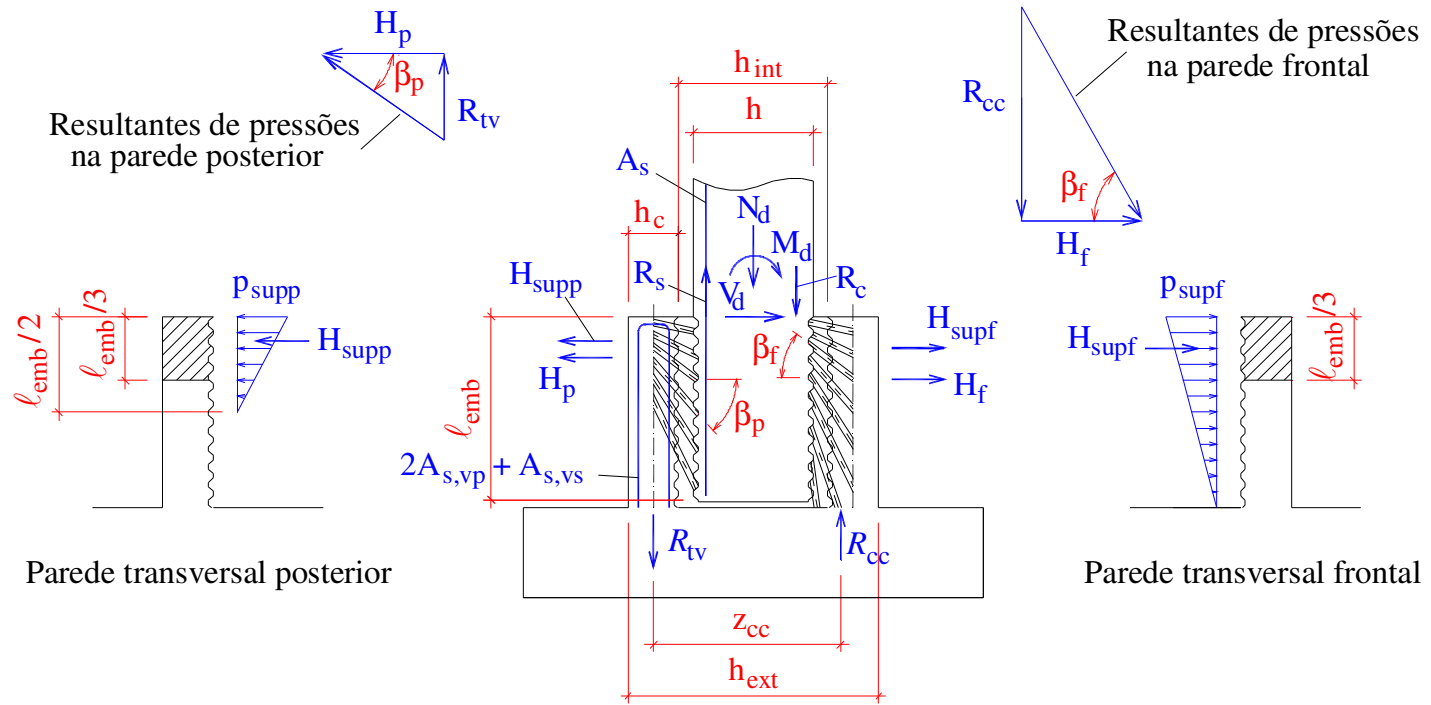

Figura 4.12 - Transferência das forças resultantes do pilar para o cálice com interface rugosa (adaptado de CANHA et al. (2009c))

Nesse modelo, bielas de compressão aparecem no lado comprimido (parede transversal frontal) por causa da transferência da resultante de compressão $R_{c}$ do pilar para a parede frontal, resultando em uma força $R_{c c}$ no cálice de fundação. Devido a essas bielas de compressão, uma pressão $H_{f}$ age na parede transversal frontal. Essa força $H_{f}$ pode ser calculada pela Equação (4.33):

$$
H_{f}=\frac{R_{c c}}{\tan \beta_{f}}
$$

sendo que:

$\beta_{f}$ : média dos ângulos de inclinação das bielas no lado comprimido.

A resultante das tensões de compressão no cálice pode ser calculada pela Equação (4.34): 


$$
R_{c c}=\frac{\left[M_{b d}+N_{d} \cdot\left(0,5 \cdot h_{e x t}-0,5 \cdot h_{c}\right)\right]}{z_{c c}}
$$

sendo que:

$$
M_{b d}=M_{d}+V_{d} \cdot l_{e m b} \quad z_{c c} \cong 0,9 \cdot d_{c c} \quad d_{c c} \cong 0,9 \cdot h_{e x t}
$$

Os valores de $z_{c c}$ e $d_{c c}$ acima apresentados são aplicáveis aos casos de força normal com grande excentricidade.

A resultante de pressão $H_{\text {sup } f}$ é igual à resultante do bloco trapezoidal das pressões no topo da parede transversal frontal, ou seja, é uma parcela de $H_{f}$ e é determinada pela Equação (4.35):

$$
H_{\text {sup } f} \cong 0,6 \cdot H_{f}
$$

No lado tracionado (parede transversal posterior), a transmissão por bielas de compressão da maior parte da força de tração $R_{s}$, oriunda do pilar para a parede posterior, resulta na força $R_{t v}$ e em uma pressão $H_{p}$ atuante na parede. Verifica-se que a pressão $H_{p}$ é mais concentrada no topo da parede, pois as bielas nessa região possuem menor inclinação em relação ao eixo horizontal, e a base da parede transversal posterior não transmite esforço.

A pressão $H_{p}$ é calculada pela Equação (4.36):

$$
H_{p}=\frac{R_{t v}}{\tan \beta_{p}}
$$

sendo que:

$\beta_{p}$ : média dos ângulos de inclinação das bielas no lado tracionado.

A força $R_{t v}$ é resultante da soma de $2 \cdot R_{v p}$ e $R_{v s t}$. A força $R_{v p}$ é a força no canto da parede posterior e determina a armadura $A_{s, v p}$. A força $R_{v s t}$ é a força que ocorre na região central da parede posterior e define a armadura $A_{s, v s t}$. Pela teoria da flexão, a força $R_{t v}$ é calculada pela Equação (4.37):

$$
R_{t v}=\frac{\left[M_{b d}-N_{d} \cdot\left(z_{c c}+0,5 \cdot h_{c}-0,5 \cdot h_{e x t}\right.\right.}{z_{c c}}
$$

A resultante de pressão $H_{\text {sup } p}$ na parede transversal posterior é aproximadamente igual à pressão $H_{p}$. 
Quanto aos valores dos ângulos médios da inclinação das bielas nas paredes, na referência de Canha et al. (2009c) é indicado o valor de $45^{\circ}$ para $\beta_{f}$ e $\beta_{p}$. Porém, observouse que com esses ângulos de inclinações, os resultados teóricos não representavam bem os resultados experimentais. Assim, foi desenvolvida uma análise com variação dos ângulos médios de inclinação das bielas nas paredes transversais frontal e posterior. Para o ângulo $\beta_{f}$ adotaram-se os valores de $45^{\circ}$ e $60^{\circ}$, e para o ângulo $\beta_{p}$ os valores de $45^{\circ}$ e $35^{\circ}$.

Foram analisados e comparados resultados experimentais e teóricos dos modelos ensaiados por Canha (2004) - IR-1 e IR-2; por Jaguaribe Jr. (2005) - IR-3; e por Nunes (2009) - IR-4. Na Tabela 4.1, são apresentados os resultados da força na armadura $A_{s, h p t}$ conforme variação do ângulo $\beta_{f}$ da parede transversal frontal e na Tabela 4.2, são apresentados os resultados conforme variação do ângulo $\beta_{p}$ da parede transversal posterior.

Tabela 4.1 - Resultados teóricos e experimentais da força na armadura $\mathrm{A}_{\text {shpt }}$ da parede transversal frontal do cálice com interface rugosa de acordo com variação do ângulo $\beta_{\mathrm{f}}$

\begin{tabular}{|c|c|c|c|c|c|c|}
\hline \multirow{2}{*}{$\begin{array}{l}\text { Modelo } \\
\text { físico }\end{array}$} & \multirow{2}{*}{$\begin{array}{l}\text { Modelo de } \\
\text { projeto }\end{array}$} & \multirow{2}{*}{$\begin{array}{c}\hat{\text { Ângulo }} \\
\beta_{\mathrm{f}}\end{array}$} & \multicolumn{2}{|c|}{$\mathrm{R}_{\mathrm{s}, \mathrm{hpte}}(\mathrm{kN})$} & \multicolumn{2}{|c|}{$\mathrm{R}_{\mathrm{s}, \mathrm{hpti}}(\mathrm{kN})$} \\
\hline & & & Teórico & Experimental & Teórico & Experimental \\
\hline \multirow{4}{*}{ IR-1 } & \multirow{2}{*}{ Flexo-tração } & $45^{\circ}$ & 205,50 & \multirow{4}{*}{87,00} & 41,80 & \multirow{4}{*}{15,70} \\
\hline & & $60^{\circ}$ & 118,60 & & 24,10 & \\
\hline & \multirow{2}{*}{ Tração } & $45^{\circ}$ & 145,50 & & 145,50 & \\
\hline & & $60^{\circ}$ & 84,00 & & 84,00 & \\
\hline \multirow{4}{*}{ IR-2 } & \multirow{2}{*}{ Flexo-tração } & $45^{\circ}$ & 206,80 & \multirow{4}{*}{51,40} & 42,10 & \multirow{4}{*}{9,90} \\
\hline & & $60^{\circ}$ & 119,40 & & 24,30 & \\
\hline & \multirow{2}{*}{ Tração } & $45^{\circ}$ & 146,40 & & 146,40 & \\
\hline & & $60^{\circ}$ & 84,50 & & 84,50 & \\
\hline \multirow{4}{*}{ IR-3 } & \multirow{2}{*}{ Flexo-tração } & $45^{\circ}$ & 172,40 & \multirow{4}{*}{42,00} & 33,60 & \multirow{4}{*}{20,50} \\
\hline & & $60^{\circ}$ & 99,50 & & 19,40 & \\
\hline & \multirow{2}{*}{ Tração } & $45^{\circ}$ & 121,10 & & 121,10 & \\
\hline & & $60^{\circ}$ & 69,90 & & 69,90 & \\
\hline \multirow{4}{*}{ IR-4 } & \multirow{2}{*}{ Flexo-tração } & $45^{\circ}$ & 208,20 & \multirow{4}{*}{54,90} & 25,20 & \multirow{4}{*}{4,20} \\
\hline & & $60^{\circ}$ & 120,20 & & 14,50 & \\
\hline & \multirow{2}{*}{ Tração } & $45^{\circ}$ & 137,30 & & 137,30 & \\
\hline & & $60^{\circ}$ & 79,30 & & 79,30 & \\
\hline
\end{tabular}


Analisando os resultados, verifica-se que para todos os casos quando considerado $\beta_{f}=60^{\circ}$, as forças teóricas resultaram mais próximas das forças experimentais. Por exemplo, para o modelo IR-2 considerando flexo-tração e ângulo de $60^{\circ}$ a diferença entre a força teórica e experimental é de aproximadamente 132\%, contra aproximadamente 300\% de diferença quando consideramos ângulo de inclinação das bielas de $45^{\circ}$.

Para o modelo IR-3, na situação de flexo-tração e ângulo $\beta_{f}=60^{\circ}$, a força teórica interna ficou abaixo da força experimental. Porém, esse modelo ensaiado por Jaguaribe Jr. (2005), possui comprimento de embutimento reduzido, e consequentemente os resultados experimentais foram alterados devido esse fator. Para o modelo IR-1, considerando tração e ângulo de $60^{\circ}$, o resultado da força teórica no ramo externo ficou abaixo do resultado experimental em aproximadamente 3,5\%. No entanto, para a determinação dos valores experimentais adotou-se a aproximação do módulo de elasticidade do aço da armadura de 210 GPa que na realidade pode ser um pouco menor, encobrindo assim essa pequena diferença.

Em uma análise geral, observa-se que o modelo teórico que representa melhor os resultados experimentais é aquele que utiliza o ângulo médio de $60^{\circ}$ de inclinação das bielas no lado comprimido do cálice de fundação. Por isso, esse será o ângulo adotado para esse estudo.

Tabela 4.2 - Resultados teóricos e experimentais da força na armadura $A_{\text {shpt }}$ da parede transversal posterior do cálice com interface rugosa de acordo com variação do ângulo $\beta_{\mathrm{p}}$

\begin{tabular}{|c|c|c|c|c|c|c|}
\hline \multirow{2}{*}{$\begin{array}{l}\text { Modelo } \\
\text { físico }\end{array}$} & \multirow{2}{*}{$\begin{array}{l}\text { Modelo de } \\
\text { projeto }\end{array}$} & \multirow{2}{*}{$\begin{array}{c}\text { Ângulo } \\
\beta_{\mathrm{p}}\end{array}$} & \multicolumn{2}{|c|}{$\mathrm{R}_{\mathrm{s}, \mathrm{hpte}}(\mathrm{kN})$} & \multicolumn{2}{|c|}{$\mathrm{R}_{\mathrm{s}, \mathrm{hpti}}(\mathrm{kN})$} \\
\hline & & & Teórico & Experimental & Teórico & Experimental \\
\hline \multirow{4}{*}{ IR-3 } & \multirow{2}{*}{ Flexo-tração } & $45^{\circ}$ & 159,90 & \multirow{4}{*}{100,30} & 31,20 & \multirow{4}{*}{46,50} \\
\hline & & $35^{\circ}$ & 228,40 & & 44,50 & \\
\hline & \multirow{2}{*}{ Tração } & $45^{\circ}$ & 112,40 & & 112,40 & \\
\hline & & $35^{\circ}$ & 160,50 & & 160,50 & \\
\hline \multirow{4}{*}{ IR-4 } & \multirow{2}{*}{ Flexo-tração } & $45^{\circ}$ & 199,60 & \multirow{4}{*}{101,30} & 24,10 & \multirow{4}{*}{33,80} \\
\hline & & $35^{\circ}$ & 285,10 & & 34,50 & \\
\hline & \multirow{2}{*}{ Tração } & $45^{\circ}$ & 131,60 & & 131,60 & \\
\hline & & $35^{\circ}$ & 188,00 & & 188,00 & \\
\hline
\end{tabular}

Analisando a Tabela 4.2, verifica-se que as bielas no lado tracionado do cálice (parede posterior) possuem menor inclinação quando comparadas com as bielas do lado comprimido 
(parede frontal), por isso para essa parede os ângulos adotados para o estudo foram de $35^{\circ} \mathrm{e}$ $45^{\circ}$. Instrumentou-se a parede transversal posterior somente nos modelos IR-3 e IR-4, assim a Tabela 4.2 só apresenta dados para esses dois cálices.

Como pode ser observado, para os dois modelos na situação de flexo-tração e ângulo de $45^{\circ}$, as forças teóricas no ramo interno da armadura resultam menores que as forças experimentais para o ramo inetrno, assim não é possível considerar esse ângulo de inclinação da biela. Já se for considerado ângulo de $35^{\circ}$, não negligenciamos a verificação das forças para o modelo IR-4. No modelo IR-3 a força teórica ficou um pouco abaixo da força experimental, mas como já dito, esse modelo possui comprimento de embutimento reduzido.

Mesmo dispondo de poucos resultados experimentais, indica-se adotar $\beta_{p}=35^{\circ}$, pois para essa situação, a força teórica resulta acima da força experimental. Não se optou pelo ângulo de $30^{\circ}$, porque os resultados para essa situação seriam muito conservadores para a tração ou ficariam contra a segurança no caso da flexo-tração.

\subsubsection{Armadura horizontal principal longitudinal $-A_{s, h p l}$}

A armadura $A_{s, h p l}$ localizada na parte superior das paredes longitudinais do cálice com interface rugosa, como indicado na Figura 4.14, deve ser dimensionada considerando a atuação das pressões $H_{\sup f}$ e $H_{\sup p}$ nas paredes transversais do cálice.

Assim como para o caso de cálice de interface lisa, a armadura horizontal principal é dividida em dois ramos: ramo externo e ramo interno e deve ser distribuída na parte superior do cálice referente à altura $l_{e m b} / 3$.

Após o cálculo das pressões atuantes nas paredes transversais, de acordo com o método indicado em Canha et al. (2009c), é necessário calcular a área de aço resultante pela atuação da pressão atuante na parede frontal e também pela ação de uma força na parede posterior. O dimensionamento da armadura é feito pelas Equações (4.38) e (4.39) e deve-se adotar para $A_{s, h p l}$ o maior valor.

$$
\begin{aligned}
A_{s, h p l} & =\frac{H_{\sup f}}{2 \cdot f_{y d}} \\
A_{s, h p l} & =\frac{H_{\sup p}}{2 \cdot f_{y d}}
\end{aligned}
$$




\subsubsection{Armadura horizontal principal transversal $-A_{s, h p t}$}

O modelo de projeto proposto por Canha et al. (2009c), ilustrado na Figura 4.13 para dimensionamento da armadura $A_{s, h p t}$ das paredes transversais em cálice com interface rugosa é similar ao proposto para o dimensionamento da armadura $A_{s, h p t}$ da parede frontal para cálice com interface lisa, pois a configuração das fissuras e as medições dos extensômetros nos ensaios realizados indicam que a parede transversal posterior do cálice com interface rugosa é submetida a uma pressão similar ao que acontece na parede transversal frontal de cálices com interface lisa.
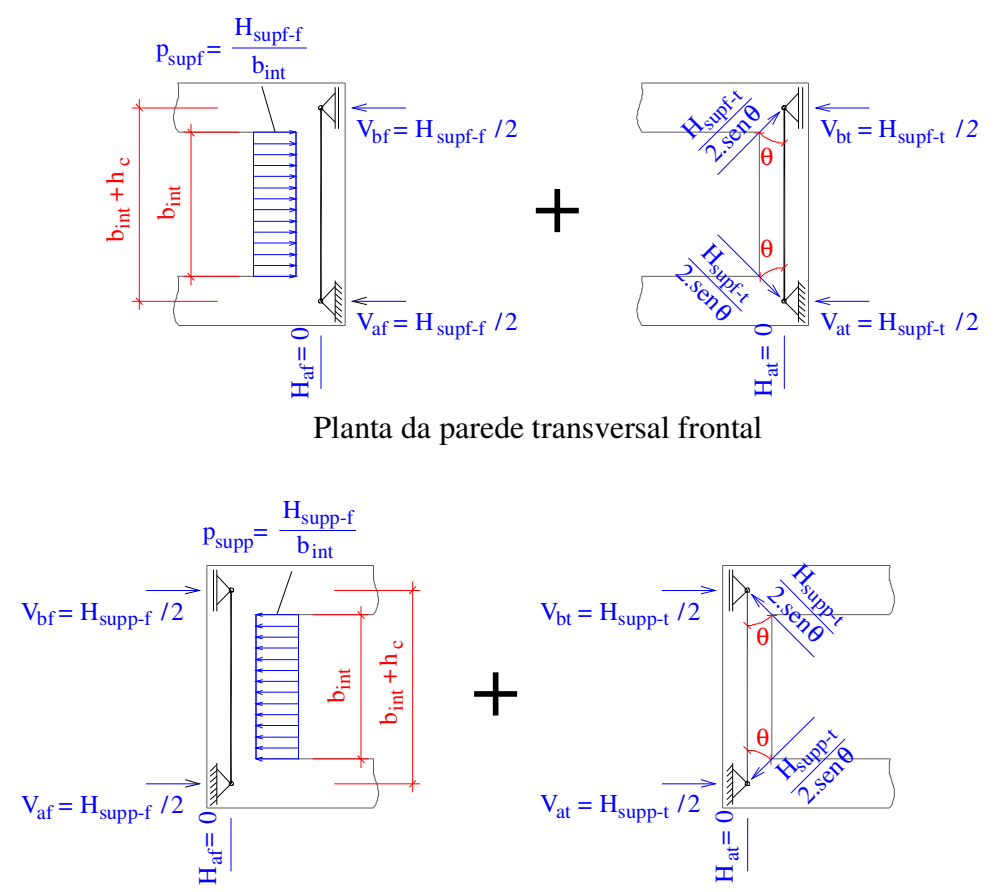

Planta da parede transversal posterior

Figura 4.13 - Modelo de projeto proposto para a parede frontal e posterior do cálice com interface rugosa (adaptado de CANHA et al. (2009c))

Nesse modelo, também é considerada uma flexo-tração das paredes transversais, onde uma parcela das resultantes de pressão causa flexão na parede e outra parcela causa tração. O valor total da pressão superior na parede frontal $H_{\text {sup } f}$ e na parede posterior $H_{\text {sup } p}$ é definido como uma soma das duas parcelas.

Para o cálice de interface rugosa, também foi considerado uma distribuição uniforme do carregamento e as porcentagens adotadas para os casos de flexo-tração foram de $15 \%$ para as pressões $H_{\text {sup } f-f}$ e $H_{\text {sup } p-f}$ e de $85 \%$ para as pressões $H_{\text {sup } f-t}$ e $H_{\text {sup } p-t}$. Além desses 
percentuais, somente a atuação da força de tração, em que $H_{\sup f}=H_{\sup f-t}$ e $H_{\sup p}=H_{\text {sup } p-t}$, pode ser considerada.

O roteiro para dimensionamento da armadura $A_{s, h p t}$ é o mesmo apresentado no item 4.1.2. Como as armaduras $A_{s, h p l}$ e $A_{s, h p t}$ são distribuídas na mesma altura do cálice rugoso, e pelo motivo de posicionamento do arranjo de armaduras do cálice na obra, deve-se adotar para o projeto dessa ligação o maior valor entre as armaduras e dispô-las simetricamente. $\mathrm{Na}$ Figura 4.14 está representada a localização dessas armaduras.

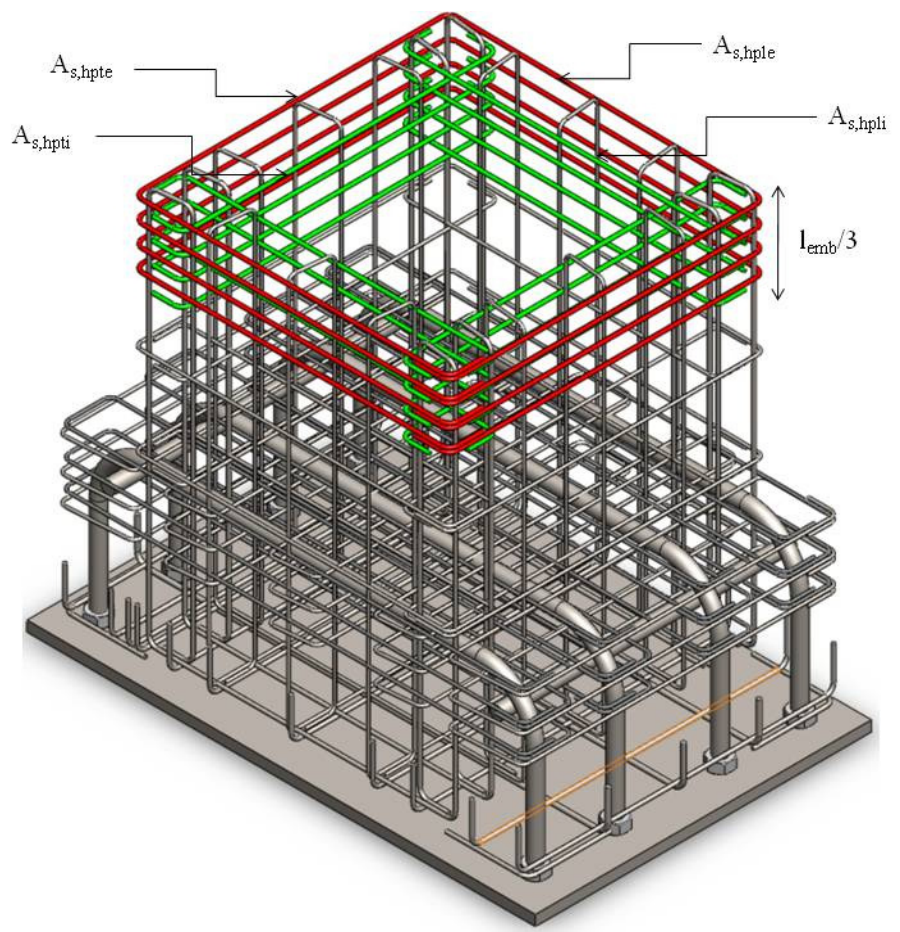

Figura 4.14 - Localização das armaduras horizontais principais no cálice com interface rugosa

\subsubsection{Armadura vertical principal - $A_{s, v p}$}

Após todos os ensaios desenvolvidos na EESC-USP, foi verificado que os modelos com interface rugosa, com comprimento de embutimento definido de acordo com a ABNT NBR 9062:2006, apresentaram um comportamento próximo de uma ligação monolítica, ou seja, ocorreu a transferência total do momento e da força normal do pilar para o cálice.

Portanto, a teoria da flexão é recomendada para determinação da armadura vertical principal nos cálice com interface rugosa. Na Figura 4.15, um modelo com o esquema de forças atuantes é apresentado. Esse modelo só é válido para cálice com comprimento de 
embutimento determinado pela norma ABNT NBR 9062:2006, pois verificou-se, nos ensaios de Jaguaribe Jr. (2005), que com a diminuição do comprimento de embutimento, o cálculo da resistência da ligação pela teoria da flexão forneceu um valor maior que a resistência experimental obtida nos modelos ensaiados por esse autor.

Para um cálculo mais preciso, devem ser consideradas todas as armaduras verticais contribuindo para a resistência da ligação e um diagrama parabólico-retangular de tensões de compressão no concreto.

Para aplicações práticas, um cálculo simplificado pode ser utilizado, considerando um diagrama simplificado de tensões no concreto com altura igual a 0,8 da profundidade da linha neutra e a resultante de tração determinada pela contribuição somente das armaduras verticais principais situadas nos cantos da parede posterior e pela armadura vertical secundária dessa mesma parede. Assim, a armadura total resultante do cálculo pela teoria da flexão é determinada pela Equação (4.40) e a armadura $A_{s, v p}$ pode ser encontrada.

$$
A_{s, t o t}=2 \cdot A_{s, v p}+A_{s, v s}
$$

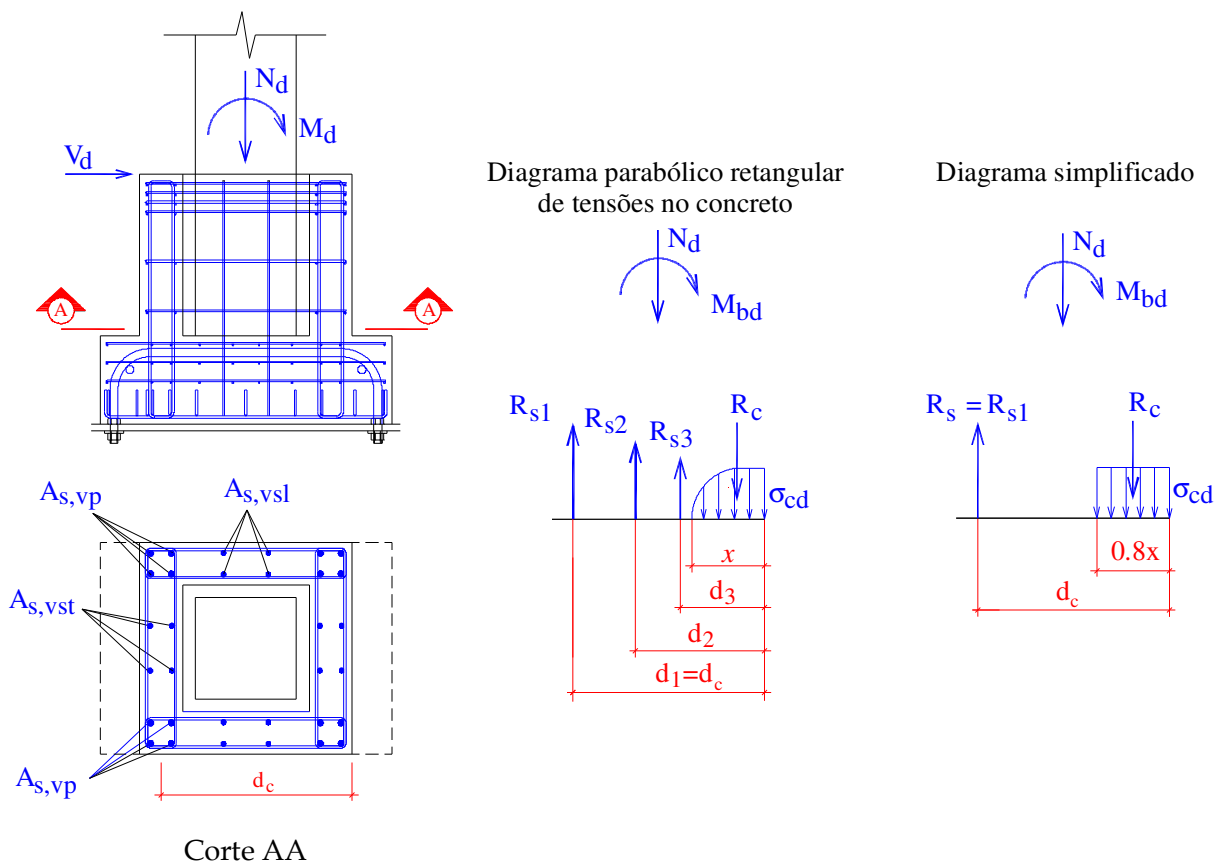

Figura 4.15 - Esquema de forças para determinar a armadura vertical para cálice com interface rugosa

(CANHA et al. (2007))

sendo que:

$M_{b d}$ : Momento fletor de cálculo na base do cálice

$R_{c}$ : Resultante de compressão no concreto 
$R_{s=} R_{s 1}$ : Resultante de forças nas armaduras verticais $2 . A_{s, v p}+A_{s, v s t}$ situadas na altura útil $d_{c}$ $R_{s 2}$ : Resultante de forças na armadura vertical secundária $A_{s, v s l}$ situada na altura útil $d_{2}$ $R_{s 3}$ : Resultante de forças na armadura vertical secundária $A_{s, v s l}$ situada na altura útil $d_{3}$ $\sigma_{c d}:$ Valor de cálculo da tensão de compressão no concreto

$x$ : Profundidade da linha neutra

Com essas considerações a armadura $A_{s, v p}$ é definida de acordo com as Equações (4.41) a (4.43):

$$
\begin{aligned}
& R_{c d}=R_{s d}+N_{d} \\
& R_{c d}=A_{c c} \cdot \sigma_{c d}=0,8 \cdot x \cdot h_{e x t} \cdot \sigma_{c d} \\
& R_{s d}=A_{s, v p} \cdot f_{y d}=\frac{M_{b d}-N_{d} \cdot\left(0,5 \cdot h_{e x t}-0,4 \cdot x\right)}{d_{c}-0,4 \cdot x}
\end{aligned}
$$

sendo que:

$M_{b d}=M_{d}+V_{d} \cdot l_{e m b}$

Substituindo as Equações (4.42) e (4.43) na Equação (4.41), é possível determinar a posição da linha neutra através da Equação (4.44), e consequentemente calcular o valor de $A_{s, v p}$.

$$
M_{b d}-0,5 \cdot N_{d} \cdot h_{e x t}+N_{d} \cdot d_{c}-0,8 \cdot x \cdot h_{e x t} \cdot \sigma_{c d} \cdot d_{c}+0,32 \cdot x^{2} \cdot h_{e x t} \cdot \sigma_{c d}=0
$$

A tensão $\sigma_{c d}$ no concreto é definida de acordo com o domínio em que está sendo feito o dimensionamento. No domínio 2, a ruína acontece por deformação plástica excessiva do aço, com deformação máxima na armadura de $\varepsilon_{s}=10 \%$ e a deformação no concreto variando de 0 a 3,5\% . A tensão no concreto, no intervalo de variação de 0 a 2,0\%o, é calculada de acordo com a Equação (4.45), e no intervalo de deformação de 2 a 3,5\%o, a tensão é constante e equivale a $0,85 . f_{c d}$.

$$
\sigma_{c d}=0,85 \cdot f_{c d} \cdot\left[1-\left(1-\frac{\varepsilon_{c}}{2}\right)^{2}\right]
$$

No domínio 3, a ruína acontece por ruptura do concreto com uma deformação máxima de $3,5 \%$, e a armadura tracionada escoa e a deformação varia de $\varepsilon_{y}$ até $10 \%$. A tensão no concreto $\sigma_{c d}$ equivale a $0,85 . f_{c d}$.

A armadura vertical resultante deve ser distribuída nos canto das paredes longitudinais e transversais. Na Figura 4.16, a armadura já está representada com simetria. 


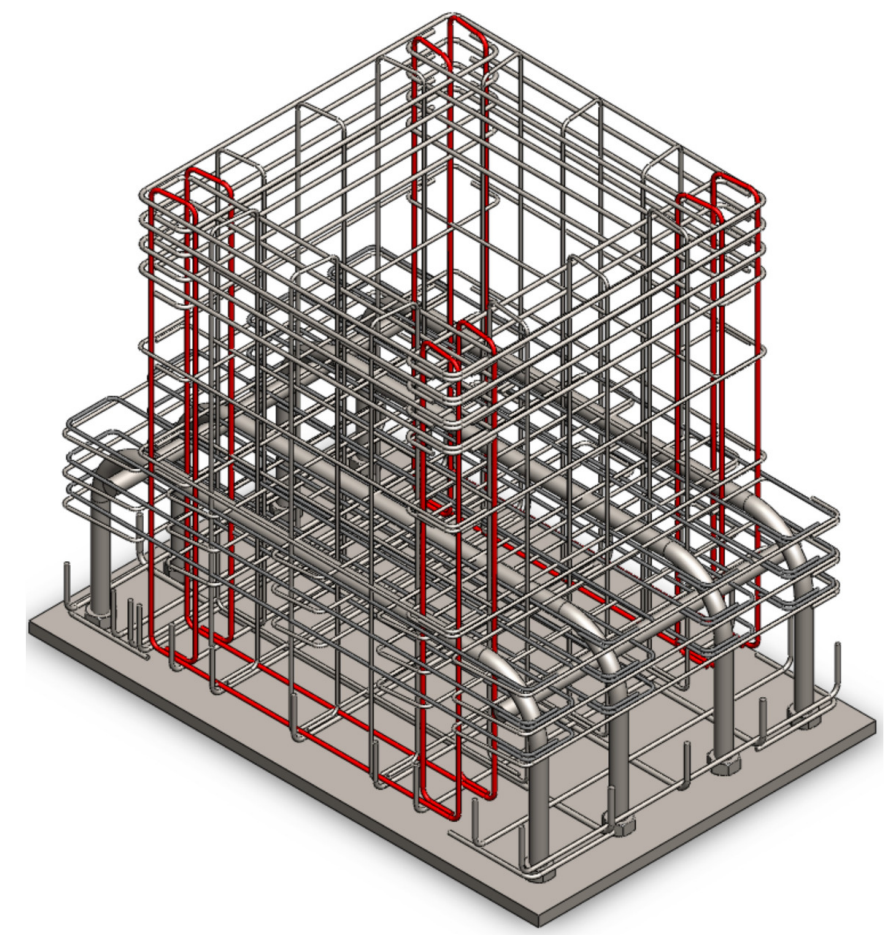

Figura 4.16 - Localização da armadura vertical principal em cálice com interface rugosa

\subsubsection{Armaduras secundárias - $A_{s, v s}$ e $A_{s, h s}$}

Para o dimensionamento das armaduras secundárias do cálice com interface rugosa, devem ser adotadas as mesmas recomendações que consideram o comportamento de consolo curto das paredes longitudinais. Observa-se que no cálculo pela teoria da flexão, a armadura $A_{s, v s}$ já está incluída e tem valor de $0,40 \cdot A_{s, v p}$.

Como no cálice com interface lisa, as armaduras secundárias são utilizadas no cálice para resistir a esforços secundários e controlar a fissuração nas paredes do colarinho.

\subsection{BASE DO PILAR PRÉ-MOLDADO}

Como a ligação cálice-fundação é estabelecida por uma porção do pilar pré-moldado embutido numa cavidade da fundação, é necessário analisar, além do cálice, a base do pilar pré-moldado no projeto da ligação. Mecanismos de resistência como o confinamento do concreto na base do pilar, e redução dos esforços devido a forças de atrito, devem ser considerados no dimensionamento dessa região. 


\subsubsection{Modelo de projeto proposto por Canha et al. (2009a)}

Considerando a distribuição de forças e caminho de tensões, um modelo de biela e tirante é proposto na dissertação de Ebeling (2006), para representar o comportamento relativo da base do pilar pré-moldado em cálices de fundação. Esse modelo, é novamente apresentado em Canha et al. (2009a) com algumas modificações (Figura 4.17). Percebe-se que nesse modelo, não foram consideradas as forças de atrito na base do pilar, diferentemente do modelo de projeto do cálice de fundação.

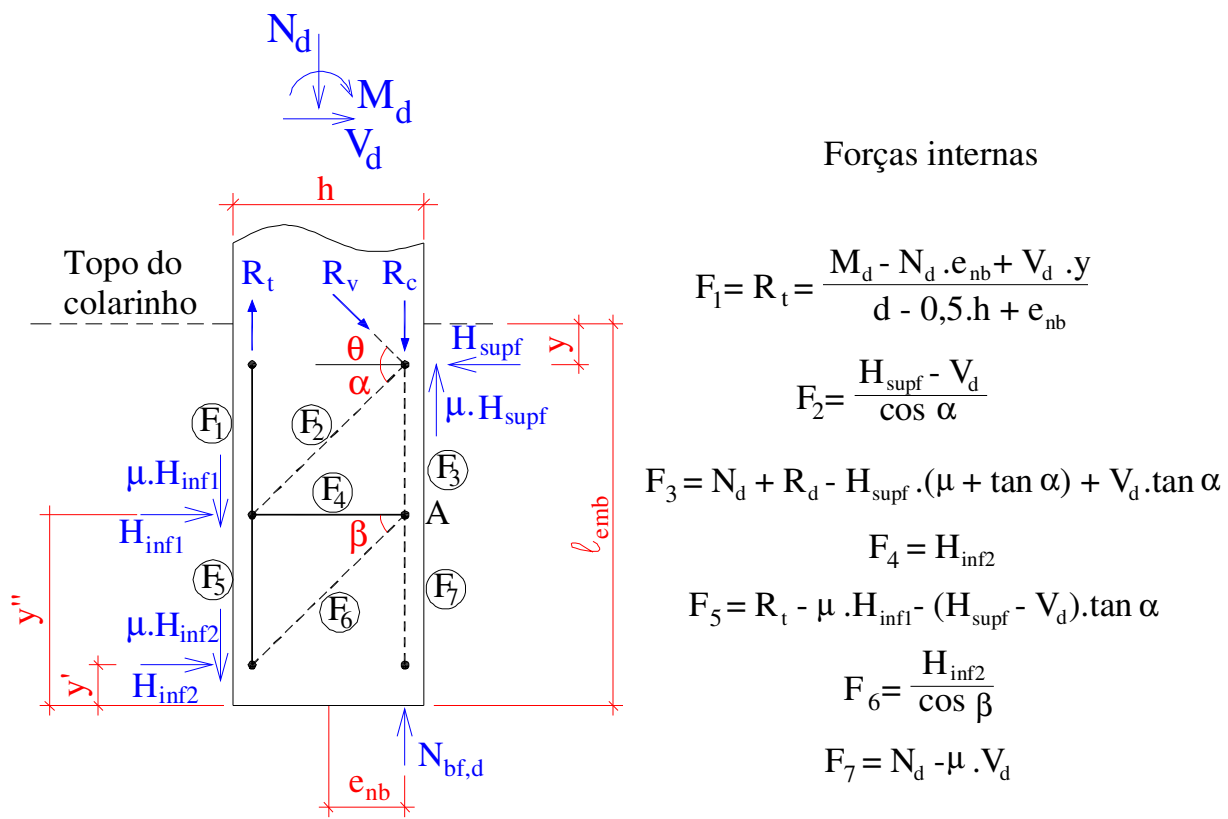

Figura 4.17- Modelo de projeto proposto por Canha et al. (2009a)

São identificadas na base do pilar, duas bielas de compressão, sendo que uma causa pressões no topo da parede frontal e no meio da parede posterior, e outra que causa pressão no fundo da parede posterior. Canha et al. (2009a) sugere que essas bielas inclinadas são similares a uma caminho de tensões de cargas próximo aos apoios de uma viga. Assim, a partir desses caminhos das tensões, é possível determinar as resultantes de pressões nas paredes e a excentricidade da reação na base da fundação.

A partir da equação de equilíbrio de momentos no ponto A da Figura 4.17 e procedendo as combinações necessárias, resulta a Equação (4.46) para cálculo de $H_{\sup f}$ :

$$
H_{\text {sup } f}=\frac{\frac{M_{d}-N_{d} \cdot e_{n b}}{d-0,5 \cdot h+e_{n b}}+V_{d} \cdot\left(\mu+\operatorname{tg} \alpha+\eta \cdot \operatorname{tg} \beta+\frac{y}{d-0,5 \cdot h+e_{n b}}\right)}{\operatorname{tg} \alpha+\mu+\eta \cdot \operatorname{tg} \beta}
$$


O cálculo dos demais parâmetros, já foi apresentado no item 3.3 que se refere à dissertação de Ebeling (2006).

A partir da determinação da força $\mathrm{F}_{4}$, a armadura transversal necessária pode ser calculada. Essa armadura deve ser distribuída na região da base do pilar equivalente a distância de $y^{\prime}-y^{\prime \prime}$. Para esse modelo, a força de atrito na base não foi considerada porque as deformações no estribo nessa região foram pequenas.

\subsubsection{Modelo de projeto adaptado}

Analisando o modelo de projeto proposto por Canha et al. (2009a), que é um modelo adaptado do proposto por Ebeling (2006), para análise da base do pilar pré-moldado, verificase que esse é incompatível com o modelo proposto para dimensionamento do cálice de fundação. No modelo de biela e tirante do pilar, apresentado na Figura 4.17, existem duas resultantes de pressão inferior $H_{\text {inf }}$ no lado tracionado do pilar, sendo que no modelo de comportamento do cálice, existe somente uma resultante $H_{\text {inf }}$ na parede posterior.

Dessa maneira, um novo modelo de projeto adaptado será proposto nesse estudo para análise da base do pilar. Além da retirada do apoio intermediário, será analisada a inclusão das forças de atrito na base do pilar para que esse modelo fique semelhante ao modelo de comportamento do cálice de fundação. No Capítulo 5 será analisada a modificação decorrente da inclusão dessas forças na base do pilar.

Outra verificação feita foi de que o modelo de biela e tirante proposto por Ebeling (2006) não considera a parcela resistida pelo concreto na determinação das forças e posteriormente no dimensionamento da armadura transversal. É necessário considerar a contribuição do concreto na resistência da ligação para que o modelo da base do pilar represente bem o comportamento dessa região. Sabe-se ainda, que na região de embutimento, o concreto está confinado, sendo assim a sua contribuição é maior.

O modelo adaptado, com as modificações propostas, está representado na Figura 4.18. Esse modelo é indicado para cálices submetidos à força normal de grande excentricidade e com comprimentos de embutimento determinados de acordo com a ABNT NBR 9062:2006, pois nos estudos de Ebeling (2006) verificou-se que o modelo físico com comprimento de embutimento menor que o recomendado, apresentou maiores deslocamentos e tensões nas armaduras. Também foram inseridos sinais nas equações de determinação das forças internas, sendo que o sinal positivo indica tração e o negativo indica compressão. 


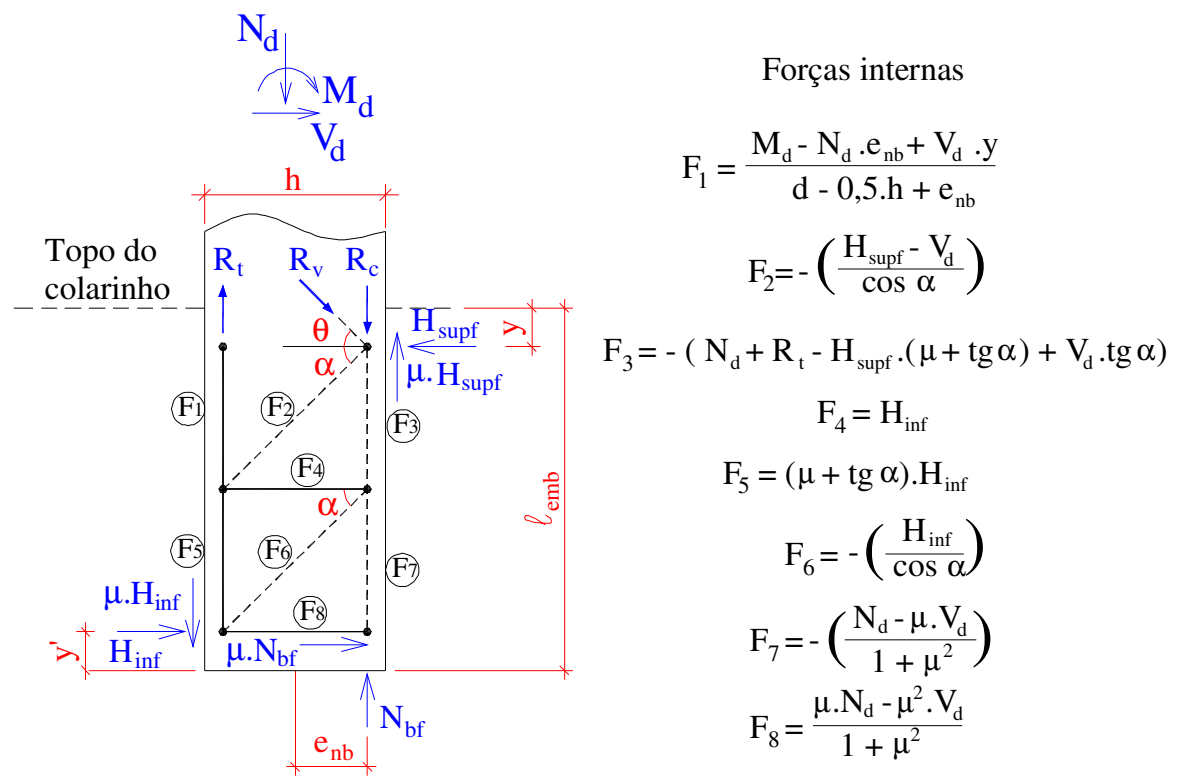

Figura 4.18 - Modelo de projeto adaptado para análise da base do pilar pré-moldado

Os valores de $y, y^{\prime}$ e $e_{n b}$ são calculadas pelas Equações (4.47), (4.48) e (4.49)

$$
\begin{aligned}
& y=\frac{l_{e m b}}{10} \\
& y^{\prime}=\frac{l_{e m b}}{10} \\
& e_{n b}=0,5 \cdot h-\frac{0,8 \cdot x}{2}
\end{aligned}
$$

Por questões práticas, é permitido definir a excentricidade $e_{n b}$ na base do pilar sendo de $h / 4$, assim como no modelo do cálice de fundação.

E as resultantes $R_{v}, R_{c}$ e $R_{t}$ são definidas pelas Equações (4.50), (4.51) e (4.52):

$$
\begin{aligned}
& R_{v}=\frac{V_{d}}{\cos \theta} \\
& R_{c}=N_{d}-V_{d} \cdot \operatorname{tg} \theta+R_{t} \\
& R_{t}=\frac{M_{d}+V_{d} \cdot y-N_{d} \cdot e_{n b}}{d-0,5 \cdot h+e_{n b}}
\end{aligned}
$$

O ângulo $\alpha$, inclinação das bielas em relação às armaduras, é determinado de acordo pela Equação (4.53):

$$
\operatorname{tg} \alpha=\frac{\left(l_{e m b}-y-y^{\prime}\right) / 2}{d-0,5 \cdot h+e_{n b}}
$$


Após equacionamento, através de equações de equilíbrio, é definida a Equação (4.54) para cálculo da pressão na parede transversal frontal $H_{\text {sup } f}$.

$H_{\text {sup } f}=\frac{\frac{M_{d}}{d-0,5 h+e_{n b}}+N_{d} \cdot\left(\frac{\mu^{2}}{1+\mu^{2}}-\frac{e_{n b}}{d-0,5 h+e_{n b}}\right)+V_{d} \cdot\left(\frac{\mu}{1+\mu^{2}}+\frac{y}{d-0,5 h+e_{n b}}+2 \cdot \operatorname{tg} \alpha\right)}{\mu+2 \cdot \operatorname{tg} \alpha}$

Em Canha et al. (2009a), foi comprovada a importância da consideração das forças de atrito na determinação das pressões, pois essa concepção aproxima os valores teóricos dos experimentais, sendo indicado o valor de $\mu=0,3$ para o coeficiente de atrito.

Para os casos em que a força normal resultar de pequena excentricidade, deve-se adotar um modelo de projeto que não considere forças de atrito nem a excentricidade da reação normal na base do pilar, para que esse seja compatível com o modelo de comportamento do cálice para esses casos. O cálculo da pressão superior atuante na parede transversal frontal, para essa situação, é feito de acordo com a Equação (4.55):

$$
H_{\text {sup } f}=\frac{\frac{M_{d}}{d-0,5 \cdot h}+V_{d} \cdot\left(\frac{y}{d-0,5 \cdot h}+2 \cdot \operatorname{tg} \alpha\right)}{2 \cdot \operatorname{tg} \alpha}
$$

\subsubsection{Ancoragem da armadura longitudinal pilar}

Através das análises das deformações no pilar na região de embutimento, observou-se que na distância de $0,5 \cdot l_{e m b}$ e $0,6 \cdot l_{e m b}$ na direção base-topo colarinho, as deformações foram próximas das deformações de escoamento, para os dois modelos ensaiados por Ebeling (2006). Esses valores indicam que as transferências das tensões da armadura para o concreto ocorrem a partir desses pontos no sentindo descendente.

Assim, a recomendação apresentada pelo modelo de Leonhardt \& Mönnig (1978), que indica o comprimento de ancoragem definido pela Equação (4.56) é válida.

$$
l_{\text {anc }}=\frac{l_{\text {emb }}}{2}
$$

O comprimento adequado para ancoragem reta, na região de embutimento do pilar é muito pequeno, portanto deve-se recorrer a uma ancoragem por gancho ou por barra transversal soldada a armadura longitudinal do pilar. Nos ensaios, Ebeling (2006) verificou que o sistema de ancoragem através de barra transversal soldada apresentou um bom desempenho. 


\subsection{SITUAÇÃO DE MONTAGEM}

É importante uma análise do comportamento das paredes transversais na fase de montagem do cálice de fundação, pois, no posicionamento do pilar pré-moldado na cavidade da fundação e na fixação temporária para o prumo, são utilizadas cunhas de madeira, sendo gerados já na montagem forças transversais nas paredes. Na Figura 4.19, são ilustrados os elementos utilizados para montagem da ligação.

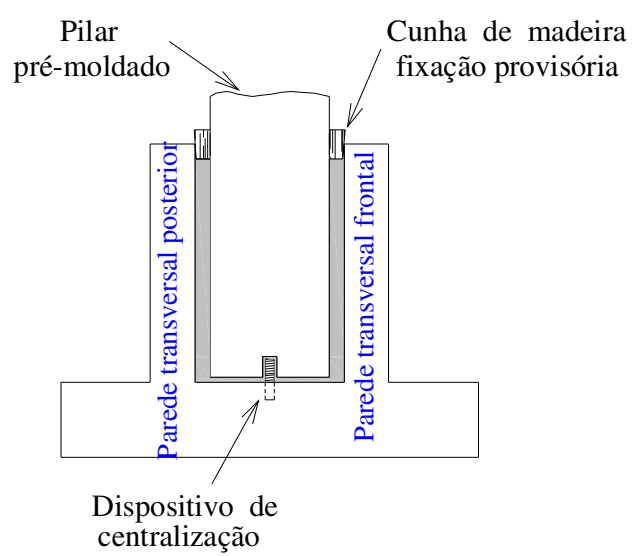

Figura 4.19 - Elementos utilizados na montagem da ligação cálice-fundação

Uma pesquisa experimental realizada na EESC-USP teve como objetivo avaliar o comportamento das paredes transversais na fase de montagem. O modelo ensaiado para análise foi o mesmo modelo ensaiado por Nunes (2009) e, portanto, a instrumentação na parede transversal frontal do modelo é a indicada na dissertação do autor.

No ensaio, foram posicionadas cunhas de madeira na parede transversal frontal do modelo com interface lisa, como ilustrado na Figura 4.20 e Figura 4.21. Foram realizadas duas análises: na primeira análise, cravou-se somente uma cunha, (Figura 4.20) e, na segunda, cravaram-se três cunhas (Figura 4.21), sendo utilizado somente um modelo para essas duas situações. No ensaio em que foram utilizadas três cunhas, primeiramente fixou-se a cunha central e depois simultaneamente fixaram-se as laterais.

Foi posicionada também na parede transversal posterior uma célula de carga, ilustrada na Figura 4.22, para medição da força atuante na parede durante o encunhamento.

Durante a realização dos ensaios, foi verificado que, com a utilização de somente uma cunha, para fixação temporária do pilar, não ocorreram forças significativas nas paredes transversais, pois não houve modificação nas medições da célula de carga. Isso provavelmente ocorreu porque a força aplicada não foi grande o suficiente. No entanto, 
quando foram utilizadas três cunhas, as forças de fixação das cunhas resultaram em deformações e fissuras nas duas paredes transversais. Na Figura 4.23, Figura 4.24 e Figura 4.25 são apresentadas os danos e fissuras resultantes nas paredes transversais após aplicação da força de encunhamento.

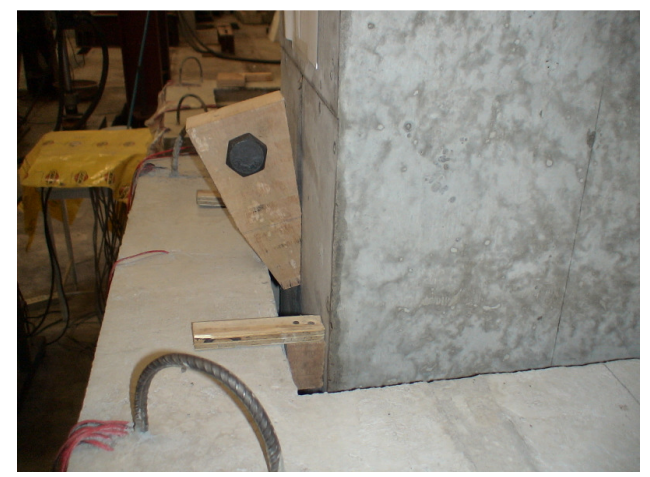

Figura 4.20 - Fixação temporária com utilização de uma cunha

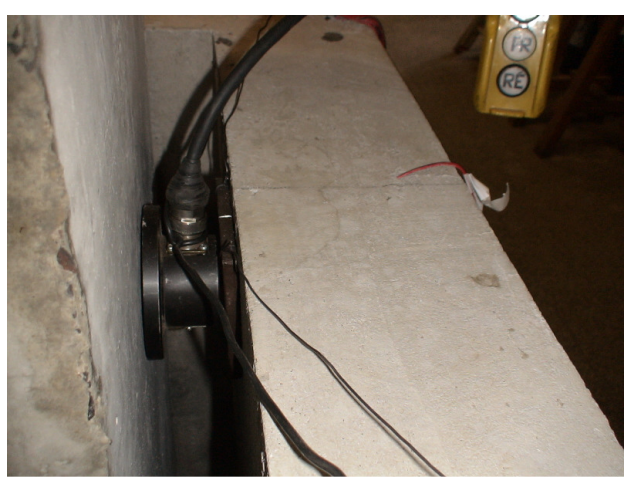

Figura 4.22 - Célula de carga localizada na parede transversal posterior

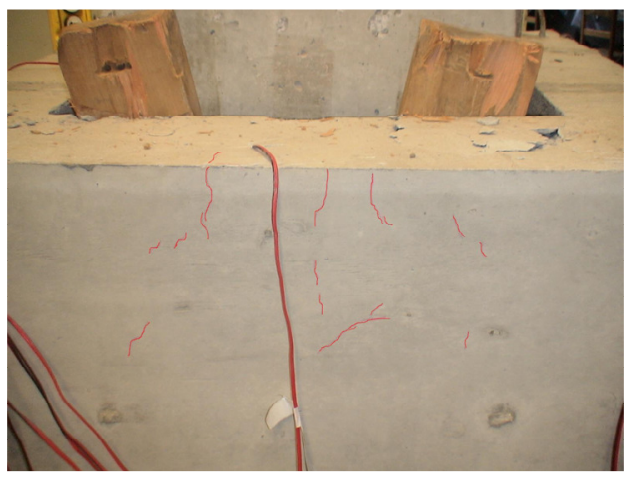

Figura 4.24 - Fissuras na parede transversal frontal

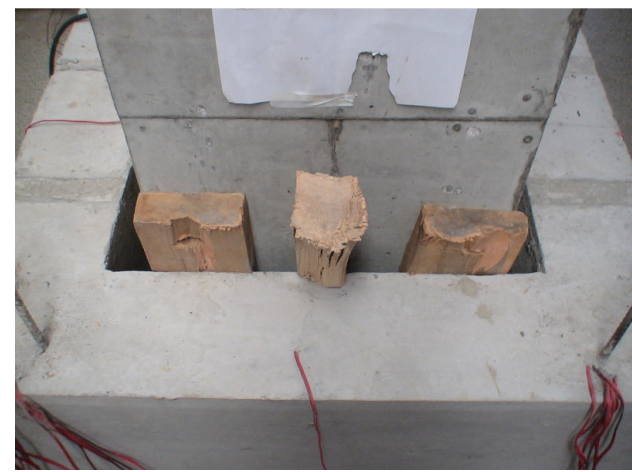

Figura 4.21 - Fixação temporária com utilização de três cunhas

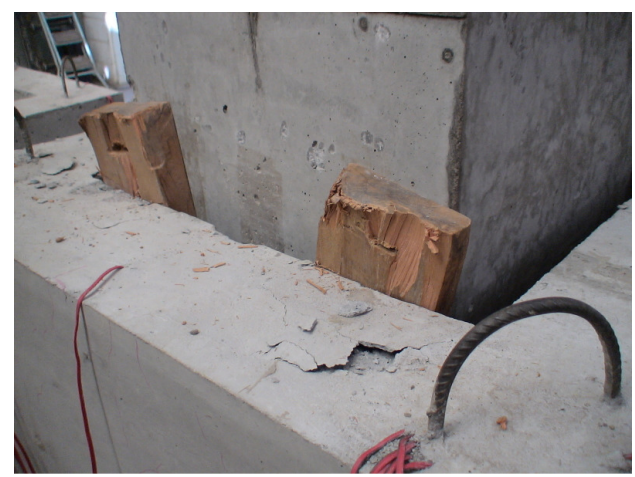

Figura 4.23 - Parede transversal frontal após encunhamento

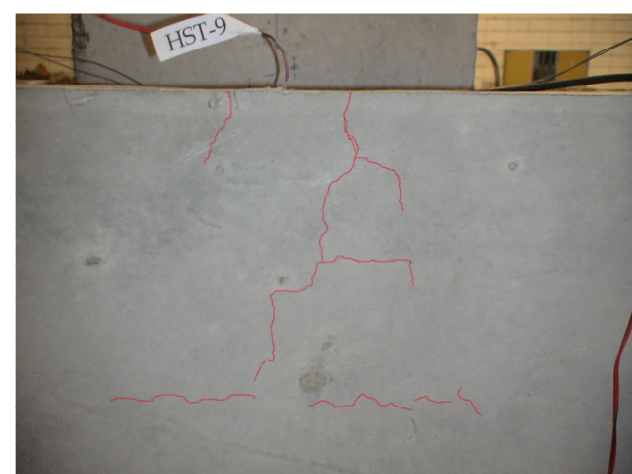

Figura 4.25 - Fissuras na parede transversal posterior

Com os valores das forças medidas pela célula de carga e das deformações medidas pelos extensômetros, foi elaborado o gráfico da Figura 4.26, que apresenta a curva força 
aplicada versus deformação nas armaduras horizontais principais transversais da parede transversal frontal do modelo.

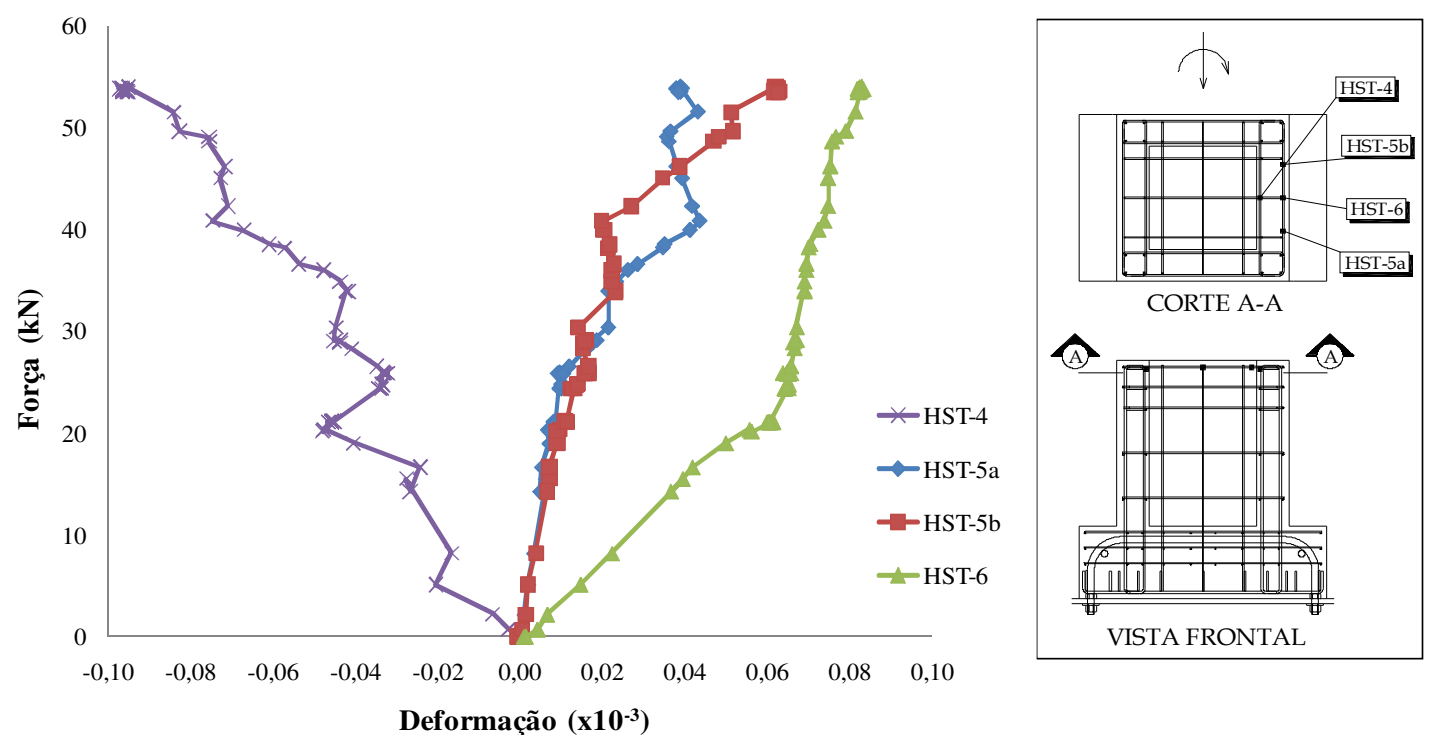

Figura 4.26 - Curva força aplicada versus deformação na armadura horizontal principal transversal situada na parede transversal frontal

Analisando a Figura 4.26, verifica-se que o extensômetro HST4 teve deformação negativa, indicando que a região interna da parede transversal frontal está comprimida. Para os três extensômetros externos (HST-5a, HST-5b e HST-6), foram observadas deformações positivas, indicando que a região externa da parede está tracionada. Esse fenômeno caracteriza uma situação de flexão da parede transversal na situação de montagem.

Nota-se também que as deformações das armaduras foram muito pequenas, não chegando a $0,1 \%$, que é um valor bem abaixo do limite de escoamento do aço CA-50.

Pelas deformações das armaduras, determinou-se a força máxima de compressão transmitida pela armadura interna e a força máxima de tração transmitida pela armadura externa que foi de $1 \mathrm{kN}$ e $0,88 \mathrm{kN}$, respectivamente.

Analisando as fissuras decorrentes da situação de montagem ilustradas na Figura 4.24 e Figura 4.25, verifica-se que essas têm aspecto semelhante às fissuras ocorridas no cálice com interface lisa para situação de ruptura, porém ocorrem em menor quantidade e com menores aberturas.

A formação de fissuras nas paredes transversais na fase de montagem também pode ser verificada comparando o momento atuante no topo da parede transversal devido à força de encunhamento com o momento de fissuração da parede. O momento atuante é determinado 
considerando a parede como uma viga biapoiada de base $l_{e m b} / 3$ e altura $h_{c}$ e com atuação de uma força concentrada no meio do vão ou com três forças concentradas ao longo do vão.

De acordo com os resultados experimentais, a parede transversal foi submetida aproximadamente a uma força máxima de $55 \mathrm{kN}$. Para o cálculo do momento máximo solicitante, será utilizado o sistema apresentado na Figura 4.27.

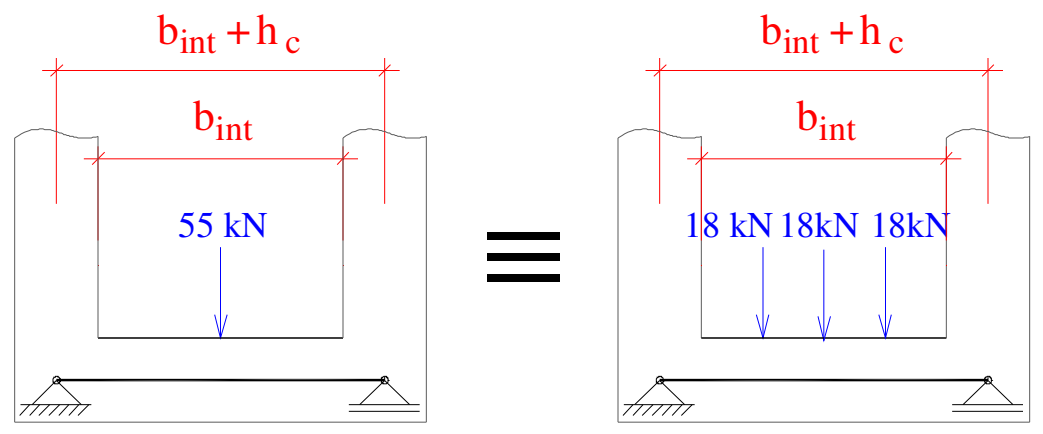

Figura 4.27 - Esquema estático equivalente para determinação do momento solicitante

Com a consideração de três forças concentradas de $18 \mathrm{kN}$ cada, resultantes da cravação das três cunhas de madeira dispostas em cada quarto do vão, o momento máximo solicitante é de 6,0 kN.m.

O momento de fissuração, referente ao instante no qual o concreto deixa de resistir à tração, é determinado pela Equação (4.57):

$$
M_{r}=\frac{1,5 \cdot f_{c t} \cdot I_{c}}{y_{t}}
$$

sendo que:

$$
\begin{aligned}
& y_{t}=h_{c} / 2 \\
& f_{c t}=f_{c t k, \mathrm{inf}}=0,21 \cdot f_{c h}^{2 / 3} \\
& I_{c}=\frac{\left(l_{e m b} / 3\right) \cdot h_{c}}{12}
\end{aligned}
$$

O momento de fissuração resulta, no caso do modelo ensaiado, igual a 4,82 kN.m. Como o momento atuante é de maior magnitude que o momento de fissuração, verifica-se que podem ocorrer fissuras nas paredes transversais.

A fixação temporária do pilar pode causar fissuração nas paredes do colarinho de cálices de fundação e, conseqüentemente, alterar a rigidez dessas paredes. Dependendo da intensidade das forças resultantes, é necessário considerar a fase de montagem no projeto da ligação. 
Os resultados experimentais indicam que na execução da ligação in loco, devem ser tomados os devidos cuidados na fixação temporária do pilar pré-moldado, como evitar uma força excessiva de cravação das cunhas que possa gerar, além de uma fissuração intensa nas paredes, danos como quebras das bordas das mesmas.

Devido à verificação da situação de montagem, recomenda-se que seja feito o cálculo da armadura horizontal externa das paredes transversais para essa fase, considerando a flexão das paredes devido à força de encunhamento. É necessário verificar se a armadura definitiva, proveniente da situação de pequena ou grande excentricidade da força normal, cobre a situação de montagem.

No capítulo 5, serão desenvolvidos exemplos de dimensionamento da parede do colarinho na fase de montagem.

\subsection{OUTRAS RECOMENDAÇÕES DE PROJETO}

\subsubsection{Pequena excentricidade}

Todas as recomendações apresentadas acima, para o projeto do cálice de fundação, se referem aos casos de grande excentricidade, em que a relação $M_{d} / N_{d} \geq 2 h$ é atendida.

Buscando atender as situações em que a relação momento fletor e força normal resultar menor que 0,15 (pequena excentricidade da força normal) é desenvolvido esse tópico.

Para os casos intermediários, ou seja, quando a relação entre momento fletor e força normal estiver no intervalo de $0,15 \leq M_{d} / N_{d} \geq 2 h$, uma análise deve ser feita. Caso a excentricidade resulte próximo dos limites, recomenda-se adotar as respectivas recomendações de pequena ou grande excentricidade. Entretanto, é favorável que os cálculos sejam feitos de maneira que resultem a favor da segurança.

Para cálices de interface lisa e situações de pequena excentricidade, a Equação (4.1) que determina a pressão superior atuante na parede frontal, deve ser analisada, pois as forças de atrito geradas na parede transversal posterior podem mudar de sentido devido ao carregamento e geometria do cálice e as forças de atrito na base podem ser desconsideradas, por não considerar o desenvolvimento pleno de força atrito nessa região.

Ainda, numa situação mais conservadora, desconsidera-se todas as forças de atrito nas paredes, e também a excentricidade da força normal na base do pilar, como indicado na 
Figura 4.28. Essa consideração leva a um modelo de comportamento semelhante ao proposto por Leonhardt \& Mönnig (1978).

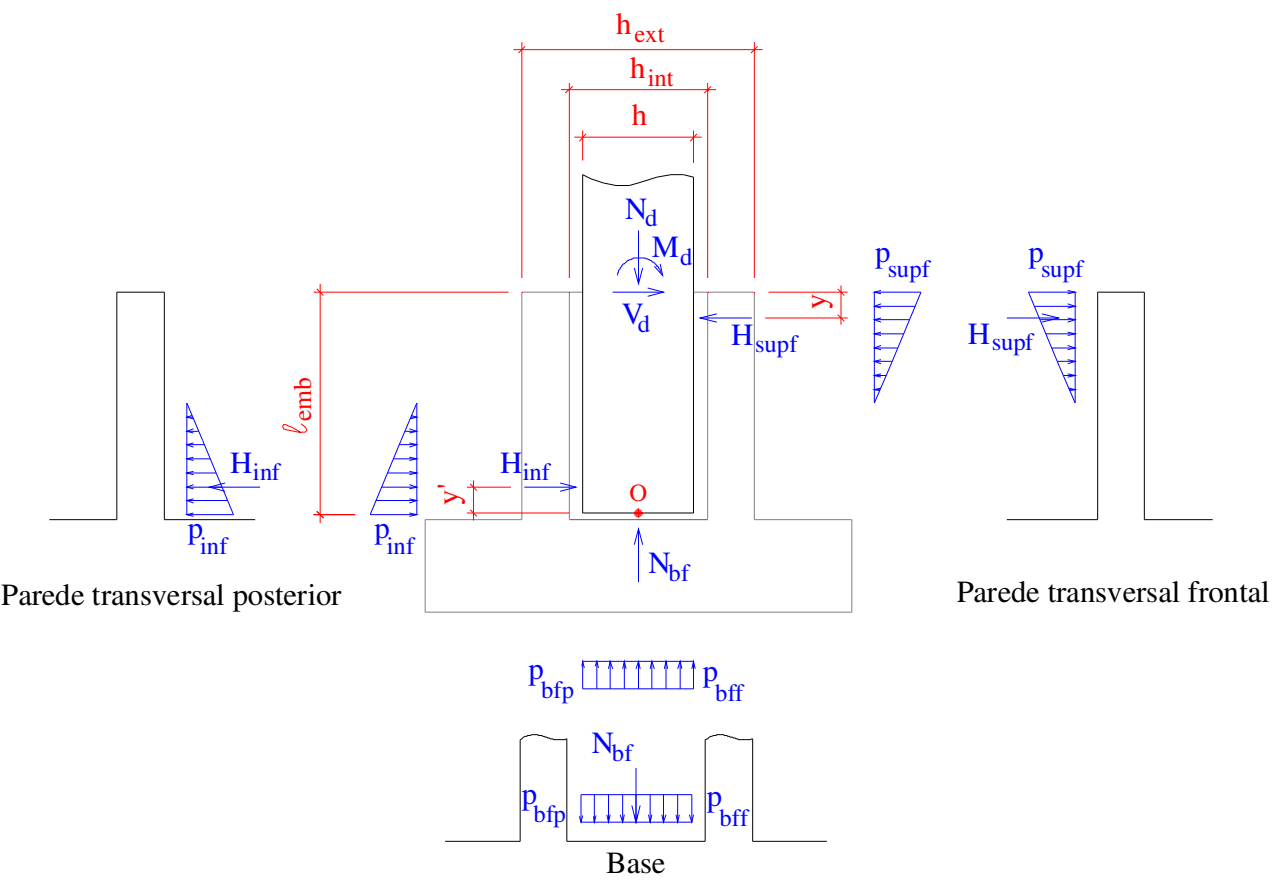

Figura 4.28 - Transferência de forças no cálice liso submetido a pequena excentricidade

Através das equações de equilíbrio, de forças horizontais, verticais e de momentos no ponto O, resultam as Equações (4.58), (4.59) e (4.60), respectivamente:

$$
\begin{aligned}
& V_{d}+H_{\mathrm{inf}}-H_{\mathrm{sup} f}=0 \\
& N_{d}-N_{b f}=0 \\
& M_{d}+V_{d} \cdot l_{e m b}-H_{\sup f} \cdot\left(l_{e m b}-y\right)+H_{\mathrm{inf}} \cdot y^{\prime}=0
\end{aligned}
$$

Fazendo os equacionamentos necessários, determina-se a Equação (4.61) para cálculo da pressão na parede frontal para casos de pequena excentricidade em cálice de interface lisa.

$$
H_{\text {sup } f}=\frac{M M_{d}+v_{d} \cdot\left(l_{e m b}-y\right)}{l_{e m b}-y-y^{\prime}}
$$

Outra opção, para determinação da resultante de pressão superior nos casos de pequena excentricidade, é considerar a excentricidade da reação da força normal na base. $\mathrm{O}$ cálculo da excentricidade $e_{n b}$ deve ser feito pela Equação (4.62):

$$
e_{n b}=\frac{h}{6}
$$


É recomendado o valor de $h / 6$ para pequena excentricidade, pois nessa situação o deslocamento da força normal é menor que nos casos de grande excentricidade. A determinação de $e_{n b}$ pela Equação (4.62) é recomendado também na referência de Olin et al. (1985).

Com a consideração da excentricidade, a determinação da pressão $H_{\sup f}$ se faz pela Equação (4.63):

$$
H_{\text {sup } f}=\frac{M_{d}-N_{d} \cdot e_{n b}+V_{d} \cdot\left(l_{e m b}-y^{\prime}\right)}{l_{e m b}-y-y}
$$

No Capítulo 5, aplicações práticas serão desenvolvidas considerando o modelo de comportamento de cálices com interface lisa, indicado na Figura 4.28, e outro considerando a excentricidade da força normal na base, sendo possível verificar a influência dessa modificação.

Para cálices de interface rugosa e pequena excentricidade de força normal o dimensionamento deve ser feito pela teoria da flexão assim como para os casos de grande excentricidade da força normal.

\subsubsection{Flexão oblíqua}

Outro tópico que deve ser analisado no cálice é o caso de flexão oblíqua (atuação simultânea de momentos fletores em duas direções ortogonais). Essa é uma realidade comum nos dimensionamentos de estruturas de concreto e para essa situação alguns cuidados devem ser tomados no projeto do cálice de fundação, tais como:

a) O dimensionamento das armaduras verticais deve ser feito isoladamente nas duas direções e posteriormente é necessário somar as armaduras resultantes de cada caso. Essa recomendação é indicada com o intuito de cobrir a situação de atuação simultânea dos momentos nas duas direções;

b) Deve-se adotar para as armaduras horizontais o maior valor entre as armaduras resultantes da atuação do momento em cada direção;

c) Reduzir a tensão última de contato de $0,6 \cdot f_{c d}$ para $0,5 \cdot f_{c d}$ na verificação do esmagamento da biela de compressão (EL DEBS (2000));

d) Na definição do comprimento de embutimento, deve-se adotar o maior valor de $l_{e m b}$ obtido da análise isolada em cada direção, estando assim a favor da segurança. 


\subsection{DISPOSIÇÕES CONSTRUTIVAS}

Para o projeto do cálice, algumas recomendações quanto às dimensões mínimas e controle de qualidade na execução dos elementos constituintes da ligação se faz necessária, sendo apresentadas nesse item essas indicações.

\subsubsection{Comprimento de embutimento}

Nos ensaios experimentais realizados, a maioria dos modelos de cálice de fundação foi construída com comprimentos de embutimento recomendados pela ABNT NBR 9062:2006, como indicado na Tabela 4.3. Os comprimentos de embutimento são determinados de acordo com a interface das paredes do colarinho e do pilar e de acordo com a excentricidade da força normal: pequena ou grande excentricidade. Para valores intermediários de excentricidade, pode-se interpolar linearmente a relação de momento fletor e força normal para definição. $\mathrm{O}$ valor mínimo recomendado pela Norma Brasileira é de $40 \mathrm{~cm}$.

Tabela 4.3 - Comprimentos de embutimento recomendados pela ABNT NBR 9062:2006

\begin{tabular}{c|c|c|c}
\hline \multicolumn{2}{c|}{ Interface lisa } & \multicolumn{2}{c}{ Interface Rugosa } \\
\hline$\frac{M_{d}}{N_{d} \cdot h} \leq 0,15$ & $\frac{M_{d}}{N_{d} \cdot h} \geq 2$ & $\frac{M_{d}}{N_{d} \cdot h} \leq 0,15$ & $\frac{M_{d}}{N_{d} \cdot h} \leq 2$ \\
\hline $1,50 h^{*}$ & $2,00 h^{*}$ & $1,20 h^{*}$ & $1,60 h^{*}$ \\
\hline
\end{tabular}

*h é a dimensão da seção transversal do pilar paralela ao plano de ação do momento

Com o objetivo de avaliar a possibilidade de redução desse comprimento, Jaguaribe Jr. (2005) ensaiou dois modelos com comprimentos de embutimento reduzidos. Após análise dos resultados experimentais, verificou-se que a resistência dos modelos diminuiu quando comparado aos modelos com comprimento de embutimento definidos pela norma. Portanto, para o projeto da ligação cálice-fundação, devem ser respeitados os comprimentos de embutimento definidos pela Norma Brasileira.

\subsubsection{Chaves de cisalhamento}

As chaves de cisalhamento são utilizadas em cálices de interface rugosa, com a função de melhorar a transmissão de tensões de cisalhamento na região de embutimento do pilar pré- 
moldado no cálice de fundação. Nos estudos, verificou-se que os modelos com interface rugosa, com a utilização de chaves de cisalhamento, apresentaram um comportamento semelhante ao de uma ligação monolítica.

As chaves de cisalhamento devem ser construídas respeitando limites impostos por normas, e as variáveis envolvidas estão ilustradas na Figura 4.29.

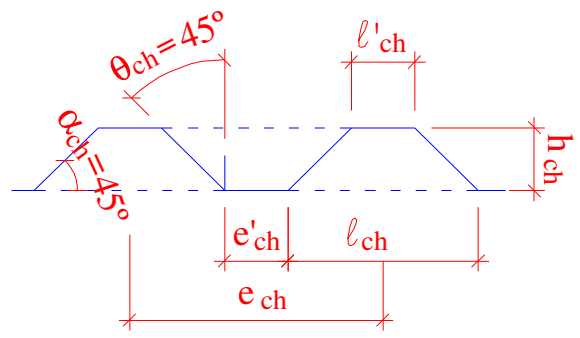

Figura 4.29 - Variáveis das chaves de cisalhamento (CANHA (2004))

Nessa figura as grandezas envolvidas são:

$e_{c h}$ : Espaçamento entre eixos das chaves de cisalhamento

$e_{c h}^{\prime}$ : Espaçamento interno entre chaves de cisalhamento

$h_{c h}:$ Altura da chave de cisalhamento

$l_{c h}:$ Base maior da chave de cisalhamento

$l_{c h}^{\prime}:$ Base menor da chave de cisalhamento

$\alpha_{c h}$ : Inclinação da face da chave de cisalhamento em relação à linha paralela ao eixo da junta $\lambda_{c h}:$ Relação entre a base maior e a altura da chave de cisalhamento

$\theta_{c h}:$ Inclinação da face da chave em relação à linha perpendicular ao eixo da junta.

É possível definir a relação geométrica da chave de cisalhamento através da Equação (4.64):

$\lambda_{c h}=l_{c h} / h_{c h}$

A ABNT NBR 9062:2006 recomenda uma rugosidade mínima de $h_{c h}=1 \mathrm{~cm}$ a cada $10 \mathrm{~cm}$ de junta, para que essa ligação apresente um comportamento monolítico. No entanto, não especifica a que distância esses $10 \mathrm{~cm}$ de junta se refere. Assim, será adotado que o comprimento de $10 \mathrm{~cm}$ seja igual à soma da base maior da chave $l_{c h}$ e o espaçamento interno entre as chaves $e_{c h}^{\prime}$ como ilustrado na Figura 4.30. 


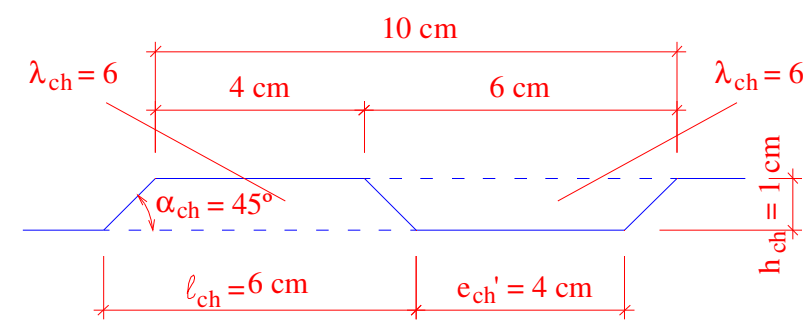

Figura 4.30 - Dimensões máximas para as chaves de cisalhamento de acordo com a rugosidade mínima da ABNT NBR 9062:2006 e avaliação teórica segundo Canha (2004)

Através da avaliação teórica de Canha (2004), espera-se que uma relação geométrica da chave $\lambda_{c h} \leq 6$, proporcione uma transferência de tensões adequada na interface pilarcolarinho. Adotando chaves com ângulo $\alpha_{c h}=45^{\circ}$, espaçamento interno de $e_{c h}^{\prime}=4 \mathrm{~cm}$ e uma relação máxima $\lambda_{c h}=6$, para considerar a simetria da chave de cisalhamento no lado inverso da interface, ocorre uma boa transferência de tensões de cisalhamento.

Para dimensões mínimas das chaves de cisalhamento é indicado que a base maior da chave seja igual a duas vezes o diâmetro máximo do agregado graúdo e que a altura seja no mínimo equivalente a metade desse agregado, como ilustra a Figura 4.31. Dessa maneira, ocorre a entrada do agregado graúdo na chave durante a concretagem.

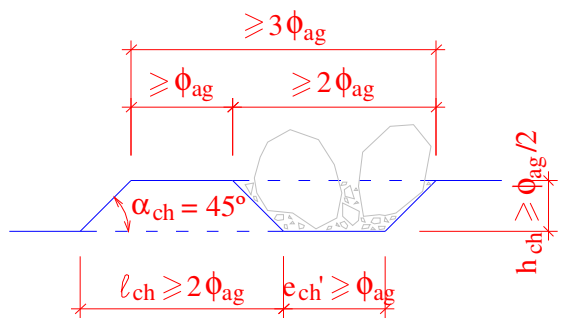

Figura 4.31 - Dimensões mínima para as chaves de cisalhamento em função do diâmetro do agregado (CANHA (2004))

Nos ensaios de Canha (2004), foram utilizadas duas configurações de chaves de cisalhamento, e após análise dos resultados, verificou-se que a resistência experimental resultante foi próxima nos dois modelos. Isso indica que, a modificação nas dimensões das chaves não influencia na resistência do cálice e sim, apenas na rigidez da ligação.

Na Figura 4.32, está ilustrada a configuração das chaves de cisalhamento no pilar e nas paredes do colarinho do modelo IR-1, ensaiado por Canha (2004), com as dimensões indicadas pela ABNT NBR 9062:2006. 

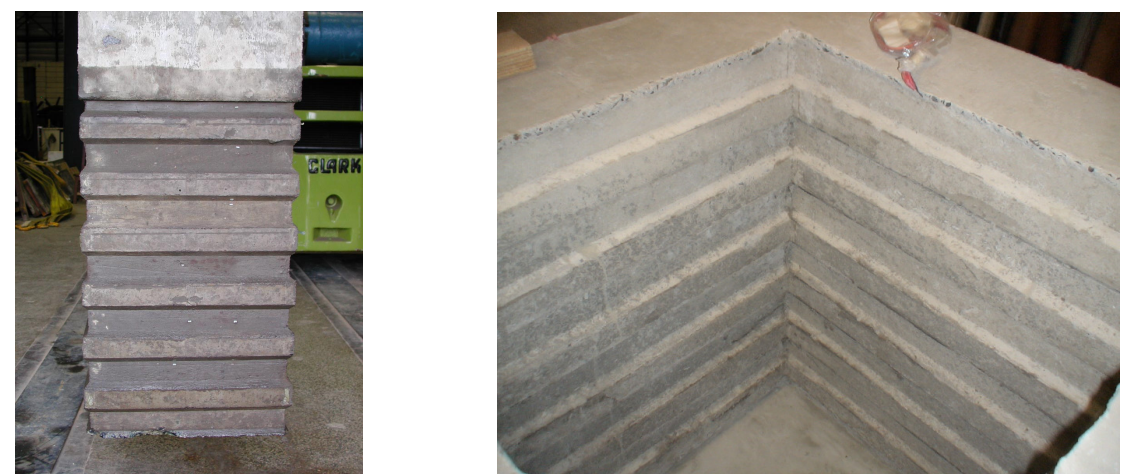

Figura 4.32 - Chaves de cisalhamento no pilar e colarinho de modelos ensaiados por Canha (2004)

\subsubsection{Espessura das paredes do colarinho}

A espessura das paredes do colarinho pode ser definida conforme o modelo de Leonhardt \& Mönnig (1978) pela Equação (4.65):

$$
h_{c} \geq \frac{1}{3} \cdot\left(h_{\mathrm{int}} \text { ou } b_{\mathrm{int}}\right)
$$

Este valor foi utilizado nos modelos ensaiados por Canha (2004) e Jaguaribe Jr. (2005) para determinação da espessura das paredes do colarinho. No estudo de Nunes (2009), foi adotada uma nova relação para a definição dessa espessura, a fim de avaliar o impacto da redução da espessura na resistência do cálice de fundação, sendo utilizada a Equação (4.66) para o cálculo da espessura da parede:

$$
h_{c} \geq \frac{1}{3,5} \cdot\left(h_{\mathrm{int}} \text { ou } b_{\mathrm{int}}\right)
$$

Comparando os valores da resistência experimental obtida dos modelos ensaiados por Nunes (2009) e Canha (2004), verifica-se que os modelos com menor espessura da parede, submetidos à mesma excentricidade, foram menos resistentes, no entanto as armaduras utilizadas também foram diferentes. Assim não é possível fazer uma comparação direta desses modelos.

Recomenda-se nesse trabalho a espessura mínima do colarinho, de acordo com a Equação (4.67). Devendo sempre verificar, se o resultado atende o valor mínimo indicado pela norma ABNT NBR 9062:2006, que é de $10 \mathrm{~cm}$, e também se o espaço resultante é adequado para o alojamento de todas as armaduras resultantes do dimensionamento, respeitando os valores de cobrimento indicado em norma.

$$
h_{c} \geq \frac{1}{4} \cdot\left(h_{\mathrm{int}} \text { ou } b_{\mathrm{int}}\right)
$$


No Capítulo 5, no item de análise da situação de montagem, será abordada, em uma das aplicações, a influência da modificação da espessura na determinação das áreas de aço.

\subsubsection{Recomendações gerais}

Para o projeto do cálice, apresentam-se as seguintes recomendações gerais:

a) Adotar para o graute ou concreto de preenchimento da junta, uma resistência igual ou superior a resistência do concreto do pilar ou das paredes do colarinho;

b) Proceder ao correto adensamento do concreto da junta com uso de vibrador de agulha;

c) A cavidade entre as paredes internas do colarinho e do pilar deve ter espaço suficiente para permitir a entrada do aparelho de vibração. O valor mínimo e usualmente empregado para a espessura da junta é de $5 \mathrm{~cm}$. Essa espessura é importante para acomodação de erros de locação de pilares e desvios da fundação;

d) No caso de graute auto adensável a espessura da junta pode ser reduzida;

e) O cobrimento das armaduras do cálice deve seguir os valores indicados na Tabela 7.2 da ABNT NBR 6118:2003, podendo, no entanto, reduzir esse valor para as armaduras localizadas na face interna das paredes do cálice;

f) As dimensões da base da fundação são definidas conforme o tipo de fundação adotada para cada projeto. No caso de utilização de sapata, recomenda-se a espessura mínima de $20 \mathrm{~cm}$;

g) As superfícies internas do cálice devem ter a mesma característica superficial que a superfície dos pilares na região de embutimento.

\subsection{DETALHAMENTO DAS ARMADURAS}

Um item de detalhamento das armaduras do cálice é necessário e importante, pois indica qual a melhor maneira de proceder à armação dos elementos constituintes do cálice de fundação. A configuração das armaduras influencia na eficácia da ancoragem e também na facilidade de montagem.

\subsubsection{Armaduras horizontais}

Nos estudos desenvolvidos, duas configurações para a armadura horizontal do cálice foram empregadas e analisadas. Canha (2004) seguiu o formato normalmente utilizado, e 
recomendado por Leonhardt \& Mönnig (1978), modificando somente a região de traspasse dos estribos com a finalidade de se instrumentar nos pontos centrais dessas armaduras. $\mathrm{Na}$ Figura 4.33 é apresentado o detalhamento da armadura utilizada nos ensaios de Canha (2004).

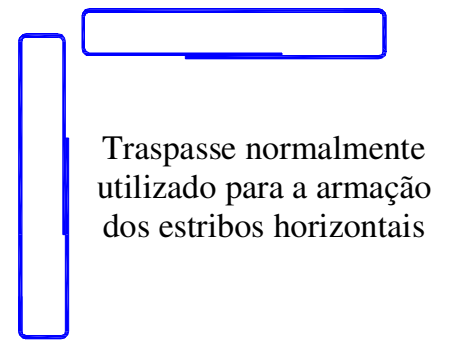

Detalhamento adotado para os estribos horizontais dos modelos ensaiados por CANHA (2004)

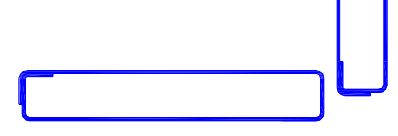

Figura 4.33 - Detalhamento da armadura horizontal utilizada nos modelos de Canha (2004)

Percebeu-se certa dificuldade no posicionamento da armadura horizontal, em forma de estribos, nos ensaios de Canha (2004) durante a montagem do cálice. Assim visando à facilidade de montagem dessas armaduras, outra configuração foi utilizada nos ensaios de Jaguaribe Jr. (2005) e Nunes (2009). O esquema utilizado por esses autores está ilustrado na Figura 4.34, e é composto de um quadro de armadura fechado disposto ao longo do perímetro externo das paredes do colarinho e de mais quatro elementos de armadura em forma de $\mathrm{U}$ dispostos na parte interna das quatro paredes do cálice.

A armadura em forma de $\mathrm{U}$ atua como o ramo interno e a armadura em quadro atua como o ramo externo da armadura horizontal do cálice.

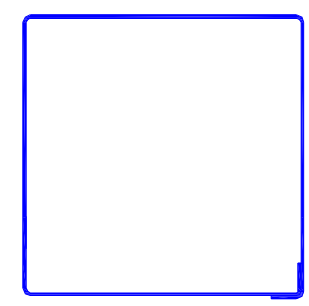

Ramo externo da armadura horizontal

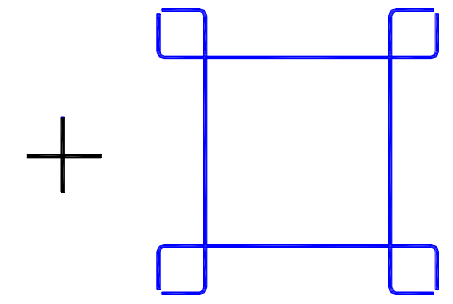

Ramo interno da armadura horizontal

Figura 4.34 - Detalhamento da armadura horizontal utilizada nos modelos de Jaguaribe Jr. (2005) e Nunes (2009)

Recomenda-se a utilização da configuração ilustrada na Figura 4.34, pois essa disposição possibilita a utilização de diferentes áreas de aço para o ramo interno e ramo externo da armadura horizontal principal. Por exemplo, no caso da consideração do esforço de flexo-tração das paredes transversais do cálice, as áreas resultantes de aço para o ramo interno é diferente da área de aço para o ramo externo. 
Além dessa vantagem, foi observado nos ensaios realizados maior facilidade no posicionamento dessas amadura nas paredes do cálice, apresentando, portanto, essa configuração, melhor facilidade de montagem.

\subsubsection{Armaduras verticais}

Para a armadura vertical do cálice de fundação, o detalhamento recomendado está representado na Figura 4.35. Com essas configurações assegura-se uma boa ancoragem da armadura vertical no elemento de fundação, transferindo todas as tensões da armadura para o concreto. E no caso da alternativa 3, a armadura horizontal localizada abaixo da junta do pilar contribui no controle da fissuração nessa região da fundação.

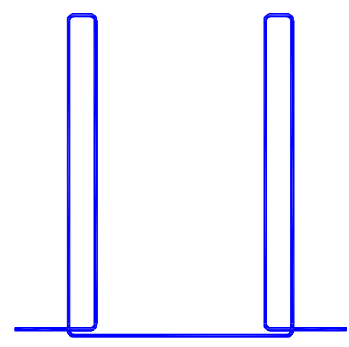

Alternativa 1

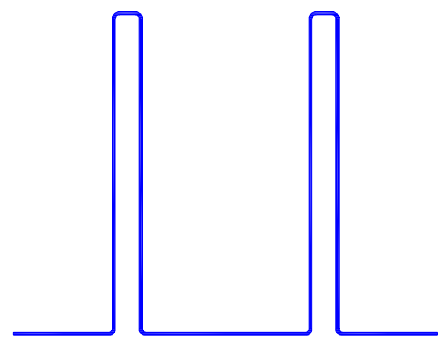

Alternativa 2

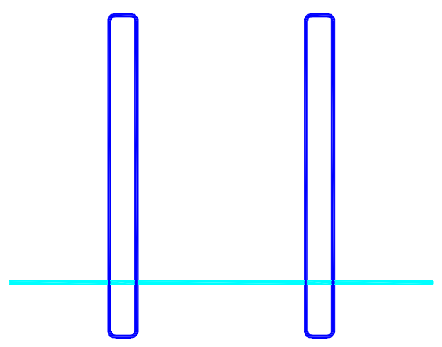

Alternativa 3

Figura 4.35 - Detalhamento da armadura vertical

Quanto à disposição da armadura vertical nas paredes do colarinho dos cálices, foi observado nos ensaios dos modelos com interface lisa da pesquisa de Nunes (2009), que além das armaduras verticais principais, as armaduras verticais secundárias situadas nas proximidades da intersecção das paredes, contribuíram para a resistência da ligação. Assim é possível posicionar as armaduras verticais nas proximidades da intersecção das paredes, pois essas contribuem na resistência. Na Figura 4.36, está representado o posicionamento dessas armaduras.

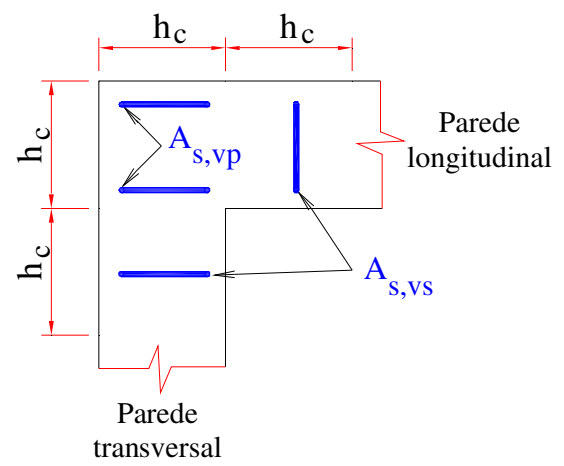

Figura 4.36 - Detalhe da distribuição das armaduras verticais principais e secundárias no cálice 


\section{AVALIAÇÃO E APLICAÇÃO DAS RECOMENDAÇÕES}

Devido a divergências de algumas recomendações para o projeto de cálices de fundação, apresentadas no Capítulo 4, e também para efeito de comparação de alguns parâmetros, será analisada e verificada a influência da modificação desses no dimensionamento do cálice. Essas verificações possibilitarão elaborar um roteiro completo e prático de projeto da ligação cálice de fundação e da base do pilar pré-moldado.

Serão avaliados casos de variações das seções de pilares pré-moldados e tipo de interface, distância de aplicação da pressão superior no cálice liso, pressões atuantes nas paredes transversais do cálice rugoso, comportamento das paredes transversais do colarinho, situação de montagem da ligação, grande e pequena excentricidades ou somente existência de força normal e análise da base do pilar pré-moldado. E ainda apresenta um item com detalhamento da armadura do cálice.

\subsection{VARIAÇÃO DAS SEÇÕES DOS PILARES}

As seções dos pilares estudadas foram determinadas a partir de constatações práticas, de estruturas de concreto pré-moldado, usualmente utilizadas. Optou-se por avaliar duas seções retangulares e duas quadradas. A primeira seção analisada foi de um pilar de 40x40 $\mathrm{cm}^{2}$. Essas dimensões foram escolhidas por se acreditar ser uma das menores seções utilizadas em estruturas de concreto pré-moldado. Adotou-se um valor de força normal e o momento fletor foi calculado pela Equação (5.1) para resultar em uma situação de grande excentricidade.

$$
\frac{M_{d}}{N_{d} \cdot h} \geq 2
$$

A partir do carregamento dessa seção, foram calculados os coeficientes $v$ e $\mu^{\prime}$, conforme as Equações (5.2) e (5.3), respectivamente. Fixando-se esses dois coeficientes, os 
esforços solicitantes de força normal e momento fletor das outras seções puderam ser determinados.

$$
\begin{aligned}
& \nu=\frac{N_{d}}{A_{c} \cdot f_{c d}} \\
& \mu^{\prime}=\frac{M_{d}}{A_{c} \cdot h \cdot f_{c d}}
\end{aligned}
$$

A força cortante foi determinada através de uma relação linear com o momento fletor, considerando atuação de força concentrada. As seções e os respectivos carregamentos estão apresentados na Tabela 5.1. Para os quatro casos, serão abordadas as configurações de cálice com interface lisa e rugosa.

Tabela 5.1 - Dimensões das seções pilares e ações

\begin{tabular}{c|c|c|c}
\hline \multirow{2}{*}{\begin{tabular}{c} 
Seção do pilar $\begin{array}{c}\mid 3 \\
\text { bxh } \\
\left(\mathrm{cm}^{2}\right)\end{array}$ \\
\cline { 2 - 4 }
\end{tabular}} & $\begin{array}{c}\text { Força Normal } \\
\mathrm{N}_{\mathrm{d}}(\mathrm{kN})\end{array}$ & $\begin{array}{c}\text { Força cortante } \\
\mathrm{V}_{\mathrm{d}}(\mathrm{kN})\end{array}$ & $\begin{array}{c}\text { Momento fletor } \\
\mathrm{M}_{\mathrm{d}}(\mathrm{kN} . \mathrm{m})\end{array}$ \\
\hline $40 \times 40$ & 250 & 50 & 200 \\
\hline $40 \times 60$ & 375 & 112,5 & 450 \\
\hline $60 \times 40$ & 375 & 75 & 300 \\
\hline $60 \times 60$ & 560 & 168,75 & 675 \\
\hline
\end{tabular}

O dimensionamento do cálice seguiu um padrão na definição de algumas variáveis de disposições construtivas, sendo:

a) Junta de $5 \mathrm{~cm}$ e comprimento de embutimento para grande excentricidade definido conforme ABNT NBR 9062:2006

- interface lisa: $l_{e m b}=2,0 \cdot h$ e interface rugosa: $l_{e m b}=1,6 \cdot h$

b) Coeficiente de atrito para cálice liso $\mu=0,3$;

c) Espessura da parede do colarinho: $h_{c} \geq 1 / 3,5 \cdot\left(h_{\text {int }}\right.$ ou $\left.b_{\text {int }}\right)$, que é um valor intermediário entre o mínimo recomendado (por esse trabalho) e o valor indicado por Leonhardt \& Mönnig (1978);

d) Aço CA-50 $f_{y k}=500 \mathrm{MPa}$ e $f_{y d}=435 \mathrm{MPa}$;

e) Resistência característica à compressão do concreto do cálice $f_{c k}=20 M P a$ e $\gamma_{c}=1,4$ 


\subsubsection{Cálice com interface lisa}

$\mathrm{Na}$ Tabela 5.2, estão apresentadas as características geométricas, as armaduras resultantes e a verificação da ruptura do concreto da biela nas paredes longitudinais para cada seção analisada.

A efeito de exemplificação, um roteiro completo de cálculo é apresentado no Apêndice A, com o dimensionamento de um cálice de fundação de interface lisa, determinado a partir da seção do pilar pré-moldado de $40 \times 40 \mathrm{~cm}^{2}$. O memorial do dimensionamento, desse exemplo e de todos os demais desse trabalho, foi feito com o programa Mathcad versão 14 .

Tabela 5.2 - Resultados para cálice com interface lisa

\begin{tabular}{|c|c|c|c|c|}
\hline \multirow{2}{*}{ Variáveis } & \multicolumn{4}{|c|}{ Medidas dos lados do pilar $\left(\mathrm{cm}^{2}\right)$} \\
\hline & $40 \times 40$ & $40 \times 60$ & $60 \times 40$ & $60 \times 60$ \\
\hline $\mathrm{b}_{\mathrm{int}}(\mathrm{cm})$ & 50 & 50 & 70 & 70 \\
\hline $\mathrm{h}_{\mathrm{int}}(\mathrm{cm})$ & 50 & 70 & 50 & 70 \\
\hline $\mathrm{h}_{\mathrm{c}}(\mathrm{cm})$ & 15 & 20 & 20 & 20 \\
\hline $\mathrm{b}_{\mathrm{ext}}(\mathrm{cm})$ & 80 & 90 & 110 & 110 \\
\hline $\mathrm{h}_{\mathrm{ext}}(\mathrm{cm})$ & 80 & 110 & 90 & 110 \\
\hline $1_{\mathrm{emb}}(\mathrm{cm})$ & 80 & 120 & 80 & 120 \\
\hline $1_{\mathrm{c}}(\mathrm{cm})$ & 79 & 119 & 79 & 119 \\
\hline $\mathrm{e}_{\mathrm{nb}}(\mathrm{cm})$ & 10 & 15 & 10 & 15 \\
\hline $\mathrm{y}(\mathrm{cm})$ & 8 & 12 & 8 & 12 \\
\hline $\mathrm{y}^{\prime}(\mathrm{cm})$ & 8 & 12 & 8 & 12 \\
\hline $\mathrm{H}_{\text {supf }}(\mathrm{kN})$ & 284,40 & 466,53 & 426,61 & 700,12 \\
\hline $\mathrm{H}_{\mathrm{inf}}(\mathrm{kN})$ & 234,40 & 354,03 & 351,61 & 531,37 \\
\hline $\mathrm{A}_{\mathrm{s}, \mathrm{hpl}}\left(\mathrm{cm}^{2}\right)$ & 3,28 & 5,38 & 4,92 & 8,06 \\
\hline $\mathrm{A}_{\mathrm{s}, \mathrm{hpt}}{ }^{*}\left(\mathrm{~cm}^{2}\right)$ & 3,28 & 5,38 & 4,92 & 8,02 \\
\hline $\mathrm{A}_{\mathrm{s}, \mathrm{hpt}}{ }^{* *}\left(\mathrm{~cm}^{2}\right)$ & 2,78 & 4,56 & 4,17 & 6,84 \\
\hline$A_{s, v p}\left(\mathrm{~cm}^{2}\right)$ & 3,84 & 6,88 & 5,24 & 10,32 \\
\hline$A_{s, v s}\left(\mathrm{~cm}^{2}\right)$ & 1,54 & 2,75 & 2,10 & 4,13 \\
\hline$A_{s, h s}\left(\mathrm{~cm}^{2}\right)$ & 0,96 & 1,72 & 1,31 & 2,58 \\
\hline $\begin{array}{c}\text { Ruptura } \\
\text { concreto biela }\end{array}$ & Verifica & Verifica & Verifica & Verifica \\
\hline
\end{tabular}

Considerando tração da parede transversal frontal

** Considerando flexo-tração da parede transversal 


\subsubsection{Cálice com interface rugosa}

Os cálculos para cálice rugoso seguiram o método proposto por Canha et al. (2009c) e as características geométricas e as armaduras resultantes para cada seção analisada estão apresentadas Tabela 5.3.

A efeito de exemplificação, um roteiro completo de cálculo é apresentado no Apêndice B, com o dimensionamento de um cálice de fundação com interface rugosa, determinado a partir da seção do pilar pré-moldado de 40x40 $\mathrm{cm}^{2}$.

Tabela 5.3 - Resultados cálice com interface rugosa

\begin{tabular}{|c|c|c|c|c|}
\hline \multirow{2}{*}{ Variáveis } & \multicolumn{4}{|c|}{ Medidas dos lados do pilar $\left(\mathrm{cm}^{2}\right)$} \\
\hline & $40 \times 40$ & $40 \times 60$ & $60 \times 40$ & $60 \times 60$ \\
\hline $\mathrm{b}_{\text {int }}(\mathrm{cm})$ & 50 & 50 & 70 & 70 \\
\hline $\mathrm{h}_{\text {int }}(\mathrm{cm})$ & 50 & 70 & 50 & 70 \\
\hline $\mathrm{h}_{\mathrm{c}}(\mathrm{cm})$ & 15 & 20 & 20 & 20 \\
\hline $\mathrm{b}_{\mathrm{ext}}(\mathrm{cm})$ & 80 & 90 & 110 & 110 \\
\hline $\mathrm{h}_{\mathrm{ext}}(\mathrm{cm})$ & 80 & 110 & 90 & 110 \\
\hline $1_{\mathrm{emb}}(\mathrm{cm})$ & 64 & 96 & 64 & 96 \\
\hline $1_{c}(\mathrm{~cm})$ & 63 & 95 & 63 & 95 \\
\hline$\beta_{\mathrm{f}}$ & $60^{\circ}$ & $60^{\circ}$ & $60^{\circ}$ & $60^{\circ}$ \\
\hline $\mathrm{H}_{\mathrm{f}}(\mathrm{kN})$ & 279,10 & 470,92 & 379,55 & 705,65 \\
\hline $\mathrm{H}_{\text {supf }}(\mathrm{kN})$ & 167,43 & 282,55 & 227,73 & 423,39 \\
\hline$\beta_{\mathrm{p}}$ & $35^{\circ}$ & $35^{\circ}$ & $35^{\circ}$ & $35^{\circ}$ \\
\hline $\mathrm{H}_{\mathrm{p}}(\mathrm{kN})$ & 333,34 & 629,32 & 403,32 & 945,75 \\
\hline $\mathrm{H}_{\text {supp }}(\mathrm{kN})$ & 333,34 & 629,32 & 403,32 & 945,75 \\
\hline $\mathrm{A}_{\mathrm{s}, \mathrm{hpl}}\left(\mathrm{cm}^{2}\right)$ & 3,84 & 7,24 & 4,64 & 10,88 \\
\hline $\mathrm{A}_{\mathrm{s}, \mathrm{hpt}}{ }^{*}\left(\mathrm{~cm}^{2}\right)$ & 3,84 & 7,24 & 4,64 & 10,88 \\
\hline $\mathrm{A}_{\mathrm{s}, \mathrm{hpt}}{ }^{* *}\left(\mathrm{~cm}^{2}\right)$ & 3,26 & 6,15 & 3,94 & 9,24 \\
\hline $\mathrm{A}_{\mathrm{s}, \mathrm{vp}}\left(\mathrm{cm}^{2}\right)$ & 1,92 & 3,64 & 2,40 & 5,59 \\
\hline $\mathrm{A}_{\mathrm{s}, \mathrm{vs}}\left(\mathrm{cm}^{2}\right)$ & 0,77 & 1,46 & 0,96 & 2,24 \\
\hline $\mathrm{A}_{\mathrm{s}, \mathrm{hs}}\left(\mathrm{cm}^{2}\right)$ & 0,48 & 0,91 & 0,60 & 1,40 \\
\hline
\end{tabular}

Considerando tração das paredes transversais

** Considerando flexo-tração das paredes transversais 


\subsubsection{Comparação de resultados}

Na Figura 5.1, é apresentada uma comparação entre os resultados das áreas de armaduras provenientes da consideração de cálice com interface lisa ou rugosa, submetidos ao mesmo carregamento, e com seção do pilar pré-moldado 40x40 cm².

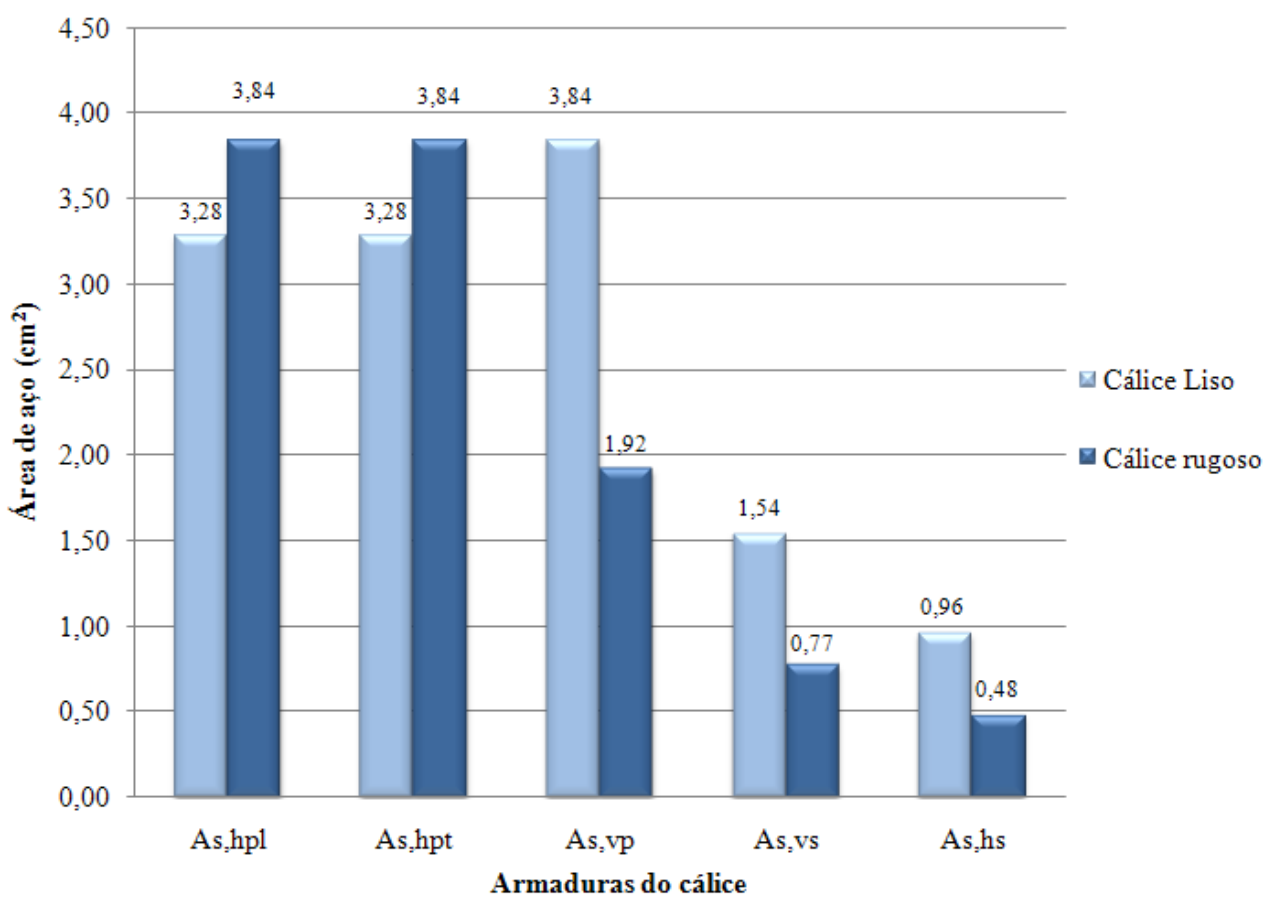

Figura 5.1 - Comparação resultados de áreas de aço entre cálice liso e rugoso

Analisando os valores de área de aço, verifica-se que com a opção de cálice com interface rugosa três armaduras resultaram menores e duas maiores quando comparados com o cálice de interface lisa. As armaduras horizontais principais foram aproximadamente 17\% maiores para o cálice rugoso, pois nessa situação o comprimento de embutimento é menor. Já as armaduras vertical principal, vertical secundária e horizontal secundária corresponderam à metade das respectivas armaduras na situação de cálice com interface lisa.

No cálice com interface rugosa, além da redução das áreas de armadura verticais (provenientes do dimensionamento pela teoria da flexão), há um menor consumo de concreto, pois o comprimento de embutimento do cálice para essa situação é menor quando comparado ao cálice de interface lisa. No entanto, muitas vezes opta-se moldar a ligação com interface lisa pela facilidade construtiva dessa opção. O tempo de execução do cálice rugoso é maior, quando comparado com o liso, visto que as formas do cálice de interface rugosa são mais detalhadas devido a chaves de cisalhamento, como ilustra a Figura 5.2. Dessa maneira, cada 
projetista deve fazer uma análise e decidir qual é a melhor interface a ser adotada para a estrutura que está sendo projetada.
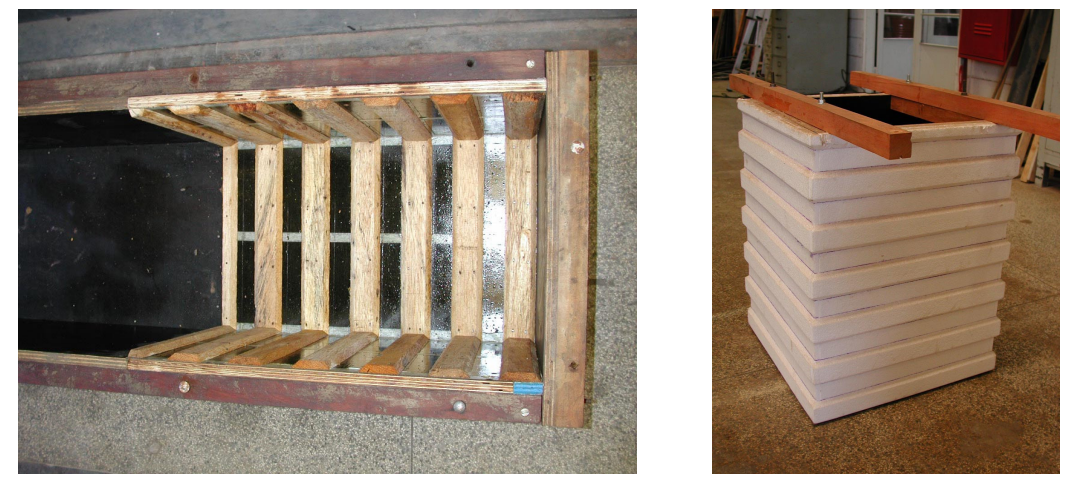

Figura 5.2 - Formas para moldagem do pilar e do cálice com interface rugosa

Nas Figura 5.3 e Figura 5.4, são apresentados gráficos com comparações ilustrativas das áreas de aço resultantes da variação das seções dos pilares pré-moldados e respectivos carregamentos, considerando cálice de interface lisa e rugosa.

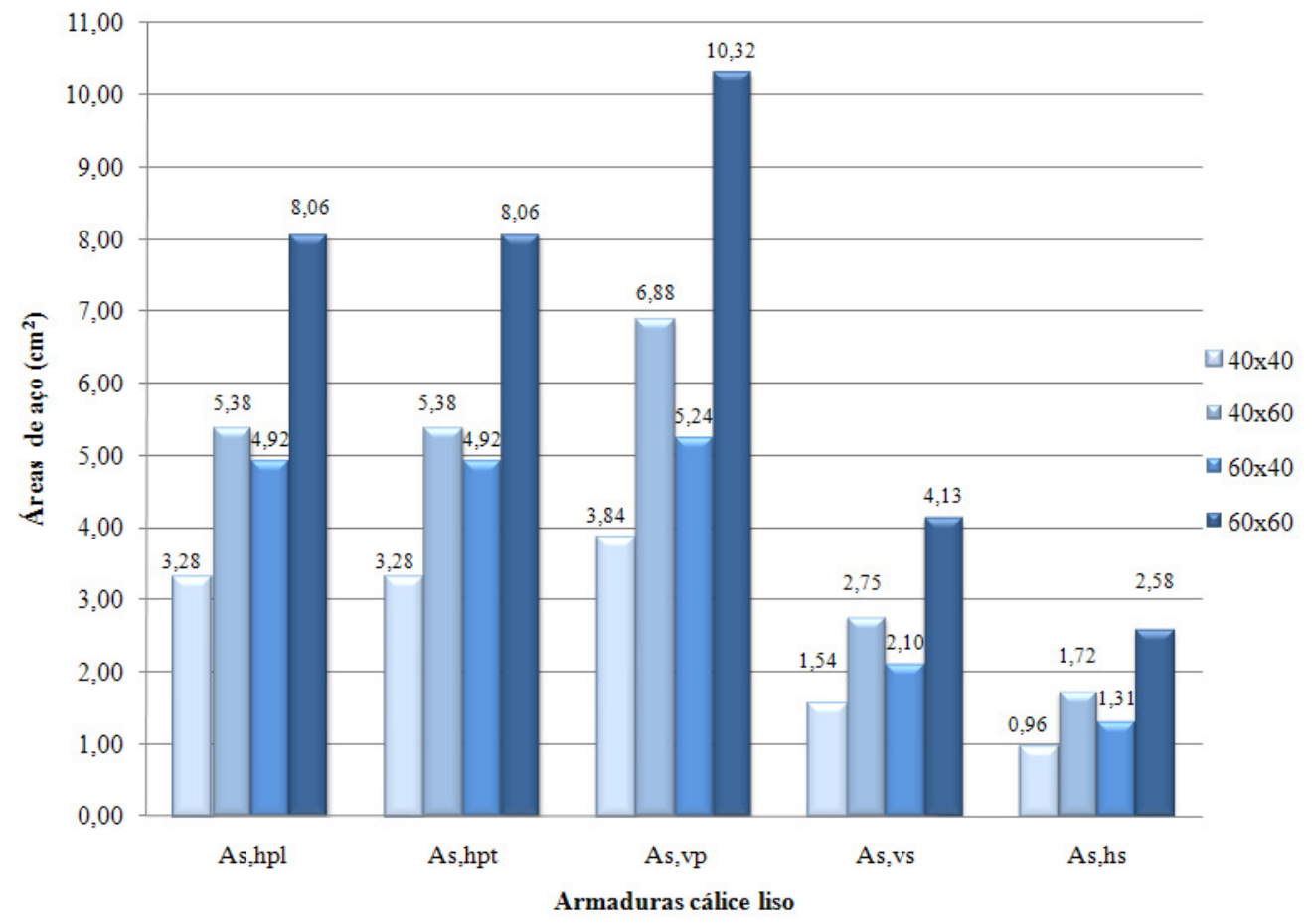

Figura 5.3 - Gráfico comparativo de armaduras de cálice com interface lisa 


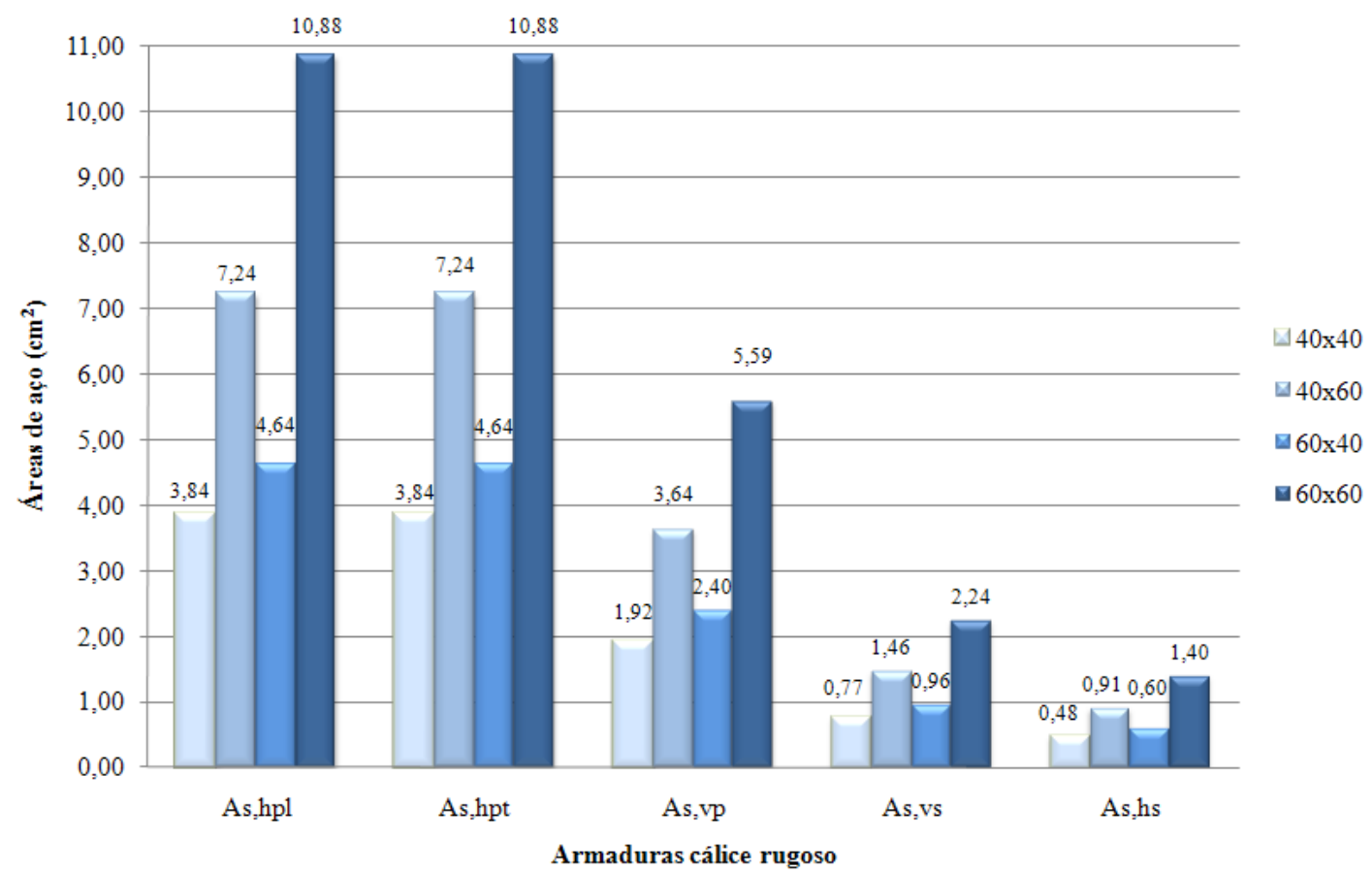

Figura 5.4 - Gráfico comparativo de armaduras de cálice com interface rugosa

Analisando as seções retangulares $40 \times 60 \mathrm{~cm}^{2}$ e $60 \times 40 \mathrm{~cm}^{2}$, verifica-se que as áreas resultantes para a seção $60 \times 40 \mathrm{~cm}^{2}$ foram um pouco menores. Isso se deve ao carregamento e também as resultantes de pressão dessa seção serem menores e também por sua configuração geométrica.

O comprimento de embutimento para a seção $60 \times 40 \mathrm{~cm}^{2}$ com interface lisa é $80 \mathrm{~cm}$, pois a atuação do momento se dá na direção de $40 \mathrm{~cm}$. Enquanto que o comprimento de embutimento da seção 40x60 $\mathrm{cm}^{2}$ é de $120 \mathrm{~cm}$. Essa diferença do comprimento de embutimento interfere na determinação do ângulo de inclinação das bielas das paredes longitudinais do cálice com interface lisa. Na seção $60 \times 40 \mathrm{~cm}^{2}$, a inclinação da biela das paredes longitudinais é de $46,87^{\circ}$, enquanto que a biela da seção $40 \times 60 \mathrm{~cm}^{2}$ tem ângulo de $52,03^{\circ}$. Por esse motivo, a diferença de áreas entre as seções retangulares foi maior para as armaduras vertical principal e secundária e horizontal secundária, pois essas são determinadas a partir do ângulo de inclinação da biela de compressão.

No entanto, tanto para o cálice liso quanto para o cálice rugoso, percebe-se que as diferenças relativas entre as áreas de armaduras das seções analisadas são iguais.

Concluindo, verifica-se que as áreas de aço aumentam conforme o acréscimo de área da seção transversal, o que é consequência do aumento do carregamento. 


\subsection{DISTÂNCIA DE APLICAÇÃO DA PRESSÃO $\mathrm{H}_{\text {supf }}$}

Nesse item é avaliada a influência da modificação do parâmetro $y$, que é o ponto de aplicação da pressão superior $H_{\sup f}$ na parede frontal, para o dimensionamento de um cálice de fundação com interface lisa. A avaliação será feita considerando a seção transversal do pilar 40x40 $\mathrm{cm}^{2}$ e o carregamento correspondente para essa seção. Os valores de $y$ avaliados serão de $y=l_{e m b} / 6$, admitindo uma distribuição triangular de pressões em uma altura de $l_{\text {emb }} / 2$ e $y=l_{\text {emb }} / 10$, considerando um bloco retangular de pressões concentrado no topo do colarinho com altura de $l_{\text {emb }} / 5$.

Na Tabela 5.4 são apresentados os resultados provenientes dessa variação.

Tabela 5.4 - Influência da modificação da distância de aplicação da pressão $\mathrm{H}_{\text {supf }}$

\begin{tabular}{c|c|c}
\hline \multirow{2}{*}{ Variáveis } & \multicolumn{2}{|c}{ Distância de aplicação } \\
\cline { 2 - 3 } & $\mathrm{y}=\mathrm{l}_{\mathrm{emb}} / 6$ & $\mathrm{y}=\mathrm{l}_{\mathrm{emb}} / 10$ \\
\hline $\mathrm{H}_{\text {supf }}(\mathrm{kN})$ & 305,87 & 284,40 \\
\hline $\mathrm{A}_{\mathrm{s}, \mathrm{hpl}}\left(\mathrm{cm}^{2}\right)$ & 3,52 & 3,28 \\
\hline $\mathrm{A}_{\mathrm{s}, \mathrm{hpt}}\left(\mathrm{cm}^{2}\right)$ & 3,52 & 3,28 \\
\hline $\mathrm{A}_{\mathrm{s}, \mathrm{vp}}\left(\mathrm{cm}^{2}\right)$ & 3,82 & 3,84 \\
\hline $\mathrm{A}_{\mathrm{s}, \mathrm{is}}\left(\mathrm{cm}^{2}\right)$ & 1,53 & 1,54 \\
\hline $\mathrm{A}_{\mathrm{s}, \text { hs }}\left(\mathrm{cm}^{2}\right)$ & 0,95 & 0,96 \\
\hline $\begin{array}{c}\text { Ruptura } \\
\text { concreto biela }\end{array}$ & Verifica & Verifica \\
\hline
\end{tabular}

Analisando os resultados, percebe-se que com a consideração de $y=l_{\text {emb }} / 10$, a resultante de pressão $H_{\sup f}$ diminui de $305,87 \mathrm{kN}$ para $284,40 \mathrm{kN}$. Com essa redução, de aproximadamente 7,5\%, a área resultante para a armadura horizontal principal, consequentemente diminui. Para as demais áreas, os resultados ficaram bem próximos nas duas situações, indicando que a modificação do parâmetro y não influencia de modo significativo no dimensionamento das armaduras verticais principais e secundárias e horizontais secundárias de cálices de fundação com interface lisa.

Será considerada, para o projeto do cálice de fundação, a distância de $y=l_{e m b} / 10$, porém adotando uma distribuição triangular de pressões na parede transversal frontal. Essa consideração é razoável em função das incertezas do real funcionamento de transferências dos 
esforços advindos do pilar para o cálice de fundação e apresentará ainda uma compatibilidade, do modelo de comportamento do cálice com interface lisa com o modelo de comportamento do cálice com interface rugosa.

Enfatiza-se que essa solução está a favor da segurança, pois comparado aos resultados experimentais, os respectivos valores teóricos ainda são conservadores, como comprovado em Canha et al. (2009b).

\subsection{COMPORTAMENTO DAS PAREDES TRANSVERSAIS}

Como já discutido no Capítulo 4, de recomendações para o dimensionamento do cálice, existem dois métodos para o dimensionamento das paredes transversais. É possível considerar para o cálculo da armadura $A_{s, h p t}$, somente forças de tração atuantes nas paredes transversais ou então optar por um comportamento intermediário de flexo-tração da parede.

Nos cálices com interface lisa, a análise é feita somente na parede frontal, que é onde a resultante de pressão atua. No cálice de interface rugosa, em razão de haver pressão atuando tanto na parede frontal quanto na parede posterior, como ilustrado pela Figura 4.12, as duas paredes transversais devem ser analisadas. Na Tabela 5.5 é apresentado o dimensionamento da armadura $A_{s, h p t}$, resultante da consideração da seção de um pilar pré-moldado de 40x40 $\mathrm{cm}^{2}$ e respectivo carregamento.

Tabela 5.5 - Área de aço da armadura horizontal principal transversal

\begin{tabular}{|c|c|c|c|c|c|}
\hline \multirow{2}{*}{$\begin{array}{c}\text { Tipo } \\
\text { interface }\end{array}$} & \multirow{2}{*}{\multicolumn{2}{|c|}{$\begin{array}{l}\text { Comportamento da parede } \\
\text { transversal }\end{array}$}} & \multicolumn{3}{|c|}{ Armaduras $\left(\mathrm{cm}^{2}\right)$} \\
\hline & & & $\mathrm{A}_{\mathrm{s}, \mathrm{hpte}}$ & $\mathrm{A}_{\mathrm{s}, \mathrm{hpti}}$ & $\mathrm{A}_{\mathrm{s}, \mathrm{hpt}}$ \\
\hline \multirow{2}{*}{ Lisa } & \multirow{2}{*}{ Frontal } & Flexo-tração & 2,48 & 0,30 & 2,78 \\
\hline & & Tração & 1,64 & 1,64 & 3,28 \\
\hline \multirow{4}{*}{ Rugosa } & \multirow{2}{*}{ Frontal } & Flexo-tração & 1,46 & 0,18 & 1,64 \\
\hline & & Tração & 0,96 & 0,96 & 1,92 \\
\hline & \multirow{2}{*}{ Posterior } & Flexo-tração & 2,91 & 0,35 & 3,26 \\
\hline & & Tração & 1,92 & 1,92 & 3,84 \\
\hline
\end{tabular}

Analisando os resultados, verifica-se que para os dois comportamentos, flexo-tração e tração da parede transversal frontal, as áreas de armadura resultaram próximas, chegando a no máximo $18 \%$ de diferença. No entanto, os cálculos considerando somente força de tração na 
parede transversal proporcionaram sempre resultados um pouco maiores, quando comparados aos resultados de flexo-tração da parede transversal. Avaliando o comportamento das paredes transversais do cálice com interface rugosa, percebe-se que a parede posterior é mais solicitada, como comprovado na referência de Canha et al. (2009c). A fissuração mais intensa nessa parede comprova a maior solicitação. Assim para a armação do cálice rugoso, deve ser utilizada a área resultante da consideração da pressão $H_{\text {sup } p}$ na parede posterior.

Verificando o pequeno acréscimo da área de aço quando considerado somente força de tração nas paredes transversais, e pelo cálculo por essa opção ser mais simplificado, este será o método indicado de dimensionamento. Entretanto, no que diz respeito ao detalhamento da armadura, é sugerida uma área de aço para o ramo externo diferente da área de aço para o ramo interno.

Após análise dos estudos desenvolvidos na EESC-USP, chegou-se a conclusão que uma distribuição com maior área de aço para o ramo externo é a melhor situação, pelo esforço nessa região ser mais intenso, como comprovado nos ensaios experimentais. E também devido à situação de montagem do cálice, onde uma força de encunhamento causa flexão nas paredes, tracionando a armadura. É indicado nesse trabalho, como sugestão, a distribuição de $1 / 3 \cdot A_{s, h p t}$ para o ramo interno e de $2 / 3 \cdot A_{s, h p t}$ para o ramo externo.

$\mathrm{Na}$ Tabela 5.6, são apresentados os resultados com a variação sugerida entre as áreas do ramo externo e interno de $A_{s, h p t}$, para a parede transversal frontal do cálice de interface lisa, e para a parede transversal posterior do cálice com interface rugosa (parede mais solicitada).

Tabela 5.6 - Variação da área de aço para o ramo interno e externo

\begin{tabular}{c|c|c|c|c|c}
\hline \multirow{2}{*}{ Parede } & \multicolumn{2}{|c|}{ Porcentagem } & \multicolumn{3}{c}{ Armaduras $\left(\mathrm{cm}^{2}\right)$} \\
\cline { 2 - 6 } & $\begin{array}{c}\text { Ramo } \\
\text { externo }\end{array}$ & $\begin{array}{c}\text { Ramo } \\
\text { interno }\end{array}$ & $\mathrm{A}_{\mathrm{s}, \mathrm{hpte}}$ & $\mathrm{A}_{\mathrm{s}, \mathrm{hpti}}$ & $\mathrm{A}_{\mathrm{s}, \mathrm{hpt}}$ \\
\hline Frontal Lisa & $2 / 3$ & $1 / 3$ & 2,18 & 1,10 & 3,28 \\
\hline Posterior Rugosa & $2 / 3$ & $1 / 3$ & 2,56 & 1,28 & 3,84 \\
\hline
\end{tabular}

Nos dois casos, a área de aço para o ramo interno da armadura horizontal principal transversal fica acima da área necessária quando considerada a situação de flexo-tração da parede, estando assim segura essas proporções de armaduras. Outra distribuição para o detalhamento da armadura $A_{s, h p t}$ poderia ser adotada, desde que a situação de flexo-tração seja atendida. 


\subsection{PRESSÕES ATUANTES CÁLICE RUGOSO}

A determinação da pressão superior para o cálice com interface rugosa pode ser feita por duas maneiras. Na Figura 5.5, estão apresentados os dois modelos de transferências de esforços no cálice de interface rugosa.

No primeiro caso, Figura 5.5 (a), a pressão $H_{\text {sup } f}$ é calculada através de um coeficiente de atrito $\mu=1$ e utilizando a Equação (4.1). Com essa consideração, somente a parede transversal frontal é solicitada por uma resultante de pressão, já que a pressão inferior no lado posterior é considerada como transmitida diretamente para a base da fundação.

No segundo método, ilustrado na Figura 5.5 (b), existem duas pressões atuantes, uma agindo na parede transversal frontal $\left(H_{\sup f}\right)$ e a outra na parede posterior do cálice $\left(H_{\sup p}\right)$. Com esse modelo de comportamento, duas resultantes de pressão atuam nas paredes transversais. Foi observado nos ensaios experimentais dos estudos de Canha et al. (2009c), que a parede transversal posterior apresentou fissuração mais intensa que a parede transversal frontal, indicando a existência de uma resultante de pressão na parede transversal posterior. Por isso, o modelo de comportamento de Canha et al. (2009c) é mais representativo.

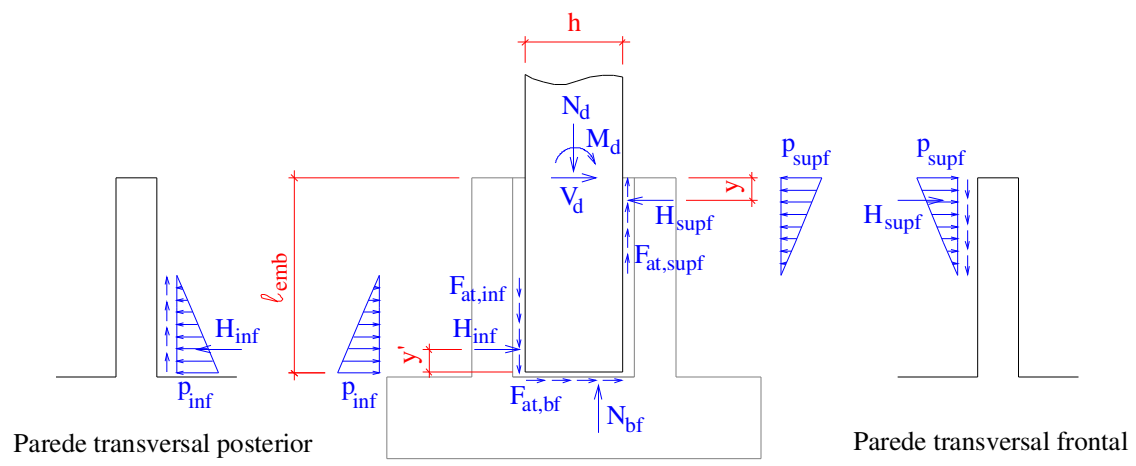

(a)

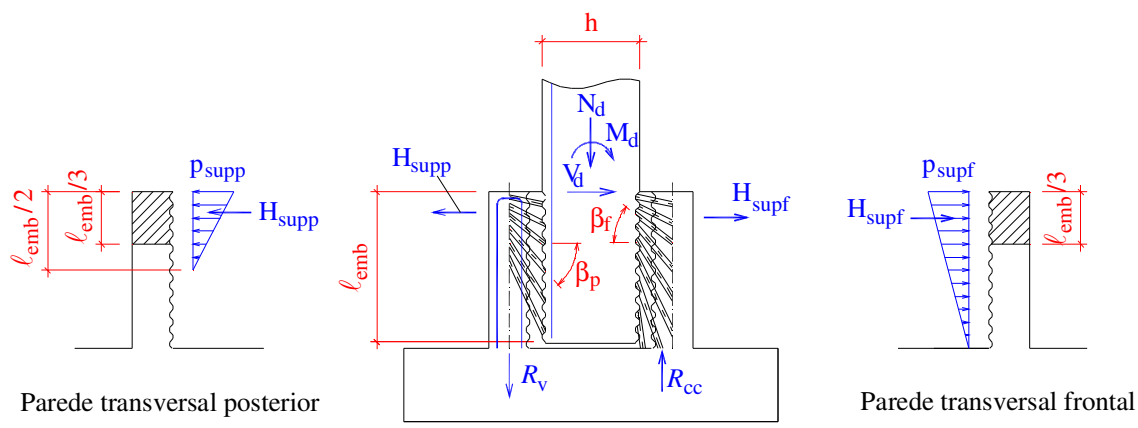

(b)

Figura 5.5 - Modelos de transferência de esforços em cálice de interface rugosa 
Para analisar a diferença entre uma solução e outra, é apresentado na Tabela 5.7 os valores resultantes de pressão $H_{\text {sup } f}$ e $H_{\text {sup } p}$, a partir da seção e carregamento do pilar prémoldado de $40 \times 40 \mathrm{~cm}^{2}$.

\begin{tabular}{c|c|c} 
Tabela 5.7 - Pressões atuantes no cálice de interface rugosa \\
\hline \multirow{2}{*}{ Método de cálculo } & \multicolumn{2}{|c}{ Pressões $(\mathrm{kN})$} \\
\cline { 2 - 3 } & $\mathrm{H}_{\text {supf }}$ & $\mathrm{H}_{\text {supp }}$ \\
\hline $\begin{array}{c}\text { Coeficiente de } \\
\text { atrito } \mu=1\end{array}$ & 275,44 & - \\
\hline $\begin{array}{c}\text { Canha et al. } \\
(2009 \mathrm{c})\end{array}$ & $167,46^{*}$ & $333,34^{*}$ \\
\hline \multicolumn{2}{|c|}{ ângulo de inclinação da biela: $\beta_{\mathrm{f}}=60^{\circ}$ e $\beta_{\mathrm{p}}=35^{\circ}$}
\end{tabular}

Analisando os resultados, percebe-se que a pressão $H_{\sup f}$ resultante do método de cálculo que utiliza coeficiente de atrito $\mu=1$ é maior que a pressão $H_{\text {sup } f}$ do modelo de Canha et al. (2009c), porém menor que a pressão $H_{\text {sup } p}$. Como no modelo proposto por Canha et al. (2009c), a pressão utilizada para o dimensionamento é a $H_{\text {sup } p}$, por essa ser maior, e pelo modelo do coeficiente de atrito utilizar a pressão $H_{\sup f}$, observa-se uma diferença entre os dois valores utilizados para o dimensionamento de mais ou menos $20 \%$.

No entanto, o método que considera o coeficiente de atrito é baseado em um modelo não consistente, pois mesmo que o cálice tenha interface rugosa não é correto indicarmos um coeficiente de atrito entre as interfaces igual a um. Dessa maneira, recomenda-se o método de Canha et al. (2009c) para a determinação das pressões atuantes nas paredes transversais frontal e posterior de cálices com interface rugosa.

\subsection{SITUAÇÃO DE MONTAGEM}

Durante a fixação temporária do pilar pré-moldado no cálice, significativos esforços solicitantes ocorrem nas paredes do colarinho devido à força de encunhamento, sendo preciso dimensionar uma armadura resistente a essa solicitação.

A partir de resultados experimentais, provenientes de ensaios desenvolvidos na EESCUSP, sugere-se um método de cálculo para fase de montagem da ligação pilar-fundação. Esse método é somente uma indicação, pois a maneira da montagem da ligação varia conforme a 
execução, sendo dependente: a inclinação e quantidade de cunhas utilizadas, a força aplicada para nivelamento, etc.

Nesse estudo, será sugerido o esquema representado na Figura 5.6. Essa situação considera uma força de encunhamento concentrada de $55 \mathrm{kN}$, aplicada a uma viga elasticamente engastada de comprimento $b_{i n t}+h_{c}$. $O$ valor de $55 \mathrm{kN}$ é resultante do caso analisado, e foi obtido pela célula de carga no ensaio de encunhamento realizado, como apresentado no item 4.4. Verificou-se que o momento solicitante proveniente da aplicação da força concentrada ultrapassou o momento de fissuração da viga, sendo necessário dimensionar uma armadura para resistir a essa solicitação.

O dimensionamento é feito considerando flexão das paredes devido à força de encunhamento e o momento é calculado segundo a Equação (5.4).

$$
M_{\text {mont }}=\frac{p \cdot l}{6}=\frac{55 \cdot\left(b_{\mathrm{int}}+h_{c}\right)}{6}
$$

Deve-se majorar o momento pelo coeficiente $\gamma_{f}=1,2$, que é o valor indicado pela Tabela 11.1 da ABNT NBR 6118:2003, para combinações de ações para cargas de construção.

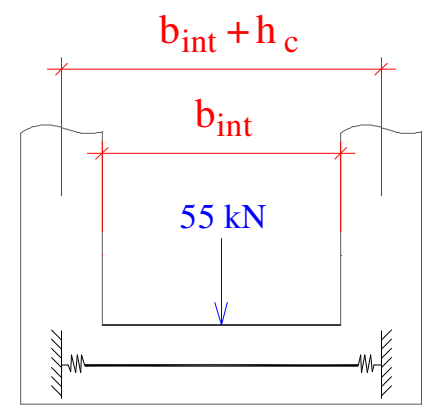

Figura 5.6 - Esquema de carregamento na fase de montagem da ligação pilar-fundação por meio de cálice

Definido o momento atuante, a armadura $A_{s}$ é determinada, e deve-se comparar a área de aço resultante da situação definitiva (ramo externo de $A_{s, h p}$ ) com a área de aço resultante da fase de montagem, e adotar a maior delas.

Por exemplo, se a armadura definitiva resultar maior, a situação transitória de montagem do pilar pré-moldado na cavidade da fundação está verificada. Se não, é necessário armar o cálice com a armadura de montagem. 
Com o intuito de analisar a situação de montagem do cálice, serão feitas aplicações de dimensionamento do cálice para fase de montagem, onde serão variadas as espessuras da parede do colarinho e também as dimensões da base da "viga".

A espessura da parede será variada, conforme as Equações (5.5), (5.6) e (5.7) e as bases adotadas das vigas serão de $l_{e m b} / 3$ e $l_{e m b} / 4$.

$$
\begin{aligned}
& h_{c} \geq \frac{1}{3} \cdot\left(h_{\mathrm{int}} \text { ou } b_{\mathrm{int}}\right) \\
& h_{c} \geq \frac{1}{3,5} \cdot\left(h_{\mathrm{int}} \text { ou } b_{\mathrm{int}}\right) \\
& h_{c} \geq \frac{1}{4} \cdot\left(h_{\mathrm{int}} \text { ou } b_{\mathrm{int}}\right)
\end{aligned}
$$

Para os cálculos foi adotada seção de $40 \times 40 \mathrm{~cm}^{2}$ do pilar pré-moldado e os demais dados seguem a especificação do item 5.1. Na Tabela 5.8 estão os resultados dessa variação.

Tabela 5.8 - Análise do dimensionamento da armadura do cálice para situação de montagem

\begin{tabular}{c|c|c|c|c|c|c}
\hline $\begin{array}{c}\text { Espessura do } \\
\text { colarinho }\end{array}$ & $h_{c}=\frac{1}{3}$ & $h_{c}=\frac{1}{3}$ & $h_{c}=\frac{1}{3,5}$ & $h_{c}=\frac{1}{3,5}$ & $h_{c}=\frac{1}{4}$ & $h_{c}=\frac{1}{4}$ \\
\hline Base da viga & $l_{\text {emb }} / 3$ & $l_{\text {emb }} / 4$ & $l_{\text {emb }} / 3$ & $l_{\text {emb }} / 4$ & $l_{\text {emb }} / 3$ & $l_{\text {emb }} / 4$ \\
\hline$h_{\text {int }}+h_{c}(\mathrm{~cm})$ & 67 & 67 & 65 & 65 & 63 & 63 \\
\hline$M_{m o n t, d}(\mathrm{kN} . \mathrm{cm})$ & 737 & 737 & 715 & 715 & 693 & 693 \\
\hline$A_{s}\left(\mathrm{~cm}^{2}\right)$ & 1,32 & 1,32 & 1,49 & 1,55 & 1,80 & 1,94 \\
\hline
\end{tabular}

Comparando as áreas de armaduras necessárias para a situação de montagem, percebese que a pior situação é quando a espessura da parede é a mínima recomendada $\left(h_{c}=1 / 4\right)$ e a base da viga é de $l_{\text {emb }} / 4$.

Observa-se que para uma mesma espessura da parede do colarinho, e diferentes bases, as armaduras resultam iguais ou então bem próximas, concluindo que esse parâmetro não afeta de maneira significativa o resultado. Entretanto, a modificação de $h_{c}$ influencia no resultado de $A_{s}$. Um aumento de até $47 \%$ é observado quando a espessura diminui de $h_{c}=1 / 3$ para $h_{c}=1 / 4$. Os resultados para a espessura $h_{c}=1 / 3,5$ são intermediários.

Como a armadura proveniente da situação definitiva deve resultar maior que a armadura da situação de montagem, será feito uma comparação da armadura do ramo externo de $A_{s, h p}$ do dimensionamento do cálice com interface lisa e interface rugosa com a armadura 
de montagem. Comparando os resultados das áreas de $A_{s, h p t e}$ da Tabela 5.6 com a área de aço para $h_{c}=1 / 3,5$ da Tabela 5.8, verifica-se que a armadura da situação definitiva é maior que a armadura da fase de montagem tanto no cálice com interface lisa quanto rugoso, ficando verificada a fase de montagem do cálice resultante da seção do pilar de $40 \times 40 \mathrm{~cm}^{2}$.

\subsection{PEQUENA EXCENTRICIDADE}

Na situação de pequena excentricidade, a relação entre momento fletor e força normal fica abaixo de 0,15 . Nessas condições, deve ser analisada a consideração ou não de forças de atrito nas paredes transversais e também na base do cálice.

Sabendo-se que na parede transversal posterior as forças de atrito podem mudar de sentido conforme a geometria e o carregamento que o cálice está submetido, e que na base pode não existir uma força de atrito plena, essas duas forças são desconsideradas nos casos de pequena excentricidade da força normal. Adotando ainda, uma solução mais segura, serão desconsideradas também as forças de atrito na parede transversal posterior.

Com essa definição, serão feitas duas análises no dimensionamento do cálice submetido à pequena excentricidade da força normal, considerando:

a) Força normal centrada na base do pilar pré-moldado, semelhante ao modelo de Leonhardt \& Mönnig (1978);

b) Excentricidade da força normal na base.

Com o carregamento advindo do pilar de $250 \mathrm{kN}$ de força normal, $15 \mathrm{kN} . \mathrm{m}$ de momento fletor e $50 \mathrm{kN}$ de força cortante, determina-se a excentricidade da força normal segundo a Equação (5.8).

$\frac{M_{d}}{N_{d} \cdot h}=\frac{1500}{250 \cdot 40} \leq 0,15$

Os parâmetros utilizados para o cálculo são:

a) Junta de $5 \mathrm{~cm}$ e comprimento de embutimento para pequena excentricidade definido conforme ABNT NBR 9062:2006 (interface lisa: $l_{\text {emb }}=1,5 \cdot h$ );

b) Parede transversal do cálice submetida ao esforço de tração;

c) Excentricidade da reação normal na base $h / 6$;

d) Resistência característica a compressão do concreto do cálice $f_{c k}=20 \mathrm{MPa}$ e $\gamma_{c}=1,4$ 
Com todos os dados definidos, foram realizados os cálculos seguindo as duas opções e os resultados obtidos estão apresentados na Tabela 5.9.

Tabela 5.9 -Resultados para cálice com interface lisa e pequena excentricidade

\begin{tabular}{c|c|c}
\hline \multirow{2}{*}{ Variáveis } & \multicolumn{2}{|c}{ Situações } \\
\cline { 2 - 3 } & $\begin{array}{c}\text { Força normal } \\
\text { excêntrica na } \\
\text { base }\end{array}$ & $\begin{array}{c}\text { Força normal } \\
\text { centrada na base }\end{array}$ \\
\hline $1_{\mathrm{emb}}(\mathrm{cm})$ & 60 & 60 \\
\hline $\mathrm{e}_{\mathrm{nb}}(\mathrm{cm})$ & 6,67 & 0 \\
\hline $\mathrm{y}(\mathrm{cm})$ & 6 & 6 \\
\hline $\mathrm{y}^{\prime}(\mathrm{cm})$ & 6 & 6 \\
\hline $\mathrm{H}_{\mathrm{supf}}(\mathrm{kN})$ & 52,78 & 87,5 \\
\hline $\mathrm{A}_{\mathrm{s}, \mathrm{hpl}}\left(\mathrm{cm}^{2}\right)$ & 0,61 & 1,01 \\
\hline $\mathrm{A}_{\mathrm{s}, \mathrm{hpt}}\left(\mathrm{cm}^{2}\right)$ & 0,61 & 1,01 \\
\hline $\mathrm{A}_{\mathrm{s}, \mathrm{vp}}\left(\mathrm{cm}^{2}\right)$ & 0,53 & 0,88 \\
\hline $\mathrm{A}_{\mathrm{s}, \mathrm{vs}}\left(\mathrm{cm}^{2}\right)$ & 0,21 & 0,35 \\
\hline $\mathrm{A}_{\mathrm{s}, \mathrm{hs}}\left(\mathrm{cm}^{2}\right)$ & 0,13 & 0,22 \\
\hline $\begin{array}{c}\text { Ruptura } \\
\text { concreto biela }\end{array}$ & Verifica & Verifica \\
\hline
\end{tabular}

Analisando os resultados da Tabela 5.9, verifica-se que a opção mais conservadora e que resulta em maiores áreas de aço, como já esperado, é quando consideramos a força normal centrada na base do pilar. Com essa opção as áreas de armadura horizontais e verticais resultaram aproximadamente $65 \%$ maiores.

Por se tratar de uma análise mais conservadora, é recomendado dimensionar o cálice com força normal na base centrada quando esse estiver submetido à pequena excentricidade da força normal.

Quando existir somente força normal, deve-se dimensionar o cálice de fundação com uma armadura mínima. Recomenda-se que essa armadura mínima seja equivalente a uma situação de carregamento que resulte em pequena excentricidade da força normal. Assim, o dimensionamento deve ser feito como indicado para esses casos. Enfatiza-se que nessa situação a verificação mais importante é a de punção na fundação, pois a força normal é transferida diretamente para o elemento de fundação na área da seção do pilar, sem nenhuma redução. 
Relembra-se que independente da excentricidade da força normal resultar pequena ou grande, é necessário sempre verificar a situação de montagem do cálice e armar as paredes do colarinho com a maior área de aço encontrada.

\subsection{FLEXÃO OBLÍQUA}

A ocorrência de flexão oblíqua dos pilares é comum nas estruturas de concreto prémoldado, devido à atuação de vento nas edificações. Assim, esse item é necessário para exemplificar o dimensionamento do cálice submetido a esse tipo de solicitação.

O carregamento advindo do pilar admitido para os cálculos foi de $250 \mathrm{kN}$ de força normal, $50 \mathrm{kN}$ de força cortante, $200 \mathrm{kN} . \mathrm{m}$ de momento fletor na direção x e $50 \mathrm{kN} . \mathrm{m}$ de momento fletor na direção y. A seção do pilar pré-moldado também foi de $40 \times 40 \mathrm{~cm}^{2}$ e demais dados já expostos.

Na Tabela 5.10, estão apresentadas as áreas de armaduras resultantes devido à atuação dos momentos nas duas direções e também a envoltória que define as armaduras finais.

Tabela 5.10 - Armaduras resultantes para casos de flexão oblíqua

\begin{tabular}{c|c|c|c}
\hline \multirow{2}{*}{ Variáveis } & \multicolumn{3}{|c}{ Armaduras } \\
\cline { 2 - 4 } & Devido a $\mathrm{M}_{\mathrm{xd}}$ & Devido a $\mathrm{M}_{\mathrm{yd}}$ & Finais \\
\hline $\mathrm{l}_{\mathrm{emb}}(\mathrm{cm})$ & $80^{*}$ & 60 & - \\
\hline $\mathrm{H}_{\text {supf }}(\mathrm{kN})$ & 284,40 & 84,38 & - \\
\hline $\mathrm{A}_{\mathrm{s}, \mathrm{hpl}}\left(\mathrm{cm}^{2}\right)$ & 3,27 & 1,54 & 3,27 \\
\hline $\mathrm{A}_{\mathrm{s}, \mathrm{hpt}}\left(\mathrm{cm}^{2}\right)$ & 3,27 & 1,54 & 3,27 \\
\hline $\mathrm{A}_{\mathrm{s}, \mathrm{vp}}\left(\mathrm{cm}^{2}\right)$ & 3,84 & 1,81 & 5,65 \\
\hline $\mathrm{A}_{\mathrm{s}, \mathrm{vs}}\left(\mathrm{cm}^{2}\right)$ & 1,54 & 0,73 & 2,26 \\
\hline $\mathrm{A}_{\mathrm{s}, \mathrm{hs}}\left(\mathrm{cm}^{2}\right)$ & 0,96 & 0,45 & 0,96 \\
\hline $\begin{array}{c}\text { Ruptura } \\
\text { concreto biela }\end{array}$ & Verifica & Verifica & Verifica \\
\hline
\end{tabular}

" $1_{\text {emb }}$ adotado para os cálculos

Obviamente, as armaduras resultantes do momento $M_{x d}$ foram maiores, pois o momento na direção x tem maior valor do que o momento na direção y. 
Para armar o cálice deve-se adotar para as armaduras horizontais o maior valor entre as duas análises, e para as armaduras verticais é necessário somar as áreas de aço resultantes, com o objetivo de cobrir a situação de atuação simultânea dos momentos $M_{x d}$ e $M_{y d}$.

Quanto ao comprimento de embutimento, o valor para cálculo e construção do cálice deve ser de $80 \mathrm{~cm}$, que é o maior resultado obtido da análise isolada.

No Apêndice C, encontra-se o um roteiro de cálculo com o dimensionamento detalhado do cálice submetido à flexão oblíqua.

\subsection{BASE DO PILAR PRÉ-MOLDADO}

Um modelo de biela e tirante adaptado foi proposto nesse trabalho com intuito de compatibilização do modelo de comportamento do cálice de fundação com o da base do pilar pré-moldado proposto por Ebeling (2006).

As modificações realizadas foram a retirada de um dos apoios existentes no lado tracionado do pilar e a verificação da inclusão das forças de atrito na base do pilar prémoldado. Para quantificar a diferença entre a consideração ou não dessas forças, um exemplo de cálculo foi feito e os resultados estão apresentados na Tabela 5.11. No Apêndice D é apresentado o roteiro de cálculo da determinação das forças internas das bielas e tirantes.

Para o cálculo, o carregamento utilizado foi o observado nos ensaios dos modelos de Ebeling (2006), que foi de $242 \mathrm{kN}$ de força normal e $290 \mathrm{kN} . \mathrm{m}$ de momento fletor. Não houve aplicação de força cortante nos modelos ensaiados. Optou-se por esse carregamento, pois dessa maneira é possível comparar os resultados teóricos do modelo ensaiado com os resultados teóricos. Com esse carregamento chega-se a uma situação de grande excentricidade da força normal.

Foi adotada seção do pilar pré-moldado de $40 \times 40 \mathrm{~cm}^{2}$ e os demais parâmetros foram:

a) Junta de $5 \mathrm{~cm}$ e comprimento de embutimento para grande excentricidade definido conforme ABNT NBR 9062:2006 (interface lisa: $l_{e m b}=2,0 \cdot h$ );

b) Coeficiente de atrito $\mu=0,3$;

c) Excentricidade da reação normal na base $e_{n b}=h / 4$;

d) Distância de aplicação de $H_{\text {sup } f}$ e $H_{\text {inf }}$ determinados por $y=y^{\prime}=l_{e m b} / 10$;

e) Resistência média a compressão do concreto $f_{c m}=54 \mathrm{MPa}$ (resistência do pilar prémoldado ensaiado por Ebeling (2006)). 
O ângulo de inclinação $\alpha$ das bielas em relação às armaduras resultante dessa situação é de $49,84^{\circ} k N$. As forças internas determinadas a seguir são as indicadas na Figura 4.18 apresentada no Capítulo 4, item 4.3.

Tabela 5.11 - Análise da base do pilar pré-moldado

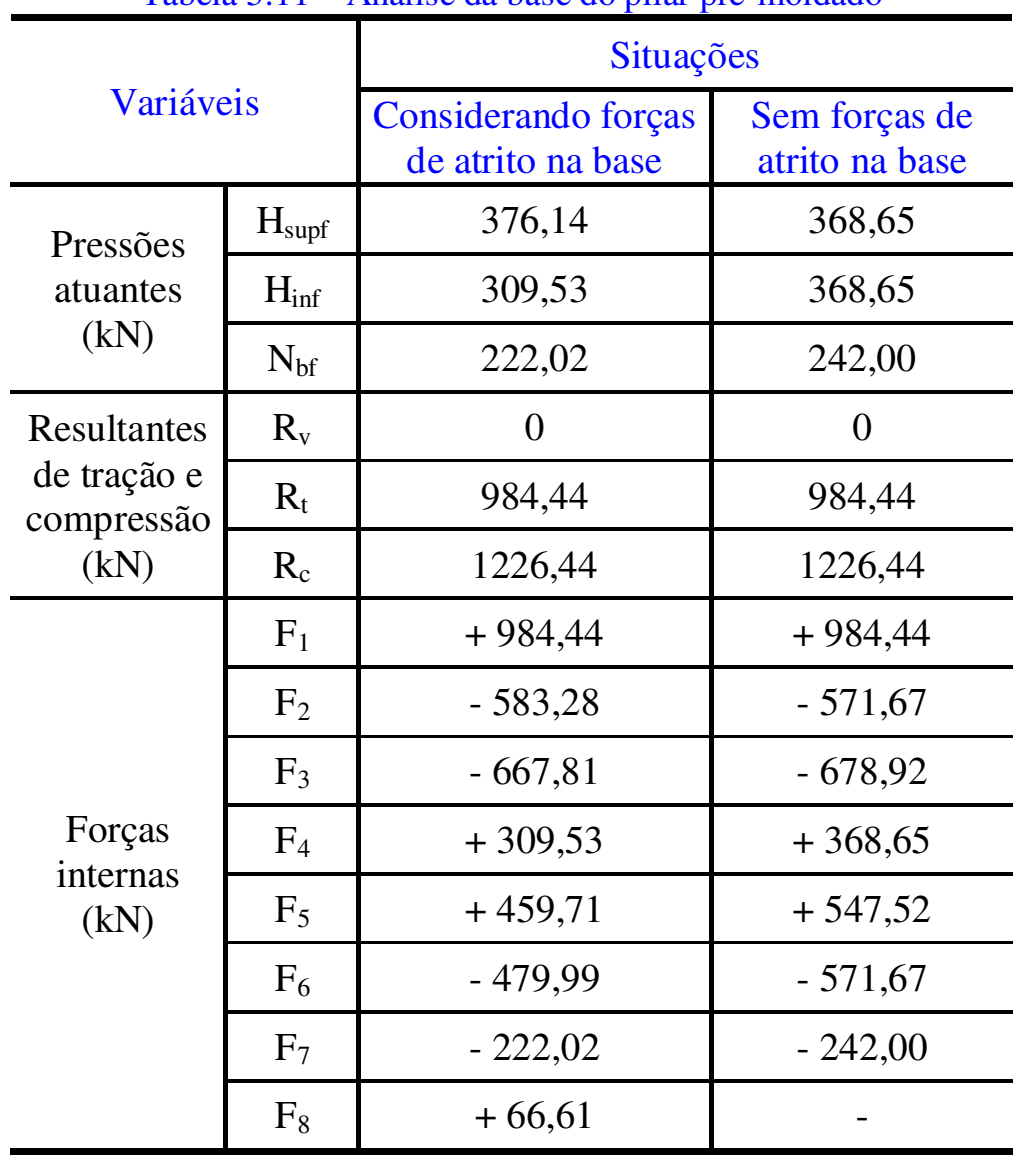

Convenção: + para forças de tração e - para forças de compressão

Analisando os resultados, verifica-se que a resultante $H_{\text {sup } f}$ resulta próxima nas duas situações, sendo apenas $2 \%$ maior, quando se considera forças de atrito na base. Observa-se que na situação da ausência das forças de atrito, as resultantes $H_{\sup f}$ e $H_{\text {inf }}$ são iguais, assim como as reações $N_{b f}$ e $N_{d}$.

As resultantes de tração e compressão, independente da situação, têm o mesmo valor, e a resultante $R_{v}$ é nula, pois não existe aplicação de força horizontal.

Quanto às forças internas, verifica-se que os valores foram pouco divergentes, sendo a principal diferença, a existência da força $\mathrm{F}_{8}$ quando consideramos as forças de atrito na base. A força $\mathrm{F}_{4}$, que é a força na armadura na metade do comprimento de embutimento, resultou 
aproximadamente $20 \%$ maior quando não existe força de atrito na base. Isso ocorre, pois é a única região com armadura.

Em geral, é possível afirmar que a consideração da força de atrito na base não influencia de maneira significativa no dimensionamento da base do pilar pré-moldado. Assim, com o objetivo de compatibilizar os modelos do cálice e do pilar e também apresentar uma distribuição de armaduras em todo o comprimento de embutimento do pilar, será recomendado, para os casos de grande excentricidade, o modelo que considera as forças de atrito na base. Entretanto, para a situação em que a força normal resultar de pequena excentricidade, deve ser utilizado o modelo que não considera nenhuma força de atrito, assim como foi adotado para o dimensionamento do cálice.

Para cálculo da área de aço transversal do pilar na região do comprimento de embutimento, é necessário determinar a parcela resistida pelo concreto e reduzi-la das forças nos tirantes. Para esse exemplo, como a resistência média à compressão do concreto é de $f_{c m}=54 \mathrm{MPa}$, a parcela resistida pelo concreto é de $V_{c}=266,42 \mathrm{kN}$.

Com o valor da força no tirante $\mathrm{F}_{4}$, apresentado na Tabela 5.11, e da parcela $V_{c}$ é possível determinar a força que deve ser resistida pela armadura na região da metade do comprimento de embutimento. Após os cálculos define-se o valor de 43,11 kN, que é a força que deve ser resistida pela armadura. Esse resultado equivale a uma armadura de apenas 3,10 $\mathrm{cm}^{2} / \mathrm{m}$.

Analisando os resultados de Ebeling (2006), observa-se que a força experimental no tirante $\mathrm{F}_{4}$, medida pelo extensômetro, foi de $41 \mathrm{kN}$, enquanto que a força resultante pela aplicação do seu modelo foi de $127 \mathrm{kN}$ (considerando coeficiente de atrito $\mu=0,3$ ).

Comparando as forças teóricas resultantes da aplicação dos dois modelos com a força experimental obtida, percebe-se que o modelo proposto nesse estudo fornece um resultado mais compatível com o valor experimental, sendo, portanto mais adequado para análise da base do pilar pré-moldado.

Como o pilar pré-moldado nessa região deve ser armado com uma armadura transversal mínima, é necessário calculá-la e compará-la com a armadura resultante do dimensionamento. Para esse caso a armadura mínima é de $6,90 \mathrm{~cm}^{2} / \mathrm{m}$ e a obtida pela aplicação do modelo adaptado é de $3,10 \mathrm{~cm}^{2} / \mathrm{m}$. Assim, deve-se adotar armadura mínima na região de embutimento do pilar pré-moldado no cálice de fundação. 


\subsection{DETALHAMENTO DAS ARMADURAS}

O objetivo desse item é apresentar um detalhamento completo do projeto de um cálice de fundação com as distribuições e posições das armaduras componentes desse elemento. A seção detalhada será a mesma utilizada em todas as análises anteriores, que é a proveniente de um pilar pré-moldado de $40 \times 40 \mathrm{~cm}^{2}$, como ilustra a Figura 5.7. Optou-se por detalhar o cálice de interface lisa com os esforços da Tabela 5.1.

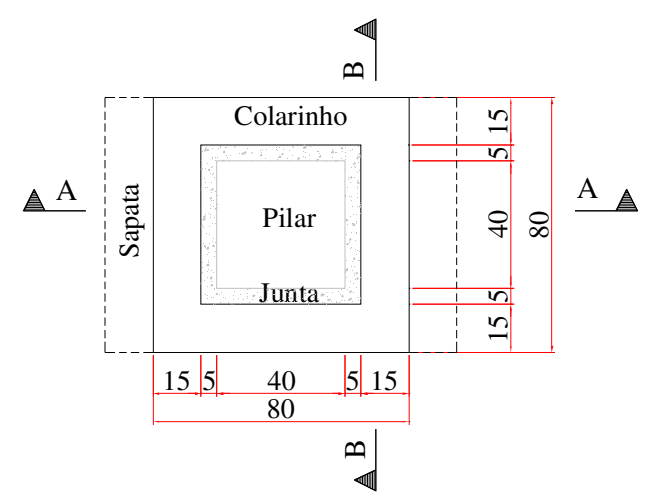

Planta do cálice de fundação

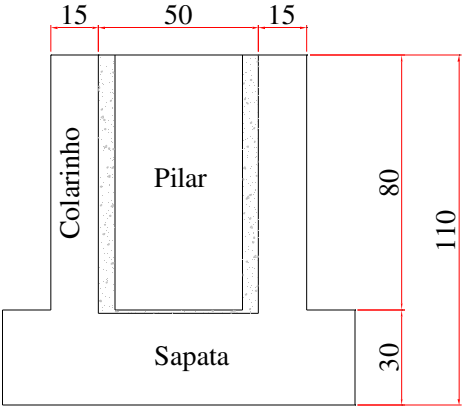

Corte AA

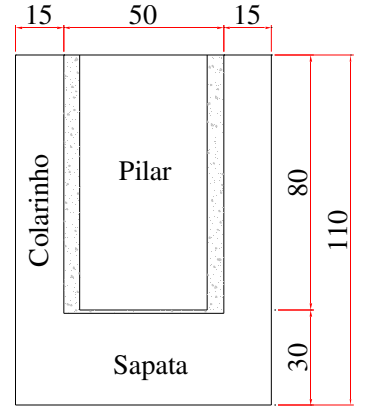

Corte BB

Figura 5.7 - Características geométricas do cálice de fundação

\subsubsection{Armadura vertical}

Consultando a Tabela 5.2, encontra-se a área de aço necessária para as armaduras verticais e assim é possível determinar a bitola e a quantidade de aço para cada uma.

a) Armadura vertical principal: $A_{s, v p}=3,84 \mathrm{~cm}^{2}$.

Como a armadura é disposta em estribo de dois ramos, a área de aço resulta em $A_{s, v p}=1,92 \mathrm{~cm}^{2}$. Esta armadura deve ser distribuída nas intersecções das paredes.

$A_{s, v p}=1,92 \mathrm{~cm}^{2}$ equivale a $4 \phi 8 \mathrm{~mm}\left(2,02 \mathrm{~cm}^{2}\right)$ 
É importante observar a quantidade de bitolas para optar por uma solução com facilidade construtiva.

b) Armadura vertical secundária: $A_{s, v s}=1,54 \mathrm{~cm}^{2}$

Como a armadura é disposta em estribo de dois ramos, a área de aço é de $A_{s, v s}=0,77 \mathrm{~cm}^{2}$. Esta armadura deve ser distribuída no meio das paredes transversais e longitudinais.

$$
A_{s, v s}=0,77 \mathrm{~cm}^{2} \text { equivale a } 2 \phi 8 \mathrm{~mm}\left(1,01 \mathrm{~cm}^{2}\right) \text { ou } 3 \phi 6,3 \mathrm{~mm}\left(0,94 \mathrm{~cm}^{2}\right)
$$

\subsubsection{Armadura horizontal}

Da mesma maneira que foi feito para a armadura vertical, consultando a Tabela 5.2, encontra-se a área de aço necessária para a armadura horizontal principal e secundária e assim determina-se a bitola e a quantidade de aço.

a) Armadura horizontal principal: $A_{s, h p l}=A_{s, h p t}=3,28 \mathrm{~cm}^{2}$

Dividindo essa área de armadura em proporções diferentes para ramo externo e interno, como apresentado na Tabela 5.6, tem-se para a armadura horizontal do ramo externo $A_{s, h p e}=2,18 \mathrm{~cm}^{2}$, e para a armadura horizontal do ramo interno $A_{s, h p i}=1,10 \mathrm{~cm}^{2}$.

$$
\begin{aligned}
& A_{s, h p e}=2,18 \mathrm{~cm}^{2}, \text { equivale a } 3 \phi 10 \mathrm{~mm}\left(2,36 \mathrm{~cm}^{2}\right) \\
& A_{s, h p i}=1,10 \mathrm{~cm}^{2} \text {, equivale a } 3 \phi 8 \mathrm{~mm}\left(1,51 \mathrm{~cm}^{2}\right)
\end{aligned}
$$

b) Armadura horizontal secundária: $A_{s, h s}=0,96 \mathrm{~cm}^{2}$

Dividindo essa área em proporções iguais, o ramo externo resulta igual ao interno. Optou-se por uma distribuição igual entre os ramos externo e interno, pois essa armadura tem a função de controlar a fissuração no cálice de fundação.

$$
A_{s, h s e}=A_{s, h s i}=0,48 \mathrm{~cm}^{2} \text {, equivale a } 2 \phi 6,3 \mathrm{~mm}\left(0,62 \mathrm{~cm}^{2}\right)
$$

\subsubsection{Detalhamento das armaduras do cálice}

Na Figura 5.8, é apresentado o detalhamento das armaduras e a Figura 5.9 ilustra a distribuição das mesmas no cálice de fundação. 

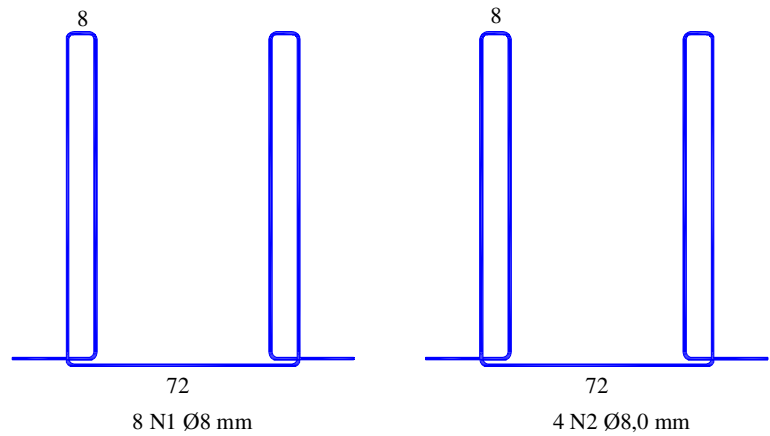

Armadura vertical principal e secundária

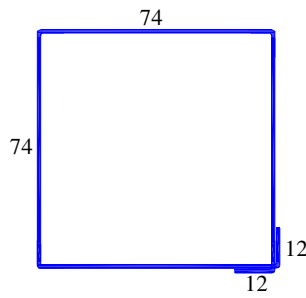

$3 \mathrm{~N} 3 \varnothing 10,0 \mathrm{~mm} \mathrm{C}=320$

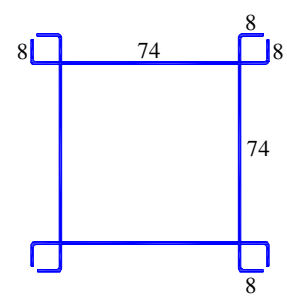

$12 \mathrm{~N} 4 \varnothing 8,0 \mathrm{~mm} \mathrm{C}=90$

Armadura horizontal principal

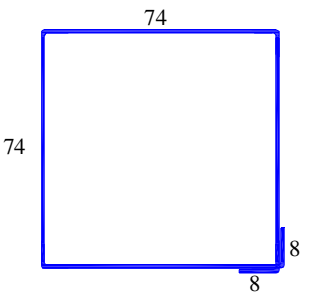

2 N5 Ø6,3 mm C=312

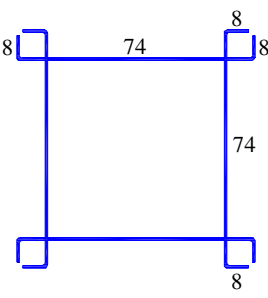

8 N6 Ø6,3 mm C=90

Figura 5.8 - Detalhamento das armaduras do cálice

ص

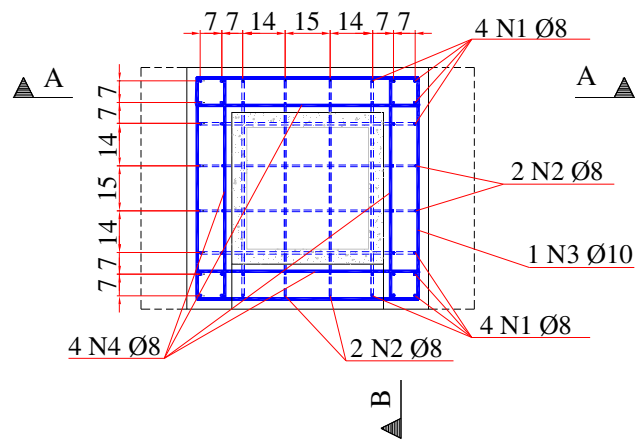

Planta das armaduras do cálice de fundação

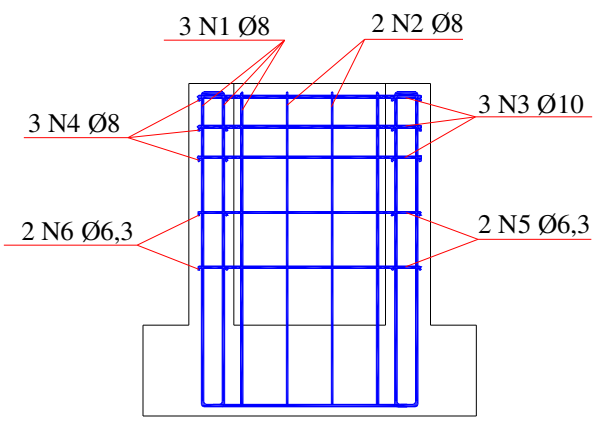

Corte AA

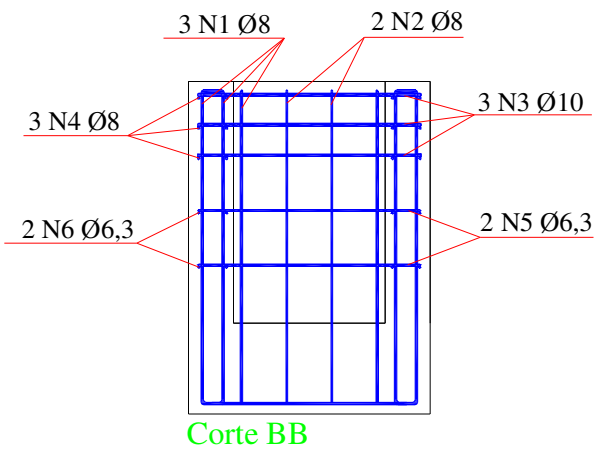

Figura 5.9 - Posicionamento das armaduras no cálice 


\section{CONCLUSÃO}

Essa pesquisa foi desenvolvida com o objetivo de integrar uma série de estudos, baseados em ensaios experimentais e análises numéricas, realizados na EESC-USP a respeito da ligação pilar-fundação por meio de cálice com uso de colarinho. Foram analisadas e estudadas uma tese de doutorado e três dissertações de mestrado, sendo essas desenvolvidas por Canha (2004), Jaguaribe Jr. (2005), Ebeling (2006) e Nunes (2009).

Com os resultados, recomendações para o projeto de cálices de fundação com colarinho foram elaboradas e estão apresentadas no Capítulo 4. Essas recomendações englobam situações de cálice com interface lisa, cálice com interface rugosa, montagem da ligação cálice de fundação, disposições construtivas e detalhamento das armaduras constituintes do elemento e abrangem casos de esforços de força normal com grande e pequena excentricidade, existência somente de força normal e atuação de flexão oblíqua.

Também foram apresentadas recomendações para o projeto da base do pilar prémoldado. Essas se baseiam em um modelo de biela e tirante proposto por Ebeling (2006) que é válido tanto para cálice com colarinho como para cálice sem colarinho, pois apesar do cálice sem colarinho apresentar, em tese, maior rigidez, a base do pilar não deve apresentar mudanças significativas na intensidade e posição de forças atuantes.

Após o capítulo de recomendações, foram feitas algumas aplicações e avaliações das indicações de cálculo para verificação da necessidade de adaptação ou modificação dos modelos teóricos propostos. Algumas das principais conclusões incorporadas às recomendações para o projeto do cálice de fundação foram:

a) Determinação da posição de aplicação da pressão $H_{\text {sup } f}$ na parede transversal frontal, sendo adotada a distância de $y=l_{e m b} / 10$ com uma distribuição triangular de pressões. Anteriormente, estava sendo considerada uma distribuição triangular de pressões com $y=l_{\text {emb }} / 6$, que é o valor indicado pelo modelo de Leonhardt \& Mönnig (1978). 
Porém por observações práticas de que essa resultante seja aplicada um pouco acima na parede frontal, por incertezas do real funcionamento de transferências de esforços nessa região e verificando que a diferença entre uma solução ou outra é de apenas $7,5 \%$ adotou-se para o cálice de interface lisa o valor de $y=l_{\text {emb }} / 10$. Esse valor é o mesmo indicado pelo Eurocode 2;

b) Consideração somente de força de tração atuante nas paredes transversais do cálice. Foi constatado experimentalmente nos estudos anteriores o comportamento de flexotração dessas paredes, porém as áreas de armaduras resultam próximas nas duas situações, chegando a uma diferença máxima de $18 \%$. Como há pouco acréscimo de área de aço na consideração somente de tração, e por essa opção resultar num cálculo mais prático este é o método indicado para o dimensionamento das paredes transversais de cálices de fundação;

c) Recomendações para o projeto de cálices de fundação submetidos à força normal de pequena excentricidade;

d) Adaptação do modelo proposto por Ebeling (2006) para análise da base do pilar prémoldado para que houvesse uma compatibilidade desse modelo de comportamento com o modelo do cálice. As modificações realizadas no modelo de biela e tirante foram a retirada de um apoio intermediário no lado tracionado do pilar (parede transversal posterior do cálice) e a inclusão das forças de atrito na base. Ainda, para que o modelo represente melhor o comportamento dessa região deve ser considerada a contribuição do concreto na resistência da ligação. Verificou-se que o modelo adaptado apresentou resultado mais próximo do valor experimental para a força no tirante $\mathrm{F}_{4}$. Enquanto a força obtida experimentalmente foi de $41 \mathrm{kN}$, as forças teóricas foram de 43,11 kN e $127 \mathrm{kN}$, para o modelo adaptado nesse estudo e o proposto por Ebeling (2006), respectivamente.

Ainda, algumas recomendações foram propostas para a otimização do projeto do cálice de fundação com colarinho, como:

a) Distribuição diferenciada entre o ramo externo/interno da armadura horizontal principal. Foi sugerida uma relação de $1 / 3 A_{s, h p t}$ para o ramo interno e de $2 / 3 A_{s, h p t}$ para o ramo externo, pois é preferível que o ramo externo possua uma maior área de aço, em virtude da força nessa região ser mais intensa e também devido à situação de montagem do cálice, onde uma força de encunhamento causa flexão das paredes; 
b) Determinação da espessura mínima da parede do colarinho diferentemente dos valores recomendados por modelos da literatura. O modelo de Leonhardt \& Mönnig (1978) recomenda o cálculo da espessura pela relação $h_{c} \geq 1 / 3$. $\left(b_{\text {int }}\right.$ ou $\left.h_{\text {int }}\right)$, no entanto esse método resulta em valores conservadores. Assim, recomenda-se que a espessura mínima seja calculada pela expressão $h_{c} \geq 1 / 4 .\left(b_{\text {int }}\right.$ ou $\left.h_{\text {int }}\right)$, sendo respeitado sempre o limite mínimo imposto pela ABNT NBR 9062:2006 que é de $10 \mathrm{~cm}$. Cabe ao projetista avaliar cada caso de dimensionamento e adotar um método que implique em resultados coerentes e compatíveis.

Nos apêndices, exemplos completos de dimensionamento de cálice com interface lisa e rugosa e da base do pilar pré-moldado são apresentados. É elaborado ainda, um roteiro simplificado com recomendações de projeto do cálice, que possam subsidiar futuras revisões da ABNT NBR 9062:2006 - Projeto e Execução de Estruturas de Concreto Pré-Moldado.

Essa pesquisa representa um avanço no estudo a respeito de cálices de fundação, que é o tipo de ligação pilar-fundação mais utilizado em estruturas de concreto pré-moldado no Brasil. Entretanto, como as recomendações de projeto apresentadas referem-se especificamente a cálices com colarinho, sugere-se para futuras pesquisas:

a) Adaptação do modelo de comportamento apresentado do cálice com colarinho para os casos de cálice embutido e semi-embutido;

b)Elaboração de recomendações práticas para o projeto e dimensionamento de cálices embutido e semi-embutido;

c) Análise da inclusão do coeficiente $\gamma_{n}$ para o dimensionamento da ligação cálice de fundação, visto que o modelo de projeto apresentado se refere a uma ligação de grande importância para a transferência de esforços provenientes do pilar pré-moldado para o elemento de fundação, pois dependendo do arranjo estrutural a estabilidade da estrutura fica somente sob a responsabilidade da ligação. 


\section{REFERÊNCIAS}

ASSOCIAÇÃO BRASILEIRA DE NORMAS TÉCNICAS. NBR 6118: Projeto de estruturas de concreto - Procedimento. Rio de Janeiro, 2003.

ASSOCIAÇÃO BRASILEIRA DE NORMAS TÉCNICAS. NBR 9062: Projeto e execução de estruturas de concreto pré-moldado. Rio de Janeiro, 2006.

CANHA, R. M. F. Estudo teórico-experimental da ligação pilar-fundação por meio de cálice em estruturas de concreto pré-moldado. 2004. 279 f. Tese (Doutorado) - Escola de Engenharia de São Carlos, Universidade de São Paulo, São Carlos, 2004.

CANHA, R. M. F.; EBELING, E. B.; EL DEBS, A. L. H. C; EL DEBS, M. K. Analysing the base of precast column in socket foundations with smooth interfaces. Materials and Structures, v.42 n.6, p. 725-737, jul, 2009a.

CANHA, R. M. F.; EL DEBS, A. L. H. C.; EL DEBS, M. K. Design model for socket base connections adjusted from experimental results. Structural Concrete, Lausanne, v.8, n.1, p.3-10, mar, 2007.

CANHA, R. M. F.; EL DEBS, M. K.; JAGUARIBE JUNIOR, K. B.; EL DEBS, A. L. H. C. Behavior of socket base connections emphasizing pedestal walls. ACI Structural Journal, Farmington Hills, v.106, n.3, p. 268-278, mai/jun, 2009b.

CANHA, R. M. F.; JAGUARIBE JUNIOR, K. B.; EL DEBS, A. L. H. C; EL DEBS, M. K. Analysis of the behavior of transverse walls of socket base connections. Engineering Structures, Amsterdã, v.31, n.3, p. 788-798, mar, 2009c. 
CONSIGLIO NAZIONALE DELLE RICERCHE. CNR-10025: Istruzioni per il progetto, l'esecuzione ed il controllo delle strutture prefabbricate in calcestruzzo. ITEC/La prefabricazione. Roma, 1998.

EBELING, E. B. Análise da base de pilares pré-moldados na ligação com cálice de fundação. 2006. 103 f. Dissertação (Mestrado) - Escola de Engenharia de São Carlos, Universidade de São Paulo, São Carlos, 2006.

EL DEBS, M. K. Concreto pré-moldado: fundamentos e aplicações. 1.ed. São Carlos: EESC-USP, 2000.

EUROCODE 2. Design of concrete structures - part 1-1: General rules and rules for buildings. Brussels, 2004.

JAGUARIBE JR., K. B. Ligação pilar fundação por meio de cálice em estruturas de concreto pré-moldado com profundidade de embutimento reduzida. 2005. $177 \mathrm{f}$. Dissertação (Mestrado) - Escola de Engenharia de São Carlos, Universidade de São Paulo, São Carlos, 2005.

LEONHARDT, F.; MÖNNIG, E. Construções de concreto: princípios básicos sobre armação de estruturas de concreto armado. v.3. Rio de Janeiro: Interciência, 1978.

MELlO, C. E. E. Manual Munte de Projetos em Pré-fabricados em Concreto. São Paulo: Pini, 2004.

NUNES, V. C. P. Análise experimental de cálice de fundação com ênfase nos esforços nas paredes transversais do colarinho. 2009. 132 f. Dissertação (Mestrado) - Escola de Engenharia de São Carlos, Universidade de São Paulo, São Carlos, 2009.

OLIN, J.; HAKKARAINEN, T.; RÄMÄ, M. Connections and joints between precast concrete units. Espoo: Julkaisija-Utgivare, 1985. 
OSANAI, Y.; WATANABE, F.; OKAMOTO, S. Stress Transfer Mechanism of Socket Base Connections with Precast Concrete Columns. ACI Structural Journal, Detroit, v.93, n.3, p.266-276, may/jun, 1996. 


\section{APÊNDICE A- EXEMPLO DE DIMENSIONAMENTO DE CÁLICE COM INTERFACE LISA}

Considerando pilar pré-moldado com seção $40 \times 40 \mathrm{~cm}^{2}$ e carregamento de $N_{d}=250 \mathrm{kN}, M_{d}=200 \mathrm{kN} . \mathrm{m}$ e $V_{d}=50 \mathrm{kN}$, um roteiro de cálculo para cálice com interface lisa é apresentado a seguir.

1. Cálculo de $b_{\text {int }}$ e $h_{\text {int }}$
$b_{\text {int }}=b+2 \cdot b_{j}$
$b_{\text {int }}=40+2 \cdot 5$
$b_{\text {int }}=50 \mathrm{~cm}$
$h_{\text {int }}=h+2 \cdot h_{j}$
$h_{\text {int }}=40+2 \cdot 5$
$h_{\text {int }}=50 \mathrm{~cm}$

2. Cálculo da espessura da parede do colarinho
$h_{c} \geq \frac{1}{3,5} \cdot\left(h_{\mathrm{int}}\right.$ ou $\left.b_{\mathrm{int}}\right)$
$h_{c} \geq \frac{1}{3,5} \cdot 50$
$h_{c}=15 \mathrm{~cm}$

3. Cálculo de $b_{e x t}$ e $h_{e x t}$
$b_{\text {ext }}=b_{\mathrm{int}}+2 \cdot h_{c}$
$b_{\text {ext }}=50+2 \cdot 15$
$b_{\text {ext }}=80 \mathrm{~cm}$
$h_{\text {ext }}=h_{\mathrm{int}}+2 \cdot h_{c}$
$h_{\text {ext }}=50+2 \cdot 15$
$h_{\text {ext }}=80 \mathrm{~cm}$

4. Cálculo do comprimento de embutimento

$e=\frac{20000}{250 \cdot 40}=2$, fazendo a verificação da excentricidade, resulta grande excentricidade, assim: $l_{e m b}=2,0 \cdot h$

$$
l_{\text {emb }}=2,0 \cdot 40 \quad l_{\text {emb }}=80 \mathrm{~cm}
$$

5. Cálculo do comprimento do colarinho
$l_{c}=l_{\text {emb }}-1 \mathrm{~cm}^{*}$
$l_{c}=80-1 \mathrm{~cm}$
$l_{c}=79 \mathrm{~cm}$ 
* Podem ser adotados valores maiores que $1 \mathrm{~cm}$ para a espessura da junta abaixo do pilar prémoldado, com a finalidade de possíveis ajustes e acomodação de erros.

6. Cálculo da excentricidade da reação normal na base do pilar (considerando uma aplicação prática)
$e_{n b}=\frac{h}{4}$
$e_{n b}=\frac{40}{4}$
$e_{n b}=10 \mathrm{~cm}$

7. Cálculo de y (distância de aplicação da resultante $H_{\text {sup } f}$ até o topo do colarinho)
$y=\frac{l_{e m b}}{10}$
$y=\frac{80}{10}$
$y=8 \mathrm{~cm}$

8. Cálculo de y' (distância de aplicação da resultante $H_{\text {inf }}$ até a base da fundação)

$y^{\prime}=\frac{l_{\text {emb }}}{10} \quad y^{\prime}=\frac{80}{10} \quad y^{\prime}=8 \mathrm{~cm}$

9. Cálculo da resultante de pressão superior na parede frontal

$H_{\text {sup } f}=\frac{M_{d}-N_{d} \cdot\left(e_{n b}+\frac{\mu \cdot y^{\prime}-\mu^{2} \cdot\left(0,5 \cdot h+e_{n b}\right)}{1+\mu^{2}}\right)+V_{d} \cdot\left(l_{e m b}-\frac{y^{\prime}-\mu \cdot\left(0,5 \cdot h+e_{n b}\right)}{1+\mu^{2}}\right)}{l_{e m b}-y-y^{\prime}+\mu \cdot h}$

$H_{\text {sup } f}=\frac{20000-250 \cdot\left(10+\frac{0,3 \cdot 8-0,3^{2} \cdot(0,5 \cdot 40+10)}{1+0,3^{2}}\right)+50 \cdot\left(80-\frac{8-0,3 \cdot(0,5 \cdot 40+10)}{1+0,3^{2}}\right)}{80-8-8+0,3 \cdot 40}$

$H_{\text {sup } f}=284,40 \mathrm{kN}$

10. Cálculo da resultante de pressão inferior na parede posterior
$H_{\text {inf }}=H_{\text {sup } f}-V_{d}$
$H_{\text {inf }, d}=284,40-50$
$H_{\text {inf,d }}=234,40 k N$

11. Cálculo de $A_{s, h p l}$
$A_{s, h p l}=\frac{H_{\text {sup } f}}{2 \cdot f_{y d}}$
$A_{s, h p l}=\frac{284,40}{2 \cdot 43,5}$
$A_{s, h p l}=3,28 \mathrm{~cm}^{2}$

Considerando uma distribuição da armadura horizontal principal longitudinal diferencial para os ramos externo e interno, tem-se: 
$A_{s, h p l e}=2 / 3 \cdot 3,28=2,18 \mathrm{~cm}^{2}$ e $A_{s, h p l i}=1 / 3 \cdot 3,28=1,10 \mathrm{~cm}^{2}$

12. Cálculo de $A_{s, h p t}$

12.1 Considerando tração da parede transversal frontal

a) Resultante de pressão superior:

$H_{\text {sup } f-f}=0$

$H_{\text {sup } f-t}=H_{\text {sup } f} \quad H_{\text {sup } f-t}=284,40 \mathrm{kN}$

b) Força normal:

$$
\begin{array}{rlrl}
N_{\text {sup } f-t}=\frac{H_{\text {sup } f-t}}{2 \cdot \operatorname{sen} \theta} \cdot \cos \theta & N_{\text {sup } f-t}=\frac{284,40}{2 \cdot \operatorname{sen} 45} \cdot \cos 45 & N_{\text {sup } f-t}=142,20 \mathrm{kN} \\
\text { c) Momento fletor: } & M_{\text {sup } f-f}=0 \\
\text { d) Cálculo das resultantes } &
\end{array}
$$

$$
\begin{array}{lll}
d=h_{c}-c-\frac{\phi}{2} & d=15-2,5-0,5 & d=12 \mathrm{~cm} \\
d^{\prime}=c+\frac{\phi}{2} & d^{\prime}=2,5+0,5 & d^{\prime}=3 \mathrm{~cm} \\
z=d-d^{\prime} & z=12-3 & z=9 \mathrm{~cm} \\
R_{s, h p t e}=\frac{N_{\text {sup } f-t}}{2}+\frac{M_{\text {sup } f-f}}{z} & R_{s, h p t e}=\frac{142,20}{2}+0 & R_{s, h p t e}=71,10 \mathrm{kN} \\
R_{s, h p t i}=\frac{N_{\text {sup } f-t}}{2}-\frac{M_{\text {sup } f-f}}{z} & R_{s, h p t i}=\frac{142,20}{2}-0 & R_{s, h p t i}=71,10 \mathrm{kN}
\end{array}
$$

e) Cálculo da armadura $A_{s, h p t}$ :
$A_{s, h p t e}=\frac{R_{s, h p t e}}{f_{y d}}$
$A_{s, h p t e}=\frac{71,10}{43,5}$
$A_{s, h p t e}=1,64 \mathrm{~cm}^{2}$
$A_{s, h p t i}=\frac{R_{s, h p t i}}{f_{y d}}$
$A_{s, h p t i}=\frac{71,10}{43,5}$
$A_{s, h p t i}=1,64 \mathrm{~cm}^{2}$
$A_{s, h p t}=A_{s, h p t e}+A_{s, h p t i}$
$A_{s, h p t}=1,64+1,64$
$A_{s, h p t}=3,28 \mathrm{~cm}^{2}$

Considerando uma distribuição da armadura horizontal principal transversal diferencial para os ramos externo e interno, tem-se:

$A_{s, h p t e}=2 / 3 \cdot 3,28=2,18 \mathrm{~cm}^{2}$ e $A_{s, h p t i}=1 / 3 \cdot 3,28=1,10 \mathrm{~cm}^{2}$ 
12.2 Considerando flexo-tração da parede transversal frontal

a) Resultante de pressão superior:

$$
\begin{array}{lll}
H_{\text {sup } f-f}=0,15 \cdot H_{\sup f, d} & H_{\sup f-f}=0,15 \cdot 284,40 & H_{\sup f-f}=42,66 k N \\
H_{\text {sup } f-t}=0,85 \cdot H_{\sup f, d} & H_{\sup f-t}=0,85 \cdot 284,40 & H_{\sup f-t}=241,74 k N
\end{array}
$$

b) Força normal:

$$
N_{\text {sup } f-t}=\frac{H_{\text {sup } f-t}}{2 \cdot \operatorname{sen} \theta} \cdot \cos \theta \quad N_{\text {sup } f-t}=\frac{241,74}{2 \cdot \operatorname{sen} 45} \cdot \cos 45 \quad N_{\text {sup } f-t}=120,87 \mathrm{kN}
$$

c) Momento fletor:

$$
\begin{aligned}
& M_{\text {sup } f-f}=H_{\text {sup } f-f} \cdot\left(\frac{b_{\text {int }}+h_{c}}{4}-\frac{b_{\text {int }}}{8}\right) \quad M_{\text {sup } f-f}=42,66 \cdot\left(\frac{50+15}{4}-\frac{50}{8}\right) \\
& M_{\text {sup } f-f}=426,61 \mathrm{kN} . \mathrm{cm}
\end{aligned}
$$

d) Cálculo das resultantes

$$
\begin{array}{lll}
R_{s, h p t e}=\frac{N_{\text {sup } f-t}}{2}+\frac{M_{\text {sup } f-f}}{z} & R_{s, h p t e}=\frac{120,87}{2}+\frac{426,61}{9} & R_{s, h p t e}=107,84 \mathrm{kN} \\
R_{s, h p t i}=\frac{N_{\sup f-t}}{2}-\frac{M_{\sup f-f}}{z} & R_{s, h p t i}=\frac{120,87}{2}-\frac{426,61}{9} & R_{s, h p t i}=13,04 \mathrm{kN}
\end{array}
$$

e) Cálculo da armadura $A_{s, h p t}$ :
$A_{s, h p t e}=\frac{R_{s, h p t e}}{f_{y d}}$
$A_{s, h p t e}=\frac{107,84}{43,5}$
$A_{s, h p t e}=2,48 \mathrm{~cm}^{2}$
$A_{s, h p t i}=\frac{R_{s, h p t i}}{f_{y d}}$
$A_{s, h p t i}=\frac{13,04}{43,5}$
$A_{s, h p t i}=0,30 \mathrm{~cm}^{2}$
$A_{s, h p t}=A_{s, h p t e}+A_{s, h p t i}$
$A_{s, h p t}=2,48+0,30$
$A_{s, h p t}=2,78 \mathrm{~cm}^{2}$

\section{Cálculo de $A_{s, v p}$}

Inclinação da biela da parede longitudinal:

$\beta=\operatorname{arctg} \frac{l_{c}-y}{0,85 \cdot h_{\text {ext }}-h_{c} / 2} \quad \beta=\operatorname{arct} \frac{79-8}{0,85 \cdot 80-15 / 2} \quad \beta=49,57^{\circ}$

Verificação tipo de consolo:

$\operatorname{tg} \beta=1,17 \rightarrow$ Consolo longo $(\operatorname{tg} \beta>1,0)$, porém os cálculos também devem ser feitos para consolo curto a fim de verificar quais valores resultam maiores. 
13.1 Cálculo como consolo longo (cálculo como viga)

a) Cálculo da altura útil:
$d_{c}=h_{e x t}-h_{c} / 2$
$d_{c}=84-17 / 2$
$d_{c}=75,5 \mathrm{~cm}$

b) Cálculo do momento fletor
$M_{d}=\frac{H_{\sup f}}{2} \cdot\left(l_{c}-y\right)$
$M_{d}=\frac{284,40}{2} \cdot(79-8)$
$M_{d}=10096,20 \mathrm{kN} . \mathrm{cm}$

c) Determinação dos coeficientes
$k_{c}=\frac{h_{c} \cdot d_{c}{ }^{2}}{M_{d}}$
$k_{c}=\frac{15 \cdot 75,5^{2}}{10096,2}$
$k_{c}=7,81$
$k_{s}=0,024$

d) Cálculo de $A_{s, v p}$ :
$A_{s, v p}=\frac{k_{s} \cdot M_{d}}{d_{c}}$
$A_{s, v p}=\frac{0,024 \cdot 10096,20}{75,5}$
$A_{s, v p}=3,34 \mathrm{~cm}^{2}$

e) Verificação da força cortante
$V_{R d 2}=0,27 \cdot\left(1-\frac{f_{c k}}{250}\right) \cdot f_{c d} \cdot h_{c} \cdot d_{c} \quad V_{R d 2}=0,27 \cdot\left(1-\frac{20}{250}\right) \cdot 10 \cdot 43 \cdot 15 \cdot 75,5$
$V_{R d 2}=385,91 \mathrm{kN}$
$V_{s d}=\frac{H_{\sup f}}{2}$
$V_{s d}=\frac{284,40}{2}$
$V_{s d}=142,20 \mathrm{kN}$
$V_{s d} \leq V_{R d 2} \quad \rightarrow$
$142,20 k N \leq 385,91 k N$
$\rightarrow \quad$ Verifica

13.2 Cálculo como consolo curto

a) Força na armadura vertical:
$R_{v p}=\frac{H_{\sup f}}{2} \cdot \operatorname{tg} \beta$
$R_{v p}=\frac{284,40}{2} \cdot 1,17$
$R_{v p}=166,88 \mathrm{kN}$

b) Cálculo de $A_{s, v p}$ :
$A_{s, v p}=\frac{R_{v p}}{f_{y d}}$
$A_{s, v p}=\frac{166,88}{43,5}$
$A_{s, v p}=3,84 \mathrm{~cm}^{2}$

c) Verificação do esmagamento da biela:
$R_{c b}=\frac{H_{\sup f}}{2 \cdot \cos \beta}$
$R_{c b}=\frac{284,40}{2 \cdot \cos 49,57}$
$R_{c b}=219,25 \mathrm{kN}$
$h_{\text {bie }}=\left(0,15 \cdot h_{\text {ext }} \cdot \operatorname{sen} \beta\right) \cdot 2$
$h_{\text {bie }}=(0,15 \cdot 80 \cdot \operatorname{sen} 49,57) \cdot 2$
$h_{b i e}=18,27 \mathrm{~cm}$ 


$$
\begin{array}{ll}
\sigma_{c d}=\frac{R_{c b}}{h_{b i e} \cdot h_{c}} \leq 0,85 \cdot f_{c d} \quad & \sigma_{c d}=\frac{219,25}{18,27 \cdot 15} \leq 0,85 \cdot 1,43 \\
\sigma_{c d} & =0,80 \mathrm{kN} / \mathrm{cm}^{2} \leq 1,21 \mathrm{kN} / \mathrm{cm}^{2} \rightarrow \text { Verifica }
\end{array}
$$

Adotando o maior valor entre os resultados de consolo curto e longo: $A_{s, v p}=3,84 \mathrm{~cm}^{2}$

14. Cálculo de $A_{s, v s}$

14.1 Cálculo como consolo longo
$A_{s, v s}=0,10 \% \cdot h_{c} \cdot h_{e x t}$
$A_{s, v s}=0,10 \% \cdot 15 \cdot 80$
$A_{s, v s}=1,20 \mathrm{~cm}^{2}$

14.2 Cálculo como consolo curto
$A_{s, v s}=0,40 \cdot A_{s, v p}$
$A_{s, v s}=0,40 \cdot 3,84$
$A_{s, v s}=1,54 \mathrm{~cm}^{2}$

Adotando o maior valor entre os resultados de consolo curto e longo: $A_{s, v s}=1,54 \mathrm{~cm}^{2}$

15. Cálculo de $A_{s, h s}$

15.1 Cálculo como consolo longo (segundo os Modelos I ou II da ABNT NBR 6118:2003 para elementos lineares sujeitos a força cortante)

Admitindo modelo de cálculo I:

$$
\begin{aligned}
& \frac{A_{s, h s}}{s}=\frac{H_{\text {sup } f} / 2-0,6 \cdot f_{c t d} \cdot h_{c} \cdot d_{c}}{0,9 \cdot d_{c} \cdot f_{y d}} \quad \frac{A_{s, h s}}{s}=\frac{284,40 / 2-0,6 \cdot 0,111 \cdot 15 \cdot 72,5}{0,9 \cdot 72,5 \cdot 43,5} \\
& \frac{A_{s, h s}}{s}=0,0246 \mathrm{~cm}^{2} / \mathrm{cm}
\end{aligned}
$$

Adotando estribo de $6,3 \mathrm{~mm}$ de $2 \operatorname{ramos} 0,312 \cdot 2=0,624 \mathrm{~cm}^{2}$

$s=\frac{0,624}{0,0246} \cong 25 \mathrm{~cm}$

15.2 Cálculo como consolo curto
$A_{s, h s}=0,25 \cdot A_{s, v p}$
$A_{s, h s}=0,25 \cdot 3,84$
$A_{s, h s}=0,96 \mathrm{~cm}^{2}$

Adotando o maior valor entre os resultados de consolo curto e longo: $A_{s, h s}=0,96 \mathrm{~cm}^{2}$ 
Resumo das armaduras necessárias

- Armadura horizontal principal

$$
\begin{aligned}
& A_{s, h p l}=A_{s, h p t}=3,28 \mathrm{~cm}^{2} \\
& A_{s, h p l e}=A_{s, h p t e}=2,18 \mathrm{~cm}^{2} \\
& A_{s, h p l i}=A_{s, h p t i}=1,10 \mathrm{~cm}^{2}
\end{aligned}
$$

- Armadura vertical principal

$$
A_{s, v p}=3,84 \mathrm{~cm}^{2}
$$

- Armadura vertical secundária

$$
A_{s, v s}=1,54 \mathrm{~cm}^{2}
$$

- Armadura horizontal secundária

$$
A_{s, h s}=0,96 \mathrm{~cm}^{2}
$$




\section{APÊNDICE B- EXEMPLO DE DIMENSIONAMENTO DE CÁLICE COM INTERFACE RUGOSA}

Considerando pilar pré-moldado com seção $40 \times 40 \mathrm{~cm}^{2}$ e carregamento de $N_{d}=250 \mathrm{kN}, M_{d}=200 \mathrm{kN} . \mathrm{m}$ e $V_{d}=50 \mathrm{kN}$, um roteiro de cálculo para cálice com interface rugosa é apresentado a seguir.

1. Cálculo de $b_{\text {int }}$ e $h_{\text {int }}$
$b_{\text {int }}=b+2 \cdot b_{j}$
$b_{\text {int }}=40+2 \cdot 5$
$b_{\text {int }}=50 \mathrm{~cm}$
$h_{\text {int }}=h+2 \cdot h_{j}$
$h_{\text {int }}=40+2 \cdot 5$
$h_{\text {int }}=50 \mathrm{~cm}$

2. Cálculo da espessura da parede do colarinho
$h_{c} \geq \frac{1}{3,5} \cdot\left(h_{\mathrm{int}}\right.$ ou $\left.b_{\mathrm{int}}\right)$
$h_{c} \geq \frac{1}{3,5} \cdot 50$
$h_{c}=15 \mathrm{~cm}$

3. Cálculo de $b_{e x t}$ e $h_{e x t}$
$b_{\text {ext }}=b_{\text {int }}+2 \cdot h_{c}$
$b_{\text {ext }}=50+2 \cdot 15$
$b_{\text {ext }}=80 \mathrm{~cm}$
$h_{\text {ext }}=h_{\mathrm{int}}+2 \cdot h_{c}$
$h_{\text {ext }}=50+2 \cdot 15$
$h_{\text {ext }}=80 \mathrm{~cm}$

4. Cálculo do comprimento de embutimento

$e=\frac{20000}{250 \cdot 40}=2$, fazendo a verificação da excentricidade, resulta grande excentricidade

$l_{\text {emb }}=1,6 \cdot h \quad l_{\text {emb }}=1,6 \cdot 40 \quad l_{\text {emb }}=64 \mathrm{~cm}$

5. Cálculo do comprimento do colarinho
$l_{c}=l_{\text {emb }}-1 \mathrm{~cm}^{*}$
$l_{c}=64-1 \mathrm{~cm}$
$l_{c}=63 \mathrm{~cm}$ 
* Podem ser adotados valores maiores que $1 \mathrm{~cm}$ para a espessura da junta abaixo do pilar prémoldado, com a finalidade de possíveis ajustes e acomodação de erros.

6. Cálculo da resultante de pressão superior na parede transversal frontal

$$
\begin{array}{lll}
M_{b d}=M_{d}+V_{d} \cdot l_{e m b} & M_{b d}=200+50 \cdot 0,64 & M_{b d}=232 \mathrm{kN} . \mathrm{m} \\
d_{c c}=0,9 \cdot h_{e x t} & d_{c c}=0,9 \cdot 80 & d_{c c}=72 \mathrm{~cm} \\
z_{c c}=0,9 \cdot d_{c c} & z_{c c}=0,9 \cdot 72 & z_{c c}=64,80 \mathrm{~cm} \\
R_{c c}=\frac{M_{b d}+N_{d} \cdot\left(0,5 \cdot h_{e x t}-0,5 \cdot h_{c}\right)}{z_{c c}} & R_{c c}=\frac{23200+250 \cdot(0,5 \cdot 80-0,5 \cdot 15)}{64,80} R_{c c}=483,41 \mathrm{kN}
\end{array}
$$

Adotando $\beta_{f}=60^{\circ}$
$H_{f}=\frac{R_{c c}}{\operatorname{tg} \beta_{f}}$
$H_{f}=\frac{483,41}{\operatorname{tg} 60^{\circ}}$
$H_{f}=279,10 \mathrm{kN}$
$H_{\text {sup } f}=0,6 \cdot H_{f}$
$H_{\text {sup } f}=0,6 \cdot 279,10$
$H_{\text {sup } f}=167,46 \mathrm{kN}$

7. Cálculo da resultante de pressão superior na parede transversal posterior

$$
R_{t v}=\frac{M_{b d}-N_{d} \cdot\left(z_{c c}+0,5 \cdot h_{c}-0,5 \cdot h_{e x t}\right)}{z_{c c}} \quad R_{t v}=\frac{23200-250 \cdot(64,80+0,5 \cdot 15-0,5 \cdot 80)}{64,80}
$$

$R_{t v}=233,41 \mathrm{kN}$

Adotando $\beta_{p}=35^{\circ}$
$H_{p}=\frac{R_{t v}}{\operatorname{tg} \beta_{p}}$
$H_{p}=\frac{233,41}{\operatorname{tg} 35^{\circ}}$
$H_{p}=333,34 k N$
$H_{\text {sup } p}=H_{p}$
$H_{\text {sup } p}=333,34 k N$

8. Cálculo de $A_{s, h p l}$
$A_{s, h p l}=\frac{H_{\sup f}}{2 \cdot f_{y d}}$
$A_{s, h p l}=\frac{167,46}{2 \cdot 43,5}$
$A_{s, h p l}=1,93 \mathrm{~cm}^{2}$
$A_{s, h p l}=\frac{H_{\text {sup } p}}{2 \cdot f_{y d}}$
$A_{s, h p l}=\frac{333,34}{2 \cdot 43,5}$
$A_{s, h p l}=3,84 \mathrm{~cm}^{2}$

Adotando o maior valor $A_{s, h p l}=3,84 \mathrm{~cm}^{2}$

Considerando uma distribuição da armadura horizontal principal longitudinal diferencial para os ramos externo e interno, tem-se: 
$A_{s, h p l e}=2 / 3 \cdot 3,84=2,56 \mathrm{~cm}^{2}$ e $A_{s, h p l i}=1 / 3 \cdot 3,84=1,28 \mathrm{~cm}^{2}$

9. Cálculo de $A_{s, h p t}$ da parede transversal frontal

9.1 Considerando tração da parede transversal frontal

a) Resultante de pressão superior:

$H_{\text {sup } f-f}=0$

$H_{\text {sup } f-t}=H_{\text {sup } f} \quad H_{\text {sup } f-t}=167,46 \mathrm{kN}$

b) Força normal:

$N_{\text {sup }-t}=\frac{H_{\text {sup } f-t}}{2 \cdot \operatorname{sen} \theta} \cdot \cos \theta$

$N_{\text {sup }-t}=\frac{167,46}{2 \cdot \operatorname{sen} 45} \cdot \cos 45$

$N_{\text {sup } p-t}=83,73 \mathrm{kN}$

c) Momento fletor:

$M_{\text {sup }-f}=0$

d) Cálculo das resultantes
$d=h_{c}-c-\frac{\phi}{2}$
$d=15-2,5-0,5$
$d=12 \mathrm{~cm}$
$d^{\prime}=c+\frac{\phi}{2}$
$d^{\prime}=2,5+0,5$
$d^{\prime}=3 \mathrm{~cm}$
$z=d-d^{\prime}$
$z=12-3$
$z=9 \mathrm{~cm}$
$R_{s, h p t e}=\frac{N_{\sup f-t}}{2}+\frac{M_{\sup f-f}}{z}$
$R_{\text {s,shpte }}=\frac{83,73}{2}+0$
$R_{s, h p t e}=41,86 \mathrm{kN}$
$R_{s, h p t i}=\frac{N_{\sup f-t}}{2}-\frac{M_{\sup f-f}}{z}$
$R_{s, h p t i}=\frac{83,73}{2}-0$
$R_{s, h p t i}=41,86 k N$

e) Cálculo da armadura $A_{s, h p t}$ :
$A_{s, h p t e}=\frac{R_{s, h p t e}}{f_{y d}}$
$A_{s, h p t e}=\frac{41,86}{43,5}$
$A_{s, h p t e}=0,96 \mathrm{~cm}^{2}$
$A_{s, h p t i}=\frac{R_{s, h p t i}}{f_{y d}}$
$A_{s, h p t i}=\frac{41,86}{43,5}$
$A_{s, h p t i}=0,96 \mathrm{~cm}^{2}$
$A_{s, h p t}=A_{s, h p t e}+A_{s, h p t i}$
$A_{s, h p t}=0,96+0,96$
$A_{s, h p t}=1,94 \mathrm{~cm}^{2}$

9.2 Considerando flexo-tração da parede transversal frontal

a) Resultante de pressão superior:
$H_{\text {sup } f-f}=0,15 \cdot H_{\text {sup } f}$
$H_{\text {sup } f-f}=0,15 \cdot 167,46$
$H_{\text {sup } f-f}=25,12 k N$ 


$$
H_{\text {sup } f-t}=0,85 \cdot H_{\text {sup } f} \quad H_{\text {sup } f-t}=0,85 \cdot 167,46 \quad H_{\text {sup } f-t}=142,34 k N
$$

b) Força normal:

$N_{\text {sup }-t}=\frac{H_{\text {sup } f-t}}{2 \cdot \operatorname{sen} \theta} \cdot \cos \theta \quad N_{\text {sup }-t}=\frac{142,34}{2 \cdot \operatorname{sen} 45} \cdot \cos 45 \quad N_{\text {sup }-t}=71,17 \mathrm{kN}$

c) Momento fletor:

$M_{\text {sup }-f}=H_{\text {sup } f-f} \cdot\left(\frac{b_{\text {int }}+h_{c}}{4}-\frac{b_{\text {int }}}{8}\right) \quad M_{\text {sup }-f}=25,12 \cdot\left(\frac{50+15}{4}-\frac{50}{8}\right)$

$M_{\text {sup-f }}=251,19 k N . c m$

d) Cálculo das resultantes
$R_{s, h p t e}=\frac{N_{\text {sup } f-t}}{2}+\frac{M_{\text {sup } f-f}}{z}$
$R_{s, h p t e}=\frac{71,17}{2}+\frac{251,19}{9}$
$R_{s, h p t e}=63,49 \mathrm{kN}$
$R_{s, h p t i}=\frac{N_{\text {sup } f-t}}{2}-\frac{M_{\text {sup } f-f}}{z}$
$R_{s, h p t i}=\frac{71,17}{2}-\frac{251,19}{9}$
$R_{s, h p t i}=7,68 \mathrm{kN}$

e) Cálculo da armadura $A_{s, h p t}$ :
$A_{s, h p t e}=\frac{R_{s, h p t e}}{f_{y d}}$
$A_{s, h p t e}=\frac{63,49}{43,5}$
$A_{s, h p t e}=1,46 \mathrm{~cm}^{2}$
$A_{s, h p t i}=\frac{R_{s, h p t i}}{f_{y d}}$
$A_{s, h p t i}=\frac{7,68}{43,5}$
$A_{s, h p t i}=0,18 \mathrm{~cm}^{2}$
$A_{s, h p t}=A_{s, h p t e}+A_{s, h p t i}$
$A_{s, h p t}=1,46+0,18$
$A_{s, h p t}=1,64 \mathrm{~cm}^{2}$

10. Cálculo de $A_{s, h p t}$ da parede transversal posterior

10.1 Considerando tração da parede transversal posterior

a) Resultante de pressão superior:

$$
\begin{aligned}
& H_{\text {sup } p-f}=0 \\
& H_{\text {sup } p-t}=H_{\text {sup } p} \quad H_{\text {sup } p-t}=333,34 k N
\end{aligned}
$$

b) Força normal:

$$
\begin{array}{rlrl}
N_{\text {sup }-t} & =\frac{H_{\text {sup } f-t}}{2 \cdot \operatorname{sen} \theta} \cdot \cos \theta & N_{\text {sup }-t}=\frac{333,34}{2 \cdot \operatorname{sen} 45} \cdot \cos 45 & N_{\text {sup }-t}=166,67 \mathrm{kN} \\
\text { c) Momento fletor: } & M_{\text {sup }-f}=0 \\
\text { d) Cálculo das resultantes } &
\end{array}
$$$$
R_{s, h p t e}=\frac{N_{\text {sup } f-t}}{2}+\frac{M_{\text {sup } f-f}}{z} \quad R_{s, h p t e}=\frac{1666,67}{2}+0 \quad R_{s, h p t e}=83,34 \mathrm{kN}
$$ 
$R_{s, h p t i}=\frac{N_{\text {sup } f-t}}{2}-\frac{M_{\sup f-f}}{z} \quad R_{s, h p t i}=\frac{1666,67}{2}-0 \quad R_{s, h p t i}=83,34 k N$

e) Cálculo da armadura $A_{s, h p t}$ :
$A_{s, h p t e}=\frac{R_{s, h p t e}}{f_{y d}}$
$A_{s, h p t e}=\frac{83,34}{43,5}$
$A_{s, h p t e}=1,92 \mathrm{~cm}^{2}$
$A_{s, h p t i}=\frac{R_{s, h p t i}}{f_{y d}}$
$A_{s, h p t i}=\frac{83,34}{43,5}$
$A_{s, h p t i}=1,92 \mathrm{~cm}^{2}$
$A_{s, h p t}=A_{s, h p t e}+A_{s, h p t i}$
$A_{s, h p t}=1,82+1,82$
$A_{s, h p t}=3,84 \mathrm{~cm}^{2}$

10.2 Considerando flexo-tração da parede transversal posterior

a) Resultante de pressão superior:
$H_{\text {sup } p-f}=0,15 \cdot H_{\text {sup } f}$
$H_{\text {sup } p-f}=0,15 \cdot 333,34$
$H_{\text {sup } p-f}=50 \mathrm{kN}$
$H_{\text {sup } p-t}=0,85 \cdot H_{\text {sup } f}$
$H_{\text {sup } p-t}=0,85 \cdot 333,34$
$H_{\text {sup } p-t}=283,34 k N$

b) Força normal de tração:
$N_{\text {sup }-t}=\frac{H_{\text {sup } f-t}}{2 \cdot \operatorname{sen} \theta} \cdot \cos \theta$
$N_{\text {sup }-t}=\frac{283,34}{2 \cdot \operatorname{sen} 45} \cdot \cos 45 \quad N_{\text {sup }-t}=141,67 \mathrm{kN}$

c) Momento fletor:

$M_{\text {sup }-f}=H_{\text {sup } f-f} \cdot\left(\frac{b_{\text {int }}+h_{c}}{4}-\frac{b_{\text {int }}}{8}\right) \quad M_{\text {sup }-f}=50 \cdot\left(\frac{50+15}{4}-\frac{50}{8}\right) M_{\text {sup }-f}=500,02 \mathrm{kN} . \mathrm{cm}$

d) Cálculo das resultantes
$R_{s, h p t e}=\frac{N_{\sup f-t}}{2}+\frac{M_{\sup f-f}}{z}$
$R_{s, h p t e}=\frac{141,67}{2}+\frac{500,02}{9}$
$R_{s, h p t e}=126,39 \mathrm{kN}$
$R_{s, h p t i}=\frac{N_{\sup f-t}}{2}-\frac{M_{\sup f-f}}{z}$
$R_{s, h p t i}=\frac{141,67}{2}-\frac{500,02}{9}$
$R_{s, h p t i}=15,28 \mathrm{kN}$

e) Cálculo da armadura $A_{s, h p t}$ :
$A_{s, h p t e}=\frac{R_{s, h p t e}}{f_{y d}}$
$A_{s, h p t e}=\frac{126,39}{43,5}$
$A_{s, h p t e}=2,91 \mathrm{~cm}^{2}$
$A_{s, h p t i}=\frac{R_{s, h p t i}}{f_{y d}}$
$A_{s, h p t i}=\frac{15,28}{43,5}$
$A_{s, h p t i}=0,35 \mathrm{~cm}^{2}$
$A_{s, h p t}=A_{s, h p t e}+A_{s, h p t i}$
$A_{s, h p t}=2,91+0,35$
$A_{s, h p t}=3,26 \mathrm{~cm}^{2}$ 
Adotando o maior valor de área entre os resultados, tem-se para a consideração somente de tração da parede posterior $A_{s, h p t}=3,84 \mathrm{~cm}^{2}$ e para flexo-tração $A_{s, h p t}=3,26 \mathrm{~cm}^{2}$. E considerando uma distribuição da armadura horizontal principal transversal diferencial para os ramos externo e interno, tem-se:

$$
A_{s, h p t e}=2 / 3 \cdot 3,84=2,56 \mathrm{~cm}^{2} \text { e } A_{s, h p t i}=1 / 3 \cdot 3,84=1,28 \mathrm{~cm}^{2}
$$

11. Cálculo de $A_{s, v p}$

a) Cálculo da altura útil

$$
d_{c}=h_{e x t}-h_{c} / 2 \quad d_{c}=80-15 / 2 \quad d_{c}=72,5 \mathrm{~cm}
$$

b) Determinação da posição da linha neutra:

\section{Considerando Domínio 2:}

$\sigma_{c d}=0,85 \cdot f_{c d} \cdot\left[1-\left(1-\frac{\varepsilon_{c}}{2}\right)^{2}\right] \quad \sigma_{c d}=0,85 \cdot 4,43 \cdot\left[1-\left(1-\frac{1,11}{2}\right)^{2}\right] \quad \sigma_{c d}=0,97 \mathrm{kN} / \mathrm{cm}^{2}$

Conhecendo a seção e o carregamento, pode-se determinar a posição da linha neutra para armadura simples.

$$
M_{b d}-0,5 \cdot N_{d} \cdot h_{e x t}+N_{d} \cdot d_{c}-0,8 \cdot x \cdot \sigma_{c d} \cdot d_{c}+0,32 \cdot x^{2} \cdot h_{e x t} \cdot \sigma_{c d}=0 \quad x=7,22 \mathrm{~cm}
$$

c) Cálculo da resultante de tração e compressão

$$
\begin{array}{lll}
R_{s}=\frac{M_{b d}-N_{d} \cdot\left(0,5 \cdot h_{e x t}-0,4 \cdot x\right)}{d_{c}-0,4 \cdot x} & R_{s}=\frac{232-250 \cdot(0,5 \cdot 80-0,4 \cdot 7,22)}{72,5-0,4 \cdot 7,22} & R_{s}=200 \mathrm{kN} \\
R_{c}=0,8 \cdot x \cdot h_{\text {ext }} \cdot \sigma_{c d} & R_{c}=0,8 \cdot 7,00 \cdot 80 \cdot 0,97 & R_{c}=450 \mathrm{kN}
\end{array}
$$

d) Cálculo de $A_{s, v p}$
$A_{s, t o t}=\frac{R_{s d}}{f_{y d}}$
$A_{s, t o t}=\frac{200}{43,5}$
$A_{s, t o t}=4,60 \mathrm{~cm}^{2}$
$A_{s, v p}=\frac{A_{s, t o t}}{2+0,4}$
$A_{s, v p}=\frac{4,60}{2+0,4}$
$A_{s, v p}=1,92 \mathrm{~cm}^{2}$

12. Cálculo de $A_{s, v s}$ (considerando as indicações para consolo curto)
$A_{s, v s}=0,40 \cdot A_{s, v p}$
$A_{s, v s}=0,40 \cdot 1,92$
$A_{s, v s}=0,77 \mathrm{~cm}^{2}$ 
13. Cálculo de $A_{s, h s}$ (considerando as indicações para consolo curto)
$A_{s, h s}=0,25 \cdot A_{s, v p}$
$A_{s, h s}=0,25 \cdot 1,92$
$A_{s, h s}=0,48 \mathrm{~cm}^{2}$

\section{Resumo das armaduras necessárias}

- Armadura horizontal principal

$$
\begin{aligned}
& A_{s, h p l}=A_{s, h p t}=3,84 \mathrm{~cm}^{2} \\
& A_{s, h p l e}=A_{s, h p t e}=2,30 \mathrm{~cm}^{2} \\
& A_{s, h p l i}=A_{s, h p t i}=1,54 \mathrm{~cm}^{2}
\end{aligned}
$$

- Armadura vertical principal

$$
A_{s, v p}=1,92 \mathrm{~cm}^{2}
$$

- Armadura vertical secundária

$$
A_{s, v s}=0,77 \mathrm{~cm}^{2}
$$

- Armadura horizontal secundária

$$
A_{s, h s}=0,48 \mathrm{~cm}^{2}
$$




\section{APÊNDICE $C$ - EXEMPLO DE DIMENSIONAMENTO DE CÁLICE SUBMETIDO À FLEXÃO OBLÍQUA}

Considerando pilar pré-moldado com seção $40 \times 40 \mathrm{~cm}^{2}$ e carregamento de $N_{d}=250 \mathrm{kN}, M_{x d}=200 \mathrm{kN} . \mathrm{m}, M_{y d}=50 \mathrm{kN} . \mathrm{m}$ e $V_{d}=50 \mathrm{kN}$, um roteiro de cálculo para cálice de interface lisa submetido à flexão oblíqua é apresentado a seguir.

1. Cálculo de $b_{\text {int }}$ e $h_{\text {int }}$
$b_{\text {int }}=b+2 \cdot b_{j}$
$b_{\text {int }}=40+2 \cdot 5$
$b_{\text {int }}=50 \mathrm{~cm}$
$h_{\text {int }}=h+2 \cdot h_{j}$
$h_{\text {int }}=40+2 \cdot 5$
$h_{\text {int }}=50 \mathrm{~cm}$

2. Cálculo da espessura da parede do colarinho
$h_{c} \geq \frac{1}{3,5} \cdot\left(h_{\mathrm{int}}\right.$ ou $\left.b_{\mathrm{int}}\right)$
$h_{c} \geq \frac{1}{3,5} \cdot 50$
$h_{c}=15 \mathrm{~cm}$

3. Cálculo de $b_{e x t}$ e $h_{e x t}$
$b_{\text {ext }}=b_{\mathrm{int}}+2 \cdot h_{c}$
$b_{\text {ext }}=50+2 \cdot 15$
$b_{\text {ext }}=80 \mathrm{~cm}$
$h_{\text {ext }}=h_{\mathrm{int}}+2 \cdot h_{c}$
$h_{\text {ext }}=50+2 \cdot 15$
$h_{\text {ext }}=80 \mathrm{~cm}$

4. Cálculo do comprimento de embutimento

Determinando as excentricidades:
$\operatorname{exc}_{x}=\frac{M_{x d}}{N_{d} \cdot h}$
$\operatorname{exc}_{x}=\frac{20000}{250 \cdot 40}$
$\operatorname{exc}_{x}=2$

Grande excentricidade
$l_{\text {emb }}=2,0 \cdot h$
$l_{\text {emb }}=2,0 \cdot 40$
$l_{\text {emb }}=80 \mathrm{~cm}$
$\operatorname{exc} c_{y}=\frac{M_{y d}}{N_{d} \cdot b}$
$e x c_{y}=\frac{5000}{250 \cdot 40}$
$e x c_{y}=0,50$ 
Situação intermediária entre grande e pequena excentricidade
$l_{\text {emb }}=1,5 \cdot h$
$l_{\text {emb }}=1,5 \cdot 40$
$l_{\text {emb }}=60 \mathrm{~cm}$

Adotando o maior valor, tem-se $l_{e m b}=80 \mathrm{~cm}$.

5. Cálculo do comprimento do colarinho
$l_{c}=l_{\text {emb }}-1 \mathrm{~cm}^{*}$
$l_{c}=80-1 \mathrm{~cm}$
$l_{c}=79 \mathrm{~cm}$

* Podem ser adotados valores maiores que $1 \mathrm{~cm}$ para a espessura da junta abaixo do pilar prémoldado, com a finalidade de possíveis ajustes e acomodação de erros.

6. Cálculo da excentricidade da reação normal na base do pilar (considerando uma aplicação prática)
$e_{n b}=\frac{h}{4}$
$e_{n b}=\frac{40}{4}$
$e_{n b}=10 \mathrm{~cm}$

7. Cálculo de y (distância de aplicação da resultante $H_{\text {sup } f}$ até o topo do colarinho)

$y=\frac{l_{\text {emb }}}{10} \quad y=\frac{80}{10} \quad y=8 \mathrm{~cm}$

8. Cálculo de y' (distância de aplicação da resultante $H_{\text {inf }}$ até a base da fundação)

$y^{\prime}=\frac{l_{\text {emb }}}{10} \quad y^{\prime}=\frac{80}{10} \quad y^{\prime}=8 \mathrm{~cm}$

\section{Armaduras resultantes da atuação de $M_{x d}$}

9. Cálculo da resultante de pressão superior na parede frontal

$$
\begin{aligned}
& H_{\text {sup } f}=\frac{M_{d}-N_{d} \cdot\left(e_{n b}+\frac{\mu \cdot y^{\prime}-\mu^{2} \cdot\left(0,5 \cdot h+e_{n b}\right)}{1+\mu^{2}}\right)+V_{d} \cdot\left(l_{e m b}-\frac{y^{\prime}-\mu \cdot\left(0,5 \cdot h+e_{n b}\right)}{1+\mu^{2}}\right)}{l_{e m b}-y-y^{\prime}+\mu \cdot h} \\
& H_{\text {sup } f}=\frac{20000-250 \cdot\left(10+\frac{0,3 \cdot 8-0,3^{2} \cdot(0,5 \cdot 40+10)}{1+0,3^{2}}\right)+50 \cdot\left(80-\frac{8-0,3 \cdot(0,5 \cdot 40+10)}{1+0,3^{2}}\right)}{80-8-8+0,3 \cdot 40} \\
& H_{\text {sup } f}=284,40 \mathrm{kN}
\end{aligned}
$$


10. Cálculo de $A_{s, h p l_{-} x}$
$A_{s, h p l_{-} x}=\frac{H_{\text {sup } f}}{2 \cdot f_{y d}}$
$A_{s, h p l_{-} x}=\frac{284,40}{2 \cdot 43,5}$
$A_{s, h p l_{-} x}=3,27 \mathrm{~cm}^{2}$

11. Cálculo de $A_{s, h p t_{-} x}$

a) Resultante de pressão superior:

$H_{\text {sup } f-f}=0$

$H_{\text {sup } f-t}=H_{\text {sup } f} \quad H_{\text {sup } f-t}=284,40 \mathrm{kN}$

b) Força normal de tração:
$N_{\text {sup }-t}=\frac{H_{\text {sup } f-t}}{2 \cdot \operatorname{sen} \theta} \cdot \cos \theta$
$N_{\text {sup }-t}=\frac{284,40}{2 \cdot \operatorname{sen} 45} \cdot \cos 45$
$N_{\text {sup }-t}=142,20 \mathrm{kN}$
c) Momento fletor:
$M_{\text {sup }-f}=0$
d) Cálculo das resultantes
$d=h_{c}-c-\frac{\phi}{2}$
$d=15-2,5-0,5$
$d=12 \mathrm{~cm}$
$d^{\prime}=c+\frac{\phi}{2}$
$d^{\prime}=2,5+0,5$
$d^{\prime}=3 \mathrm{~cm}$
$z=d-d^{\prime}$
$z=12-3$
$z=9 \mathrm{~cm}$
$R_{s, h p t e}=\frac{N_{\sup f-t}}{2}+\frac{M_{\sup f-f}}{z}$
$R_{s, h p t e}=\frac{142,20}{2}+0$
$R_{s, \text { hpte }}=71,10 \mathrm{kN}$
$R_{s, h p t i}=\frac{N_{\sup f-t}}{2}-\frac{M_{\sup f-f}}{z}$
$R_{s, h p t i}=\frac{142,20}{2}-0$
$R_{s, h p t i}=71,10 \mathrm{kN}$

e) Cálculo da armadura $A_{s, h p t_{-} x}$ :
$A_{s, h p t e_{-}-}=\frac{R_{s, h p t e}}{f_{y d}}$
$A_{s, h p t e_{-} x}=\frac{71,10}{43,5}$
$A_{s, h p t e_{-} x}=1,64 \mathrm{~cm}^{2}$
$A_{s, h p t i-x}=\frac{R_{s, h p t i}}{f_{y d}}$
$A_{s, h p t i \_x}=\frac{71,10}{43,5}$
$A_{s, h p t i_{-} x}=1,64 \mathrm{~cm}^{2}$
$A_{s, h p t_{-} x}=A_{s, h p t e_{-} x}+A_{s, h p t i_{-} x}$
$A_{s, h p t_{-} x}=1,64+1,64$
$A_{s, h p t_{-} x}=3,28 \mathrm{~cm}^{2}$

\section{Cálculo de $A_{s, v p_{-} x}$}

Inclinação da biela da parede longitudinal:

$\beta=\operatorname{arctg} \frac{l_{c}-y}{0,85 \cdot h_{\text {ext }}-h_{c} / 2} \quad \beta=\operatorname{arct} \frac{79-8}{0,85 \cdot 80-15 / 2} \quad \beta=49,57^{\circ}$ 
Calculando como consolo curto:

a) Força na armadura vertical:
$R_{v p}=\frac{H_{\sup f}}{2} \cdot \operatorname{tg} \beta$
$R_{v p}=\frac{284,40}{2} \cdot 1,17$
$R_{v p}=166,88 \mathrm{kN}$

b) Cálculo de $A_{s, v p_{-} x}$ :
$A_{s, v p_{-} x}=\frac{R_{v p}}{f_{y d}}$
$A_{s, v p_{-} x}=\frac{166,88}{43,5}$
$A_{s, v p_{-} x}=3,84 \mathrm{~cm}^{2}$

c) Verificação do esmagamento da biela:
$R_{c b}=\frac{H_{\sup f}}{2 \cdot \cos \beta}$
$R_{c b}=\frac{284,40}{2 \cdot \cos 49,57}$
$R_{c b}=219,25 \mathrm{kN}$
$h_{\text {bie }}=\left(0,15 \cdot h_{\text {ext }} \cdot \operatorname{sen} \beta\right) \cdot 2$
$h_{\text {bie }}=(0,15 \cdot 80 \cdot \operatorname{sen} 49,57) \cdot 2 \quad h_{b i e}=18,27 \mathrm{~cm}$
$\sigma_{c d}=\frac{R_{c b}}{h_{b i e} \cdot h_{c}} \leq 0,85 \cdot f_{c d}$
$\sigma_{c d}=\frac{219,25}{18,27 \cdot 15} \leq 0,85 \cdot 1,43$
$\sigma_{c d}=0,80 \mathrm{kN} / \mathrm{cm}^{2} \leq 1,21 \mathrm{kN} / \mathrm{cm}^{2} \rightarrow$ Verifica

13. Cálculo de $A_{s, v s_{-} x}$
$A_{s, v s_{-} x}=0,40 \cdot A_{s, v p_{-} x}$
$A_{s, v s_{-} x}=0,40 \cdot 3,84$
$A_{s, v s_{-} x}=1,54 \mathrm{~cm}^{2}$

14. Cálculo de $A_{s, h s_{-} x}$
$A_{s, h s_{-} x}=0,25 \cdot A_{s, v p_{-} x}$
$A_{s, h s_{-} x}=0,25 \cdot 3,84$
$A_{s, h s_{-} x}=0,96 \mathrm{~cm}^{2}$

\section{Armaduras resultantes da atuação de $M_{y d}$}

15. Cálculo da resultante de pressão superior na parede frontal

$H_{\text {sup } f}=\frac{M_{y d}+V_{d} \cdot\left(l_{e m b}-y^{\prime}\right)}{l_{e m b}-y-y^{\prime}} \quad H_{\text {sup } f}=\frac{5000+50 \cdot(80-8)}{80-8-8} \quad H_{\text {sup } f}=134,38 \mathrm{kN}$

16. Cálculo de $A_{s, h p l_{-} y}$
$A_{s, h p l_{-} y}=\frac{H_{\sup f}}{2 \cdot f_{y d}}$
$A_{s, h p l_{-} y}=\frac{134,38}{2 \cdot 43,5}$
$A_{s, h p l_{-} x}=1,54 \mathrm{~cm}^{2}$ 
17. Cálculo de $A_{s, h p t_{-} y}$

a) Resultante de pressão superior:

$H_{\text {sup } f-f}=0$

$H_{\text {sup } f-t}=H_{\text {sup } f} \quad H_{\text {sup } f-t}=134,38 k N$

b) Força normal de tração:
$N_{\text {sup }-t}=\frac{H_{\text {sup } f-t}}{2 \cdot \operatorname{sen} \theta} \cdot \cos \theta$
$N_{\text {sup }-t}=\frac{134,38}{2 \cdot \operatorname{sen} 45} \cdot \cos 45$
$N_{\text {sup }-t}=67,19 \mathrm{kN}$
c) Momento fletor:
$M_{s p u-f}=0$
d) Cálculo das resultantes
$R_{s, h p t e}=\frac{N_{\sup f-t}}{2}+\frac{M_{\sup f-f}}{z}$
$R_{s, h p t e}=\frac{67,19}{2}+0$
$R_{s, h p t e}=33,60 \mathrm{kN}$
$R_{s, h p t i}=\frac{N_{\sup f-t}}{2}-\frac{M_{\sup f-f}}{z}$
$R_{s, h p t i}=\frac{67,19}{2}-0$
$R_{s, h p t i}=33,60 \mathrm{kN}$

e) Cálculo da armadura $A_{s, h p t_{-} y}$ :
$A_{s, h p t e_{-} y}=\frac{R_{s, h p t e}}{f_{y d}}$
$A_{s, h p t e_{-} y}=\frac{33,60}{43,5}$
$A_{s, h p t e_{-} y}=0,77 \mathrm{~cm}^{2}$
$A_{s, h p t i_{-} y}=\frac{R_{s, h p t i}}{f_{y d}}$
$A_{s, h p t i_{-} y}=\frac{33,60}{43,5}$
$A_{s, h p t i_{-} y}=0,77 \mathrm{~cm}^{2}$
$A_{s, h p t_{-} y}=A_{s, h p t e_{-} y}+A_{s, h p t i_{-} y}$
$A_{s, h p t_{-} y}=1,64+1,64$
$A_{s, h p t_{-} y}=1,54 \mathrm{~cm}^{2}$

18. Cálculo de $A_{s, v p_{-} y}$

Calculando como consolo curto:

a) Força na armadura vertical:
$R_{v p}=\frac{H_{\sup f}}{2} \cdot \operatorname{tg} \beta$
$R_{v p}=\frac{134,38}{2} \cdot 1,17$
$R_{v p}=78,85 \mathrm{kN}$

b) Cálculo de $A_{s, v p_{-} y}$
$A_{s, v p_{-} y}=\frac{R_{v p}}{f_{y d}}$
$A_{s, v p_{-} y}=\frac{78,85}{43,5}$
$A_{s, v p_{-} y}=1,81 \mathrm{~cm}^{2}$ 
c) Verificação do esmagamento da biela:

$$
\begin{array}{lll}
R_{c b}=\frac{H_{\text {sup } f}}{2 \cdot \cos \beta} & R_{c b}=\frac{134,38}{2 \cdot \cos 49,57} & R_{c b}=103,60 \mathrm{kN} \\
\sigma_{c d}=\frac{R_{c b}}{h_{b i e} \cdot h_{c}} \leq 0,85 \cdot f_{c d} & \sigma_{c d}=\frac{103,60}{18,27 \cdot 15} \leq 0,85 \cdot 1,43 & \\
\sigma_{c d}=0,38 \mathrm{kN} / \mathrm{cm}^{2} \leq 1,21 \mathrm{kN} / \mathrm{cm}^{2} & \rightarrow \text { Verifica }
\end{array}
$$

19. Cálculo de $A_{s, v s_{-} y}$
$A_{s, v s_{-} y}=0,40 \cdot A_{s, v p_{-} y}$
$A_{s, v s_{-} y}=0,40 \cdot 1,81$
$A_{s, v s_{-} y}=0,73 \mathrm{~cm}^{2}$

20. Cálculo de $A_{s, h s_{-} y}$
$A_{s, h s_{-} y}=0,25 \cdot A_{s, v p_{-} y}$
$A_{s, h s_{-} y}=0,25 \cdot 1,81$
$A_{s, h s_{-} y}=0,45 \mathrm{~cm}^{2}$

\section{Armaduras finais}

- Armadura horizontal principal

Maior valor entre $A_{s, h p l_{-} x}=A_{s, h p t_{-} x}=3,27 \mathrm{~cm}^{2}$ e $A_{s, h p l_{-} y}=A_{s, h p t_{-} y}=1,54 \mathrm{~cm}^{2}$

- Armadura vertical principal

Soma de $A_{s, v p_{-} x}$ e $A_{s, v p_{-} y}$

$$
A_{s, v p}=A_{s, v p_{-} x}+A_{s, v p_{-} y} \quad A_{s, v p}=3,84+1,81 \quad A_{s, v p}=5,65 \mathrm{~cm}^{2}
$$

- Armadura vertical secundária

Soma de $A_{s, v s_{-} x}$ e $A_{s, v s_{-} y}$

$$
A_{s, v s}=A_{s, v s_{-} x}+A_{s, v s_{-} y} \quad A_{s, v s}=1,54+0,73 \quad A_{s, v s}=2,26 \mathrm{~cm}^{2}
$$

- Armadura horizontal secundária

Maior valor entre $A_{s, h s_{-} x}=0,96 \mathrm{~cm}^{2}$ e $A_{s, h s_{-} y}=0,45 \mathrm{~cm}^{2}$ 


\section{APÊNDICE D - ANÁLISE DO PILAR PRÉ- MOLDADO NA REGIÃO DE EMBUTIMENTO}

Considerando pilar pré-moldado com seção $40 \times 40 \mathrm{~cm}^{2}$ e carregamento último, observado nos ensaios de Ebeling (2006), de $N_{d}=242 \mathrm{kN}, M_{d}=290 \mathrm{kN} . \mathrm{m}$ e $V_{d}=0$, é apresentado a seguir um roteiro de cálculo para análise da base do pilar pré-moldado com interface lisa, considerando forças de atrito na base. A resistência média do concreto do pilar determinada dos ensaios foi de $f_{c m}=54 \mathrm{MPa}$.

1. Cálculo do comprimento de embutimento

Determinando a excentricidade:
$\operatorname{exc}=\frac{M_{d}}{N_{d} \cdot h}$
exc $=\frac{29000}{242 \cdot 40}$
exc $=3$
$l_{\text {emb }}=2,0 \cdot h$
$l_{\text {emb }}=2,0 \cdot 40$
$l_{\text {emb }}=80 \mathrm{~cm}$

2. Cálculo do comprimento do colarinho
$l_{c}=l_{\text {emb }}-1 \mathrm{~cm}$
$l_{c}=80-1 \mathrm{~cm}$
$l_{c}=79 \mathrm{~cm}$

3. Cálculo da altura útil
$d=h-c-\frac{\phi}{2}$
$d=40-2,5-0,5$
$d=37 \mathrm{~cm}$

4. Cálculo da excentricidade da reação normal na base do pilar
$e_{n b}=\frac{h}{4}$
$e_{n b}=\frac{40}{4}$
$e_{n b}=10 \mathrm{~cm}$

5. Cálculo de y (distância de aplicação da resultante $H_{\text {sup } f}$ até o topo do colarinho)
$y=\frac{l_{e m b}}{10}$
$y=\frac{80}{10}$
$y=8 \mathrm{~cm}$ 
6. Cálculo de y' (distância de aplicação da resultante $H_{\text {inf }}$ até a base da fundação)
$y^{\prime}=\frac{l_{\text {emb }}}{10}$
$y^{\prime}=\frac{80}{10}$
$y^{\prime}=8 \mathrm{~cm}$

7. Determinação do ângulo entre a biela de compressão e a armadura

$\operatorname{tg} \alpha=\frac{\frac{l_{\text {emb }}-y-y^{\prime}}{2}}{d-0,5 \cdot h+e_{n b}} \quad \operatorname{tg} \alpha=\frac{\frac{80-8-8}{2}}{37-0,5 \cdot 40+10} \quad \operatorname{tg} \alpha=1,19 \quad \alpha=49,84^{\circ}$

8. Cálculo da resultante de pressão superior na parede frontal

$H_{\text {sup } f}=\frac{\frac{M_{d}}{d-0,5 \cdot h+e_{n b}}+N_{d} \cdot\left(\frac{\mu^{2}}{1+\mu^{2}}-\frac{e_{n b}}{d-0,5 \cdot h+e_{n b}}\right)+V_{d} \cdot\left(\frac{\mu}{1+\mu^{2}}+\frac{y}{d-0,5 \cdot h+e_{n b}}+2 \cdot \operatorname{tg} \alpha\right)}{\mu+2 \cdot \operatorname{tg} \alpha}$

$H_{\text {sup } f}=\frac{\frac{29000}{37-0,5 \cdot 40+10}+242 \cdot\left(\frac{0,3^{2}}{1+0,3^{2}}-\frac{10}{37-0,5 \cdot 40+10}\right)+0}{0,3+2 \cdot \operatorname{tg} 49,84}$

$H_{\text {sup } f}=376,14 \mathrm{kN}$

9. Cálculo da resultante na base do pilar
$N_{b f}=\frac{N_{d}-\mu \cdot V_{d}}{1+\mu^{2}}$
$N_{b f}=\frac{242-0}{1+0,3^{2}}$
$N_{b f}=222,02 k N$

10. Cálculo da resultante de pressão na parede posterior

$H_{\text {inf }}=H_{\text {sup } f}-\mu \cdot N_{b f}-V_{d} \quad H_{\text {inf }}=376,14-0,3 \cdot 222,02-0 \quad H_{\text {inf }}=309,53 k N$

11. Cálculo das resultantes de tração e compressão

$$
\begin{array}{lll}
R_{v}=\frac{V_{d}}{\cos \theta} & R_{v}=0 & \\
R_{t}=\frac{M_{d}+V_{d} \cdot y-N_{d} \cdot e_{n b}}{d-0,5 \cdot h+e_{n b}} & R_{t}=\frac{29000+0-242 \cdot 10}{37-0,5 \cdot 40+10} & R_{t}=984,44 \mathrm{kN} \\
R_{c}=N_{d}-V_{d} \cdot \operatorname{tg} \alpha+R_{t} & R_{c}=242-0+984,44 & R_{c}=1226,44 \mathrm{kN}
\end{array}
$$


12. Cálculo da forças internas

a) $\mathrm{F}_{1}$

$$
F_{1}=R_{t} \quad F_{1}=984,44 k N
$$

b) $\mathrm{F}_{2}$

$$
\begin{array}{lr}
F_{2}=-\left(\frac{H_{\text {sup } f}-V_{d}}{\cos \alpha}\right) \quad F_{2}=-\left(\frac{376,14-0}{\cos 49,84}\right) & F_{2}=-583,23 k N \\
& \text { c) } F_{3} \\
F_{3}=-\left(N_{d}+R_{t}-H_{\sup f} \cdot(\mu+\operatorname{tg} \alpha)+V_{d} \cdot \operatorname{tg} \alpha\right) & \\
F_{3}=-(242+984,44-376,14 \cdot(0,3+\operatorname{tg} 49,84)+0) & F_{3}=-667,81 \mathrm{kN}
\end{array}
$$

d) $\mathrm{F}_{4}$

$$
F_{4}=H_{\text {inf }} \quad F_{4}=309,53 k N
$$

e) $\mathrm{F}_{5}$

$$
F_{5}=H_{\mathrm{inf}} \cdot(\mu+\operatorname{tg} \alpha) \quad F_{5}=309,53 \cdot(0,3+\operatorname{tg} 49,84) \quad F_{5}=459,71 \mathrm{kN}
$$

f) $\mathrm{F}_{6}$

$$
\begin{aligned}
F_{6}=-\left(\frac{H_{\text {inf }}}{\cos \alpha}\right) & F_{6}=-\left(\frac{309,53}{\cos 49,84}\right) & F_{6}=-479,99 \mathrm{kN} \\
\text { g) } \mathrm{F}_{7} & F_{7}=-\left(\frac{242-0}{1+0,3^{2}}\right) & F_{7}=-222,02 \mathrm{kN} \\
F_{7}=-\left(\frac{N_{d}-\mu \cdot V_{d}}{1+\mu^{2}}\right) & &
\end{aligned}
$$

h) $F_{8}$
$F_{8}=\frac{\mu \cdot N_{d}-\mu^{2} \cdot V_{d}}{1+\mu^{2}}$
$F_{8}=\frac{0,3 \cdot 242-0}{1+0,3^{2}}$
$F_{8}=66,61 \mathrm{kN}$

13. Cálculo das armaduras horizontais (estribos)

13.1 Parcela resistida pelo concreto

$$
\begin{array}{ll}
V_{c}=0,6 \cdot f_{c t d} \cdot b \cdot d & \\
f_{c t d}=0,21 \cdot 54^{2 / 3} & f_{c t d}=0,3 \mathrm{kN} / \mathrm{cm}^{2} \\
V_{c}=0,6 \cdot 0,30 \cdot 40 \cdot 37 & V_{c}=266,42 \mathrm{kN}
\end{array}
$$


13.2 Armadura resultante da força $\mathrm{F}_{4}$
$A_{s 4}=\frac{F_{4}-V_{c}}{f_{y d}}$
$A_{s 4}=\frac{309,53-266,42}{43,5}$
$A_{s 4}=0,99 \mathrm{~cm}^{2}$

Essa armadura contempla a distância de $\frac{l_{e m b}-y-y^{\prime}}{2}=32 \mathrm{~cm}$, assim a área de armadura por metro é de $A_{s 4}=3,10 \mathrm{~cm}^{2} / \mathrm{m}$.

13.3 Armadura mínima

$\frac{A_{s w, \min }}{s} \geq 0,2 \cdot \frac{f_{c t m}}{f_{y k}} \cdot b$

$$
\frac{A_{s w, \min }}{s} \geq 0,2 \cdot \frac{0,3 \cdot 54^{2 / 3}}{500} \cdot 40
$$

$\frac{A_{s w, \min }}{s} \geq 0,069 \mathrm{~cm}^{2} / \mathrm{cm}$

$A_{s w, \min } \geq 6,90 \mathrm{~cm}^{2} / \mathrm{m}$

Como $A_{s, \min } \geq A_{s 4}$ utilizar armadura mínima.

13.4 Armadura resultante da força $F_{8}$

Como a força $\mathrm{F}_{8}$ é menor que a parcela $V_{c}$ resistida pelo concreto, deve-se adotar para essa região a armadura mínima. 


\section{APÊNDICE E - SÍNTESE DAS RECOMENDAÇÕES DE PROJETO DE CÁLICES DE FUNDAÇÃO PARA SUBSIDIAR FUTURAS REVISÕES DA ABNT NBR 9062:2006}

Esse apêndice tem como objetivo apresentar uma síntese das recomendações de projeto de cálices de fundação por meio de colarinho e também para a base do pilar prémoldado na região de embutimento que poderão subsidiar futuras revisões da norma ABNT NBR 9062:2006 - Projeto e Execução de Estruturas de Concreto Pré-Moldado.

1. Definições

a) Ligação pilar-fundação por meio de cálice consiste num embutimento de parte do pilar pré-moldado em uma cavidade na base do elemento de fundação;

b) Colarinho é um tipo de cálice composto por um conjunto de paredes salientes que contornam a cavidade destinada ao encaixe dos pilares;

c) Cunhas de madeira e dispositivos de centralização são utilizadas para encaixe do pilar, para o prumo e posicionamento do pilar em planta e fixação temporária;

d) Junta é o espaço entre as paredes do colarinho e do pilar, o preenchimento é feito com graute ou concreto moldado no local.

2. Características geométricas cálice

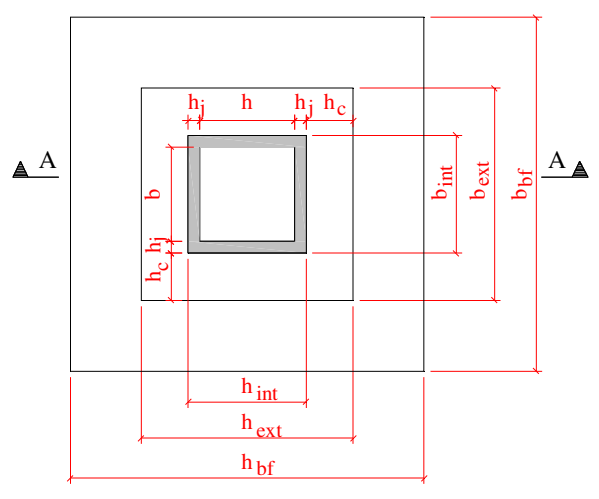

PLANTA

Figura A.1 - Características geométricas do cálice com colarinho

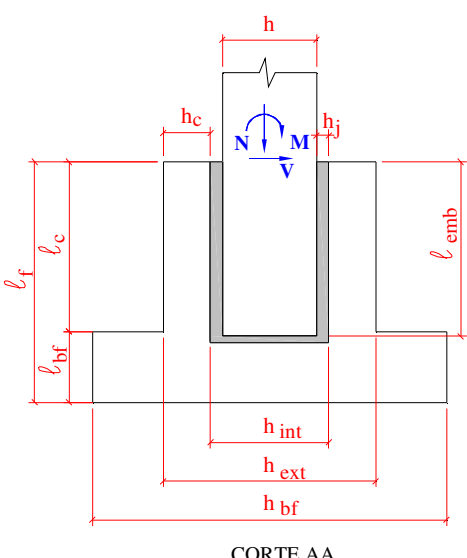

CORTE AA 
Nessa figura são determinadas as seguintes notações:

$b:$ Base da seção transversal do pilar

$b_{b f}$ : Base da seção em planta da base da fundação

$b_{\text {int }} / b_{\text {ext }}$ : Base interna/Base externa entre as paredes do colarinho

$h$ : Largura da seção transversal do pilar

$h_{b f}$ : Largura da seção em planta da base da fundação

$h_{\mathrm{int}} / h_{\text {ext }}$ : Largura interna/Largura externa entre as paredes do colarinho

$h_{j}$ : Espessura da junta de ligação do cálice com o pilar

$h_{c}$ : Espessura da parede do colarinho

$l_{b f}:$ Espessura da base da fundação

$l_{c}$ : Comprimento do consolo

$l_{f}:$ Comprimento da fundação

$l_{\text {emb }}$ : Comprimento de embutimento do pilar no cálice (não considerando a altura da junta abaixo do pilar)

$N, M e V:$ Esforços solicitantes atuantes na ligação

Identificação das paredes do colarinho
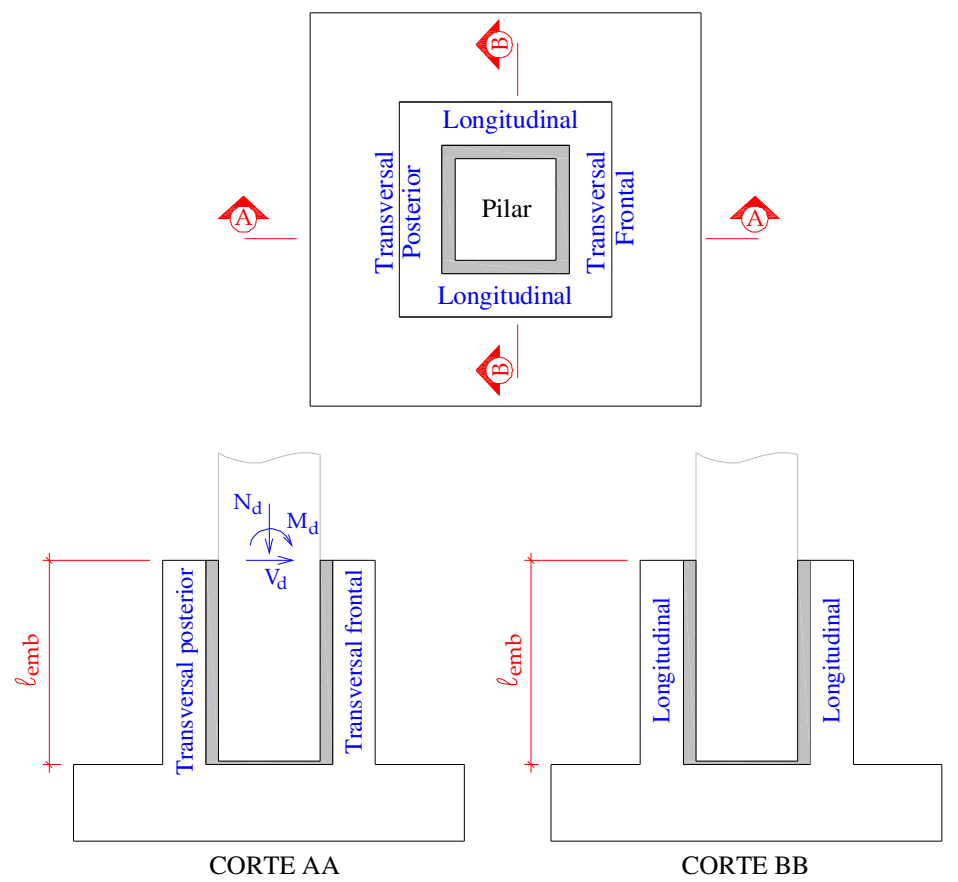

Figura A.2 - Identificação das paredes do colarinho 
3. Comportamento da ligação

3.1 Cálice com interface lisa

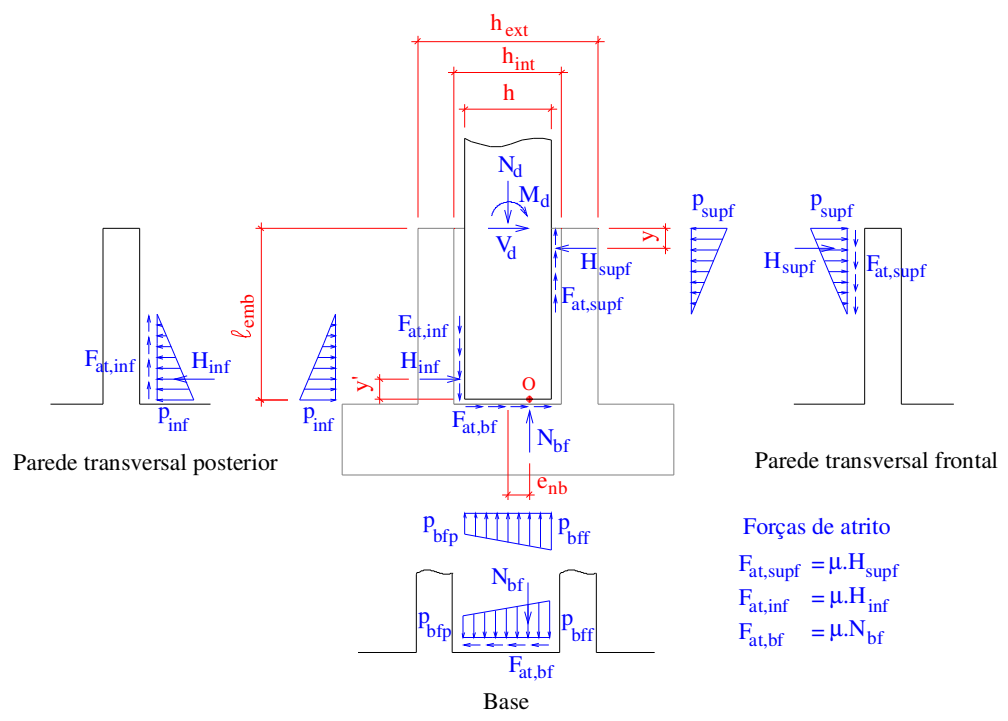

(a) Principais forças atuantes nos cálices com interface lisa

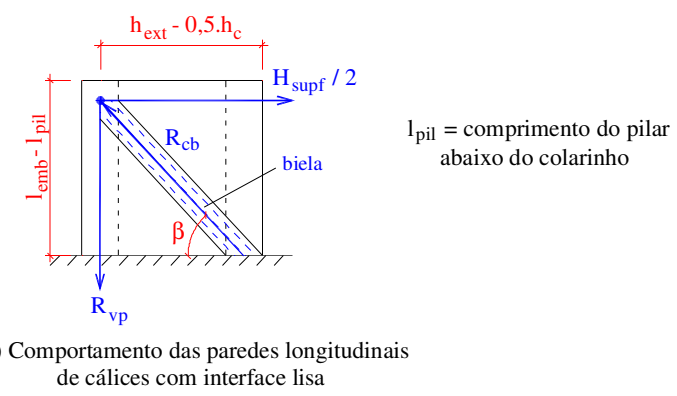

Figura A.3 - Transferência de forças no cálice com interface lisa

a) Paredes transversais e longitudinais são as responsáveis pela transferência de esforços provenientes do pilar até a fundação;

b) Concreto de preenchimento da junta responsável por transmitir os esforços solicitantes do pilar para as paredes transversais do cálice através das resultantes de pressões;

c) Pressão $H_{\text {inf }}$ atuante na parede transversal posterior é transmitida praticamente de forma direta para a base devido à pequena distância entre a resultante de pressão inferior e a base.

d) Forças de atrito surgem na interface pilar-colarinho das paredes transversais frontal e posterior devido as pressões;

e) Intensidade da força normal transmitida para a base do cálice pode ser reduzida pelas forças de atrito. 
f) Paredes longitudinais apresentam comportamento de consolo engastado na fundação.

A pressão atuante na parede transversal frontal é definida por:

$$
H_{\text {sup } f}=\frac{M_{d}-N_{d} \cdot\left(e_{n b}+\frac{\mu \cdot y^{\prime}-\mu^{2} \cdot\left(0,5 \cdot h+e_{n b}\right)}{1+\mu^{2}}\right)+V_{d} \cdot\left(l_{e m b}-\frac{y^{\prime}-\mu \cdot\left(0,5 \cdot h+e_{n b}\right)}{1+\mu^{2}}\right.}{l_{e m b}-y-y^{\prime}+\mu \cdot h}
$$

sendo que:

$e_{n b}=h / 4$

$y=y^{\prime}=l_{\text {emb }} / 10$

\subsection{Interface rugosa}

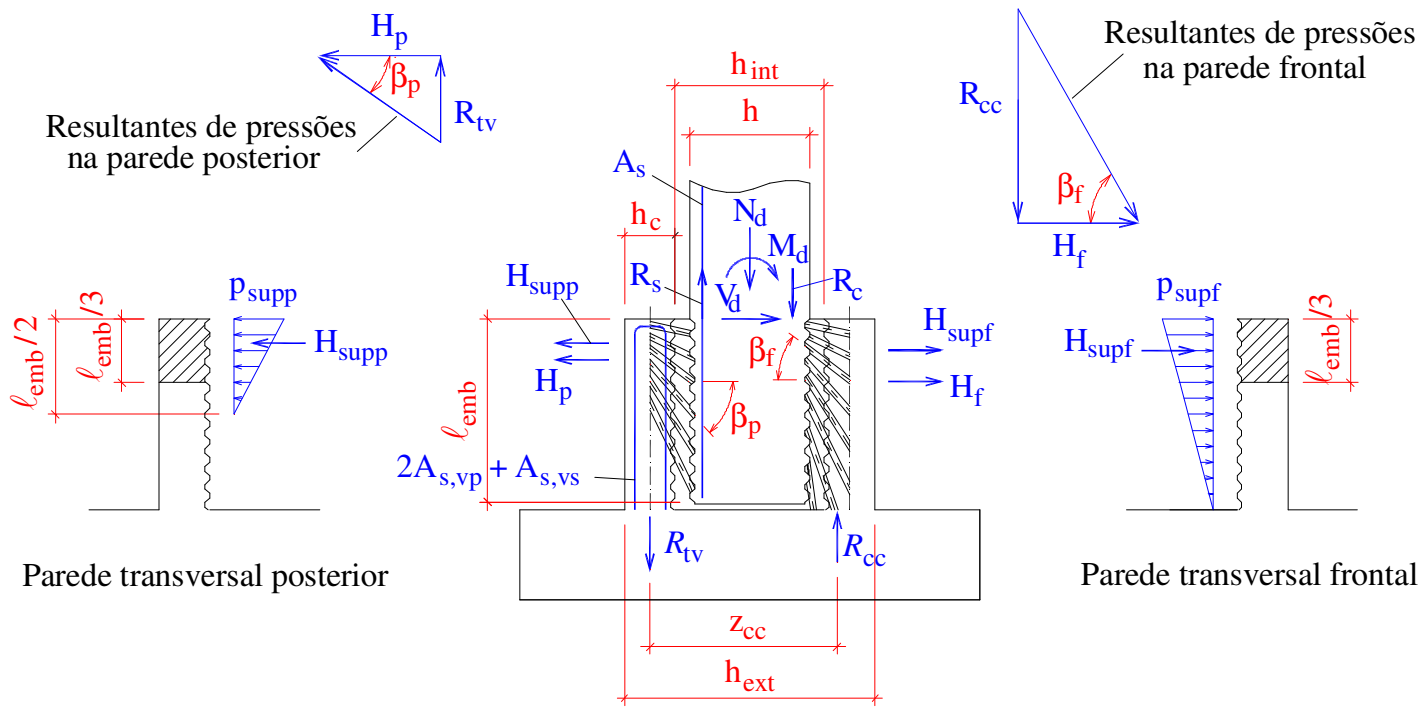

Figura A.4 - Transferência das forças no cálice com interface rugosa

a) Comportamento de uma ligação monolítica

b) Ocorrência de bielas de compressão no lado comprimido (parede transversal frontal) por causa da transferência da resultante de compressão $R_{c}$ do pilar para a parede frontal;

A pressão $H_{f}$ age na parede transversal frontal é definida por:

$$
H_{f}=\frac{R_{c c}}{\tan \beta_{f}}
$$

sendo que:

$$
\beta_{f}=60^{\circ}
$$




$$
\begin{aligned}
& R_{c c}=\frac{\left[M_{b d}+N_{d} \cdot\left(0,5 \cdot h_{e x t}-0,5 \cdot h_{c}\right)\right]}{z_{c c}} \\
& M_{b d}=M_{d}+V_{d} \cdot l_{e m b} \\
& z_{c c} \cong 0,9 \cdot d_{c c} \\
& d_{c c} \cong 0,9 \cdot h_{e x t} \\
& H_{\text {sup } f} \cong 0,6 \cdot H_{f}
\end{aligned}
$$

c) No lado tracionado (parede transversal posterior), a transmissão por bielas de compressão da maior parte da força de tração $R_{s}$, oriunda do pilar para a parede posterior, resulta na força $R_{t v}$ e em uma pressão $H_{p}$ atuante na parede;

A pressão $H_{p}$ é mais concentrada no topo da parede, bielas com menor inclinação em relação ao eixo horizontal e é definida por:

$$
H_{p}=\frac{R_{t v}}{\tan \beta_{p}}
$$

sendo que:

$\beta_{p}=35^{\circ}$

$$
\begin{aligned}
& R_{t v}=\frac{\left[M_{b d}-N_{d} \cdot\left(z_{c c}+0,5 \cdot h_{c}-0,5 \cdot h_{e x t}\right)\right]}{z_{c c}} \\
& H_{\text {sup } p}=H_{p}
\end{aligned}
$$

4. Armaduras constituintes de um cálice de fundação com colarinho

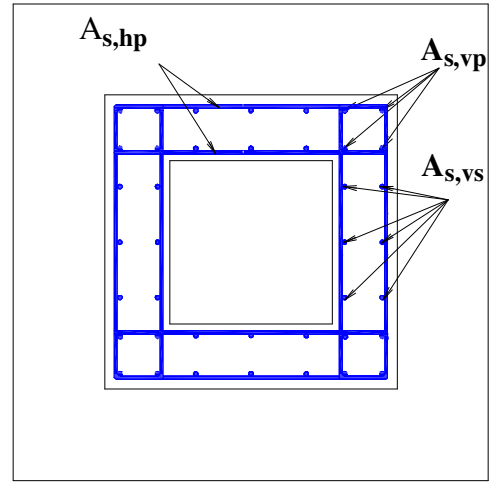

PLANTA

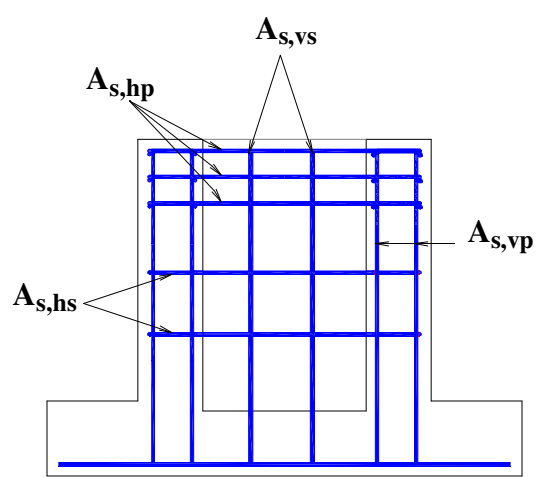

CORTE

Figura A.5 - Armaduras constituintes do cálice de fundação 
4.1 Armadura horizontal principal

4.1.1 Interface lisa

$$
A_{s, h p l}=\frac{H_{\sup f, d}}{2 \cdot f_{y d}}
$$

4.1.2 Interface rugosa
$A_{s, h p l}=\frac{H_{\sup f}}{2 \cdot f_{y d}}$
ou $\quad A_{s, h p l}=\frac{H_{\text {sup } p}}{2 \cdot f_{y d}}$
(maior valor)

\subsection{Armadura vertical principal}

\subsubsection{Interface lisa}

a) Dimensionamento da armadura e verificação da resistência a compressão do concreto considerando o comportamento e tipo de consolo:

- Consolo curto $(1,0 \geq \operatorname{tg} \beta>0,5)$ : modelo de biela e tirante

- Consolo muito curto $(\operatorname{tg} \beta \leq 0,5)$ : modelo de atrito-cisalhamento

- Consolo longo $(\operatorname{tg} \beta>1,0)$ : teoria da flexão

\subsubsection{Interface rugosa}
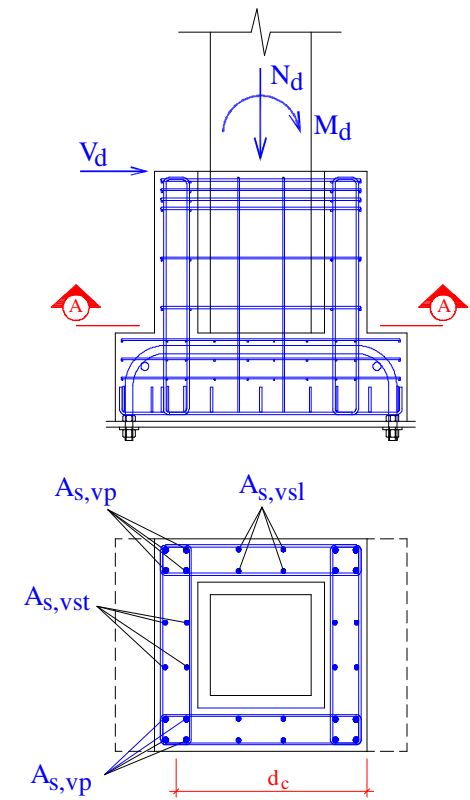

Corte AA
Diagrama parabólico retangular de tensões no concreto

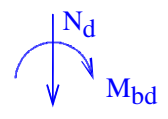

$\mathrm{R}_{\mathrm{S} 1}$

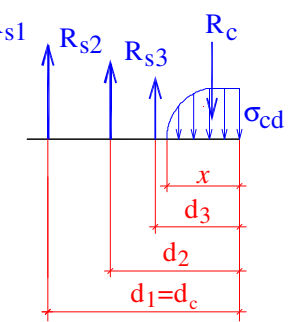

Diagrama simplificado
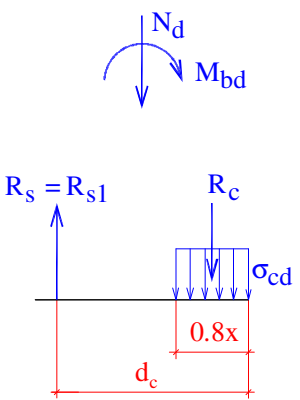

Figura A.6 - Esquema de forças para determinar a armadura vertical para cálice rugoso 
Teoria da flexão é recomendada para determinação da armadura vertical principal nos cálices com interface rugosa.

4.3 Armadura vertical e horizontal secundária

a) Recomendações de dimensionamento de consolo indicadas para cálculo da armadura vertical e horizontal secundária;

b) Utilizadas para resistir a esforços secundários e controlar a fissuração nas paredes do colarinho.

5. Base do pilar pré-moldado

- O modelo de biela e tirante para análise da base do pilar pré-moldado é indicado para cálices submetidos à força normal de grande excentricidade e com comprimentos de embutimento determinados de acordo com a ABNT NBR 9062:2006.

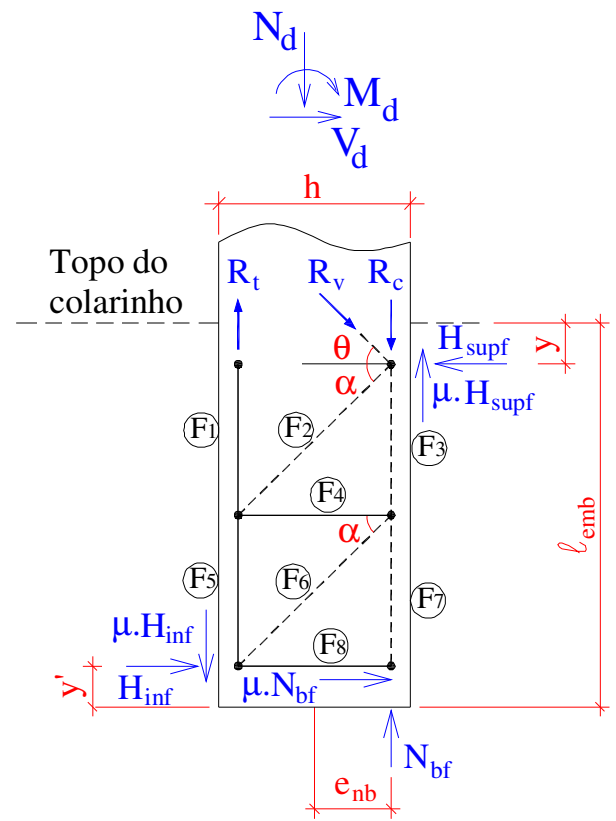

$$
\begin{gathered}
\text { Forças internas } \\
F_{1}=\frac{M_{d}-N_{d} \cdot e_{n b}+V_{d} \cdot y}{d-0,5 \cdot h+e_{n b}} \\
F_{2}=-\left(\frac{H_{\text {supf }}-V_{d}}{\cos \alpha}\right) \\
F_{3}=-\left(N_{d}+R_{t}-H_{\text {supf }} \cdot(\mu+\operatorname{tg} \alpha)+V_{d} \cdot \operatorname{tg} \alpha\right) \\
F_{4}=H_{\text {inf }} \\
F_{5}=(\mu+\operatorname{tg} \alpha) \cdot H_{\text {inf }} \\
F_{6}=-\left(\frac{H_{\text {inf }}}{\cos \alpha}\right) \\
F_{7}=-\left(\frac{N_{d}-\mu \cdot V_{d}}{1+\mu^{2}}\right) \\
F_{8}=\frac{\mu \cdot N_{d}-\mu^{2} \cdot V_{d}}{1+\mu^{2}}
\end{gathered}
$$

Figura A.7 - Modelo de projeto para análise da base do pilar pré-moldado

Os valores de $y, y^{\prime}$ e $e_{n b}$ são os mesmos indicados para o cálice. As resultantes $R_{v}$, $R_{c}$ e $R_{t}$ são definidas por:

$$
\begin{aligned}
& R_{v}=\frac{V_{d}}{\cos \theta} \\
& R_{c}=N_{d}-V_{d} \cdot \operatorname{tg} \theta+R_{t}
\end{aligned}
$$




$$
R_{t}=\frac{M_{d}+V_{d} \cdot y-N_{d} \cdot e_{n b}}{d-0,5 \cdot h+e_{n b}}
$$

O ângulo $\alpha$, inclinação das bielas em relação às armaduras é:

$$
\operatorname{tg} \alpha=\frac{\left(l_{e m b}-y-y^{\prime}\right) / 2}{d-0,5 \cdot h+e_{e n b}}
$$

A pressão na parede transversal frontal $H_{\text {sup } f}$ é determinada por:

$$
H_{\text {sup } f}=\frac{\frac{M_{d}}{d-0,5 \cdot h+e_{n b}}+N_{d} \cdot\left(\frac{\mu^{2}}{1+\mu^{2}}-\frac{e_{n b}}{d-0,5 \cdot h+e_{n b}}\right)+V_{d} \cdot\left(\frac{\mu}{1+\mu^{2}}+\frac{y}{d-0,5 \cdot h+e_{n b}}+2 \cdot \operatorname{tg} \alpha\right)}{\mu+2 \cdot \operatorname{tg} \alpha}
$$

6. Pequena excentricidade da força normal

- Relação momento fletor e força normal menor que 0,15 , o comportamento do cálice é semelhante ao modelo proposto por Leonhardt \& Mönnig (1978), sem consideração de forças de atrito e de excentricidade na base da fundação

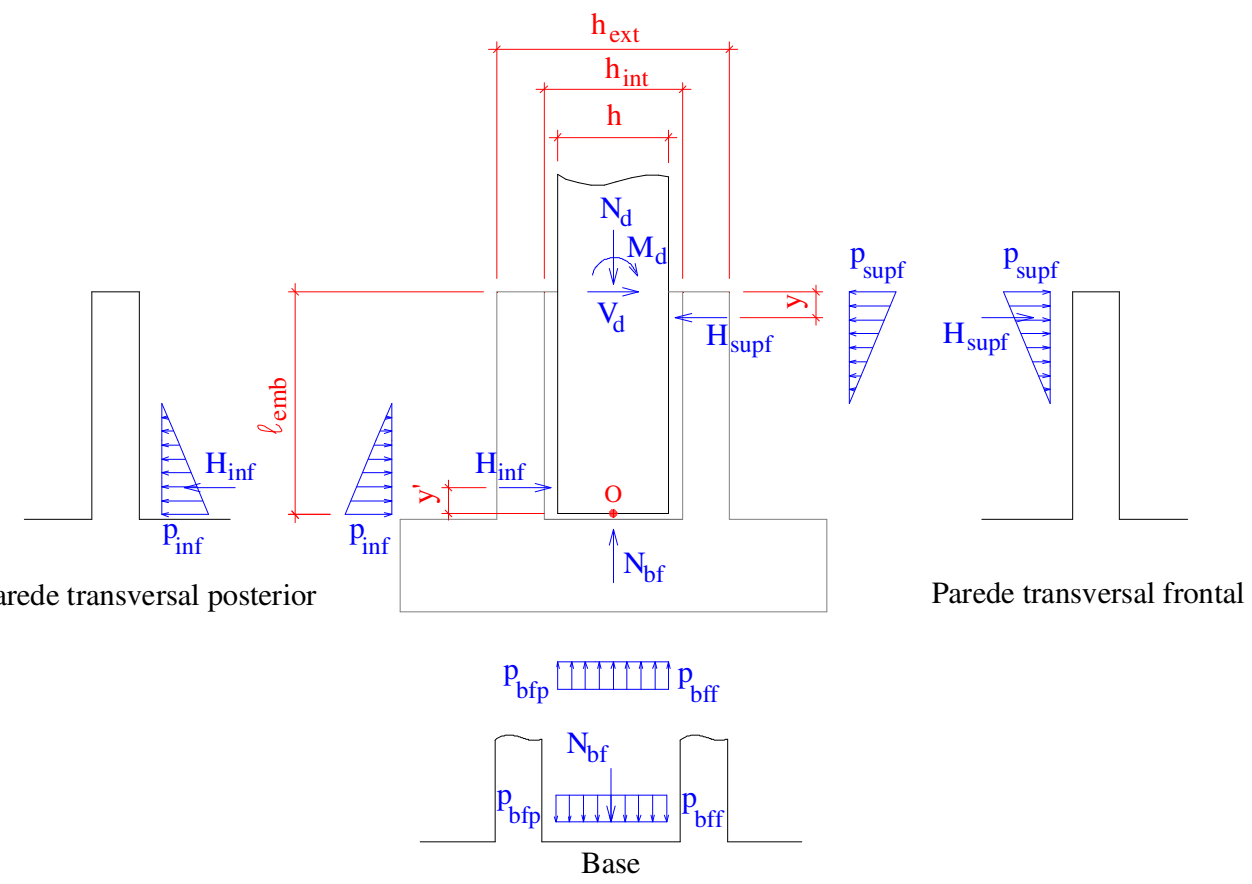

Figura A.8- Transferência de forças no cálice na situação de pequena excentricidade para cálice de interface lisa

A pressão atuante na parede transversal frontal é definida por:

$$
H_{\text {sup } f}=\frac{M_{d}+V_{d} \cdot\left(l_{e m b}-y^{\prime}\right)}{l_{e m b}-y-y^{\prime}}
$$


7. Flexão obliqua

a) Atuação simultânea de momentos fletores em duas direções ortogonais;

b) Armaduras verticais devem ser dimensionadas isoladamente nas duas direções e posteriormente é necessário somar as armaduras resultantes de cada caso;

c) Adotar para as armaduras horizontais o maior valor entre as armaduras resultantes da atuação do momento em cada direção;

d) Reduzir a tensão última de contato de $0,6 . f_{c d}$ para $0,5 . f_{c d}$ na verificação do esmagamento da biela de compressão;

e) Na definição do comprimento de embutimento, deve-se adotar o maior valor de $l_{e m b}$ obtido da análise isolada em cada direção, estando assim a favor da segurança.

8. Fase de montagem da ligação

a) No posicionamento do pilar pré-moldado na cavidade da fundação e na fixação temporária para o prumo, são utilizadas cunhas de madeira, sendo gerados esforços transversais nas paredes;

b) Fixação temporária do pilar pode causar fissuração nas paredes do colarinho de cálices de fundação e, conseqüentemente, alterar a rigidez dessas paredes. Dependendo do nível dos esforços resultantes, é necessário considerar a fase de montagem no projeto da ligação.

c) Na execução da ligação in loco, devem ser tomados os devidos cuidados na fixação temporária do pilar pré-moldado, como evitar uma força excessiva de cravação das cunhas que possa gerar, além de uma fissuração intensa nas paredes, danos como quebras das bordas das mesmas.

9. Disposições construtivas

\subsection{Embutimento na base}

a) Os comprimentos de embutimento são determinados de acordo com a interface das paredes do colarinho e do pilar: lisa ou rugosa, e de acordo com a excentricidade da força normal: pequena ou grande excentricidade.

b) Para valores intermediários de excentricidade, pode-se interpolar linearmente a relação de momento fletor e força normal para definição.

c) O valor mínimo recomendado é de $40 \mathrm{~cm}$. 


\begin{tabular}{c}
\begin{tabular}{c|c|c|c}
\hline \multicolumn{3}{c|}{ Comprimentos de embutimento } \\
\hline \multicolumn{2}{c|}{ Interface lisa } & \multicolumn{2}{c}{ Interface Rugosa } \\
\hline$\frac{M_{d}}{N_{d} \cdot h} \leq 0,15$ & $\frac{M_{d}}{N_{d} \cdot h} \geq 2$ & $\frac{M_{d}}{N_{d} \cdot h} \leq 0,15$ & $\frac{M_{d}}{N_{d} \cdot h} \leq 2$ \\
\hline $1,50 h^{*}$ & $2,00 h^{*}$ & $1,20 h^{*}$ & $1,60 h^{*}$ \\
\hline
\end{tabular} \\
\hline
\end{tabular}

9.2 Chaves de cisalhamento

a) Cálices de interface rugosa devem ter chaves de cisalhamento;

b) Rugosidade mínima de $h_{c h}=1 \mathrm{~cm}$ a cada $10 \mathrm{~cm}$ de junta;

c) Superfícies internas do cálice devem ter a mesma característica superficial dos pilares.

9.3 Espessura das paredes do colarinho

a) Definida por $h_{c} \geq \frac{1}{4} \cdot\left(h_{\text {int }}\right.$ ou $\left.b_{\text {int }}\right)$;

b) Valor mínimo indicado é de $10 \mathrm{~cm}$;

c) Verificar se o espaço resultante é adequado para o alojamento de todas as armaduras resultantes do dimensionamento, respeitando os valores de cobrimento indicado na norma ABNT NBR 6118:2003.

\subsection{Detalhamento de armaduras}

a) Armadura horizontal: armadura em forma de $U$ atua como o ramo interno e a armadura em quadro atua como o ramo externo da armadura horizontal do cálice.

b) Maior facilidade no posicionamento dessas amadura nas paredes do cálice, apresentando essa configuração melhor construtibilidade.

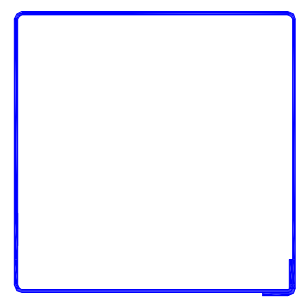

Ramo externo da armadura horizontal

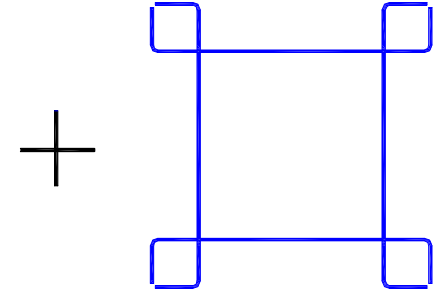

Ramo interno da armadura horizontal

Figura A.9 - Detalhamento da armadura horizontal 
c) Armadura vertical: garantir boa ancoragem da armadura no elemento de fundação, transferindo todas as tensões da armadura para o concreto. No caso da alternativa 3, a armadura horizontal localizada abaixo da junta do pilar contribui no controle da fissuração nessa região da fundação.

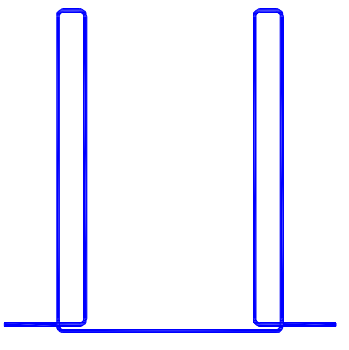

Alternativa 1

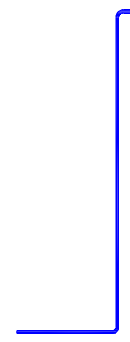

Alternativa 2

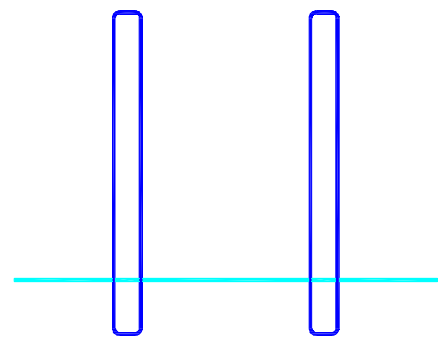

Alternativa 3

Figura A.10 - Detalhamento da armadura vertical

9.5 Recomendações gerais

a) Adotar para o graute ou concreto de preenchimento da junta, uma resistência igual ou superior a resistência do concreto do pilar ou das paredes do colarinho;

b) Proceder ao correto adensamento do concreto da junta com uso de vibrador de agulha;

c) A cavidade entre as paredes internas do colarinho e do pilar deve ter espaço suficiente para permitir a entrada do aparelho de vibração. O valor mínimo e usualmente empregado para a espessura da junta é de $5 \mathrm{~cm}$;. Essa espessura é importante para acomodação de erros de locação de pilares e desvios da fundação;

d) No caso de graute auto adensável a espessura da junta pode ser reduzida;

e) O cobrimento das armaduras do cálice deve seguir os valores indicados na Tabela 7.2 da ABNT NBR 6118:2003, podendo, no entanto, reduzir esse valor para as armaduras localizadas na face interna das paredes do cálice;

f) As dimensões da base da fundação são definidas conforme o tipo de fundação adotada para cada projeto. Recomenda-se a espessura mínima de $20 \mathrm{~cm}$;

g) Projetar o cálice com uma armadura mínima. Para os casos de grande excentricidade da força normal, armadura mínima é resultante do dimensionamento da situação de montagem. E para pequena excentricidade, a armadura mínima deve ser o maior valor entre o dimensionamento da armadura na fase de montagem e o cálculo resultante de uma excentricidade de 0,15 . 